Universidad deValladolid

PROGRAMA DE DOCTORADO EN

INVESTIGACIÓN EN CIENCIAS DE LA SALUD

TESIS DOCTORAL

\title{
INFLUENCIA DEL ESTADO NUTRICIONAL E INFLAMATORIO PREOPERATORIO SOBRE LAS COMPLICACIONES TRAS CIRUGÍA CURATIVA DEL CÁNCER COLORRECTAL
}

Presentada por Martín Bailón Cuadrado para optar al grado de Doctor por la Universidad de Valladolid

Dirigida por:

Baltasar Pérez Saborido

Javier Sánchez González

Mario Rodríguez López 



\section{Universidad deValladolid}

Impreso 1T

\section{AUTORIZACIÓN DEL DIRECTOR DE TESIS}

(Art. 7.2 de la Normativa para la presentación y defensa de la Tesis Doctoral en la UVa)

D. Baltasar Pérez Saborido, con DNI 33389848N, profesor asociado del departamento de Cirugía, Oftalmología, Otorrinolaringología y Fisioterapia de la Facultad de Medicina de la Universidad de Valladolid, como Director de la Tesis Doctoral titulada "Influencia del estado nutricional e inflamatorio preoperatorio sobre las complicaciones tras cirugía curativa del cáncer colorrectal”, realizada por D. Martín Bailón Cuadrado, alumno del Programa de Doctorado "Investigación en Ciencias de la Salud", impartido por el departamento de Biología Celular, Histología y Farmacología, autoriza la presentación de la misma, considerando que la estructura y ejecución de este trabajo se ajusta a los objetivos propuestos inicialmente en su redacción y por ello puede ser presentada como trabajo original para la obtención del Título de Doctor.

Valladolid, a 25 de agosto de 2017

El Director de la Tesis,

Fdo.: Prof. Dr. D. Baltasar Pérez Saborido

SR. PRESIDENTE DE LA COMISIÓN DE DOCTORADO 



\section{Universidad deValladolid}

Impreso $1 \mathrm{~T}$

\section{AUTORIZACIÓN DEL DIRECTOR DE TESIS}

(Art. 7.2 de la Normativa para la presentación y defensa de la Tesis Doctoral en la UVa)

D. Javier Sánchez González, con DNI 12377487Z, como Director de la Tesis Doctoral titulada "Influencia del estado nutricional e inflamatorio preoperatorio sobre las complicaciones tras cirugía curativa del cáncer colorrectal”, realizada por D. Martín Bailón Cuadrado, alumno del Programa de Doctorado "Investigación en Ciencias de la Salud", impartido por el departamento de Biología Celular, Histología y Farmacología, autoriza la presentación de la misma, considerando que la estructura y ejecución de este trabajo se ajusta a los objetivos propuestos inicialmente en su redacción y por ello puede ser presentada como trabajo original para la obtención del Título de Doctor.

Valladolid, a 25 de agosto de 2017

El Director de la Tesis,

Fdo.: Dr. D. Javier Sánchez González

SR. PRESIDENTE DE LA COMISIÓN DE DOCTORADO 



\section{Universidad deValladolid}

Impreso $1 \mathrm{~T}$

\section{AUTORIZACIÓN DEL DIRECTOR DE TESIS}

(Art. 7.2 de la Normativa para la presentación y defensa de la Tesis Doctoral en la UVa)

D. Mario Rodríguez López, con DNI 12417438Z, como Director de la Tesis Doctoral titulada "Influencia del estado nutricional e inflamatorio preoperatorio sobre las complicaciones tras cirugía curativa del cáncer colorrectal”, realizada por D. Martín Bailón Cuadrado, alumno del Programa de Doctorado "Investigación en Ciencias de la Salud", impartido por el departamento de Biología Celular, Histología y Farmacología, autoriza la presentación de la misma, considerando que la estructura y ejecución de este trabajo se ajusta a los objetivos propuestos inicialmente en su redacción y por ello puede ser presentada como trabajo original para la obtención del Título de Doctor.

Valladolid, a 25 de agosto de 2017

El Director de la Tesis,

Fdo.: Dr. D. Mario Rodríguez López

SR. PRESIDENTE DE LA COMISIÓN DE DOCTORADO 



\section{INFLUENCIA DEL ESTADO NUTRICIONAL E INFLAMATORIO PREOPERATORIO SOBRE LAS COMPLICACIONES TRAS CIRUGÍA CURATIVA DEL CÁNCER COLORRECTAL}

DOCTORANDO: $\quad$ Martín Bailón Cuadrado

DIRECTORES: Baltasar Pérez Saborido

Javier Sánchez González

Mario Rodríguez López

CENTRO: $\quad$ Facultad de Medicina

Universidad de Valladolid

DEPARTAMENTO: Biología Celular, Histología y Farmacología

FINALIZACIÓN: $\quad$ Agosto de 2017 

Dedicada a mis padres y a Sofía 

ÍNDICE:

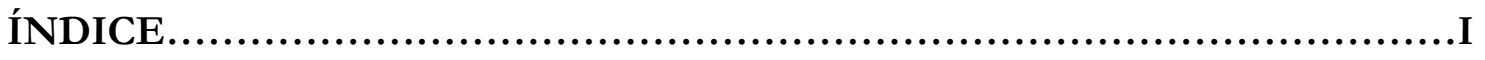

ABREVIATURAS ................................................................

AGRADECIMIENTOS.........................................................

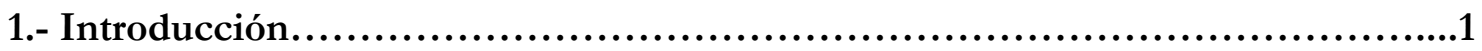

1.1.- Epidemiología del cáncer colorrectal.................................. 3

1.2.- Etiología del cáncer colorrectal........................................4

1.2.1.- Factores de riesgo para cáncer colorrectal esporádico.................4

1.2.1.1.- Antecedentes familiares................................4

1.2.1.2.- Factores raciales....................................5

1.2.1.3.- Diferencias entre sexos...........................6

1.2.1.4.- Otros factores de riesgo...........................6

1.2.2.- Cáncer colorrectal heredo-familiar............................

1.2.2.1.- Síndrome de Lynch..............................

1.2.2.2.- Poliposis adenomatosa familiar........................9

1.2.2.3.- Poliposis asociada al gen MUTHY......................10

1.2.2.4.- Síndromes de poliposis hamartomatosa.................11

1.3.- Presentación clínica del cáncer colorrectal................................12

1.4.- Cribado del cáncer colorrectal........................................15

1.4.1.- Sangre oculta en heces.....................................15

1.4.1.1.- Prueba Gauiac....................................15

1.4.1.2.- Prueba de inmunoquímica fecal.......................16

1.4.1.3.- Detección de ADN fecal..............................17 
1.4.2.- Enema de bario con doble contraste...........................17

1.4.3.- Sigmoidoscopia flexible...................................18

1.4.4.- Colonoscopia óptica.........................................18

1.4.5.- Colonoscopia virtual........................................20

1.5.- Diagnóstico de extensión del cáncer colorrectal..........................21

1.5.1.- Tomografía computarizada.................................21

1.5.2.- Resonancia magnética nuclear...............................22

1.5.3.- Ecografía transanal.......................................23

1.6.- Estadiaje del cáncer colorrectal.......................................25

1.7.- Tratamiento quirúrgico del cáncer colorrectal..........................27

1.7.1.- Cáncer de colon............................................27

1.7.2.- Cáncer de recto.............................................28

1.7.3.- Papel del abordaje laparoscópico..............................31

1.8.- Tratamiento oncológico del cáncer colorrectal...........................32

1.8.1.- Neoadyuvancia para el cáncer de recto........................32

1.8.2.- Tratamiento adyuvante para cáncer de colon......................36

1.8.2.1.- Estadio II.........................................36

1.8.2.2.- Estadio III.......................................37

1.8.3.- Tratamiento adyuvante para cáncer de recto......................38

1.9.- Patogenia del deterioro inmunonutricional...........................4

1.9.1.- Reactantes de fase aguda...................................41

1.9.2.- Anorexia................................................ 42

1.9.3.- Proteolisis.................................................43

1.9.4.- Lipolisis................................................43

1.9.5.- Alteraciones neuroendocrinas...............................43 
1.10.- Scores inmunonutricionales.

1.10.1.- Prognostic Nutritional Index....................................44

1.10.2.- Glasgow Prognostic Score........................................45

1.10.3.- Modified Glasgow Prognostic Score..................................46

1.10.4.- Granulocyte/Lymphocyte Ratio.................................47

1.10.5.- Neutrophile/Lymphocyte Ratio.................................48

1.10.6.- Platelet/Lymphocyte Ratio....................................50

1.10.7.- Albúmina y prealbúmina....................................51

1.11.- Complicaciones tras cirugía colorrectal...............................51

1.11.1.- Médicas...................................................52

1.11.2.- Quirúrgicas..............................................54

1.11.3.- Gradación de las complicaciones.............................57

1.11.4.- Relación entre la neoadyuvancia para el cáncer de recto y el desarrollo de complicaciones postoperatorias.......................58

1.11.5.- Relación entre las complicaciones postoperatorias y el pronóstico oncológico.................................................59

1.12.- Justificación.................................................60

2.- Hipótesis y objetivos..................................................63

2.1.- Hipótesis....................................................................

2.2.- Objetivos.......................................................65

3.- Pacientes y métodos.....................................................67

3.1.- Tipo de estudio.................................................69

3.2.- Población a estudio............................................69

3.2.1.- Criterios de inclusión....................................69

3.2.2.- Criterios de exclusión.....................................70 
3.2.3.- Tamaño muestral........................................ 70

3.3.- Circuito asistencial del paciente.....................................71

3.3.1.- Preoperatorio.............................................. 71

3.3.2.- Intrahospitalario.......................................73

3.3.2.1.- Preoperatorio inmediato.............................73

3.3.2.2.- Técnica quirúrgica............................. 74

3.3.2.3.- Protocolo postoperatorio...........................75

3.3.3.- Seguimiento oncológico....................................76

3.4.- Variables descritas..............................................92

3.4.1.- Variables demográficas................................... 92

3.4.2.- Variables preoperatorias..................................92

3.4.3.- Variables definitorias del estado nutricional e inflamatorio..........93

3.4.4.- Variables intraoperatorias..................................95

3.4.5.- Variables postoperatorias.................................96

3.5.- Análisis estadístico.................................................97

3.5.1.- Recogida y tratamiento de datos...........................97

3.5.2.- Estadística descriptiva...................................97

3.5.3.- Estadística inferencial.....................................98

3.5.3.1.- Análisis univariante................................98

3.5.3.2.- Análisis multivariante...............................98

3.6.- Ética y aspectos legales.......................................... 99

3.7.- Búsqueda bibliográfica............................................... 99

4.- Resultados................................................................101

4.1.- Análisis descriptivo.............................................103

4.1.1.- Variables demográficas....................................103 
4.1.2.- Variables preoperatorias....................................104

4.1.3.- Variables definitorias del estado nutricional e inflamatorio.........107

4.1.4.- Variables intraoperatorias.....................................113

4.1.5.- Variables postoperatorias..................................115

4.2.- Análisis inferencial...................................................118

4.2.1.- Complicaciones globales..................................118

4.2.1.1.- Análisis univariante................................118

4.2.1.2.- Análisis multivariante...............................119

4.2.2.- Complicaciones graves..................................122

4.2.2.1.- Análisis univariante...............................122

4.2.2.2.- Análisis multivariante.............................122

4.2.3.- Complicaciones infecciosas.................................124

4.2.3.1.- Análisis univariante................................124

4.2.3.2.- Análisis multivariante................................125

4.2.4.- Fuga anastomótica......................................127

4.2.4.1.- Análisis univariante..............................127

4.2.4.2.- Análisis multivariante.............................128

4.2.5.- Reintervención............................................131

4.2.5.1.- Análisis univariante................................131

4.2.5.2.- Análisis multivariante................................131

4.2.6.- Éxitus..................................................133

4.2.6.1.- Análisis univariante.................................133

4.2.6.2.- Análisis multivariante................................134

4.2.7.- Estancia postoperatoria prolongada..........................136

4.2.7.1.- Análisis univariante................................136 
5.- Discusión................................................................. 141

5.1.- Análisis de variables demográficas y preoperatorias........................143

5.2.- Descripción del estado nutricional e inflamatorio........................149

5.3.- Análisis de variables intraoperatorias.................................154

5.4.- Complicaciones postoperatorias e influencia de los scores..................158

5.4.1.- Complicaciones globales.....................................160

5.4.2.- Complicaciones graves..................................167

5.4.3.- Complicaciones infecciosas...............................172

5.4.4.- Fuga anastomótica.......................................175

5.4.5.- Reintervención............................................178

5.4.6.- Éxitus.................................................180

5.4.7.- Estancia postoperatoria prolongada.........................181

5.5.- Aplicabilidad..................................................184

5.6.- Limitaciones..................................................... 185

6.- Conclusiones............................................................ 187

7.- Bibliografía............................................................... 191 


\section{ABREVIATURAS:}

AAP: amputación abdominoperineal.

ADN: ácido desoxirribonucleico.

AJCC: American Joint Committee on Cancer.

ASA: American Society of Anesthesiologists.

CEA: carcinoembryonic antigen.

CCR: cáncer colorrectal.

EPOC: enfermedad pulmonar obstructiva crónica.

FPG: familiar de primer grado.

GLR: Granulocyte/Lymphocyte Ratio.

GPS: Glasgow Prognostic Score.

HTA: hipertensión arterial.

IC 95\%: intervalo de confianza al 95\%.

IHQ: infección de herida quirúrgica.

IL: interleucina.

IMC: índice de masa corporal.

mGPS: Modified Glasgow Prognostic Score.

MRC: margen de resección circunferencial.

NCCN: National Comprehensive Cancer Network.

NLR: Neutrophile/Lymphocyte Ratio.

OR: odds ratio.

PAF: poliposis adenomatosa familiar.

PCR: proteína $C$ reactiva.

PET: positron emission tomography. 
PLR: Platelet/Lymphocyte Ratio.

PNI: Prognostic Nutritional Index.

QRT: quimiorradioterapia.

QT: quimioterapia.

RIQ: rango intercuartílico.

RMN: resonancia magnética nuclear.

ROC: receiver operating characteristic.

RR: riesgo relativo.

RT: radioterapia.

SG: supervivencia global.

SL: síndrome de Lynch.

SLE: supervivencia libre de enfermedad.

SOH: sangre oculta en heces.

$\mathrm{TNF} \alpha$ : tumour necrosis factor $\alpha$.

TNM: tumour/node/metastasis.

TC: tomografía computarizada.

TRUS: transanal ultrasound, ecografía transanal. 


\section{AGRADECIMIENTOS:}

A mis padres, a mi hermana y a mi abuela, por todo lo que me han dado y por hacerme la persona que soy ahora.

A Sofía, por estar siempre a mi lado y apoyarme de forma incondicional.

A Baltasar, por inculcarme su afán investigador y demostrarme que un cirujano es mucho más que un médico que opera.

A Javi Sánchez, por su inmensa capacidad de trabajo, siempre con una sonrisa.

A Mario, buen amigo, por ser la persona que más me ha ayudado desde que comencé mi camino como cirujano.

A Agustín, por sus conocimientos estadísticos que tan esenciales han sido en este trabajo.

A mis residentes mayores y pequeños, por su amistad y por todo lo que he aprendido y aprendo de ellos. 



\section{1.- INTRODUCCIÓN.}


Martín Bailón Cuadrado 


\section{1.- INTRODUCCIÓN.}

\section{1.- EPIDEMIOLOGÍA DEL CÁNCER COLORRECTAL.}

El cáncer colorrectal (CCR) supone el 9,7\% de todos los cánceres del mundo, estando su incidencia influenciada por múltiples variables [1].

Existen importantes diferencias geográficas, siendo más frecuente en regiones más desarrolladas como Europa occidental, América del Norte, Australia y Nueva Zelanda, con incidencias por encima de los 30 nuevos casos por cada 100.000 habitantes y año; y mucho menos común en países en vías de desarrollo, con 4 - 5 nuevos casos por cada 100.000 habitantes y año [2]. Posiblemente esta disparidad esté relacionada con factores dietéticos, ambientales y genéticos. Así mismo, un bajo nivel socioeconómico (asociado a sedentarismo, obesidad, tabaquismo, alcoholismo y otros hábitos dietéticos poco saludables) también se ha vinculado con una mayor incidencia de CCR [3-5].

En cuanto a la distribución por sexo, la incidencia global es superior entre los varones, en quienes representa el segundo cáncer más frecuente, siendo el tercero entre mujeres [6]. La edad también es un factor importante, su incidencia comienza a despuntar a partir de los 50 años, aumentando progresivamente con cada década de vida [7,8]. Sin embargo, en los últimos años se ha observado un aumento de la incidencia en la franja de edad existente entre 20 y 50 años, en clara relación con síndromes hereditarios (poliposis adenomatosa familiar [PAF], síndrome de Lynch (SL), y síndromes de poliposis hamartomatosas). Se considera que el 35\% de los casos de CCR tienen su origen en estos síndromes [9-11]. 


\section{Martín Bailón Cuadrado}

La mayor parte de los cánceres colorrectales aparecen en colon descendente, sigma y recto. No obstante, en los últimos años se ha apreciado un aumento de lesiones proximales, principalmente localizadas en el ciego y predominando entre ancianos y mujeres postmenopáusicas [12].

Tanto la incidencia como la mortalidad comenzaron a disminuir desde la década de 1980 y se ha ido reduciendo lentamente cada año. Este descenso se ha relacionado con los avances realizados en diagnóstico precoz y con la capacidad de resección de pólipos por vía endoscópica [7,13].

\section{2.- ETIOLOGÍA DEL CÁNCER COLORRECTAL.}

\subsection{1.- FACTORES DE RIESGO PARA CÁNCER COLORRECTAL ESPORÁDICO.}

\subsubsection{1.- ANTECEDENTES FAMILIARES.}

Los antecedentes familiares de CCR tienen una importancia fundamental en la aparición de nuevos casos en la familia. El riesgo de desarrollar este cáncer aumenta de forma significativa cuando hay afectado algún familiar de primer grado (FPG).

Cuando hay un solo FPG el riesgo relativo (RR) es de 2,25 (intervalo de confianza al 95\% [IC 95\%] = 2,00 - 2,53), en el caso de que un progenitor o un hermano esté afectado el RR es de 2,26 (IC $95 \%=1,87-2,72)$ y de 2,57 (IC 95\% = 2,19 - 3,02), respectivamente; si hay 2 FPG el RR es de 4,25 (IC 95\% = 3,01 - 6,08). En el caso de que el FPG afectado fuese diagnosticado antes de los 45 años, el RR es de 3,87 (IC 95\%=2,40-6,22). Incluso se ha 
advertido que si el FPG presenta adenomas, aumenta el riesgo de desarrollar CCR con un RR de 1,99 (IC 95\% = 1,55 - 2,55) [14].

Todos los FPG de un paciente diagnosticado de CCR muestran un riesgo elevado de desarrollar cáncer independientemente de la edad de diagnóstico de este paciente. Aunque el riesgo es mucho mayor entre pacientes jóvenes con FPG diagnosticados a edades tempranas, los FPG de pacientes diagnosticados a edades más avanzadas también presentan un riesgo significativamente elevado [15].

\subsubsection{2.- FACTORES RACIALES.}

En Estados Unidos tanto la incidencia como la mortalidad son superiores entre los individuos de raza negra que entre los de raza blanca, lo que puede deberse a diferentes factores dietéticos o ambientales a los que se encuentran expuestos ambos grupos, a una diferente disponibilidad para acceder a los programas de cribado, o bien a factores genéticos y biológicos [6].

En pacientes asintomáticos sometidos a colonoscopia para cribado de CCR, los individuos de raza negra muestran una mayor prevalencia de pólipos mayores de 9 milímetros $(\mathrm{mm})$ de diámetro $(7,7 \%$ vs $6,2 \% ; \mathrm{p}<0,001)$. El riesgo de presentar estos pólipos es significativamente mayor para personas de raza negra que para las de raza caucásica, tanto en varones como en mujeres, con una odds ratio (OR) de 1,16 (IC 95\% = 1,01 - 1,34) y de 1,62 (IC 95\% = 1,39-1,89), respectivamente [16]. 


\section{Martín Bailón Cuadrado}

Sin embargo, la prevalencia de neoplasias locorregionalmente avanzadas es superior entre blancos que entre negros $(6,8 \%$ vs. $5,0 \% ; \mathrm{p}=0,039)$. Tras estratificar por diversos factores de riesgo de sufrir CCR, los varones negros presentan un riesgo significativamente menor de padecer neoplasias avanzadas que los blancos, con una OR de 0,59 (IC 95\% = 0,390,89), mientras que no hay diferencias relevantes entre las mujeres de ambas razas [17].

\subsubsection{3.- DIFERENCIAS ENTRE SEXOS.}

Aunque no existen diferencias en la edad de comienzo del cribado de CCR en ninguno de los programas existentes, el riesgo de desarrollar este cáncer es mayor entre los hombres que entre las mujeres [18].

Los hombres presentan un riesgo significativamente más elevado que las mujeres de desarrollar tanto adenomas $(\mathrm{OR}=1,9[\mathrm{IC} 95 \%=1,8-2,0])$ como CCR $(\mathrm{OR}=2,1$ [IC $95 \%=1,7-2,5])[19]$. Este mayor riesgo se mantiene para todas las franjas de edad, lo que podría justificar que se estableciera una diferencia en la edad de comienzo del cribado entre ambos sexos [20]. Además los varones muestran un mayor riesgo que las mujeres de desarrollar una neoplasia avanzada, con una OR de 1,73 (IC 95\% = 1,52 - 1,98) [21].

\subsubsection{4.- OTROS FACTORES DE RIESGO.}

Se han descrito otros factores de riesgo para el desarrollo de CCR, tales como el sedentarismo, la obesidad, la ingesta excesiva de alcohol y carne roja, y el tabaquismo. De todos ellos, el único que muestra una relación causal de riesgo estadísticamente significativa ha sido el consumo de tabaco. Los individuos fumadores tienen un riesgo 
significativamente mayor de desarrollar CCR $(\mathrm{RR}=1,18$ [IC 95\% $=1,11-1,25])$. Además, entre los ya afectados por este cáncer, presentan una mayor tasa de mortalidad aquellos que son o han sido fumadores (OR $=1,25[\mathrm{IC} 95 \%=1,14-1,37])[22]$.

\subsection{2.- CÁNCER COLORRECTAL HEREDO-FAMILIAR.}

\subsubsection{1.- SÍNDROME DE LYNCH.}

También es conocido como síndrome de cáncer colorrectal hereditario no polipósico y supone el 3\% de todos los cánceres colorrectales [23].

Se trata de un síndrome autosómico dominante que se produce por la mutación de alguno de los genes (MLH1, MSH2, MSH6, PMS2) que codifican las enzimas que reparan los errores ocurridos durante la replicación del ácido desoxirribonucleico (ADN) [24]. También puede originase por la mutación del gen EPCAM, que aunque no participa en la reparación de los daños generados en el ADN, su mutación inactiva en muchas ocasiones el funcionamiento del gen MSH2. En más del $80 \%$ de los casos la mutación aparece en los genes MLH1 y MSH2, en un 10\% en MSH6, en un 2-3\% en PMS2 y en un $1-3 \%$ en el gen EPCAM [25]. Puede presentar mutaciones de KRAS y menos frecuentemente de $B R A F$ V600 [26]. Existe además un pequeño porcentaje de individuos en los que la mutación se origina de novo, sin existir antecedentes familiares.

La mutación en estos genes reparadores de errores genera una "inestabilidad de microsatélites", caracterizada por la acumulación de múltiples errores en segmentos repetitivos del ADN conocidos como microsatélites [27]. 


\section{Martín Bailón Cuadrado}

Los pacientes con SL presentan el riesgo de desarrollar CCR a una edad mucho más temprana (media de aparición de 45 años) que la población media (media de 71 años). La mayor parte de las lesiones $(70 \%)$ aparecen proximalmente al ángulo esplénico del colon [28], e histológicamente muestran un componente mucinoso y un marcado infiltrado linfocitario [23].

Las mujeres afectadas por el SL poseen, además, un riesgo del $12-54 \%$ y del $1-38 \%$ de desarrollar cáncer de endometrio y de ovario, respectivamente, a lo largo de su vida [29]. Otras lesiones asociadas son las neoplasias en segmentos más proximales del tracto digestivo y también en la vía urinaria, así como glioblastomas (asociación conocida como síndrome de Turcot) y queratoacantomas (asociación conocida como síndrome de MuirTorre) [30].

Se han desarrollado diversos criterios, como los de Amsterdam y Bethesda, para definir en qué tumores se debe realizar una búsqueda de inestabilidad de microsatélites, para así tratar de detectar clínicamente los pacientes y las familias con SL [31,32].

En los pacientes afectados por este síndrome se debe realizar una colonoscopia cada 1-2 años, comenzando a los 25 años, o 5 años antes de la edad de aparición del cáncer más temprano en la familia [33]. A partir de los 30 años las mujeres afectadas con el SL se deben someter a una revisión ginecológica anual y valorar la histerectomía con doble anexectomía una vez que hayan completado su descendencia [34]. Además, algunos expertos recomiendan llevar a cabo una gastroscopia cada 1-3 años. 
En cuanto al tratamiento quirúrgico, existe debate entre la realización de una colectomía segmentaria y una colectomía subtotal. Hay que tener en cuenta que el riesgo de desarrollar un nuevo cáncer después de una colectomía segmentaria es del 6-35\% [34]. Sin embargo, no se han encontrado diferencias estadísticamente significativas en cuanto a la supervivencia global (SG) a 10 años entre los pacientes sometidos a estos dos tipos de resecciones [35].

\subsubsection{2.- POLIPOSIS ADENOMATOSA FAMILIAR.}

Esta enfermedad aparece en uno de cada 8.000-10.000 individuos y supone el 1\% de todos los cánceres colorrectales. Se produce por la mutación del gen supresor de tumores $A P C$, situado en el brazo largo del cromosoma 5 . Hasta el 25\% de estas mutaciones surgen de novo [36].

Se caracteriza por el desarrollo de cientos a miles de pólipos a lo largo de todo el colon y el recto, lo que termina generando cáncer en un $100 \%$ de los casos antes de la cuarta década de vida. El 70-80\% de estas lesiones se sitúan distales al ángulo esplénico del colon [37].

La principal causa de muerte, tras el CCR, de los pacientes afectados de PAF son los tumores duodenales y desmoides [38]. Las principales manifestaciones extraintestinales de este síndrome, además de los ya citados tumores desmoides, son la hipertrofia del epitelio pigmentario de la retina (que constituye la afectación más frecuente fuera del tracto digestivo), el cáncer papilar de tiroides, los tumores del sistema nervioso central y los osteomas (asociación conocida como síndrome de Gardner) [39]. 


\section{Martín Bailón Cuadrado}

En estos enfermos se debe llevar a cabo una sigmoidoscopia flexible cada 2 años, comenzando a los 12-14 años. Una vez que se detectan adenomas, la endoscopia baja debe tener una frecuencia anual hasta la colectomía. A partir de los 25-30 años se deben realizar endoscopias altas cada 5 años y ecografías cervicales anualmente [33].

En cuanto al tratamiento quirúrgico, se puede realizar una proctocolectomía con anastomosis ileoanal con reservorio o una colectomía total con anastomosis ileorectal. En este último caso sería necesario realizar una rectoscopia anualmente. Los tumores desmoides sintomáticos pueden tratarse con fármacos antiinflamatorios como tamoxifeno o raloxifeno, mientras que el tratamiento quirúrgico debe reservarse para centros muy experimentados en este tipo de cirugía, ya que la intervención puede resultar incluso en una progresión de la enfermedad [40].

\subsubsection{3.- POLIPOSIS ASOCIADA AL GEN MUTHY.}

Se trata de una enfermedad autosómica recesiva que condiciona la aparición de cientos de pólipos colorrectales. Supone menos del 1\% de todos los cánceres colorrectales. Genera un importante diagnóstico diferencial con la aparición de una PAF de novo, siendo el estudio genético el método fundamental para establecer la diferencia [41].

Además del CCR, este síndrome se asocia a la aparición de pólipos duodenales (20\%) y gástricos (11\%) [42]. Como diferencia relevante con la PAF en cuanto a las manifestaciones, no se asocia a la aparición de tumores desmoides [43]. 
En cuanto al seguimiento y al tratamiento quirúrgico, podría realizarse del mismo modo que en una forma atenuada de PAF. Se debe realizar una colonoscopia completa cada dos años, comenzando a los 18-20 años. Cuando se detectan adenomas, la frecuencia de esta prueba deberá pasar a ser anual [33].

\subsubsection{4.- SÍNDROMES DE POLIPOSIS HAMARTOMATOSA.}

El síndrome de Poliposis Juvenil constituye una enfermedad autosómica dominante que aparece en una de cada 15.000-50.000 personas. Los genes más frecuentemente afectados son SMAD4 y BMPR1A [44]. Supone un riesgo elevado de CCR (39-68\%) y de cáncer duodenal, gástrico o pancreático (21\%) [45]. Se asocia a la Telangiectasia Hemorrágica Hereditaria (enfermedad de Rendu-Osler-Weber) y a otras malformaciones arterio-venosas [46]. Se debe realizar una endoscopia baja cada 2 años desde los 15 años y una endoscopia alta cada 2 años desde los 25 años.

El síndrome de Peutz-Jeghers es una enfermedad autosómica dominante pero que hasta en un $40 \%$ de los casos puede originarse de novo. Se manifiesta en una de cada 50.000-200.000 personas. El gen más habitualmente afectado es STK11 [47]. Implica el desarrollo de pólipos hamartomatosos a lo largo de todo el tracto digestivo, principalmente a nivel de yeyuno. Genera un riesgo elevado de padecer diversos cánceres: colorrectal (39\%), de mama (45\%), gástrico (29\%), ginecológicos (18\%) y de páncreas (11\%) [48]. En cuanto al seguimiento de las posibles manifestaciones digestivas, se debe realizar cada 3 años una colonoscopia, una gastroscopia, y tránsito baritado, cápsula endoscópica o resonancia magnética nuclear (RMN) endoscópica. En cuanto al seguimiento por parte de 


\section{Martín Bailón Cuadrado}

Ginecología, debe llevarse a cabo un estudio mamario anual desde los 30 años, consistente en mamografía y ecografía; y una exploración pélvica cada 2 años desde los 18 años.

\section{3.- PRESENTACIÓN CLÍNICA DEL CÁNCER COLORRECTAL.}

Aproximadamente un $90 \%$ de los casos de CCR se diagnostican después de que ya se hayan mostrado sintomáticos [49].

Cuando esto sucede, se ajusta a alguna de estas presentaciones: evolución insidiosa con síntomas crónicos, obstrucción intestinal y perforación. La distribución sería del 77-92\%, 6$16 \%$ y $2-7 \%$, respectivamente, según diferentes publicaciones [50,51].

El sangrado es la manifestación más frecuente del CCR. Puede manifestarse en forma de rectorragia en el caso de lesiones localizadas en el colon izquierdo o en el recto, o bien como sangre oculta en el caso del colon derecho. Hasta en un $10 \%$ de adultos por encima de los 30 años es habitual encontrar sangrado a través del recto, aunque lo más habitual es que se deba a la existencia de hemorroides. En un grupo de pacientes mayores de 40 años, con hemorroides conocidas y sangrado habitual a través del recto, se observó que en un 14\% había pólipos en colon o recto y que en un 6\% ya existía CCR, por lo que el sangrado representa una manifestación que no se debe infravalorar en las consultas de atención primaria [52,53].

Otra manifestación habitual es el cambio en el ritmo deposicional, con alternancia entre diarrea y estreñimiento. Estos cambios de forma mantenida pueden hacer sospechar la existencia de una tumoración maligna en la luz del intestino grueso. Las lesiones más 
distales, en colon izquierdo y recto, tienen una mayor tendencia a presentarse de esta manera. Cuando el tumor se encuentra más avanzado y comienza a comprometer la luz intestinal, se puede asociar a los cambios del ritmo deposicional la existencia de heces acintadas [52].

La anemia ferropénica es un signo común que muestra hasta un 38\% de pacientes con CCR en el momento del diagnóstico. Es claramente más frecuente en las lesiones localizadas en el colon derecho, lo que se relaciona con el sangrado crónico y oculto que no se manifiesta de forma evidente. Otras formas clínicas crónicas menos frecuentes son derivadas de una presentación suboclusiva, con náuseas, vómitos y dolor abdominal. La pérdida de peso no es una manifestación habitual en el CCR, se da en lesiones muy avanzadas, por lo que asocia un mal pronóstico [54,55].

Hasta un 15\% de los CCR se manifiestan como oclusión intestinal. La evolución es insidiosa hasta el cierre completo de la luz intestinal. Mientras el tumor va evolucionando y se va comprometiendo lentamente el tránsito, el paciente puede presentar episodios de dolor cólico, náuseas, vómitos o estreñimiento. En el caso de las lesiones localizadas en el colon derecho la evolución es todavía más lenta ya que suelen desarrollarse a partir de adenomas polipoideos, lo que sumado al contenido líquido procedente del intestino delgado hace que se manifiesten de forma aún más tardía que aquellas localizadas en colon izquierdo o recto [56,57]. Debido a esto, los tumores del colon derecho que se manifiestan con oclusión intestinal tienen un peor pronóstico oncológico que aquellos que se diagnostican también como oclusión intestinal en colon izquierdo o recto, en cuanto a mayor tasa de recurrencia local y a peor supervivencia [58]. Entre los ancianos, el CCR 


\section{Martín Bailón Cuadrado}

supone el 60\% de todos los casos de oclusión intestinal, por lo que es una presentación que debería alertarnos en este tipo de pacientes.

En torno a un 5\% de pacientes con CCR sufren una perforación intestinal, bien como perforación local en forma de absceso pericólico o bien como perforación generalizada en forma de peritonitis. La combinación de obstrucción y perforación se da en el 1\% de los CCR, y entre aquellos que se presentan obstruidos, la perforación aparece en el 12-19\% de los casos. Cuando la obstrucción es distal, en colon izquierdo o recto, se puede generar una perforación diastásica del ciego. Aunque lo más frecuente entre las perforaciones secundarias al CCR es que se produzcan en el propio tumor [59,60].

De todos los cánceres colorrectales, un $79,2 \%$ se detectan mediante la realización de una colonoscopia diagnóstica indicada tras alguna manifestación clínica. Un $7,1 \%$ se diagnostican durante una cirugía urgente, habitualmente por cuadros de oclusión o perforación. Sólo un $10,7 \%$ se diagnostican durante los procedimientos habituales de cribado [61].

La forma en la que detectamos la existencia de CCR tiene una gran relación con el estadio de la enfermedad y, por lo tanto, con su pronóstico oncológico. El porcentaje de pacientes con estadio I es del 38,5\% en aquellos diagnosticados mediante cribado, del 7,2\% en aquellos con colonoscopia diagnóstica, y del $0 \%$ en los que precisan cirugía urgente. El tamaño de la tumoración en el momento del diagnóstico es de $3 \mathrm{~cm}$ en aquellos diagnosticados por cribado, de 4,6 cm en colonoscopia diagnóstica, y de $5 \mathrm{~cm}$ en los que se intervienen de forma urgente. Además, la presencia de metástasis a distancia es del $45 \%$ en la colonoscopia diagnóstica y de 46\% en los que necesitan cirugía urgente, mientras que se 
trata de un hallazgo prácticamente inexistente en aquellos que se diagnostican mediante procedimientos de cribado [61].

En cuanto a la localización del tumor, también tiene implicaciones en la presentación clínica del mismo. La rectorragia se manifiesta en el 79\% de pacientes con cáncer de recto, en el 44\% de los que poseen CCR en el lado izquierdo, y en el 21\% de los que lo tienen en el lado derecho. La obstrucción intestinal se manifiesta en el 43,6\% de los cánceres rectales, en el 27,1\% de los CCR izquierdos y en el 14,8\% de los derechos [62].

\section{4.- CRIBADO DEL CÁNCER COLORRECTAL.}

\subsection{1.- SANGRE OCULTA EN HECES.}

\subsubsection{1.- PRUEBA GAUIAC.}

La detección de sangre oculta en heces $(\mathrm{SOH})$ mediante este procedimiento se fundamenta en la reacción de la peroxidasa con el grupo hemo. Se trata de una prueba no invasiva, barata y fácilmente reproducible.

Uno de los problemas es que el grupo hemo no se encuentra exclusivamente en la hemoglobina humana, por lo que el paciente tiene que someterse a una restricción dietética. Para evitar un falso positivo, el paciente no puede consumir carne roja ni vitamina $\mathrm{C}$ los días previos a la toma de muestras [63]. 


\section{Martín Bailón Cuadrado}

Otro problema de este procedimiento tiene relación con el tamaño de los adenomas. Curiosamente, aquellos con un tamaño inferior a 1 centímetro $(\mathrm{cm})$ tienen una mayor tendencia al sangrado luminal, de tal modo que muchos pacientes con adenomas mayores de $1 \mathrm{~cm}$ muestran una prueba de $\mathrm{SOH}$ negativa. La tasa de falsos negativos puede llegar al $75 \%$ [64]. Se trata de una prueba con una baja sensibilidad (25-38\%) pero con una muy buena especificidad (98-99\%) [65].

Diversos estudios han demostrado que la utilización de la detección de $\mathrm{SOH}$ mediante la prueba de Gauiac reduce la mortalidad por CCR $(\mathrm{RR}=0,84$ [IC 95\% $=0,78-0,9])[66]$.

\subsubsection{2.- PRUEBA DE INMUNOQUÍMICA FECAL.}

Este procedimiento utiliza anticuerpos específicamente dirigidos contra la hemoglobina humana, por lo que no precisa la realización de una restricción dietética previa a la toma de muestras.

Uno de los problemas es que la globina se degrada rápidamente a lo largo del tubo digestivo, por lo que esta prueba presenta una baja sensibilidad para la detección de sangrado fuera del colon [67].

Muestra una sensibilidad muy superior a la prueba de Gauiac para el diagnóstico de CCR (61-65\%), aunque con menor especificidad. Además su capacidad predictiva disminuye mucho a la hora de detectar adenomas (27-41\%) [68]. 


\subsubsection{3.- DETECCIÓN DE ADN FECAL.}

En presencia de una neoplasia de colon, existe una liberación continua de células con mutaciones. En las heces, el ADN de estas células se mantiene estable y puede ser separado del ADN bacteriano.

Se emplea fundamentalmente la detección de la hipermetilación de determinados genes (kras, p16, APC, bMLH1, MGMT, SFRP1, SFRP2, VIM, NDRG4, BMP3, TFP12, FBN1). Presenta una sensibilidad y especificidad para la detección de CCR del 92,3\% y del 86,6\%, respectivamente. Mostrando una sensibilidad muy superior a la prueba de inmunoquímica fecal en cuanto a la detección de pólipos con displasia de alto grado $(69,2$ vs 46,2\%, p = 0,004) y pólipos de más de $1 \mathrm{~cm}(42,4 \%$ vs 5,1\%, p < 0,001) [69,70].

\subsection{2.- ENEMA DE BARIO CON DOBLE CONTRASTE.}

Se trata de una prueba cada vez menos utilizada para el cribado del CCR, en favor de procedimientos endoscópicos y radiológicos. Se tiñe la mucosa del colon y del recto mediante un enema baritado y se introduce aire a través de un catéter endorrectal.

La tasa de detección de pólipos depende del tamaño de los mismos (32\% para aquellos menores de $5 \mathrm{~mm}, 53 \%$ para los de 5 a $10 \mathrm{~mm}$ y $48 \%$ para los mayores de $1 \mathrm{~cm})$. En cuanto a la detección de cáncer, presenta una tasa de pérdidas del 22,4\% de nuevos casos $[71,72]$. 


\section{Martín Bailón Cuadrado}

\subsection{3.- SIGMOIDOSCOPIA FLEXIBLE.}

Esta prueba utiliza un endoscopio flexible capaz de llegar al ángulo esplénico del colon, hasta aproximadamente unos 50-60 cm del margen anal externo.

Hasta en un $18 \%$ de los pacientes no se puede realizar una exploración completa. Este riesgo aumenta con la edad, de un $10 \%$ a los 50 años a un $22 \%$ a los 80 años entre los varones, y de un $19 \%$ a los 50 años a un $32 \%$ a los 80 años entre las mujeres [73].

El riesgo de perforación durante una sigmoidoscopia se sitúa en 0,88 casos por cada 1.000 procedimientos, lo que supone un riesgo mucho menor que durante una colonoscopia completa (1,96 perforaciones por cada 1.000 procedimientos). El riesgo de muerte asociado a una perforación es casi 9 veces mayor comparado con el que presentan aquellos pacientes que se someten a la prueba sin ninguna complicación ( $\mathrm{OR}=8,8[\mathrm{IC} 95 \%=1,6-48,5])$ [74].

Comparando la sigmoidoscopia y la colonoscopia, se ha evidenciado que tan sólo un 35\% de mujeres y un 66\% de varones con CCR habrían sido correctamente diagnosticados con la realización de la sigmoidoscopia flexible [75].

\subsection{4.- COLONOSCOPIA ÓPTICA.}

Presenta las ventajas de una visualización directa de todo el colon y de permitir la exéresis de pólipos para estudio anatomopatológico. Precisa la preparación mecánica del colon 
durante los días previos, además de la sedación del paciente para su realización. Se trata de la prueba más utilizada actualmente en el cribado del CCR.

Presenta una gran sensibilidad para la detección de adenomas. Con una tasa de fallo del 2\% en pólipos mayores de $1 \mathrm{~cm}$, del 13\% para aquellos con una tamaño entre 5 y $10 \mathrm{~mm}$, y del $25 \%$ para los menores de $5 \mathrm{~mm}[76]$.

El riesgo de perforación durante su realización se sitúa en torno al 0,1\%. Al igual que ocurre con la sigmoidoscopia, la perforación está asociada a una gran morbilidad y mortalidad, con un riesgo de muerte asociado a esta perforación 9 veces mayor que con la realización de un procedimiento exento de complicaciones $(\mathrm{OR}=9,0$ [IC 95\% $=3,0-$ 27,3]) $[74,77]$.

Existe un riesgo significativamente menor de desarrollar CCR después de una colonoscopia negativa (Hazard Ratio $=0,44$ [IC 95\% = 0,38 - 0,52]) y tras una polipectomía endoscópica (Hazard Ratio $=0,57$ [IC 95\% $=0,45-0,72])$ [78].

Diversos estudios han mostrado una disminución del riesgo de desarrollar CCR independientemente de su localización tras la realización de una colonoscopia completa, aunque con una mayor significación estadística para esta reducción del riesgo en lesiones más distales $[79,80]$.

Existe además una disminución del riesgo de muerte por CCR tras realizarse una colonoscopia. Sin embargo, esta disminución sólo llega a ser estadísticamente significativa para lesiones distales, no así para las proximales [81,82]. 


\section{Martín Bailón Cuadrado}

\subsection{5.- COLONOSCOPIA VIRTUAL.}

Precisa, al igual que la colonoscopia, la preparación intestinal mecánica del paciente durante los días previos a su realización. Se utilizan contrastes radiopacos que van tiñendo progresivamente la mucosa colorrectal con el objeto de que la tomografía computarizada (TC) pueda representar toda la superficie del intestino grueso. A diferencia de la colonoscopia óptica, no precisa la sedación del paciente.

Muestra una sensibilidad y especificidad superiores al 90\% y al 85\%, respectivamente, para la detección de pólipos mayores de $10 \mathrm{~mm}[83,84]$. Además tiene una precisión similar a la colonoscopia óptica en la detección de CCR, con una sensibilidad, especificidad, valor predictivo positivo y valor predictivo negativo de $90 \%, 86 \%, 99 \%$ y $89 \%$, respectivamente $[85,86]$.

Como ventaja fundamental, se trata de una prueba poco invasiva con una tasa de complicaciones muy inferior a la que existe durante la realización de una colonoscopia óptica [87]. No obstante, existen algunas desventajas, ya que en muchas ocasiones los hallazgos de la colonoscopia virtual obligan a realizar una colonoscopia óptica, como por ejemplo para la exéresis de pólipos para estudio anatomopatológico. Como prueba de cribado, la repetición periódica de una alta dosis de radiación cada 5 o 10 años aumenta el riesgo de carcinogénesis. Además, la colonoscopia virtual presenta una especialmente baja sensibilidad para la detección de pólipos planos, que precisamente poseen un mayor riesgo de malignización. 


\section{5.- DIAGNÓSTICO DE EXTENSIÓN DEL CÁNCER COLORRECTAL.}

Como hemos comentado previamente, el diagnóstico del CCR se basa en la colonoscopia óptica y en la toma de muestras para estudio anatomopatológico.

El estudio preoperatorio para estadiar la lesión se asienta en las pruebas de imagen. La TC es fundamental para la valoración de complicaciones locales de la tumoración y para descartar la existencia de adenopatías patológicas y de metástasis a distancia, tanto para las lesiones de colon como para las de recto. La PET (positron emission tomography) no está indicada de rutina en las guías de manejo del CCR y se reserva para aquellos casos en los que existen dudas diagnósticas de enfermedad a distancia $[88,89]$.

En el caso del cáncer de recto, es esencial completar el estadiaje con otra prueba que sea capaz de valorar la relación de la tumoración con los esfínteres y con el plano muscular de los elevadores, así como la posible afectación de la fascia mesorrectal. Esta prueba puede ser una RMN o una ecografía endoscópica transanal (TRUS).

\subsection{1.- TOMOGRAFÍA COMPUTARIZADA.}

Permite valorar la afectación local (T del TNM [tumour/node/metastasis]), ya que estudia el nivel de deformación de la pared intestinal, que se relaciona con el grado de invasión local de la tumoración. Tanto la deformación de la pared intestinal en más del 50\% de la circunferencia como la afectación de los tejidos blandos pericólicos con proyecciones espiculadas irregulares se asocian a una afectación más profunda (T3/T4) [90,91]. La precisión para detectar el grado de afectación de la T oscila entre el 73 y el 83\%. Asciende 


\section{Martín Bailón Cuadrado}

hasta el 93\% para la detección de lesiones T3-T4 cuando se utiliza TC con doble contraste $[92,93]$.

Las adenopatías patológicas en el CCR suelen presentar calcificaciones y un diámetro mayor de $1 \mathrm{~cm}$. La precisión de la TC para la detección de éstas oscila entre el 59 y el 71\% $[92,94]$.

El hígado es el lugar más habitual de aparición de las metástasis secundarias a CCR. Se manifiestan como lesiones poco vascularizadas, hipodensas en la fase portal y con un posible realce periférico en la fase arterial, presentando calcificaciones en un 10-30\% de los casos. La TC muestra una sensibilidad y un especificidad del 85 y del 97\%, respectivamente, para la detección de estas metástasis hepáticas. Además permite establecer su relación con los vasos hepáticos de cara a una posible cirugía curativa [95,96].

\subsection{2.- RESONANCIA MAGNÉTICA NUCLEAR.}

Permite valorar el grado de invasión de la pared intestinal, la afectación de la fascia mesorrectal y la relación con órganos vecinos en el cáncer de recto. En fase T2, la mucosa se aprecia hipointensa, la submucosa hiperintensa, la capa muscular hipointensa, el mesorrecto hiperintenso y la fascia mesorrectal hipointensa [97]. Presenta una sensibilidad y una especificidad del 87 y del 75\%, respectivamente, para el grado de afectación T [98]. Una de sus principales limitaciones es la dificultad para diferenciar entre fibrosis e infiltración tumoral, lo que compromete la capacidad para distinguir entre T2 y T3 [99]. 
Un aspecto fundamental es la valoración de la integridad de la fascia mesorrectal, para predecir la positividad o negatividad del margen de resección circunferencial (MRC). La tasa de recidiva es mayor entre aquellos individuos que presentan un MRC positivo (19$22 \%$ ) que entre los negativos (3-5\%). La positividad del MRC no sólo se relaciona con la recidiva local, sino también con la aparición de metástasis a distancia y con la supervivencia libre de enfermedad (SLE) $[100,101]$.

La precisión a la hora de detectar adenopatías patológicas ha mejorado ostensiblemente en los últimos años, con una sensibilidad y una especificidad del 80-85 y del 97-98\%, respectivamente. La reconstrucción tridimensional a partir de imágenes en fase T2 permite apreciar la irregularidad de los bordes de las adenopatías, lo que, sumado a criterios de tamaño, permite valorar su malignidad $[102,103]$.

Además del enorme interés de la RMN para el estadiaje del cáncer de recto, esta prueba permite estudiar el hígado cuando en la TC existe la sospecha de metástasis hepáticas. Con el contraste hepato-específico de gadolinio, la RMN muestra una precisión superior al 90\% para la detección de estas lesiones. Las metástasis hepáticas aparecen en la RMN como nódulos hipointensos en T1 y ligeramente hiperintensas en T2 [104,105].

\subsection{3.- ECOGRAFÍA TRANSANAL.}

La otra prueba que puede completar a la TC en el estadiaje del cáncer de recto es la TRUS. Las lesiones del CCR se presentan como una masa hipoecoica con pérdida de la diferenciación característica entre las diferentes capas debido a la infiltración tumoral. 


\section{Martín Bailón Cuadrado}

Esta técnica muestra una sensibilidad y una especificidad del $88 \%$ y $98 \%$ para T1, del $80 \%$ y $96 \%$ para T2, del 96\% y $91 \%$ para T3, y del 95\% y 98\% para T4, respectivamente [106]. Con una precisión del 86-93\%, 88-94\%, 86-88\% y 65-96\% para T1, T2, T3 y T4, respectivamente [107-109].

En cuanto a la capacidad para determinar la integridad de la fascia mesorrectal de cara a predecir la positividad o negatividad del MRC, la precisión global de la TRUS es ligeramente inferior a la RMN (84\% vs 92\%), con similar valor predictivo negativo (97\%). Por el contrario, esta precisión se igualaba $(87 \%)$ para aquellos tumores del tercio inferior del recto, con igual valor predictivo negativo (96\%) [110].

La TRUS también es fundamental para la valoración de la malignidad de las adenopatías peritumorales. Éstas aparecen como nódulos homogéneamente hipoecoicos con un diámetro mínimo superior a $5 \mathrm{~mm}$. Este procedimiento presenta una sensibilidad y especificidad del 73 y 76\% respectivamente, con una precisión que oscila entre el 63 y el 85\% para la detección de adenopatías patológicas [106,111,112].

Una de las limitaciones fundamentales de la TRUS es que no puede diferenciar la infiltración neoplásica de la fibrosis e inflamación secundarias, ya que existe hipoecogenicidad en todos los casos. Esto hace que la prueba tienda a sobreestadificar el tumor [113]. 


\section{6.- ESTADIAJE DEL CÁNCER COLORRECTAL.}

La clasificación TNM, del American Joint Committee on Cancer (AJCC) y de la Union for International Cancer Control, es la más extendida y aceptada a nivel internacional. Se describe a continuación [Tablas 1-4]:

Tabla 1. Clasificación del tumor primario.

\begin{tabular}{|l|l|}
\hline Categoría & Criterio \\
\hline Tx & Desconocido. \\
\hline T0 & Sin evidencia de tumor primario. \\
\hline Tis & Invasión mucosa. \\
\hline T1 & Invasión submucosa. \\
\hline T2 & Invasión de la muscular propia. \\
\hline T3 & Invasión de tejidos pericólicos o perirrectales. \\
\hline T4a & Invasión del peritoneo visceral. \\
\hline T4b & Invasión de órganos o estructuras adyacentes. \\
\hline
\end{tabular}

Tabla 2. Clasificación de los ganglios linfáticos regionales.

\begin{tabular}{|l|l|}
\hline Categoría & Criterio \\
\hline $\mathbf{N} \mathbf{x}$ & Desconocido. \\
\hline $\mathbf{N 0}$ & Sin afectación linfática. \\
\hline $\mathbf{N 1 a}$ & Afectación de 1 ganglio. \\
\hline $\mathbf{N 1 b}$ & Afectación de 2-3 ganglios. \\
\hline $\mathbf{N 1 c}$ & $\begin{array}{l}\text { Depósito tumoral en subserosa, mesenterio o tejido } \\
\text { pericólico o perirrectal no peritonizado. Sin afectación } \\
\text { linfática. }\end{array}$ \\
\hline $\mathbf{N 2 a}$ & Afectación de 4-6 ganglios. \\
\hline $\mathbf{N} 2 \mathbf{b}$ & Afectación de 7 o más ganglios. \\
\hline
\end{tabular}




\section{Martín Bailón Cuadrado}

Tabla 3. Clasificación de las metástasis a distancia.

\begin{tabular}{|l|l|}
\hline Categoría & Criterio \\
\hline Mx & Desconocido. \\
\hline M0 & Sin metástasis a distancia. \\
\hline M1a & Metástasis en 1 órgano. \\
\hline M1b & Metástasis en 2 o más órganos. \\
\hline M1c & Carcinomatosis peritoneal. \\
\hline
\end{tabular}

Tabla 4. Estadio pronóstico.

\begin{tabular}{|l|l|}
\hline Estadio & TNM \\
\hline $\mathbf{0}$ & Tis. \\
\hline I & T1-T2. \\
\hline IIA & T3. \\
\hline IIB & T4a. \\
\hline IIC & T4b. \\
\hline IIIA & T1-T2, N1. \\
\hline IIIA & T1, N2a. \\
\hline IIIB & T3-T4a, N1. \\
\hline IIIB & T2-T3, N2a. \\
\hline IIIB & T1-T2, N2b. \\
\hline IIIC & T4a, N2a. \\
\hline IIIC & T3-T4a, N2b. \\
\hline IIIC & T4b, N1-N2. \\
\hline IVA & M1a. \\
\hline IVB & M1b. \\
\hline IVC & M1c. \\
\hline
\end{tabular}




\section{7.- TRATAMIENTO QUIRÚRGICO DEL CÁNCER COLORRECTAL.}

\subsection{1.- CÁNCER DE COLON.}

El tratamiento quirúrgico se fundamenta en la resección del segmento del colon donde se encuentra la tumoración; la extensión anatómica de esta resección dependerá de los vasos sanguíneos que se tengan que escindir desde su origen en función de la localización de la lesión. Se considera que tanto el margen proximal como el distal deben ser de, al menos, 5 $\mathrm{cm}$. Además es fundamental la resección del mesenterio correspondiente, para extirpar los vasos sanguíneos y ganglios linfáticos dependientes del tumor. La disección del mismo debe comenzar en la raíz de los vasos para realizar una correcta linfadenectomía [114].

La linfadenectomía representa un papel fundamental en el manejo oncológico ulterior. Las guías del National Comprehensive Cancer Network (NCCN) recomiendan que se recojan al menos 12 ganglios para un correcto estadiaje [115]. Además, la extensión de la linfadenectomía se relaciona con la supervivencia. Una revisión sistemática de múltiples estudios que comparan la supervivencia en función del número de ganglios linfáticos resecados mostró que existen diferencias significativas en cuanto a la SLE y SG en función del número de adenopatías analizadas, y no sólo para el estadio III, sino también para el estadio II (sin afectación de los ganglios linfáticos) [116]. 


\section{Martín Bailón Cuadrado}

\subsection{2.- CÁNCER DE RECTO.}

El fundamento del tratamiento quirúrgico es similar al del cáncer de colon, con la exéresis de la tumoración con márgenes de seguridad y con la escisión del mesenterio que contiene la vascularización y los ganglios linfáticos dependientes de la lesión. Existen, sin embargo, una serie de peculiaridades que comentamos a continuación.

Se pueden realizar resecciones transanales, con intención curativa, de pequeñas tumoraciones rectales evitando otros abordajes más invasivos siempre que se cumplan una serie de requisitos: que la lesión sea móvil y de menos de $3 \mathrm{~cm}$, que se encuentre entre 4 y $18 \mathrm{~cm}$ del margen anal, que la base de implantación no supere el 30\% de la circunferencia del recto, que no haya sospecha de adenopatías patológicas en las pruebas de imagen, que el informe anatomopatológico describa una lesión T1 moderadamente o muy diferenciada y sin infiltración linfovascular o perineural [89].

Mientras que el margen de resección proximal se sitúa, al igual que en el cáncer de colon, en $5 \mathrm{~cm}$, se considera que en el cáncer de recto son suficientes $2 \mathrm{~cm}$ de margen de resección distal siempre que se realice junto con quimiorradioterapia (QRT) neoadyuvante y escisión total del mesorrecto. De hecho, se estima que en aquellos tumores distales al margen mesorrectal sólo es necesario $1 \mathrm{~cm}$ de margen distal [117], ya que se ha observado que cuando se combina la QRT neoadyuvante y la escisión total del mesorrecto se elimina todo resto de enfermedad microscópica siempre que los bordes de resección sean negativos. De este modo, se obtienen cifras similares de recurrencia local y de supervivencia cuando los márgenes distales son inferiores a $1 \mathrm{~cm}$ [118]. La positividad del 
margen de resección distal conlleva un gran empeoramiento del pronóstico, con resultados significativamente peores en cuanto a tasa de recurrencia local, SLE y SG $[119,120]$.

Estos hallazgos han permitido que se puedan realizar con seguridad oncológica cirugías con preservación de esfínteres en cánceres de recto muy distales, evitando en muchos casos la amputación abdominoperineal (AAP). Puesto que estas cirugías con resecciones ultrabajas necesitan de la formación de una anastomosis coloanal, se ha abierto un nuevo debate en cuanto a qué tipo de anastomosis y reservorios ofrecen los mejores resultados en estas circunstancias.

Diversas revisiones y metaanálisis de estudios prospectivos que comparaban la anastomosis colorrectal termino-terminal con los tres tipos clásicos de reservorio (reservorio en J, reservorio transverso y anastomosis latero-terminal) mostraron que no existen diferencias en cuanto a la tasa de complicaciones de cada una de estas técnicas, pero que la anastomosis colorrectal termino-terminal presenta peores resultados funcionales, durante los 2 primeros años, que los reservorios. Además se apreció que no existen diferencias en ningún parámetro entre los tres tipos de reservorio [121,122].

El MRC es fundamental en el pronóstico del cáncer de recto desde que se generalizó la escisión completa del mesorrecto, que se puede realizar por abordaje estrictamente abdominal o bien combinando este último con un abordaje transanal [123]. Se ha observado en diversos trabajos que la positividad del MRC actúa como un factor pronóstico independiente en el pronóstico del paciente, obteniéndose resultados significativamente peores en cuanto a la tasa de recurrencia local, a la SLE y a la SG [124,125]. 


\section{Martín Bailón Cuadrado}

Se ha estudiado la relación existente entre la extensión del MRC y el pronóstico oncológico del paciente con cáncer de recto. Diversas publicaciones evidenciaron que un $\mathrm{MRC} \leq 1$ $\mathrm{mm}$ se vincula de forma estadísticamente significativa con una mayor tasa de recurrencia local y de metástasis a distancia, y con una peor supervivencia [126-128]. Además, uno de estos estudios observó que un MRC $\leq 2 \mathrm{~mm}$ se asocia de forma significativa con una menor supervivencia [128].

Recientemente se está comenzando a generalizar la utilización de una nueva clasificación del cáncer de recto inferior (a menos de $6 \mathrm{~cm}$ del margen anal) que condiciona el manejo quirúrgico [129]. El tipo I se encuentra a más de $1 \mathrm{~cm}$ por encima del esfínter anal interno, se debe realizar una resección con anastomosis coloanal. El tipo II se localiza a menos de 1 cm del esfínter anal interno, hay que efectuar una resección interesfintérica parcial. El tipo III infiltra el esfínter anal interno, se debe llevar a cabo una resección interesfintérica total. Finalmente, el tipo IV invade el esfínter anal externo o los músculos elevadores, lo que obliga a realizar una AAP [Tabla 5].

Tabla 5. Clasificación terapéutica del cáncer de recto bajo.

\begin{tabular}{|l|l|l|}
\hline Clasificación & Definición & Indicación quirúrgica \\
\hline I & $>1 \mathrm{~cm}$ del esfínter anal interno. & Anastomosis coloanal. \\
\hline II & $<1 \mathrm{~cm}$ del esfínter anal interno. & $\begin{array}{l}\text { Resección interesfintérica } \\
\text { parcial. }\end{array}$ \\
\hline III & Infiltración del esfínter anal interno. & $\begin{array}{l}\text { Resección interesfintérica } \\
\text { total. }\end{array}$ \\
\hline IV & $\begin{array}{l}\text { Infiltración del esfínter anal externo o } \\
\text { de los músculos elevadores }\end{array}$ & $\begin{array}{l}\text { Amputación abdomino- } \\
\text { perineal. }\end{array}$ \\
\hline
\end{tabular}


El papel de la linfadenectomía también presenta peculiaridades. Cuando se realiza tratamiento neoadyuvante con QRT se obtiene un número significativamente menor de ganglios linfáticos en la pieza quirúrgica y es habitual no alcanzar el límite de 12 ganglios habitualmente recomendado para el CCR, aun cuando se ha realizado adecuadamente la escisión completa del mesorrecto [130-132]. Se ha apreciado que esta disminución en el número de ganglios linfáticos resecados tras el tratamiento neoadyuvante con QRT no afecta al pronóstico oncológico, encontrándose resultados similares en cuanto a recurrencia local, SLE, SG y mortalidad asociada al cáncer [133,134].

\subsection{3.- PAPEL DEL ABORDAJE LAPAROSCÓPICO.}

Múltiples trabajos han evidenciado que el abordaje laparoscópico presenta resultados significativamente mejores en términos de menor morbilidad y mortalidad postoperatoria, menor estancia hospitalaria y menor tiempo hasta el inicio del tratamiento oncológico adyuvante (si lo hubiere) [135-137].

Sin embargo, diversos estudios han mostrado que no existen diferencias entre ambos abordajes en cuanto al pronóstico oncológico, obteniéndose resultados similares en la SLE, SG y tasa de recurrencia local [137-139]. 


\section{8.- TRATAMIENTO ONCOLÓGICO DEL CÁNCER COLORRECTAL.}

\subsection{1.- NEOADYUVANCIA PARA EL CÁNCER DE RECTO.}

Aunque las terapias dependen de las guías clínicas de diferentes países y centros, la modalidad más habitual en nuestro entorno es la neoadyuvancia de ciclo largo, con 25-30 sesiones de radioterapia (RT) a 1,8 Gy, combinado con quimioterapia (QT) mediante fluoruracilo intravenoso o capecitabina oral.

Las principales indicaciones para la aplicación de tratamiento neoadyuvante son la sospecha de afectación mural T3/T4, de presencia de ganglios positivos o de afectación de la fascia mesorrectal mediante RMN o TRUS. También supone una indicación relativa la presencia del tumor en el tercio distal, cuando existen dudas entre la realización de una AAP o una resección anterior ultrabaja. Se ha demostrado que el tratamiento neoadyuvante duplica las posibilidades de realizar este último procedimiento, lo que permite respetar los esfínteres y mejorar la función sexual y urinaria [140].

Existen diversos trabajos que comparan el tratamiento neoadyuvante con el adyuvante para cáncer de recto. Un estudio alemán observó que la tasa de recidiva local, tanto a los 5 como a los 10 años, fue significativamente menor para aquellos que recibieron tratamiento preoperatorio, sin afectar a la SG [140]. De forma similar, una publicación norteamericana mostró cómo la SLE a los 5 años fue significativamente mayor para el grupo con neoadyuvancia, sin afectar a la SG [141]. Por el contrario, un trabajo coreano evidenció que no existían diferencias en la SG, la SLE, ni en la tasa de recidiva local entre aquellos que recibían QRT preoperatoria y postoperatoria. Sólo se apreció que, en el grupo de 
neoadyuvancia, fue más frecuente la realización de cirugía con preservación de esfínteres en aquellos tumores del tercio inferior rectal [142].

Diferentes estudios han comparado la QRT con la RT en solitario como tratamientos neoadyuvantes para el cáncer de recto. Aunque se ha observado que en el grupo de la terapia combinada existen diferencias estadísticamente significativas a su favor en cuanto al control local del tumor (menor tamaño y mayor número de cirugías con preservación de esfínteres) y a la respuesta anatomopatológica (menor estadiaje T y N, menor infiltración linfovascular), no se encontraron diferencias en cuanto a las SG y a las SLE [143-145].

Hay algunos trabajos han comparado la neoadyuvancia de ciclo corto con la QRT preoperatoria habitual. La terapia de ciclo corto consiste en 5 sesiones de 5 Gy y cirugía en menos de 7 días, frente al procedimiento habitual de 25-30 sesiones a 1,8 Gy combinado con fluoruracilo intravenoso o capecitabina oral. Se ha apreciado que no hay diferencias en cuanto a la SG, a las SLE y a la toxicidad tardía entre ambas modalidades. De hecho, la tasa de toxicidad precoz es significativamente mayor entre aquellos sometidos a la neoadyuvancia de ciclo largo [146,147].

Las dos terapias más habitualmente utilizadas en la QT preoperatoria son el fluoruracilo intravenoso y la capecitabina oral. Diversos estudios han comparado sus efectos, mostrando que la tasa de remisión completa, el infraestadiaje, la tasa de cirugías con preservación de esfínteres, la SLE y la SG son similares con ambos fármacos, sin evidenciarse diferencias significativas en la toxicidad. La única diferencia relevante fue que, en uno de estos trabajos, los pacientes sometidos a capecitabina por vía oral presentaron una menor tasa de metástasis a distancia $[148,149]$. 


\section{Martín Bailón Cuadrado}

Se encuentra en entredicho en estos momentos el papel del oxaliplatino como fármaco añadido al fluoruracilo intravenoso o la capecitabina oral en la neoadyuvancia, con trabajos a favor y en contra. Algunos trabajos mostraron que la adición del oxaliplatino no mejoraba el control local del tumor, sin ningún tipo de diferencia en las tasas de resecciones R0 y de preservación de esfínteres, sin mejorar la SG ni la SLE, y a expensas de un claro aumento en la toxicidad [149-153]. Por el contrario, un estudio aleatorizado que comparaba la adición de oxaliplatino al tratamiento neoadyuvante con fluoruracilo intravenoso observó que añadiendo oxaliplatino se obtuvieron diferencias significativas en cuanto a mayores tasas de respuesta patológica completa (sin mejorar la tasa de resecciones R0) y mejor SLE, sin apreciarse mayor toxicidad $[154,155]$.

El papel del irinotecán en el tratamiento neoadyuvante del cáncer de recto también se encuentra en duda. Aunque algunas publicaciones muestran discretas mejorías en cuanto al control local de la enfermedad, un estudio aleatorizado que comparaba la adición de irinotecán al fluoruracilo intravenoso estableció que no existían diferencias en cuanto a la tasa de cirugías con resección R0 y con preservación de esfínteres, y con mismos resultados en la SLE y la SG [156].

Lo mismo ocurre con la leucovorina, a pesar de que algunos trabajos muestran la eficacia y la seguridad de combinarla con el fluoruracilo intravenoso, faltan estudios aleatorizados que comparen su adición con el tratamiento exclusivamente con fluoruracilo o capecitabina $[157,158]$. 
Otro estudio aleatorizado que comparaba la adición de oxaliplatino o leucovorina al tratamiento neoadyuvante con fluoruracilo intravenoso mostró que añadiendo oxaliplatino existían diferencias relevantes en la respuesta patológica completa (sin una mejor tasa de cirugías con preservación de esfínteres), sin diferencias en la SLE ni en la SG, y con una mayor toxicidad [159].

Se está estudiando el papel que pueden desarrollar los anticuerpos monoclonales (bevacizumab, cetuximab, panitumumab) en el tratamiento neoadyuvante del cáncer de recto. Aunque los primeros estudios (ensayos en fase II) muestran una mejoría importante en el control local de la enfermedad (a pesar de una gran toxicidad) con mayores tasas de cirugías con resecciones $\mathrm{R} 0$ y con preservación de esfínteres, faltan trabajos que muestren los resultados a largo plazo, en base a SLE, a la SG y a las complicaciones derivadas de estos tratamientos [160-162].

En cuanto a la RT utilizada en el tratamiento neoadyuvante, clásicamente supone de 25 a 30 sesiones de 1,8 Gy cada una, aplicadas 5 días por semana, para sumar un total de 45 a 54 Gy. Se utiliza la RT tridimensional, siguiendo la técnica de cuatro campos, con el objetivo de optimizar el control local de la lesión sin aumentar la toxicidad sobre órganos vecinos, principalmente vejiga e intestino delgado [159].

Uno de los aspectos más discutidos es el borde craneal de irradiación, ya que es una de las principales causas de morbilidad, en cuanto a la afectación del intestino delgado. Tradicionalmente se utilizaba la división de la arteria ilíaca común en interna y externa, lo que suele corresponderse con el promontorio sacro. Estudios recientes han mostrado que 


\section{Martín Bailón Cuadrado}

la mayoría de las recidivas ocurren en los dos tercios inferiores de la pelvis, es decir, por debajo de los agujeros vertebrales S2-S3 [163].

Otro tema ampliamente discutido es la inclusión del aparato esfinteriano dentro del campo de irradiación. Clásicamente se irradiaba en aquellos tumores que se encontrasen a menos de $6 \mathrm{~cm}$ del margen anal externo. Debido a la baja tasa de recidiva que se experimenta desde la generalización de la escisión completa del mesorrecto, se desaconseja su inclusión a menos que estén afectados los esfínteres, es decir, cuando se plantea una AAP [164].

\subsection{2.- TRATAMIENTO ADYUVANTE PARA CÁNCER DE COLON.}

\subsubsection{1.- ESTADIO II.}

Para los cánceres de colon ya intervenidos y con un estadiaje II (T3 o T4 sin adenopatías patológicas), el papel de la QT adyuvante se encuentra en duda.

El ensayo aleatorizado NSABP C-02, que comparaba el tratamiento adyuvante con fluoruracilo intravenoso frente a sólo cirugía, mostró que existía una tendencia hacia una mejor SG a los 5 años con la adyuvancia, pero que no llegaba a resultar estadísticamente significativa [165].

El ensayo aleatorizado QUASAR, que comparaba el tratamiento quirúrgico en solitario con la adyuvancia con fluoruracilo intravenoso, observó que existían diferencias estadísticamente significativas a favor del grupo con QT en cuanto a la SLE y a la SG. Se 
apreció, además, que el efecto protector de la QT adyuvante se evidenciaba principalmente durante los 2 primeros años [166].

Un metaanálisis con cinco estudios aleatorizados que comparaban la QT adyuvante con la cirugía en solitario no encontró ningún tipo de diferencias en el pronóstico de ambos grupos [167]. Sin embargo, otro metaanálisis que incluía siete ensayos aleatorizados de las mismas características observó diferencias estadísticamente significativas a favor del grupo con QT en cuanto a la SLE a los 5 años, sin evidenciar ninguna diferencia en la SG [168].

\subsubsection{2.- ESTADIO III.}

El tratamiento adyuvante de elección para aquellos cánceres de colon ya resecados y que presentan un estadio III (ganglios linfáticos afectados) consiste en 6 meses de fluoruracilo y leucovorina intravenosa o capecitabina oral, pudiendo añadir oxaliplatino [169-172].

El estudio MOSAIC comparó de forma aleatorizada el efecto de añadir oxaliplatino al tratamiento adyuvante intravenoso de fluoruracilo más leucovorina entre pacientes ya intervenidos de cáncer de colon con estadios II y III. Se observó que existían diferencias estadísticamente significativas para la SLE y la SG en el estadio III a favor del brazo sometido a tratamiento adyuvante con oxaliplatino, mientras que estos mismos parámetros no mostraban ningún tipo de diferencia entre ambos tratamientos entre aquellos pacientes con estadio II [173].

La base de datos ACCENT recoge datos de más de 12.000 pacientes procedentes de estudios que comparaban, en pacientes ya intervenidos de cáncer de colon con estadios II y 


\section{Martín Bailón Cuadrado}

III, el tratamiento neoadyuvante con fluoruracilo más leucovorina intravenosos o capecitabina oral, frente a la adición de oxaliplatino intravenoso. Se encontró que la tasa de recurrencia a los 5 años fue significativamente menor entre aquellos pacientes en los que se añadió oxaliplatino intravenoso, tanto para el estadio II como para el III. Por el contrario, la tasa de muerte asociada al cáncer a los 5 años fue significativamente menor en el brazo sometido a oxaliplatino sólo entre aquellos con estadio III, mientras que no se apreciaron diferencias entre ambos tratamientos para el estadio II [174].

\subsection{3.- TRATAMIENTO ADYUVANTE PARA CÁNCER DE RECTO.}

El tratamiento habitual para pacientes intervenidos de cáncer de recto con estadio II y III es la combinación de QT y RT.

El ensayo aleatorizado GITSG asignaba pacientes intervenidos de cáncer de recto con estadios B2 y C de la clasificación de Dukes-Astler-Coller en 4 brazos diferentes: observación, RT, QT (con fluoruracilo intravenoso y semustina) y QRT combinada. Las diferencias en cuanto a SLE y SG fueron tan significativas a favor del brazo del tratamiento combinado con QT y RT que el estudio tuvo que ser detenido [175].

El ensayo aleatorizado NCCTG comparaba la RT en solitario con la QRT (añadiendo fluoruracilo intravenoso y semustina) en pacientes intervenidos de cáncer de recto con estadios B2 y C de la clasificación de Dukes-Astler-Coller. Se encontraron diferencias estadísticamente relevantes a favor del brazo con QRT en cuanto a la tasa de recurrencia local de la enfermedad, de desarrollo de metástasis a distancia y muertes provocadas por cáncer [176]. 
El ensayo aleatorizado NSABP R01 distribuía a pacientes intervenidos de cáncer de recto con estadio B y C de la clasificación de Dukes-Astler-Coller en 3 brazos: observación, QT (con fluoruracilo, vincristina y semustina) y RT. Se apreciaron diferencias estadísticamente significativas a favor del grupo tratado con QT adyuvante en cuanto a SLE, sin encontrarse diferencias en la SG [177].

En cuanto a la forma de administración del fluoruracilo, existe debate entre la administración intravenosa continua y en bolos. En estudios comparando ambos procedimientos se evidenció que existían diferencias estadísticamente relevantes a favor del grupo que recibía el fármaco en infusión continua en cuanto a desarrollo de metástasis a distancia, SLE y SG. No se encontraron diferencias en la tasa de recurrencia local [178]. Estas ventajas se produjeron a expensas de un alto riesgo de desarrollar diarrea grave [179].

Al igual que ocurre en el tratamiento neoadyuvante, el tratamiento intravenoso con fluoruracilo se puede sustituir por capecitabina oral. En un ensayo aleatorizado, multicéntrico, centrado en demostrar la no inferioridad de la capecitabina oral en cuanto a la SG tanto en el tratamiento neoadyuvante como en el adyuvante, se observó que no existían diferencias relevantes en cuanto al control local de la enfermedad, a la tasa de cirugías con resección R0 y con preservación de esfínteres, a la SLE y a la SG. De hecho, se apreció una mayor tasa de recidiva a distancia, estadísticamente relevante, entre aquellos sometidos a tratamiento con fluoruracilo intravenoso [148].

Existe también debate sobre la adición de otros fármacos al fluoruracilo intravenoso o la capecitabina oral en el tratamiento adyuvante del cáncer de recto. 


\section{Martín Bailón Cuadrado}

El ensayo aleatorizado INT-0114 asignaba pacientes intervenidos de cáncer de recto a RT y uno de los siguientes tratamientos quimioterápicos: fluoruracilo, fluoruracilo más levamisol, fluoruracilo más leucovorina, y fluoruracilo más levamisol más leucovorina. Todos los parámetros pronósticos fueron similares en los 4 brazos de QT, por lo que se dedujo que tanto la leucovorina como el levamisol no aportaban ningún beneficio al tratamiento con fluoruracilo intravenoso para la QT adyuvante del cáncer de recto [180,181].

Un ensayo aleatorizado comparaba la combinación de fluoruracilo más leucovorina más irinotecán frente a fluoruracilo más leucovorina en pacientes intervenidos de cáncer de recto, además de la RT. Se apreció que no existía ningún tipo de diferencia entre ambos grupos en cuanto a la tasa de recurrencia, a la SLE ni a la SG. Además el brazo con irinotecán mostraba una mayor toxicidad, principalmente hematológica [182].

El ensayo aleatorizado ADORE distribuyó pacientes intervenidos de cáncer de recto a QRT con fluoruracilo más leucovorina frente a fluoruracilo más leucovorina más oxaliplatino. Se observó que la SLE a los 3 años era significativamente mayor en el grupo en el que se añadió oxaliplatino. Por el contrario, la toxicidad también fue significativamente más elevada en este mismo grupo, en especial la hematológica [183].

Por todos estos motivos, las guías del NCCN recomiendan FOLFOX (fluoruracilo intravenoso más leucovorina más oxaliplatino) o CAPOX (capecitabina oral más oxaliplatino) en combinación con RT como tratamiento adyuvante del cáncer de recto [89]. 


\section{9.- PATOGENIA DEL DETERIORO INMUNO-NUTRICIONAL.}

En el paciente oncológico se genera una interacción entre el tumor y el propio huésped, desencadenándose una reacción inflamatoria sistémica que, a su vez, conduce a una situación de desnutrición.

El tumor interactúa con el huésped generando una respuesta inflamatoria sistémica mediante la liberación de diversas citoquinas como las interleuquinas (IL) IL-1, IL-2, IL-6, IL-8, IL-10, el tumour necrosis factor $\alpha(\mathrm{TNF} \alpha)$ o el macrophage inbibitory yytokine 1 [184]. Éstas provocan anorexia, tendencia al catabolismo, alteraciones neuroendocrinas y la liberación de reactantes de fase aguda. Además, el tumor libera de forma directa factores que estimulan el catabolismo, como el TNF $\alpha$, el proteolysis inducing factor, la adiponectina o el lipid mobilising factor, lo que se traduce en un aumento de proteolisis y lipolisis [185].

\subsection{1.- REACTANTES DE FASE AGUDA.}

La liberación de citoquinas por el propio tumor estimula la liberación de reactantes de fase aguda por parte del hígado del huésped. Los reactantes positivos de fase aguda más relevantes son la proteína $\mathrm{C}$ reactiva (PCR) y el fibrinógeno [186].

Los niveles plasmáticos de PCR en pacientes oncológicos se han relacionado de forma significativa con pérdida de peso, anorexia, hipercatabolismo y peor pronóstico oncológico $[187,188]$.

Por el contrario, existe un descenso de los niveles de reactantes negativos de fase aguda. El más importante es la albúmina, cuya concentración plasmática se reduce ante situaciones de 


\section{Martín Bailón Cuadrado}

respuesta inflamatoria sistémica [189]. Se ha observado que la tasa de síntesis de esta proteína no disminuye en estas situaciones, pero sí aumenta su consumo. Por un lado, el tumor actúa como una "trampa", captando proteínas plasmáticas que degrada para su propio crecimiento [190]. Por otro lado, existe una gran extravasación de albúmina favorecida por el aumento de permeabilidad vascular que genera el TNF $\alpha$ [191].

\subsection{2.- ANOREXIA.}

El apetito y el nivel de gasto energético se regulan a nivel del hipotálamo mediante un equilibrio entre estímulos orexígenos y anorexígenos. El neuropéptido Y constituye el principal estímulo orexígeno, potenciando el efecto parasimpático, lo que genera aumento de apetito y un menor gasto de energía. La proopiomelanocortina actúa como el principal estímulo anorexígeno, potenciando el efecto simpático, lo que genera un mayor gasto energético y una disminución del apetito [192].

La leptina es una proteína que actúa como regulador del equilibrio entre estímulos orexígenos y anorexígenos. Su nivel es directamente proporcional al nivel de grasa del tejido adiposo. Actúa como un estímulo anorexígeno, disminuyendo el apetito y aumentando el gasto de energía. Ante un estado de respuesta inflamatoria sistémica, la IL-1 y el TNF $\alpha$ estimulan de forma muy importante el efecto de señalización de la leptina, mediante un aumento de la síntesis del ácido ribonucleico mensajero de ésta. Esto genera un estado de anorexia y de aumento del gasto energético en el paciente oncológico [193]. 


\subsection{3.- PROTEOLISIS.}

El proteolysis inducing factor se libera desde el tumor y desempeña un papel crucial en la proteolisis mediante la estimulación de la degradación de proteínas. El mecanismo se centra en la activación del factor de transcripción nuclear factor kappa-light-chain enhancer of activated B cells, que permite, a su vez, la activación de la vía ubicuitina-proteasoma [194]. Esto genera una gran degradación de proteínas y una subsecuente sarcopenia en el paciente oncológico.

\subsection{4.- LIPOLISIS.}

El lipid mobilising factor es creado por el propio tumor y cumple un papel fundamental en la lipolisis. Por un lado, estimula la adenil-ciclasa en procesos dependientes de guanosina trifosfato, lo que aumenta la lipolisis [195]. Por otro lado, interactúa con el receptor adrenérgico $\beta 3$ aumentado el efecto lipolítico que ejercen las catecolaminas sobre el tejido adiposo [196]. Mediante estos dos mecanismos, se potencia la lipolisis en el paciente oncológico.

\subsection{5.- ALTERACIONES NEUROENDOCRINAS.}

Durante el proceso de respuesta inflamatoria sistémica generado por la interacción entre el tumor y el huésped se produce un descenso de hormonas anabólicas (insulina, hormona del crecimiento, testosterona) y un aumento de hormonas catabólicas (cortisol, miostatina). De este modo, el paciente oncológico presenta una marcada resistencia a la insulina y a la hormona del crecimiento, hipogonadismo y niveles elevados de cortisol [197,198]. 


\section{Martín Bailón Cuadrado}

Además, esta respuesta inflamatoria sistémica provoca un desequilibrio del sistema nervioso autónomo hacia un predominio de la actividad adrenérgica, lo que estimula la angiogénesis y favorece el crecimiento del tumor [199].

\subsection{0.- SCORES INMUNONUTRICIONALES.}

En las últimas décadas se ha analizado en profundidad la íntima relación que existe entre el estado inflamatorio y nutricional con el cáncer en general. En consecuencia, para cuantificar esta situación en los pacientes oncológicos, se han desarrollado diferentes índices y scores, calculados mayoritariamente a partir de variables obtenidas de una analítica sanguínea preoperatoria.

\subsection{1.- PROGNOSTIC NUTRITIONAL INDEX (PNI).}

En 1984, Onodera desarrolló un índice biparamétrico para valorar el estado nutricional de los pacientes oncológicos, con la intención de predecir las posibles complicaciones postoperatorias que éstos pudieran desarrollar [200]. Se calcula mediante una simple fórmula matemática utilizando valores obtenidos de una analítica del paciente:

$$
\text { PNI }=(\text { Albúmina en suero }[\mathrm{g} / \mathrm{dL}] \times 10)+(\text { Linfocitos } / \mu \mathrm{L} \times 0,005)
$$

Cuanto menor es el resultado de esta variable, peor será el estado inmunonutricional del paciente.

Se han utilizado diferentes valores de corte para definir los niveles de riesgo. En estudios prospectivos los más utilizados han sido 40 y/o 45, para establecer dos o tres grupos de riesgo. Mientras que en los retrospectivos se han empleado curvas de regresión logística 
para establecer otros valores de corte con los que se logra una mayor sensibilidad y especificidad para cada muestra concreta [200].

El PNI se relaciona de forma estadísticamente significativa con un peor estadiaje anatomopatológico, es decir, con una enfermedad más avanzada en cuanto a invasión local, presencia de adenopatías patológicas o metástasis a distancia [201,202].

Se trata de una variable que influye de forma independiente y estadísticamente significativa en el pronóstico oncológico de diversos cánceres, obteniéndose peor SG y SLE cuanto menor es su valor [203-205].

Así mismo, se vincula de forma inversamente proporcional con una mayor tasa de complicaciones tras cirugía curativa para CCR, especialmente para aquellas graves (DindoClavien $\geq$ III) e infecciosas, aunque existen aún muy pocos artículos publicados [206-208].

\subsection{2.- GLASGOW PROGNOSTIC SCORE (GPS).}

Este índice fue desarrollado por el Royal Infirmary de la Universidad de Glasgow, en 2004. Utiliza los valores de albúmina y de PCR para estimar el estado inmunonutricional que presentan los pacientes oncológicos [209,210]. Se le asigna 1 punto si el valor de PCR es > $10 \mathrm{mg} / \mathrm{L}$, también se le asigna 1 punto si el valor de albúmina es $<3,5 \mathrm{~g} / \mathrm{dL}$. Por lo tanto puede tener valores de 0,1 o 2 [Tabla 6]. De este modo se establecen diferentes niveles de estado inmunonutricional. Cuanto mayor es el valor de este score, mayor es la respuesta inflamatoria sistémica que muestra el paciente. 


\section{Martín Bailón Cuadrado}

Tabla 6. Puntuación del GPS en función de los valores de PCR y albúmina.

\begin{tabular}{|c|c|c|c|}
\hline \multicolumn{2}{|c|}{ Valores de GPS } & \multicolumn{2}{c|}{ PCR $(\mathrm{mg} / \mathrm{L})$} \\
\cline { 3 - 4 } & & $\leq 10$ & $>10$ \\
\hline \multirow{2}{*}{ Albúmina $(\mathrm{g} / \mathrm{dL})$} & $>3,5$ & 0 & 1 \\
\cline { 2 - 4 } & $\geq 3,5$ & 1 & 2 \\
\hline
\end{tabular}

En múltiples estudios se ha evidenciado que se trata de una variable que se relaciona de forma independiente y estadísticamente significativa con el pronóstico oncológico de diversos cánceres, en especial del colorrectal. De tal modo, cuanto mayor es su valor, peores resultados de SG y SLE se obtienen [211-214].

Aunque se ha estudiado en menor profundidad, también se ha advertido que el GPS tiene una relación significativa con la tasa de complicaciones tras cirugía curativa de CCR, en especial con aquellas infecciosas [215,216].

\subsection{3.- MODIFIED GLASGOW PROGNOSTIC SCORE (mGPS).}

Al igual que el índice previo, también fue desarrollado por el Royal Infirmary de la Universidad de Glasgow, en 2007. Al igual que el GPS, utiliza los valores de albúmina y de PCR para estimar el estado inmunonutricional que muestran los pacientes oncológicos. Observaron que aquellos pacientes con un GPS de 2 presentaban un pronóstico oncológico mucho peor que los que tenían un GPS de 1. Además apreciaron que la hipoalbuminemia sin elevación de PCR es muy poco frecuente y que la albúmina tenía peor capacidad pronóstica que la PCR. Por estos motivos, se le otorga 1 punto si la PCR es $>10$ 
$\mathrm{mg} / \mathrm{L}$ y otro punto adicional si la albúmina es $<3,5 \mathrm{~g} / \mathrm{dL}$ además de la elevación de la PCR. De este modo la hipoalbuminemia sin elevación de la PCR obtendría 0 puntos [217].

El mGPS se relaciona de forma directamente proporcional a su puntuación con la tasa de complicaciones tras cirugía curativa para cáncer de colon y recto, en especial con aquellas infecciosas como colecciones intraabdominales o infección de la herida quirúrgica (IHQ). Además se asocia con una mayor estancia hospitalaria postoperatoria y con un peor pronóstico oncológico [218,219].

El aspecto más estudiado de este score ha sido su vinculación con el pronóstico oncológico.

De hecho, diversos artículos han concluido que el mGPS se comporta como un factor de pronóstico oncológico independiente del sexo, la edad, la localización y el estadio del tumor [220-222].

En cuanto al CCR, muestra una relación muy significativa con la OS en todos los estadios de la enfermedad, incluso cuando existen metástasis a distancia o carcinomatosis peritoneal [223-226].

\subsection{4.- GRANULOCYTE/LYMPHOCYTE RATIO (GLR).}

Se trata de la proporción entre leucocitos y linfocitos totales y se calcula dividiendo el número total de ambos recuentos celulares por $\mu \mathrm{L}$. Se han utilizado habitualmente los valores de 2,5 y de 3,5 para, de este modo, definir 3 grupos de riesgo $(<2,5 ; 2,5$ a 3,5; $>$ $3,5)$. 


\section{Martín Bailón Cuadrado}

Su valor guarda relación con el grado de respuesta inflamatoria sistémica que presenta el paciente, ya que muestra una asociación significativamente positiva con los valores de IL-6, $\mathrm{TNF} \propto$ y macrophage colony stimulating factor [227].

Ha mostrado ser una variable que se relaciona de forma independiente y estadísticamente significativa con la tasa de complicaciones y con la mortalidad postoperatoria tras la cirugía curativa de CCR [228].

Su valor, al igual que el de IL-6 (cuyos valores están relacionados), se vincula significativamente y de forma inversamente proporcional con la supervivencia en términos de SG para los pacientes con cáncer de colon y recto [229].

También se ha apreciado que entre pacientes con CCR que ya presentan una enfermedad diseminada (estadio IV), la supervivencia es marcadamente inferior entre aquellos que muestran valores de GLR más elevados [230].

\subsection{5.- NEUTROPHILE/LYMPHOCYTE RATIO (NLR).}

Este cociente fue descrito en 2005 con la intención de establecer el estado de respuesta inflamatoria sistémica de los pacientes [231]. Se trata de la proporción entre neutrófilos y linfocitos totales y se calcula dividiendo el número total de ambos recuentos celulares por $\mu \mathrm{L}$.

Se han utilizado diferentes valores de corte para definir los grupos de riesgo que presentan una mayor respuesta inflamatoria. Se correlaciona de forma directamente proporcional con 
los niveles de PCR, por lo que su valor es reflejo del estado inflamatorio que muestra el paciente [232].

Son pocos los trabajos que han evidenciado la relación existente con las complicaciones postoperatorias y con la estancia hospitalaria tras la cirugía curativa de CCR [141]. Entre otros aspectos, existe un riesgo hasta 3 veces mayor de sufrir una fuga anastomótica si el valor de este cociente se encuentra elevado [233].

Se ha estudiado el valor que presenta este score en pacientes con CCR, con pólipos colorrectales y en individuos sanos. Se observó que éste era estadísticamente superior en el primer grupo con respecto a los otros dos. Por este motivo se ha postulado como un método complementario de seguimiento en pacientes con pólipos en cuanto a que un aumento de su valor puede hacer sospechar, de forma barata y sencilla, la presencia de CCR [234].

Se ha detectado también su vinculación con el grado de avance de la enfermedad, ya que se correlaciona significativamente con el avance local (mayor T del TNM) y con la presencia de adenopatías patológicas ( $\mathrm{N}$ del TNM) [232,235].

En cuanto al pronóstico oncológico del CCR y su relación con el NLR, se ha apreciado que es peor entre aquellos pacientes con valores elevados de este score en cuanto a SG, SLE, cáncer specific survival y progression free survival [236-240].

Sin embargo, aunque los pacientes presentan una menor supervivencia cuanto mayor es su valor de NLR para estadios avanzados de CCR, se ha observado que la mejoría en 


\section{Martín Bailón Cuadrado}

supervivencia tras QT adyuvante es mayor entre aquellos que manifiestan valores más elevados tanto de NLR como de Platelet/Lymphocyte Ratio (PLR) [235].

\subsection{6.- PLATELET/LYMPHOCYTE RATIO (PLR).}

Se trata de la proporción entre plaquetas y linfocitos totales y se calcula dividiendo el número total de ambos recuentos celulares por $\mu \mathrm{L}$. A lo largo de la literatura se han utilizado diferentes puntos de corte para definir los grupos de riesgo que presentan una mayor respuesta inflamatoria sistémica.

Se ha estudiado principalmente su vinculación con el pronóstico oncológico de diferentes cánceres. En el CCR, se correlaciona de forma significativa con la supervivencia, de un modo inversamente proporcional a su valor, de tal modo que cuanto más elevado se muestra este cociente, peor es la SG, SLE y la supervivencia específica por cáncer $[235,241-245]$.

Al igual que se apreció con el NLR, el valor de PLR es muy superior en pacientes con CCR comparado con pacientes sanos o con pólipos no malignizados. Por lo que se ha propuesto como un método complementario de seguimiento en pacientes con pólipos ya que un aumento de su valor también puede hacer sospechar, de forma barata y sencilla, la presencia de CCR [234].

Al contrario que el resto de scores, su relación con la aparición de complicaciones y con la mortalidad postoperatoria apenas ha sido estudiada, y cuando lo ha sido, no ha mostrado 
una significación estadística relevante como para ser considerada una variable capaz de predecir la morbimortalidad postoperatoria [246].

\subsection{7.- ALBÚMINA Y PREALBÚMINA.}

Tanto la albúmina como la prealbúmina se han utilizado extensamente en la valoración nutricional de pacientes. $\mathrm{Y}$ aunque no reflejan de forma muy fidedigna el grado de desnutrición proteica, sus niveles sí se modifican de forma importante ante situaciones inflamatorias, lo que les hace unos marcadores fiables, rápidos y sencillos a la hora de valorar el estado nutricional e inflamatorio de los pacientes oncológicos. La prealbúmina se presenta como un marcador mucho más relevante en este sentido, ya que su vida media es de 2 días, mucho menor que la de la albúmina, que es de 20 días [247].

Diversos estudios han evidenciado que los niveles de albúmina se relacionan con la aparición de complicaciones postoperatorias tras cirugía colorrectal, incluso con un mayor número de fugas anastomóticas [248-250]. Así mismo, los niveles de prealbúmina se vinculan con un mayor número de complicaciones tras cirugía digestiva, en especial con aquellas infecciosas $[251,252]$.

\subsection{1.- COMPLICACIONES TRAS CIRUGÍA COLORRECTAL.}

La tasa de complicaciones postoperatorias se sitúa en torno al 20\% para el cáncer de colon y el $40 \%$ para el de recto según publicaciones recientes [253,254]. 


\section{Martín Bailón Cuadrado}

- Las complicaciones médicas más relevantes son edema agudo de pulmón (2,9\%), neumonía (2,4-6,2\%), insuficiencia renal (0,6-2\%), cardiopatía isquémica $(0,5 \%)$ y accidente cerebro-vascular agudo (0,4\%) [255-257].

- Entre las quirúrgicas, las más importantes son íleo paralítico (7,5\%), IHQ (3,810,5\%) y fuga anastomótica (4\% para el colon derecho, 5,2\% para el izquierdo, y hasta el 15\% para el recto) $[258,259]$. La mortalidad durante los 30 primeros días del postoperatorio se sitúa en el 1-5\% [260].

\subsection{1.- MÉDICAS.}

La insuficiencia cardiaca aparece característicamente en las primeras $24-48$ horas y puede desencadenarse por isquemia coronaria, valvulopatías, arritmias, sepsis o sobrecarga de volumen. Esta última circunstancia es uno de los aspectos más importantes del manejo médico postoperatorio. La aparición de esta complicación se manifiesta mediante taquicardia, hipotensión, edemas periféricos y desaturación secundaria al desarrollo de edema agudo de pulmón. Continúa representando una importante causa de mortalidad, por lo que hay que utilizar adecuadamente la sueroterapia para evitar un aumento de la precarga en pacientes añosos y con factores de riesgo cardiovascular [261].

La cardiopatía isquémica es una de las complicaciones más temidas de un postoperatorio, ya que alcanza unas tasas de mortalidad perioperatorias cercanas al 30\%. Casi uno de cada tres pacientes sometidos a cirugía padecen algún grado de enfermedad coronaria ateroesclerótica, en relación a hipertensión arterial (HTA), diabetes mellitus, tabaquismo y dislipemia. Existen algunas circunstancias vinculadas con la cirugía y el postoperatorio que desestabilizan el equilibrio entre el oxígeno que llega al miocardio y el 
que consume, como fiebre, taquicardia, hipotensión, hipoxemia o anemia. La liberación de catecolaminas provocada por el estrés quirúrgico se relaciona también con el desarrollo de cardiopatía isquémica, por lo que hay que intentar realizar procedimientos cada vez menos invasivos para tratar de disminuir esta agresión [262].

La atelectasia pulmonar es la complicación postoperatoria más habitual. Supone la hipoventilación de las zonas más periféricas del pulmón por el colapso de los alveolos que se produce de forma secundaria a la anestesia general, la incisión abdominal y los analgésicos opiáceos que se utilizan durante el postoperatorio inmediato. Tiene una mayor incidencia entre ancianos, pacientes inmunodeprimidos, desnutridos, fumadores, bebedores, en los que se ha colocado una sonda nasogástrica, y entre aquellos sometidos a tratamiento preoperatorio con antibióticos o con inhibidores de la bomba de protones [263].

La lesión pulmonar aguda y el síndrome de distress respiratorio del adulto son complicaciones respiratorias menos frecuentes. Se generan por una respuesta inflamatoria del parénquima pulmonar que lleva a la acumulación de líquido en el alveolo y al engrosamiento de la membrana alveolo-capilar. Algunas circunstancias que desencadenan esta entidad clínica son procesos inflamatorios, como traumatismos graves, quemaduras o neumonitis por radiación; o cuadros infecciosos graves, como sepsis, pancreatitis o neumonía [264].

La insuficiencia renal supone la acumulación en la sangre de productos de degradación del metabolismo celular, principalmente nitrogenados, por falta de eliminación de los mismos por parte del riñón. Aparece principalmente en el contexto de procedimientos de 


\section{Martín Bailón Cuadrado}

cirugía vascular mayor, o bien en contextos en las que se han generado situaciones de hipotensión arterial grave, como en grandes hemorragias. Durante el postoperatorio tenemos que evitar la deshidratación y la hipotensión en pacientes con alto riesgo de nefropatía, como son, por ejemplo, los diabéticos. Otro aspecto fundamental es tratar de controlar el uso de antiinflamatorios no esteroideos, ya que disminuyen de forma importante el filtrado glomerular mediante la inhibición de la vasodilatación aferente en la nefrona [265].

El accidente cerebro-vascular agudo supone una complicación devastadora y que conlleva una elevada morbilidad y mortalidad. El más frecuente es el de tipo isquémico y tiene su origen en graves situaciones de hipotensión arterial o en la formación de émbolos en pacientes con arritmias, en especial en aquellos con fibrilación auricular. El tipo hemorrágico es mucho menos común y se da en pacientes con una cierta predisposición, como aquellos en tratamiento con fármacos anticoagulantes, alcohólicos crónicos, consumidores de cocaína, o pacientes con síndrome de inmunodeficiencia adquirida [266].

\subsection{2.- QUIRÚRGICAS.}

El íleo postoperatorio habitual después de toda cirugía abdominal se extiende hasta unas 72 horas. Cuando es más prolongado comienza a denominarse adinámico o paralítico. Poco se conoce acerca del mecanismo que lo produce, aunque se sabe que después del estrés quirúrgico de la intervención se desencadena una respuesta inflamatoria local que, a su vez, genera una compleja interacción entre el sistema nervioso central, el sistema endocrino, el sistema nervioso entérico y diversos factores inflamatorios celulares y humorales. Durante el periodo postoperatorio, se ha observado que la dieta absoluta 
prolongada y el uso de analgésicos opiáceos favorecen la perpetuación de esta situación [267].

La fuga anastomótica es una de las complicaciones más preocupantes tanto para el cirujano como para el paciente, ya que conlleva una importante morbilidad y puede obligar a una reintervención.

El nivel anatómico de la anastomosis es importante ya que no siempre existe el mismo riesgo de fuga. Las más peligrosas son la esofagoyeyunal, la pancreatoyeyunal y la colorrectal. En el recto, el lugar que presenta una mayor tasa de fuga anastomótica es cuando la sutura se encuentra entre 6 y $8 \mathrm{~cm}$ del margen anal. Otros factores que contribuyen a la fuga en el recto son la escisión total del mesorrecto y el tratamiento neoadyuvante con QT y/o RT.

Se ha observado que algunas prácticas muy extendidas entre los cirujanos favorecen su aparición. La preparación mecánica anterógrada genera una serie de cambios inflamatorios y alteraciones estructurales en la mucosa y en la pared intestinal que favorecen la tasa de fuga anastomótica, de IHQ y de reintervención [268]. El papel de los drenajes es dudoso, y mientras que durante las primeras $24-48$ horas ayuda a eliminar sangre y detritus del lecho quirúrgico disminuyendo la respuesta inflamatoria local y contribuyendo a la integridad de la anastomosis, se ha apreciado que si se mantienen de forma más prolongada hay un aumento en la tasa de fuga anastomótica. Los estomas derivativos no disminuyen su incidencia pero disminuyen el grado de contaminación y la tasa de reintervención [269]. El bevacizumab y otros fármacos antiangiogénicos aumentan la tasa de fuga de la anastomosis, mediante la inhibición de la formación del vascular endotelial growth factor, que es fundamental para la neoangiogénesis y para la supervivencia de las células endoteliales. Este mecanismo es fundamental para luchar contra el crecimiento de un tumor de estirpe 


\section{Martín Bailón Cuadrado}

endotelial, pero también impide el desarrollo de la microvascularización de la nueva anastomosis, dificultando su adecuada cicatrización y favoreciendo su dehiscencia [270]. Otras circunstancias también afectan a la microcirculación de la anastomosis comprometiendo su integridad, como la diabetes mellitus, la HTA y el tabaquismo.

Así mismo, el consumo de corticoides disminuye la síntesis de colágeno y la formación de transforming growth factor $\beta$ y de insuline-like growth factor, lo que dificulta la adecuada cicatrización de la anastomosis.

La IHQ es una complicación relativamente frecuente que, lejos de suponer simplemente un problema estético, implica una elevada morbilidad, siendo un factor fundamental en la aparición de hernia incisional. Se suele desarrollar en los primeros 5 o 6 días de la intervención y supone el 40\% de las infecciones adquiridas en el ámbito hospitalario entre los pacientes quirúrgicos. En la mitad de los casos se aíslan cocos gram positivos, como Staphylococcus aureus y Enterococcus, y en un tercio bacilos gram negativos como Escherichia coli, Pseudomonas aeruginosa y Enterobacter. Según el National Nosocomial Infections Surveillance System, los pacientes se clasifican por su riesgo de desarrollar IHQ prestando atención a tres factores fundamentales: cirugía sucia o contaminada, tiempo de intervención que supera el percentil 75 de la duración habitual de ese procedimiento y riesgo anestésico grado III, IV o V de la ASA (American Society of Anesthesiologists) [271,272].

En cuanto a las variables intraoperatorias, un tiempo quirúrgico prolongado se relaciona con la aparición de fuga anastomótica [273]. Por su parte, la transfusión intraoperatoria de concentrados de hematíes se vincula a un peor pronóstico oncológico en cuanto a menos SG, pero también se asocia con una mayor tasa de complicaciones [274,275]. 


\subsection{3.- GRADACIÓN DE LAS COMPLICACIONES}

Desde que Dindo et al. publicaron en 2004 su clasificación de complicaciones quirúrgicas, es habitual que los estudios la utilicen para expresar los resultados de su morbilidad. El sistema de gradación que diseñaron se relaciona de forma significativa con la complejidad de los procedimientos quirúrgicos y con la estancia hospitalaria postoperatoria. La definición de los distintos niveles de gravedad se reflejan en la tabla 7 [276]. En la tabla 8 se exponen ejemplos clínicos de cada uno de estos niveles.

Tabla 7. Definición de los niveles de gravedad de las complicaciones quirúrgicas.

\begin{tabular}{|c|c|c|}
\hline \multicolumn{2}{|c|}{ Grado } & Definición \\
\hline \multicolumn{2}{|c|}{$\mathbf{I}$} & $\begin{array}{l}\text { Cualquier desviación del postoperatorio habitual. Sin tratamientos } \\
\text { farmacológicos, radiológicos, endoscópicos o quirúrgicos. Se permiten: } \\
\text { analgésicos, antipiréticos, antieméticos y diuréticos. Se contempla también } \\
\text { la IHQ explorada en la propia cama del enfermo. }\end{array}$ \\
\hline \multicolumn{2}{|c|}{ II } & $\begin{array}{l}\text { Otros tratamientos farmacológicos no contemplados en el grado I. Se } \\
\text { incluye la transfusión de hemoderivados y la nutrición parenteral. }\end{array}$ \\
\hline \multirow{2}{*}{ III } & IIIa & Intervención radiológica, endoscópica o quirúrgica sin anestesia general. \\
\hline & IIIb & Intervención radiológica, endoscópica o quirúrgica con anestesia general. \\
\hline \multirow{2}{*}{ IV } & IVa & $\begin{array}{c}\text { Fallo de un único órgano, con necesidad de manejo en unidades de } \\
\text { cuidados intensivos. }\end{array}$ \\
\hline & $\mathbf{I V b}$ & $\begin{array}{l}\text { Fallo multiorgánico, con necesidad de manejo en unidades de cuidados } \\
\text { intensivos. }\end{array}$ \\
\hline \multicolumn{2}{|c|}{ V } & Muerte del paciente. \\
\hline
\end{tabular}




\section{Martín Bailón Cuadrado}

Tabla 8. Ejemplos clínicos de cada uno de los niveles de gravedad de las complicaciones quirúrgicas.

\begin{tabular}{|c|c|c|}
\hline \multicolumn{2}{|c|}{ Grado } & Definición \\
\hline \multicolumn{2}{|c|}{ I } & $\begin{array}{c}\text { Arritmia que puede corregirse con reposición electrolítica. } \\
\text { Atelectasia que precisa fisioterapia. } \\
\text { IHQ que se explora en la cama del enfermo. }\end{array}$ \\
\hline \multicolumn{2}{|c|}{ II } & $\begin{array}{c}\text { Taquiarritmia que precisa tratamiento con antagonistas de receptores } \beta \text {. } \\
\text { Neumonía o infección urinaria tratada con antibióticos. } \\
\text { Trombosis venosa profunda que requiere anticoagulantes. }\end{array}$ \\
\hline \multirow[t]{2}{*}{ III } & IIIa & $\begin{array}{c}\text { Bradiarritmia a la que hay que colocar marcapasos. } \\
\text { Colección intraabdominal que se drena percutáneamente mediante } \\
\text { radiología intervencionista. } \\
\text { Estenosis ureteral que requiere la colocación de catéteres. }\end{array}$ \\
\hline & IIIb & $\begin{array}{l}\text { Reintervención, bien mediante laparotomía, toracotomía o apertura de } \\
\text { ventana pericárdica. }\end{array}$ \\
\hline \multirow{2}{*}{ IV } & IVa & $\begin{array}{l}\text { Insuficiencia cardiaca o respiratoria, ictus isquémico o hemorrágico, } \\
\text { insuficiencia renal que precisa diálisis, pancreatitis necrohemorrágica. }\end{array}$ \\
\hline & IVb & Combinación del fallo de 2 o más órganos. \\
\hline \multicolumn{2}{|c|}{ V } & Muerte del paciente. \\
\hline
\end{tabular}

\subsection{4.- RELACIÓN ENTRE LA NEOADYUVANCIA PARA EL CÁNCER DE RECTO Y EL}

\section{DESARROLLO DE COMPLICACIONES POSTOPERATORIAS.}

Aunque el tratamiento neoadyuvante con QRT preoperatoria para el cáncer de recto ha mostrado grandes resultados en términos de pronóstico oncológico, se ha insinuado que puede suponer una mayor tasa de complicaciones y mortalidad. Son muchos los artículos que muestran evidencias apoyando esta hipótesis, pero también hay muchos otros que no encuentran diferencia alguna entre ambos planteamientos [277-279]. En un estudio con 387 pacientes en el que se comparaba la tasa de complicaciones postoperatorias tras cirugía curativa de cáncer de recto en función de si habían recibido neoadyuvancia con QRT, se observó que aumentaban de forma muy relevante las complicaciones quirúrgicas entre los 
que habían recibido este tratamiento preoperatorio, en especial la IHQ, infección perineal tras AAP y fuga anastomótica; sin embargo, las complicaciones médicas fueron significativamente menores en este mismo grupo [280]. Otro estudio con 325 pacientes y un planteamiento similar al previo apreció que entre aquellos sometidos a AAP por cáncer de recto no existía ningún tipo de diferencia en cuanto a morbilidad o mortalidad, mientras que entre los sometidos a resecciones con anastomosis se encontró una discreta tendencia hacia una mayor morbilidad en el grupo sometido a neoadyuvancia, pero las diferencias no llegaron a ser estadísticamente significativas [281]. Un trabajo con 1798 pacientes que comparaba la morbilidad postoperatoria en aquellos sometidos a procedimiento de Hartmann por cáncer de recto en función de si habían recibido o no RT preoperatoria evidenció que la tasa de colección intraabdominal era significativamente mayor entre los que habían recibido RT, sin embargo no existían diferencias en cuanto a la tasa de reintervención o mortalidad entre ambos grupos [282]. Una publicación similar con 6297 pacientes con cáncer de recto en el que se comparaba la tasa de complicaciones y la mortalidad en función de si habían sido sometidos a RT mostró que no existían diferencias relevantes en cuanto a la tasa global de complicaciones, de complicaciones de la herida quirúrgica, de estancia hospitalaria, de reintervención o de mortalidad postoperatoria [283].

\subsection{5.- RELACIÓN ENTRE LAS COMPLICACIONES POSTOPERATORIAS Y EL} PRONÓSTICO ONCOLÓGICO.

En los últimos años se ha apreciado que el desarrollo de complicaciones durante el postoperatorio de la cirugía curativa del CCR no sólo afecta a la calidad de vida y la tasa de mortalidad a corto plazo, sino que también influye de manera muy relevante en el pronóstico oncológico a largo plazo. Un metaanálisis mostró que el desarrollo de 


\section{Martín Bailón Cuadrado}

complicaciones infecciosas y graves se relacionaba con peor SG y SLE, sin embargo las complicaciones no infecciosas no afectaban al pronóstico oncológico [284]. Otro metaanálisis también reflejó que las complicaciones, y en especial las infecciosas, se traducían en peores resultados oncológicos, con una menor SG y SLE [285]. Law et al. evidenciaron que la aparición de fuga anastomótica tras la cirugía curativa de CCR se vinculaba con un peor pronóstico oncológico en cuanto a peor supervivencia y mayores tasas de recurrencia, tanto local como a distancia [286]. Otros tres trabajos obtuvieron resultados similares, excepto porque para dos de ellos las diferencias para una mayor recurrencia a distancia no llegaron a ser estadísticamente significativas [287-289]. Sin embargo, Nachiappan et al. sólo encontraron diferencias estadísticamente significativas entre la aparición de fuga anastomótica y un peor pronóstico oncológico si el paciente tenía que ser reintervenido [290].

\subsection{2.- JUSTIFICACIÓN.}

El CCR es un importante problema tanto sanitario como social ya que su incidencia es elevada y está aumentando en los últimos años. Además, las posibles complicaciones derivadas de la cirugía pueden llegar a ser muy graves ya que es una zona contaminada por naturaleza y por el hecho de que los pacientes intervenidos cada vez son más añosos.

En los últimos años se ha analizado en profundidad la relación existente entre el estado nutricional e inflamatorio y el cáncer, observándose que en el paciente oncológico se genera una interacción entre el tumor y el propio huésped, desencadenándose una reacción inflamatoria sistémica que, a su vez, conduce a una situación de desnutrición mediante diversos mecanismos inmunológicos y neuroendocrinos. 
Todos estos hallazgos han llevado a la creación de diferentes índices y scores para valorar adecuadamente ese estado nutricional e inflamatorio en el paciente con cáncer. La mayoría de estudios relacionados con estos scores se han centrado en analizar su vinculación con el pronóstico oncológico. Son pocos los trabajos que han examinado su influencia sobre la aparición de complicaciones postoperatorias y los que hay se centran en uno o dos scores y en una o dos variables postoperatorias.

Por estos motivos resulta de gran interés analizar de forma simultánea la influencia de varios scores sobre la aparición de varios tipos de complicaciones postoperatorias tras la cirugía curativa del CCR.

Además, los scores descritos presentan información redundante ya que comparten variables analíticas en su composición. Nos hemos propuesto elaborar una o varias variables nuevas que puedan eliminar este defecto y nos permitan definir de forma más precisa el estado nutricional e inflamatorio de los pacientes oncológicos para mejorar nuestra capacidad de pronosticar las complicaciones postoperatorias. 
Martín Bailón Cuadrado 


\section{2.- HIPÓTESIS Y OBJETIVOS.}


Martín Bailón Cuadrado 


\section{2.- HIPÓTESIS Y OBJETIVOS.}

\section{1.- HIPÓTESIS.}

La alteración del estado nutricional e inflamatorio de los pacientes oncológicos, cuantificado mediante diferentes scores, se relacionaría con una tendencia hacia una mayor morbilidad y mortalidad tras la cirugía curativa del CCR.

Los scores definitorios del estado nutricional e inflamatorio se calculan empleando variables comunes, por lo que se supone que comparten información y su capacidad predictora podría verse limitada al analizarse conjuntamente. Por este motivo se pretende comprobar esta correlación y desarrollar una o varias variables que integren la información procedente de estos scores con el objetivo de definir con mayor precisión el estado nutricional e inflamatorio de nuestros pacientes, así como evaluar el grado de asociación con la aparición de complicaciones postoperatorias.

\section{2- OBJETIVOS.}

1) Describir una muestra de pacientes, mediante recogida prospectiva de datos, con diagnóstico de cáncer colorrectal y sometidos a cirugía curativa programada.

2) Cuantificar el estado nutricional e inflamatorio de esta serie de pacientes utilizando tanto scores descritos en la literatura como otras posibles variables obtenidas a partir de ellos. 


\section{Martín Bailón Cuadrado}

3) Definir la morbilidad y mortalidad postoperatorias de nuestra muestra de pacientes intervenidos.

4) Evaluar la capacidad que tienen las variables definitorias del estado nutricional e inflamatorio para predecir la morbilidad y mortalidad tras la cirugía curativa del cáncer colorrectal. 


\section{3.- PACIENTES Y MÉTODOS.}


Martín Bailón Cuadrado 


\section{3.- PACIENTES Y MÉTODOS.}

\section{1.- TIPO DE ESTUDIO.}

El diseño del estudio fue observacional, siguiendo una recogida prospectiva de datos.

\section{2.- POBLACIÓN DE ESTUDIO.}

La población de estudio fueron los pacientes sometidos a cirugía curativa para cáncer de colon y recto intervenidos en el Hospital Universitario Río Hortega (HURH) de Valladolid entre el 1 de septiembre de 2015 y el 28 de febrero de 2017.

Se incluyeron datos epidemiológicos, antropométricos, analíticos, operatorios, relativos a los antecedentes médico-quirúrgicos, relativos al estudio preoperatorio, y relativos a todas las posibles complicaciones postoperatorias durante los 30 primeros días del periodo postoperatorio o hasta el momento del alta hospitalaria. Se utilizaron claves para la identificación de los pacientes, teniéndose en cuenta las normas de confidencialidad a ese respecto.

\subsection{1.- CRITERIOS DE INCLUSIÓN.}

Los criterios empleados para la inclusión de enfermos en la muestra que se analizó en este estudio fueron los siguientes:

- Tener una edad mayor o igual a 18 años.

- Haber firmado el consentimiento informado. 


\section{Martín Bailón Cuadrado}

- La certeza de un diagnóstico anatomopatológico de adenocarcinoma infiltrante de colon o recto a través de muestra obtenida mediante endoscopia baja.

- La existencia de una indicación de cirugía curativa para cáncer de colon o recto.

\subsection{2.- CRITERIOS DE EXCLUSIÓN.}

Se excluyeron del presente estudio todos aquellos pacientes que manifestaron uno o más de los siguientes criterios, a saber:

- Las intervenciones que se hayan realizado de forma urgente.

- La imposibilidad de llevar a cabo una cirugía curativa.

- La obtención de hallazgos intraoperatorios que resulten en un diagnóstico anatomopatológico distinto al de CCR.

\subsection{3.- TAMAÑO MUESTRAL.}

La muestra estuvo formada por todos aquellos individuos de la población de estudio que quedaron seleccionados tras aplicar los criterios de inclusión y exclusión. Se reclutaron consecutivamente todos los casos que aparecieron durante el periodo de estudio, teniendo en cuenta los mencionados criterios. Se empleó una base de datos creada específicamente para la elaboración de este trabajo, con los pacientes intervenidos por la Unidad de Cirugía Colorrectal del HURH de Valladolid.

El tamaño muestral obtenido fue de 168 pacientes intervenidos de cirugía curativa de CCR en el HURH entre el 1 de septiembre de 2015 y el 28 de febrero de 2017. 


\section{3- CIRCUITO ASISTENCIAL DEL PACIENTE.}

\subsection{1.- PREOPERATORIO.}

El paciente acude a la consulta de cirugía con el diagnóstico endoscópico de CCR, confirmado mediante estudio anatomopatológico de las muestras tomadas. Se realiza una anamnesis y una exploración física completa.

Se realizan las pruebas diagnósticas para estudio de extensión:

- Para el cáncer de colon: TC de tórax, abdomen y pelvis.

- Para el cáncer de recto: además de la TC, hay que completar la valoración de la pelvis con ecografía endoscópica y/o RMN pélvica.

- Si en la TC existe sospecha de metástasis hepática, se completará el estudio de extensión con una RMN hepática o con una ecografía con potenciadores.

- La utilización de la PET se reserva para aquellos casos con dudas diagnósticas de enfermedad a distancia.

Con toda la información procedente del estudio de extensión, se decide el manejo que va a seguir el paciente:

- Cáncer de colon sin metástasis a distancia: cirugía.

- Cáncer de recto sin metástasis a distancia: el Servicio de Oncología el caso para valoración de tratamiento neoadyuvante. 


\section{Martín Bailón Cuadrado}

- Si hay afectación local avanzada (T3/T4), adenopatías patológicas $(\mathrm{N}+)$, infiltración de la fascia mesorrectal o la lesión de localiza en el tercio inferior del recto: tratamiento neoadyuvante con QT y/o RT.

- En el resto de casos: cirugía.

- Presencia de metástasis a distancia en el estudio de extensión: el caso se presenta en el comité de tumores donde se decide, desde un enfoque multidisciplinar (Cirugía General y del Aparato Digestivo, Oncología, Anatomía Patológica y Radiología), el manejo que va a seguir el paciente.

En el caso de indicarse cirugía, se le explica al paciente la técnica prevista: una colectomía (hemicolectomía derecha, hemicolectomía derecha ampliada, hemicolectomía izquierda, sigmoidectomía), una proctectomía (resección anterior, baja o ultrabaja), una técnica que implica una colostomía terminal (AAP, procedimiento de Hartmann), la posibilidad de realizar una ileostomía en asa para proteger la anastomosis colorrectal, y si se va a realizar mediante un abordaje laparotómico o laparoscópico (con su riesgo de conversión a cirugía abierta). Por lo tanto, se le informa de los riesgos quirúrgicos de la cirugía colorrectal en general, y de la técnica que se va a emplear en particular. Además hay que advertir del riesgo que existe durante la cirugía de modificar la técnica que se ha había planeado hacia otra distinta en función de los hallazgos intraoperatorios. Una vez informado, al paciente se le solicita por escrito el consentimiento para realizar la intervención quirúrgica, autorizando con su rúbrica la realización de la técnica elegida y asumiendo el riesgo de la misma.

Previamente a la intervención, el paciente acude a la consulta de preanestesia. El anestesiólogo recopila la información clínica del proceso asistencial del enfermo, revisando y evaluando todos los datos (situación clínica, pruebas complementarias realizadas). 
Determina el grado de riesgo anestésico según la escala ASA y se valora cuidadosamente la vía aérea, estableciendo en caso necesario la activación del protocolo de vía aérea difícil, según los criterios anestésicos vigentes. De igual modo, se considera, según criterio clínico, la solicitud de fisioterapia respiratoria o cualquier otra prueba o procedimiento, a la vez que se determina el ajuste de medicación del enfermo previo a la intervención. Por último, se informa al paciente de la técnica anestésica (general balanceada) y de los riesgos inherentes a la misma, así como de los específicos en la cirugía colorrectal y de la necesidad de estancia en la Unidad de Reanimación, al menos las primeras 24 horas de postoperatorio. Una vez informado, se le solicita por escrito el consentimiento para la anestesia.

\subsection{2.- INTRAHOSPITALARIO.}

\subsubsection{1.- PREOPERATORIO INMEDIATO.}

Exploración del paciente por parte del equipo médico y revisión de la historia clínica y de las pruebas complementarias para comprobar que no existe ninguna contraindicación para realizar la intervención.

El día previo a la intervención se obtiene una analítica sanguínea con hemograma, bioquímica básica, coagulación, PCR y albúmina, que nos permite calcular los scores definitorios del estado nutricional e inflamatorio.

Se pauta la profilaxis antitrombótica y antibiótica preoperatoria:

- Administración de antibiótico en el momento del traslado al quirófano: cefotaxima 2 g y metronidazol 1 g, por vía intravenosa. En alérgicos a 


\section{Martín Bailón Cuadrado}

betalactámicos, se sustituye la cefotaxima por ciprofloxacino $400 \mathrm{mg}$ por vía intravenosa, manteniendo el metronidazol.

- Administración de heparina de bajo peso molecular a dosis adecuada: bemiparina 3500 UI o enoxaparina $40 \mathrm{mg}$, por vía subcutánea, 12 horas antes de la cirugía (siguiendo las recomendaciones vigentes). Medias de compresión elástica en las extremidades inferiores o dispositivos neumáticos antitrombosis.

\subsubsection{2.- TÉCNICA QUIRÚRGICA.}

El paciente se coloca en decúbito supino con los brazos extendidos a lo largo del cuerpo y con perneras móviles específicas para estos procedimientos, además de sujeciones y protecciones adecuadas en la región de los hombros para poder soportar la posición de Trendelemburg (especialmente importante para el abordaje laparoscópico) minimizando así el riesgo de lesión del plexo braquial. Se lleva a cabo anestesia general balanceada con intubación orotraqueal (empleando fibroscopio en los enfermos catalogados como "vía aérea difícil) y se canulan vías (una vía venosa periférica de grueso calibre así como, preferentemente, una vía venosa yugular derecha y vía arterial radial izquierda). La monitorización de constantes vitales (frecuencia cardiaca, electrocardiograma, presión arterial invasiva y no invasiva, presión venosa central, etc.) se realiza según criterio del anestesiólogo. Se coloca sonda vesical con termómetro incorporado a todos los pacientes, extremando las medidas de asepsia. La intervención se lleva a cabo por dos cirujanos de la Unidad de Cirugía Colorrectal, asistidos por un médico interno residente. El procedimiento elegido depende de la localización de la lesión en el estudio de extensión (como ya se ha comentado previamente). 


\subsubsection{3.- PROTOCOLO POSTOPERATORIO.}

Los pacientes pasan desde el quirófano a la Unidad de Reanimación Quirúrgica para el control hemodinámico, respiratorio y balance hidroelectrolítico. Cuando el paciente está estabilizado, a criterio del anestesiólogo, se traslada a la planta, pasadas las primeras 24 horas.

Los cuidados requeridos son:

- Profilaxis de la úlcera de estrés: se administra un inhibidor de la bomba de protones a las dosis habituales por vía intravenosa hasta la tolerancia oral.

- Profilaxis de la enfermedad tromboembólica: se mantiene el vendaje compresivo en extremidades inferiores hasta el alta hospitalaria. Se continua con la administración de heparina de bajo peso molecular a dosis adecuadas durante un mes. Se moviliza al sillón desde el $2^{\circ}$ día postoperatorio y se estimula la deambulación precoz.

- Controles analíticos en las primeras 24 horas del postoperatorio y posteriormente según la evolución clínica del enfermo.

- Retirada de la sonda nasogástrica a la mayor brevedad posible (en el caso en el que haya sido necesaria su colocación) y retirada de la sonda vesical a las 24 horas, siempre que la situación clínica lo permita.

- Control del débito de los drenajes en caso de que se hayan colocado. Retirada de los mismos a la mayor brevedad posible, siempre que la situación clínica lo permita. 


\section{Martín Bailón Cuadrado}

- Retirada de material de sutura entre los días 8-10 del postoperatorio (se puede realizar de forma ambulatoria en su Centro de Salud).

Ante el eventual diagnóstico de complicaciones postoperatorias, ya sean médicas o quirúrgicas, se actúa convenientemente, con el tratamiento más adecuado, incluyendo un nuevo traslado a la Unidad de Reanimación o una reintervención, si fuera necesario.

El manejo postoperatorio se lleva a cabo en función del criterio del cirujano responsable. Habitualmente, la dieta oral se introduce el $2^{\circ}$ o $3^{\text {er }}$ día postoperatorio y si la evolución es favorable, el paciente es dado de alta entre el $7^{\circ}$ y el $10^{\circ}$ día postoperatorio.

\subsection{3.- SEGUIMIENTO ONCOLÓGICO.}

Tras la cirugía, el paciente es evaluado por el Servicio de Oncología para considerar, en función del estadiaje anatomopatológico del AJCC y del estado general y comorbilidades del paciente, si es sometido a tratamiento adyuvante con QT y/o RT.

El seguimiento oncológico se lleva a cabo por el Servicio de Cirugía General y del Aparato Digestivo durante 5 años, y por el Servicio de Oncología en el caso de que el paciente haya sido sometido a tratamiento adyuvante. La distribución de las consultas y de las pruebas diagnósticas que se solicitan durante este seguimiento se describe en la tabla 9. 
Tabla 9. Distribución de las consultas y de las pruebas diagnósticas que se solicitan durante el seguimiento oncológico.

\begin{tabular}{|c|c|c|c|c|}
\hline \multicolumn{5}{|c|}{ SEGUIMIENTO ONCOLÓGICO } \\
\hline CONSULTAS & CEA & TC & COLONOSCOPIA & RECTOSCOPIA \\
\hline 3 meses & & & & \\
\hline 6 meses & & & & \\
\hline 12 meses & & & & \\
\hline 24 meses & & & & \\
\hline 30 meses & & & & \\
\hline 36 meses & & & \\
\hline 42 meses & & & \\
\hline 48 meses & & & \\
\hline 54 meses & & & \\
\hline 60 meses & & & \\
\hline \#: Se realiza colonoscopia a los 3 meses cuando no se pudo realizar una completa de forma previa a la cirugía. \\
\hline \multicolumn{7}{|c|}{ CEA: carcinoembryonic antigen. } \\
\hline
\end{tabular}

Si en alguna de las pruebas endoscópicas o radiológicas aparece alguna recidiva local o a distancia, el paciente es remitido a la consulta de Oncología. Si tras 5 años se seguimiento no ha surgido ninguna muestra de recidiva, se le da de alta.

Se adjunta a continuación el protocolo clínico del "Proceso para el diagnóstico y tratamiento inicial del cáncer colorrectal”, del Sistema Global de Gestión de Procesos del Área Valladolid Oeste. 


\section{Martín Bailón Cuadrado}

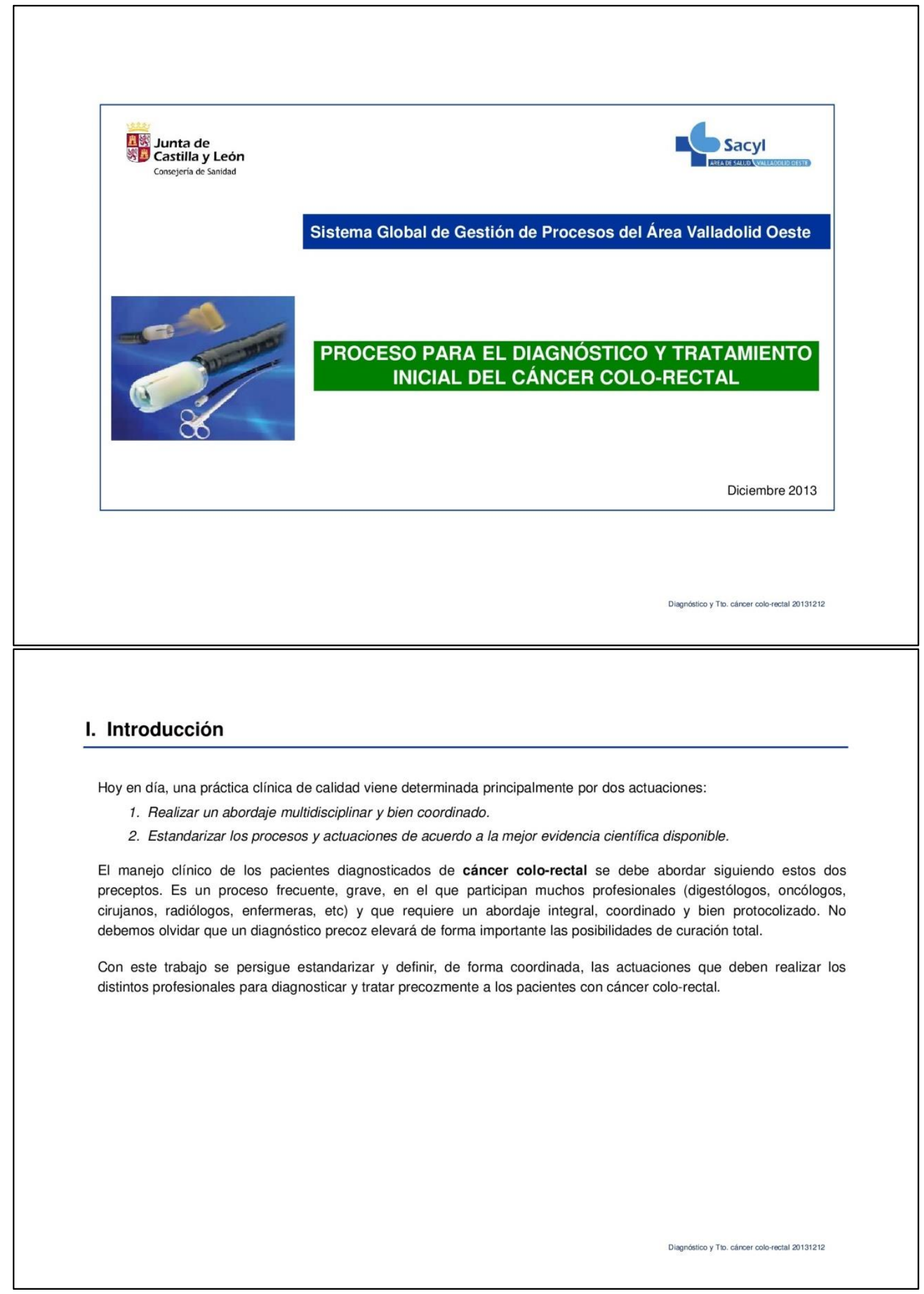




\section{Justificación}

El cáncer colo-rectal (CCR) es una de las neoplasias más frecuentes en los países occidentales. En España es la tercera causa de cáncer en varones, por detrás del de próstata y pulmón, y la segunda en mujeres tras el cáncer de mama.

Se estima que aproximadamente cada año en nuestro país se diagnostican alrededor de 22.000 nuevos casos de CCR y casi el $50 \%$ de ellos fallece debido a esta enfermedad (datos del año 2002).

La tasa ajustada de incidencia en España en el año 2002 se situaba en 36,97/100.000 habitantes en varones y en 22,5/100.000 habitantes en mujeres. Estas tasas se incrementan de forma notoria a partir de los 50 años de edad.

Se ha observado que la incidencia de cáncer colo-rectal presenta una tendencia al aumento progresivo en los últimos años.

La incidencia del cáncer de colon es 3 veces superior a la de recto.

Según el estudio Eurocare-4, para el periodo 2000-2002, la supervivencia media a los 5 años ajustada por edad para el cáncer colorectal en España es del 61,5\% [IC 95\%, 57,7-65,5]. La media europea es del 56,2\% [IC 95\%, 55,3-57,2] y la media en USA es del $65,5 \%$ [IC 95\%, 64,9-66,1].

En función del estadio TNM la supervivencia media a los 5 años se sitúan en:
Estadio I: 95-100\%
Estadio II: $70-85 \%$
Estadio III: $50-70 \%$
Estadio IV: $5-15 \%$

\section{Justificación}

En Castilla y León, según el registro poblacional de cáncer de la D. General de Salud Pública, los casos nuevos estimados por cáncer colorrectal en 2006 fueron 2.446, de los cuales1.470 fueron en hombres y 975 en mujeres.

La incidencia por grupos de edad se recoge en los cuadros adjuntos:

\begin{tabular}{|c|c|c|c|}
\hline \multicolumn{4}{|c|}{$\begin{array}{l}\text { INCIDENCIA POR GRUPOS DE EDAD } \\
\text { (tasas por cien mil habilantes) }\end{array}$} \\
\hline & Hombres & Mujeres & Total \\
\hline$<35$ años & 7.21 & 2,85 & 5,09 \\
\hline $35-49$ aก๊os & 30,20 & 19,12 & 24,80 \\
\hline 50.64 años & 133,89 & 71,22 & 103,58 \\
\hline $65-74$ años & 340,68 & 183,45 & 260,09 \\
\hline 275 años & 359,68 & 239.69 & 292,24 \\
\hline
\end{tabular}

\begin{tabular}{|c|c|c|}
\hline \multicolumn{3}{|c|}{$\begin{array}{l}\text { INCIDENCIA EN LA POBLACIÓN MUNDIAL } \\
\text { (tasas por cien mil habitantes) }\end{array}$} \\
\hline & Hombres & Mujeres \\
\hline Castilla y León (2006) & 51,5 & 28,4 \\
\hline $\begin{array}{l}\text { España } \\
(2002)\end{array}$ & 36,8 & 22,5 \\
\hline $\begin{array}{c}\text { Paises desarrollados } \\
\text { (2002) }\end{array}$ & 40 & 26 \\
\hline
\end{tabular}

En nuestra Área de Salud Valladolid Oeste se estima que aproximadamente aparecen unos 200 casos de cáncer colorectal al año. De ellos, en números redondos, unos 150 serían de colon y unos 50 casos serían de recto. Como no en todos los casos se confirma la sospecha pero sí se realiza el estudio, se estima que se estudiarán unos 250 pacientes al año, esto significa aproximadamente 4-5 casos a la semana. 


\section{Martín Bailón Cuadrado}

\section{Objetivos y alcance}

El objetivo de este trabajo es definir y estandarizar las actuaciones que deben realizar los distintos profesionales para diagnosticar y tratar precozmente a los pacientes con sospecha de cáncer colo-rectal.

\section{- Objetivos Principales:}

Ser más eficientes y sistemáticos en el diagnóstico y tratamiento de los pacientes con cáncer colo-rectal:

- Evitando ingresos innecesarios para estudio.

- Ajustando al máximo el tiempo empleado en el diagnóstico

- Definiendo las pruebas que se deben prescribir para realizar el diagnóstico.

- Definiendo los protocolos clínicos de manejo terapéutico de estos pacientes.

-Objetivos Secundarios:

- Crear un comité clínico de cáncer colo-rectal que promueva un abordaje multidisciplinar y consensuado.

- Elaborar un documento escrito que establezca los circuitos y protocolos clínicos en el manejo de estos pacientes.

- Evaluar los resultados del manejo de los pacientes con esta patología

\section{Objetivos y alcance}

El alcance del proceso que vamos a definir es el siguiente:

Inicio: Pacientes con sospecha de cáncer colo-rectal durante la realización de una colonoscopia.

Final: Paciente diagnosticado de cáncer colo-rectal que inicia su primer tratamiento (bien sea quirúrgico, o con quimio ó radioterapia neoadyuvante).

Salida marginal: pacientes en los que no se confirma la sospecha de cáncer colo-rectal.

Desde un punto de vista operativo los resultados que se persiguen son:

a) El tiempo que transcurre desde el resultado anatomopatológico de la biopsia endoscópica realizada hasta que se instaura el primer tratamiento curativo es menor a 30 días.

b) La realización del estudio diagnóstico siempre que sea posible desde el punto de vista clínico se realizará de forma ambulatoria ( $80 \%$ de los pacientes que se estudian) 


\section{Circuitos Asistenciales para el diagnóstico y tto. del Cáncer Colo-rectal}

En el siguiente flujograma se definen los distintos pasos ó trámites que se desarrollan durante el proceso diagnóstico-terapéutico del paciente con cáncer colo-rectal.

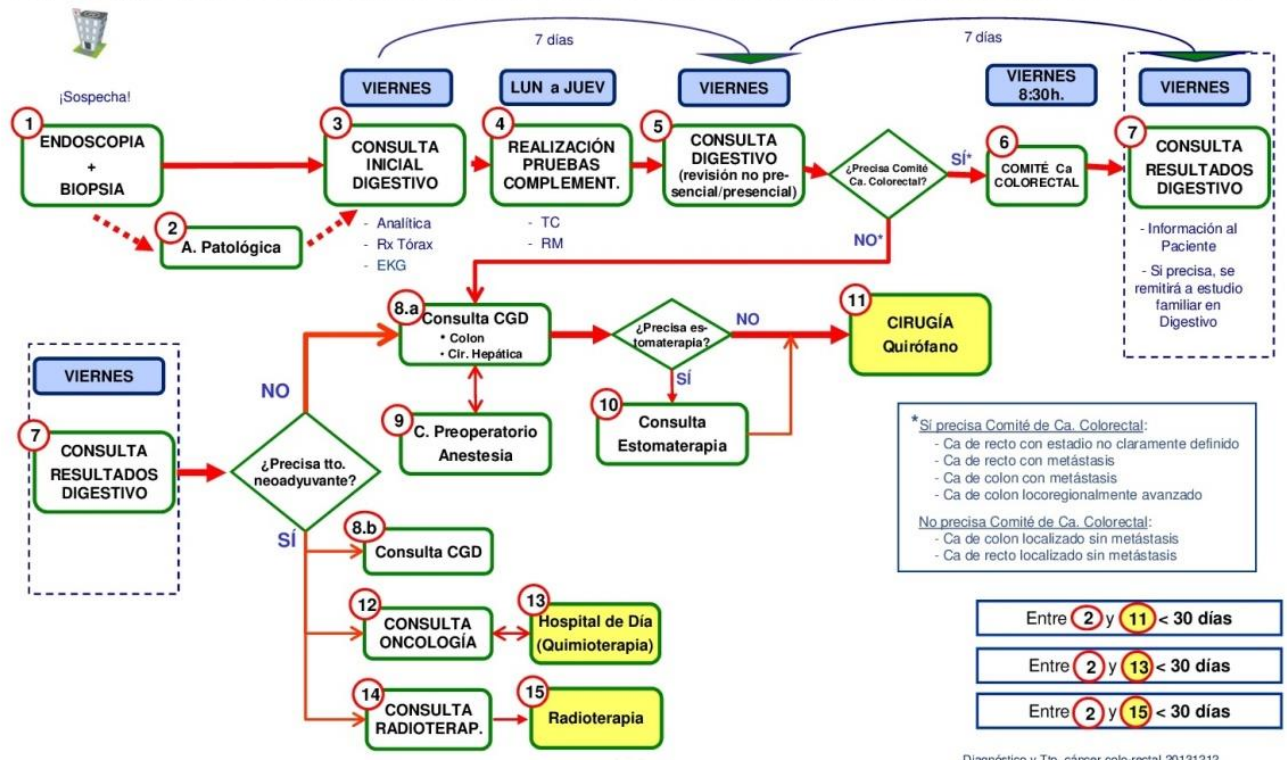

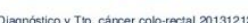

\section{Circuitos Asistenciales para el diagnóstico y tto. del Cáncer Colo-rectal}

\section{Endoscopia más biopsia:}

El endoscopista ante sospecha de cáncer colo-rectal realiza biopsia de la lesión. En caso de sospecha muy consistente debe realizar una exploración completa y si existen pólipos, siempre que sea posible, debe extirparlos en el mismo acto. Con esto se evitará la realización de otra endoscopia para completar el estudio.

Remite la muestra a A. Patolog con el volante de petición adecuadamente cumplimentado. Debe indicar en la solicitud "Proceso Colo-rectal preferente".

Posteriormente remite al paciente a la consulta de Digestivo ("Proceso Colo-rectal preferente") . Se envía la solicitud de cita para esa consulta a citaciones (SADC), para que sea citado el viernes de esa semana. Se le informará al paciente que debe acudir en ayunas.

\section{Anatomía patológica:}

La muestra y el volante de solicitud con la referencia "Proceso Colo-rectal preferente" llega al So de A. Patológica donde los patólogos procesarán la muestra de forma preferente.

Aproximadamente en 2-3 días estará el informe de A. Patológica. Este informe se podrá visualizar en el SIClínica de la forma habitual.

En el anexo Il figuran los facultativos que pertenecen a las respectivas unidades de Ca. Colo-rectal.

El compromiso de respuesta por parte de A. Patológica es:

- Estudio sin inmunohistoquímica: $<4$ días laborables

- Estudio que precisa inmunohistoquímica (solo 5\%), resultado completo (con la inmuno): $>7$ días laborables

El modelo de informe que emite A. Patológica se encuentra en el Anexo III-a y III-b 


\section{Circuitos Asistenciales para el diagnóstico y tto. del Cáncer Colo-rectal}

\section{Consulta inicial digestivo}

Existirá una consulta específica de Proceso Colorectal: Consulta no $\mathbf{3 7 3}$ que se pasará los Viernes en horario de 9-30 a 12:30 horas. Dicha consulta de Proceso Colo-rectal tendrá asociada una agenda específica llamada NDIGCCR, con 5 huecos de 15 minutos para pacientes nuevos (N), y 10 huecos de 10 minutos para revisiones presenciales (RP) ó revisiones No presenciales (RNP)

\begin{tabular}{|c|c|c|c|c|c|}
\hline Horario & Viernes & & & & \\
\hline $9: 30-9: 45$ & $\mathbf{N}$ & & & & \\
\hline \multirow{2}{*}{$9: 45-10: 00$} & \multirow{2}{*}{$\mathbf{N}$} & Horario & Viernes & & \\
\hline & & $10: 45-10: 55$ & RP ó RNP & Horario & Viernes \\
\hline $10: 00-10: 15$ & $\mathbf{N}$ & $10: 55-11: 05$ & RP ó RNP & $11: 35-11: 45$ & RP 6 o RNP \\
\hline $10: 15-10: 30$ & $\mathbf{N}$ & $11: 05-11: 15$ & RP ó RNP & $11: 45-11: 55$ & RP ó RNP \\
\hline \multirow[t]{3}{*}{$10: 30-10: 45$} & \multirow[t]{3}{*}{$\mathbf{N}$} & $11: 15-11: 25$ & RP ó RNP & $11: 55-12: 05$ & RP ó RNP \\
\hline & & $11: 25-11: 35$ & RP ó RNP & $12: 05-12: 15$ & RP ó RNP \\
\hline & & & & $12: 15-12: 25$ & RP ó RNP \\
\hline
\end{tabular}

Esta consulta, dado su carácter tan específico, debe gozar de cierta flexibilidad, esto quiere decir que puede haber, si la existencia de demanda lo requiere, hasta 2 pacientes duplicados el mismo día, o en su caso quedar algún hueco libre.

\section{Circuitos Asistenciales para el diagnóstico y tto. del Cáncer Colo-rectal}

A esta consulta serán remitidos todos los pacientes con sospecha de ca colo-rectal durante la realización de la endoscopia en los últimos 7 días. El paciente deberá acudir en ayunas, para que tras la consulta se pueda realizar una analítica y sea valorable la glucosa.

El digestólogo explora al paciente, cumplimenta la $\mathrm{H}^{\mathrm{a}}$ Clínica en el SICLINICA y solicita las siguientes pruebas complementarias.
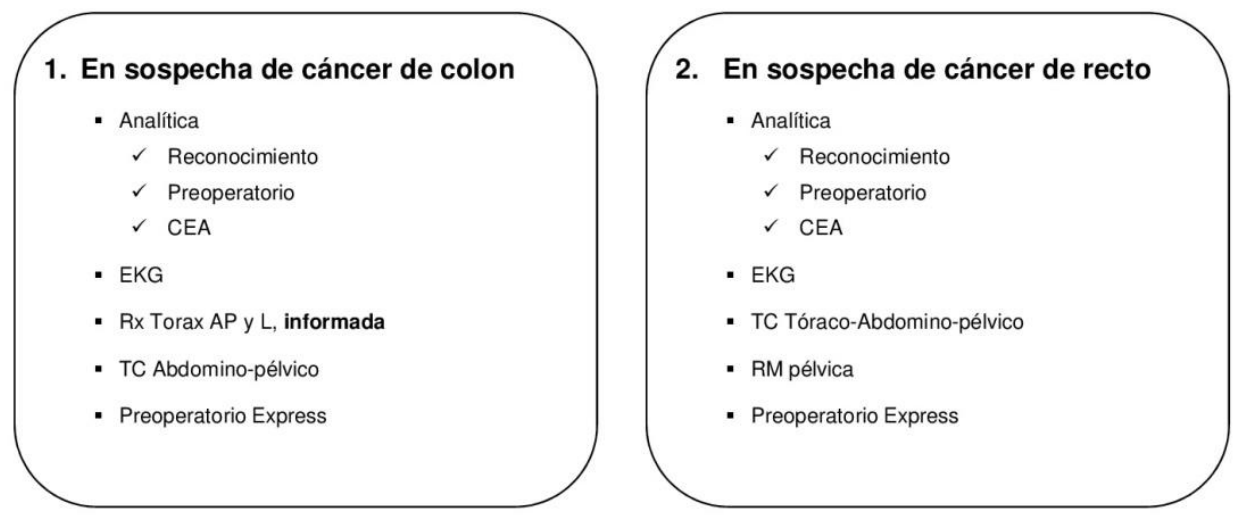


\section{Circuitos Asistenciales para el diagnóstico y tto. del Cáncer Colo-rectal}

La petición de las pruebas complementarias se realizará tal y como se detalla a continuación (El facultativo cumplimentará adecuadamente el volante de petición de las mismas indicando "Proceso Colo-rectal preferente").

$\checkmark$ Analítica: se solicita en formato electrónico. El paciente acude a la Unidad de Extracciones al finalizar la consulta para que le recojan la muestra. Debe acudir con el "resguardo" de la solicitud electrónica realizada por el médico. No es necesaria cita express.

$\checkmark$ EKG: la solicitud se realiza en papel como hasta ahora. El paciente acude al gabinete ํㅜ 267 (Nivel 2), los viernes (de Lunes a Jueves en la consulta 272). al finalizar la consulta para realizarse el electro. No es necesaria cita express. Desde la consulta de EKG se debe remitir el electro a digitalizar lo antes posible indicando en el sobre "Proceso Colo-rectal preferente".

$\checkmark$ Rx simple tórax: se solicita en formato electrónico junto con las otras pruebas radiológicas. El paciente debe acudir al finalizar la consulta a la secretaría de Radiología (nivel 2). En Radiología podrán ver la solicitud en una "sala virtual" que se va a crear al efecto, donde se encontrará la petición. En la solicitud debe figurar la frase "Proceso Colo-rectal preferente, se precisa informada"para que el radiólogo la informe.

- Existe una "Hoja Informativa" para entregar al paciente donde figura el lugar al que debe acudir para realizarse la analítica, el EKG y la Rx simple (ver anexo IX).

$\checkmark \underline{\text { Radiología TC: }}$ se solicita en formato electrónico junto con las otras pruebas radiológicas. Ese mismo viernes en Radiología podrán ver la solicitud en la "sala virtual" y organizar qué día de la semana siguiente se realizarán las pruebas. El mismo viernes, a última hora de la mañana o por la tarde, la secretaria de Rx citará telefónicamente a los pacientes. Además dará al paciente las instrucciones oportunas (acudir en ayunas, etc). Esta cita aparecerá en el Siclínica en el apartado Radiología, en el subapartado "pruebas pendientes".

\section{Circuitos Asistenciales para el diagnóstico y tto. del Cáncer Colo-rectal}

El digestólogo en la consulta deberá entregar al paciente el consentimiento informado de TC y hacerle las indicaciones clínicas que el caso requiera (acudir en ayunas, pautas para suspender metformina, etc). En Anexo IV se incluye el protocolo para suspender la metformina antes de realizar TC.

$\checkmark$ Radiología RM: se solicita en formato electrónico junto con las otras pruebas radiológicas. Ese mismo viernes en Radiología podrán ver la solicitud en la "sala virtual" y organizar qué día de la semana siguiente se realizarán las pruebas. El mismo viernes, a última hora de la mañana o por la tarde, la secretaria de Rx citará telefónicamente a los pacientes. Además dará al paciente las instrucciones oportunas (acudir en ayunas, etc). Esta cita aparecerá en el Siclínica en el apartado Radiología, en el subapartado "pruebas pendientes".

El digestólogo en la consulta deberá entregar al paciente el consentimiento informado de RM y hacerle las indicaciones clínicas que el caso requiera (acudir en ayunas, existencia de prótesis, etc).

En esta consulta inicial el digestólogo debe informar brevemente al paciente de las pruebas que se le realizarán y como ya hemos referido le entregará al paciente el documento de $\mathrm{Cl}$ informado (de TC y de RM). El paciente deberá traer dicho documento firmado el día que le realicen la prueba y entregárselo al Radiólogo responsable.

Posteriormente cumplimenta las "indicaciones para cita sucesiva" que se remitirá al SADC. En función de las necesidades le puede citar a consulta de Digestivo ("Proceso Colo-rectal") para una consulta presencial (dentro de 7 días), o bien secuencialmente, para una consulta no presencial (dentro de 7 días) y otra consulta presencial (para dentro de 14 días). En la consulta de los 7 días se valorarán los resultados de todas las pruebas (con ó sin el paciente). Si el paciente debe ser valorado por el comité de cáncer colorectal habitualmente se seleccionará la segunda opción (consulta no presencial en 7 dias y consulta presencial en 14 días).

En algunos casos la consulta no presencial (de los 7 días) podría ser reconvertida a presencial (este cambio se realizará telefónicamente por indicación del digestólogo). La consulta presencial tiene el objetivo de informar al paciente de los resultados antes de derivarle a otro especialista (habitualmente CGD). 


\section{Martín Bailón Cuadrado}

\section{Circuitos Asistenciales para el diagnóstico y tto. del Cáncer Colo-rectal}

\section{Realización Pruebas complementarias}

* Las pruebas de Laboratorio se realizarán el mismo día de la consulta inicial

* El EKG se realizará el mismo día de la consulta inicial

* Las pruebas complementarias de Radiología se realizarán: La Rx simple de tórax se realizará el mismo día de la consulta inicial. La solicitud se recibirá en radiología en formato electrónico ("sala virtual")

La TC se realizará entre el lunes y el jueves de la semana siguiente al viernes que se solicita. En alguna semana puede haber más de 5 pacientes que razonablemente se deberán asumir esa misma semana. En radiología se recibirá la solicitud en formato electrónico ("sala virtual"). Esta solicitud debe ser adecuadamente cumplimentada por el digestólogo y en ella figurará "Proceso Colo-rectal preferente".

La RM se realizará entre el lunes y el jueves de la semana siguiente al viernes que se solicita (se ha estimado que será un paciente semanal). En alguna semana puede haber más de 1 paciente que razonablemente se deberá asumir esa misma semana. En radiología se recibirá la solicitud en formato electrónico ("sala virtual"). Esta solicitud debe ser adecuadamente cumplimentada por el digestólogo y en ella figurará "Proceso Colorectal preferente".

Tanto en la TC como en la RM, el radiólogo, antes de realizar la prueba correspondiente, recabará del paciente el documento de C. Informado. Este documento habrá sido entregado la semana anterior por el facultativo de digestivo, para que el paciente pueda leerlo en su domicilio y lo traiga firmado.

Debe existir una adecuada coordinación entre la Unidad de TC y la de RM para no citar al paciente para realizarse ambas pruebas el mismo día y a la misma hora. Sería deseable que procuráramos citar a los pacientes el mismo día en horas sucesivas para que solo tuvieran que venir una vez.

\section{Circuitos Asistenciales para el diagnóstico y tto. del Cáncer Colo-rectal}

Los Informes con el resultado de las pruebas realizadas deben estar confeccionados antes del viernes de la semana en que se realiza la prueba y "colgados" en el apartado correspondiente de la $\mathrm{H}^{\mathrm{a}} \mathrm{Clínica}$ de nuestro hospital. De esta manera podrán ser valorados en la consulta de revisión no presencial/presencial de digestivo (a los 7 dias).

\section{Consulta de digestivo a los 7 días (revisión no presencial/presencial)}

En esta consulta de digestivo, monográfica de Proceso Colo-rectal Preferente, como ya hemos dicho, habrá 10 huecos para realizar "revisiones presenciales" o "revisiones no presenciales".

El digestólogo accederá a los resultados de todas las pruebas complementarias realizadas, que estarán "colgados" en SICLINICA.

A) Cuando el caso clínico no precise valorarse en el comité de Ca Colorectal, la consulta será presencial. De esta manera se le darán los resultados al paciente y se le derivará de forma express a la Consulta específica de patología colo rectal de CGD. El digestólogo debe elaborar un informe con los resultados de las pruebas complementarias realizadas.

B) Cuando el caso clínico precise valorarse en el comité de Ca Colorectal, la consulta será no presencial. Se estudiarán las pruebas pero sin la presencia del paciente. El digestólogo será el encargado de realizar la convocatoria del comité clínico de Ca Colorectal (al finalizar la consulta) que será remitida en formato electrónico. En esa convocatoria se especificará el nombre y $n^{0}$ de historia de cada paciente a valorar. De esta manera el resto de los componentes del comité podrán estudiar los casos con antelación. En anexo $\mathrm{V}$ se muestra el modelo de convocatoria. Se creará un grupo de correo (en el correo interno -outlook-) denominado "Comité Ca. Colo-rectal" para facilitar la convocatoria.

En alguna ocasión la consulta inicialmente no presencial puede ser necesario transformarla en presencial. Para ello se contactará con el paciente telefónicamente siguiendo las instrucciones del digestólogo. También se contactará con Citaciones para que anulen la siguiente consulta presencial (a los 14 dias ) que tenía citada. 


\section{Circuitos Asistenciales para el diagnóstico y tto. del Cáncer Colo-rectal}

\section{Comité Clínico de Cáncer colo-rectal}

El comité clínico de cáncer colo-rectal del HURH es el encargado de aportar un plan terapéutico individualizado y consensuado para tratar a estos pacientes.

Se reunirá los viernes a las 8:30h, en la Sala de Reuniones de DIGESTIVO (bloque 2, nivel 2). Como ya se ha comentado, el digestólogo será el encargado de realizar la convocatoria por correo electrónico.

$$
\begin{aligned}
& >\text { Se deben presentar en el Comité de Ca. Colorectal: } \\
& \text { - Ca de recto con estadio no claramente definido } \\
& \text { - Ca de recto con metástasis } \\
& \text { - Ca de colon con metástasis } \\
& \text { - Ca de colon locoregionalmente avanzado }
\end{aligned}
$$

$>$ No es necesario presentar en el Comité de Ca. Colorectal:

- Ca de colon localizado, sin metástasis ni afectación de órganos concomitantes

- Ca de recto localizado sin metástasis

La decisión que se adopte se registrará de forma resumida en un formulario diseñado al efecto (ver anexo VI). En el apartado VI se habla más ampliamente del Comité Clínico de Cáncer Colo-rectal.

Diagnosstico y Tio. carcer colo-rectal 201312

\section{Circuitos Asistenciales para el diagnóstico y tto. del Cáncer Colo-rectal}

\section{Consulta Resultados Digestivo (a los 14 días)}

En esta consulta de digestivo, monográfica de Ca Colo-rectal, habrá 10 huecos para realizar "revisiones presenciales" o "revisiones no presenciales". En las revisiones presenciales se informará a los pacientes de los resultados de las pruebas complementarias realizadas.

$>$ En el caso de que se confirme la existencia de un Ca Colo-rectal se le informará adecuadamente al paciente y se le remitirá, en función de que precise o no tratamiento neoadyuvante, a una de las siguientes situaciones (se desarrollan más adelante):

A. No precisa tratamiento neoadyuvante Se remite a la Consulta de Cirugía General.

B. Como primer tratamiento precisa tratamiento neoadyuvante (quimioterapia o radioterapia) Se remite a la Consulta de Cirugía General, a la de Oncología y a la de Radioterapia.

En todos los casos el digestólogo elaborará un informe con los resultados de las pruebas complementarias realizadas y con el resultado de la valoración del Comité de Ca Colo-rectal. Asimismo reflejará donde se remite al paciente.

$>$ En el caso de que se descarte la existencia de un Ca Colo-rectal se le informará adecuadamente al paciente y también se le entregará un Informe de Consulta escrito. Posteriormente se le dará "de alta" en digestivo o en su caso, si lo precisa, se le remitirá a la consulta convencional de digestivo (para revisión). 


\section{Martín Bailón Cuadrado}

\section{Circuitos Asistenciales para el diagnóstico y tto. del Cáncer Colo-rectal}

\section{Situación A: no precisa tratamiento neoadyuvante}

Ese mismo día se le remite desde la consulta de digestivo a la Consulta de Cirugía General a través de una cita exprés. El paciente con la hoja de remisión ("indicaciones para cita sucesiva") rellenada por el digestólogo acude a citaciones (mostrador del nivel 3) para que le citen de "forma exprés" (lo antes posible) a la Consulta específica de patología colo rectal. En esa consulta existirán 4 huecos semanales (con una prestación específica) reservados para citar a estos pacientes. En el mostrador del nivel 3 se le citará para el primer hueco. ¡Los cirujanos ya tendrán conocimiento de la existencia de todos estos pacientes porque habrán sido vistos en el Comité de Ca Colorectal unos días antes! El Jefe de Servicio de CGD gestionará los huecos para en el caso de que no se llenen sean ocupados por otros pacientes.

\section{Situación B: tratamiento neoadyuvante}

Ese mismo dia se le remite desde la consulta de digestivo a la Consulta de CGD y a la de Oncología. EI paciente con la hoja de remisión ("indicaciones para cita sucesiva") rellenada por el digestólogo acude a citaciones (mostrador del nivel 3) para que le citen de "forma exprés" (lo antes posible) a dichas Consultas (deseablemente los pacientes deben ser citados como máximo en 7 días). En la consulta de Oncología existirán 2 huecos semanales (con una prestación específica) reservados para citar a estos pacientes. Un hueco será el miércoles en la consulta del Dr. Torrego y otro será el viernes en la consulta del Dr. Fra. En el mostrador del nivel 3 se le citará para el primer hueco. Si en las $48 \mathrm{~h}$. anteriores no están rellenos los huecos específicos, desde el SADC se deberán completar con otros pacientes. ¡Los oncólogos ya tendrán conocimiento de la existencia de todos estos pacientes porque habrán sido vistos en el Comité de Ca Colorectal unos días antes!

Si el paciente precisa Radioterapia se le remite a la Consulta de Radioterapia. El facultativo debe rellenar la "Hoja de interconsulta al H. Clínico Universitario" (si el paciente es enviado al Clínico) o la "Hoja de canalización a otro Centro" (si el paciente es enviado a otro centro). Ambos documentos, junto con los informes que se puedan precisar, se remitirán al SADC (Sta. Ana Bolado). Al paciente se le informa que recibirá una llamada telefónica desde el Centro Receptor indicándole el día y la hora de la cita en la consulta de radioterapia.

IV Circuitos Asistenciales para el diagnóstico y tto. del Cáncer Colo-rectal

\section{Consulta de CGD}

\section{Consulta 8.a}

En esta consulta de CGD, se confirmará la indicación quirúrgica. En la misma el cirujano informará al paciente de la intervención que se le realizará. El facultativo rellena el formulario electrónico de "inclusión en lista de espera" y solicita la Consulta de Preanestesia (se realiza a través de una cita expréss). Además solicitará el C. Informado para la cirugía. Sería muy deseable que el cirujano supiera ya el día que se operará el paciente (ha podido reservarle hueco en la sesión de programación quirúrgica de su Servicio). De esta forma le podrá comunicar al paciente el día de la intervención.

En ocasiones el paciente requiere una cirugía hepática previa o combinada con la colorectal. Los cirujanos de ambas secciones analizarán el caso y decidirán la opción más adecuada, agilizando los trámites al máximo para cumplir el plazo de demora establecido.

Si el paciente (o sus familiares directos) precisa atención psicológica, se le puede incluir en el Programa $1^{2}$ impacto. Solo es necesario darle al paciente un díptico de la AECC donde se le informa de todo el programa, así como de la forma de acceso al mismo.

\section{Consulta 8.b}

En esta consulta de CGD el cirujano informará al paciente de la intervención que se le realizará y de los pasos que debe seguir (tratamiento neoadyuvante) hasta la cirugía.

Si el paciente (o sus familiares directos) precisa atención psicológica, se le puede incluir en el Programa $1^{9}$ impacto. Solo es necesario darle al paciente un díptico de la AECC donde se le informa de todo el programa, así como de la forma de acceso al mismo. 


\section{Circuitos Asistenciales para el diagnóstico y tto. del Cáncer Colo-rectal}

\section{Consulta de Preoperatorio de Anestesia}

En esta consulta se verá al paciente siguiendo la metodología ya establecida del "preoperatorio expréss". Primero se hace la consulta y si el anestesista necesita alguna prueba complementaria la solicita y se encarga de mirar los resultados.

Si el paciente es APTO, ya se puede programar en el quirófano. Si el paciente no es apto se actuará en consecuencia (ampliar estudios o imposibilidad de tratamiento quirúrgico).

\section{Consulta de estomaterapia}

En nuestro hospital existe una consulta de estomaterapia atendida por una enfermera. Dicha consulta se realiza de forma coordinada con el Servicio de Cirugía General, de manera que cuando se precisa, los Cirujanos Generales remiten al paciente a dicha consulta. En la consulta de estomaterapia se realiza tanto la valoración inicial (marcaje del estoma) como el seguimiento y cuidados posteriores a la cirugía.

\section{Cirugía (quirófano)}

El paciente es incluido en la Programación de Intervención Quirúrgica semanal. Desde la secretaría del Sํo de CGD Ilamarán telefónicamente al paciente indicándole, día, lugar y hora de ingreso y preparación previa si la requiere.

El tiempo que transcurre entre la fecha del Informe de A. Patológica que confirma el Ca. Colorectal y la realización de la cirugía, debe ser inferior a $\mathbf{3 0}$ días.

\section{Circuitos Asistenciales para el diagnóstico y tto. del Cáncer Colo-rectal}

\section{Consulta de Oncología}

En esta consulta de Oncología, se confirmará la indicación para la quimioterapia. En la misma el oncólogo informará al paciente de las actuaciones que se realizarán. Si se precisa, debe solicitar al paciente el C. Informado para la quimioterapia. El facultativo debe remitir al paciente al hospital de día siguiendo la sistemática habitual.

En esta consulta existirán 2 huecos semanales (con una prestación específica) reservados para citar a estos pacientes. Un hueco será el miércoles en la consulta del Dr. Torrego y otro será el viernes en la consulta del Dr. Fra. Si en las 48h. anteriores no están rellenos los huecos específicos, desde el SADC se deberán completar con otros pacientes.

Si el paciente (o sus familiares directos) precisa/n atención psicológica, se le puede incluir en el Programa $1^{\circ}$ impacto. Solo es necesario darle al paciente un díptico de la AECC donde se le informa de todo el programa, así como de la forma de acceso al mismo.

Durante todo el tratamiento neoadyuvante existirá una comunicación fluida entre el oncólogo y el radioterapéuta.

Tras finalizar el tratamiento neoadyuvante el paciente será remitido desde la Consulta de Oncología a la Consulta de CGD. 


\section{Circuitos Asistenciales para el diagnóstico y tto. del Cáncer Colo-rectal}

\section{Hospital de Día (quimioterapia)}

El paciente acude al Hospital de Día de forma ambulatoria, siguiendo el circuito convencionalmente establecido.

El tiempo que transcurre entre la fecha del Informe de A. Patológica que confirma el Ca. Colorectal y el primer día de tratamiento con quimioterapia en el $\mathrm{H}$. de Día, debe ser inferior a $\mathbf{3 0}$ días.

\section{Consulta de Radioterapia}

En esta consulta de radioterapia, se le informará al paciente de la actitud terapéutica a seguir para administrarle el tratamiento radioterapéutico.

Tras dicho tratamiento el paciente será remitido nuevamente a nuestro Hospital. Desde la consulta de radioterapia del Centro que aplique el Tto. Radioterapéutico se remitirá el informe correspondiente lo antes posible al SADC de nuestro hospital, para que desde allí se cite al paciente lo antes posible en la consulta que lo precise (Oncología/CGD). Además el SADC remitirá el informe correspondiente del tratamiento realizado al facultativo/consulta correspondiente.

\section{Tratamiento con Radioterapia}

El paciente acude al Servicio de Radioterapia, de forma ambulatoria, donde se le administrará dicho tratamiento en varias sesiones.

El tiempo que transcurre entre la fecha del Informe de A. Patológica que confirma el Ca. Colorectal y el primer día de tratamiento con radioterapia, debe ser inferior a $\mathbf{3 0}$ días.

\section{Solicitud de pruebas complementarias}

Se solicitarán las siguientes pruebas complementarias:

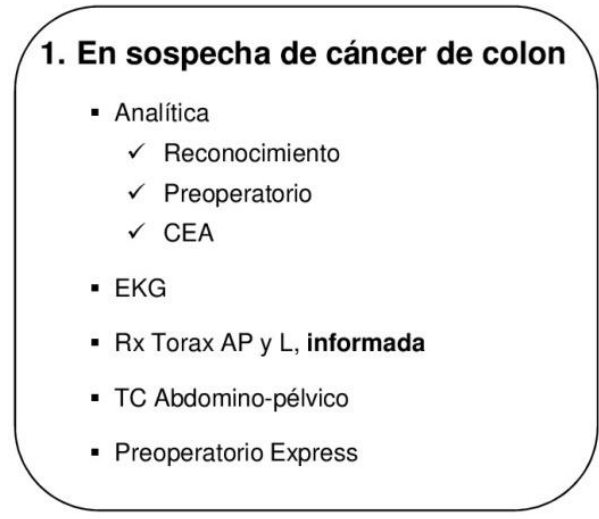

\begin{tabular}{|l} 
2. En sospecha de cáncer de recto \\
- Analítica \\
$\checkmark$ Reconocimiento \\
$\checkmark$ Preoperatorio \\
$\checkmark$ CEA \\
- EKG \\
- TC Tóraco-Abdomino-pélvico \\
- RM pélvica \\
- Preoperatorio Express
\end{tabular}




\section{Comité Clínico del Cáncer Colo-rectal en el Hospital Universitario Río Hortega}

Todo hospital que realice tratamiento de cáncer de colon y recto debe disponer de un Comité Clínico de Cáncer Colorectal que aporte una decisión terapéutica previa al tratamiento y en el que participen todos los profesionales que intervienen en el proceso diagnóstico y terapéutico.

La labor de este comité consiste en:

a) conocer la situación inicial de los pacientes afectos de esta patología

b) analizar las pruebas inicialmente consensuadas y decidir si se precisa realizar alguna más

c) en función de los resultados, marcar la pauta de tratamiento y los plazos

Por lo tanto el Comité de cáncer colorectal se puede definir como el grupo multidisciplinar integrado por especialistas de las principales disciplinas participantes en el manejo del cáncer de colon y recto (cirugía, digestivo, oncología médica, oncología radioterápica, radiología y anatomía patológica), que se reúne periódicamente y dispone de un protocolo asistencial o guía de práctica clínica propios o de una Institución de referencia.

Todos los pacientes diagnosticados de $\mathrm{Ca}$ de recto con estadio no claramente definido, Ca de recto con metástasis $\mathrm{Ca}$ de colon con metástasis y de Ca de colon con afectación de órganos concomitantes deben ser valorados por este comité, ya que supone y facilita un mejor abordaje diagnóstico y terapéutico. También se pueden remitir aquellos otros casos que a criterio de un facultativo participante deba ser valorado de forma multidisciplinar. Debe quedar constancia en la $\mathrm{HC}$ que se ha realizado esta valoración.

El comité clínico de cáncer colo-rectal del HURH se regirá por las normas que al respecto ha establecido la C. de Tejidos, Tumores y Mortalidad del hospital.

Se reunirá los viernes a las 8:30h, en la Sala de Reuniones de DIGESTIVO (bloque 2, nivel 2). Como ya se ha comentado, el digestólogo será el encargado de realizar la convocatoria por correo electrónico.

\section{Comité Clínico del Cáncer Colo-rectal en el Hospital Universitario Río Hortega}

Son miembros de ese comité, al menos, los siguientes profesionales:

- Digestólogo

- Cirujano general de la U. de colon (cuando se precise acudirá un CGD de la U. hepatobiliar)

- Oncólogo

- Radiólogo (TC y RM)

- Anatomo Patólogo

- Y en su caso, radioterapéuta.

Los casos se decidirán por consenso y la decisión que se adopte se registrará en un formulario diseñado al efecto (ver anexo VI).

Un criterio de calidad ampliamente aceptado es que todos los pacientes que presenten una patología con abordaje multidisciplinar deben ser valorados por el comité clínico de cáncer colo-rectal. 


\section{Definiciones Generales}

Con el objeto de aclarar algunos términos que hemos utilizado a lo largo del documento los definimos de manera consensuada en este apartado. También incluimos algunas de las clasificaciones tumorales más importantes.

Nota: Otros términos o clasificaciones más específicas pueden consultarse en el Anexo I.

Recto: Aunque hay diferencias entre los anatomistas y los cirujanos, desde el punto de vista quirúrgico se considera como recto el espacio del tubo digestivo comprendido entre el la unión ano-rectal y el promontorio sacro. La longitud del mismo medido mediante rectoscopia rígida desde el margen anal es de 15 centímetros. En nuestro medio no se utiliza la endoscopia rígida, por eso consideramos que la distancia debe ser hasta $20 \mathrm{~cm}$ medido con endoscopia flexible.

Cáncer de recto: Adenocarcinoma situado en los límites del recto. El cáncer de recto se disemina localmente a través del drenaje linfático asociado al pediculo vascular y circunferencialmente en la pelvis. A distancia la diseminación se produce por vía vascular dando origen a las metástasis, generalmente hepáticas.

Mesorrecto: Es el tejido graso que rodea el recto, contiene los vasos rectales y linfáticos. Está rodeado de una fascia, denominada "fascia visceral del mesorrecto".

\section{Definiciones Generales}

\section{Clasificación TNM (7a Edición, 2010):}

\section{T: TUMOR PRIMARIO}

TX Tumor primario no puede determinarse.

TO No hay evidencia de tumor primario en la pieza quirúrgica.

Tis Carcinoma "in situ" 1 , intraepitelial o invasión de lámina propia.

T1 El tumor infiltra la submucosa.

T2 El tumor infiltra la muscularis propia.

T3 El tumor infiltra a través de la muscularis propia hasta la subserosa, o dentro del tejido perirrectal o pericólico no peritonealizado.

T4a El tumor penetra en la superficie del peritoneo visceral.

T4b El tumor invade directamente otros órganos o estructuras. Si no hay invasión microscópica se clasificará entre T1 a T4a.

N: GANGLIOS LINFÁTICOS REGIONALES.

NX Ganglios linfáticos no pueden ser encontrados (p. ej. previamente extirpados)

N0 No hay metástasis en los ganglios linfáticos.

N1a Metástasis en 1 ganglio linfático regional.

N1b Metástasis en 2-3 ganglios linfáticos regionales.

N1c Depósitos tumorales en la subserosa, mesenterio ó en tejidos pericólicos o perirrectales no peritoneales sin metástasis ganglionares regionales.

N2a Metástasis en 4 a 6 ganglios linfáticos regionales.

N2b Metástasis en 7 ó más ganglios linfáticos regionales

M: METÁSTASIS A DISTANCIA

M0 Metástasis a distancia no se puede comprobar.

M1 Metástasis a distancia.

M1a Metástasis confinada a un órgano o localización.

M1b Metástasis en más de un órgano o localización o en el peritoneo. 


\section{Definiciones Generales}

Se relacionan a continuación las clasificaciones de Dukes y de Astler-Coller, si bien en nuestro medio cada vez son menos utilizadas.

\section{Estadio de Dukes:}

A Tumor limitado a la pared (sin extenderse más allá de la muscularis propia).

B El tumor se extiende a través de la pared hasta la subserosa y/o serosa, o tejidos extrarectales.

C El tumor metastatiza en los ganglios linfáticos.

D Metástasis a distancia (tumor más allá de los límites de resección quirúrgica).

\section{Estadio modificado de ASTLER-COLLER:}

A Tumor limitado a la mucosa.

B1 Tumor que infiltra la muscularis propia pero sin penetrarla totalmente.

B2 Tumor que penetra la muscularis propia, alcanzando la serosa.

B3 Tumor que invade las estructuras adyacentes.

C1 Tumor que infiltra la muscularis propia (sin penetrarla), con metástasis en los ganglios linfáticos regionales.

C2 Tumor que penetra la muscularis propia, alcanzando la serosa, con metástasis en ganglios linfáticos regionales.

C3 Tumor que invade las estructuras adyacentes, con metástasis en ganglios linfáticos regionales.

D Metástasis a distancia

\section{Definiciones Generales}

\section{Agrupación por estadios del TNM:}

\begin{tabular}{lccc} 
Sistema TNM & & & \\
ESTADIO & T & N & M \\
\hline Estadio 0 & Tis & N0 & M0 \\
\hline Estadio I & T1 & N0 & M0 \\
\hline Estadio II A & T2 & N0 & M0 \\
Estadio II B & T3 & N0 & M0 \\
Estadio II C & T4a & N0 & M0 \\
\hline Estadio III A & T4b & N0 & M0 \\
\hline Estadio III B & T1-T2 & N1-N1c & M0 \\
& T1 & N2a & M0 \\
\hline Estadio III C & T3-T4a & N1-N1C & M0 \\
& T2-T3 & N2a & M0 \\
& T1-T2 & N2b & M0 \\
\hline Estadio IV A & T4a & N2a & M0 \\
Estadio IV B & T3-T4a & N2b & M0 \\
\hline
\end{tabular}

Linfadenectomia correcta: El examen histológico de una linfadenectomía regional debe contener al menos 12 ganglios linfáticos. 


\section{Martín Bailón Cuadrado}

\section{4.- VARIABLES DESCRITAS.}

\subsection{1.- VARIABLES DEMOGRÁFICAS.}

Las variables demográficas que se analizaron fueron las siguientes:

- Sexo: variable cualitativa dicotómica (hombre/mujer).

- Edad: variable cuantitativa, medida en años.

\subsection{2.- VARIABLES PREOPERATORIAS.}

Las variables preoperatorias que se evaluaron fueron:

- Índice de masa corporal (IMC): variable cuantitativa, medida en $\mathrm{Kg} / \mathrm{m}^{2}$, utilizando dos decimales. Determinado por la fórmula de Quetelet $\left[\mathrm{masa} /(\text { altura })^{2}\right]$.

- Antecedentes médicos personales:

○ HTA: variable cualitativa dicotómica (sí/no).

- Diabetes mellitus: variable cualitativa dicotómica (sí/no).

○ Dislipemia: variable cualitativa dicotómica (sí/no).

○ Tabaquismo: variable cualitativa dicotómica (sí/no).

○ Insuficiencia cardiaca: variable cualitativa dicotómica (sí/no).

- Cardiopatía isquémica: variable cualitativa dicotómica (sí/no).

○ Enfermedad pulmonar obstructiva crónica (EPOC): variable cualitativa dicotómica (sí/no). 
- Riesgo anestésico alto: variable cualitativa dicotómica (sí/no). Siguiendo la clasificación ASA se crearon dos grupos: riesgo alto (grados III y IV) y bajo (grados I y II).

- Colocación de prótesis endoscópica: variable cualitativa dicotómica (sí/no). En función de si se ha posicionado mediante abordaje endoscópico una prótesis intraluminal por una presentación clínica estenosante de la tumoración.

- QT neoadyuvante: variable cualitativa dicotómica (sí/no).

- RT neoadyuvante: variable cualitativa dicotómica (sí/no).

\subsection{3.- VARIABLES DEFINITORIAS DEL ESTADO NUTRICIONAL E INFLAMATORIO.}

Se recogieron 4 scores nutricionales e inflamatorios:

- PNI: variable cuantitativa. Tiene en consideración los valores de linfocitos y albúmina. Se establece mediante la siguiente fórmula: (Albúmina en $\mathrm{g} / \mathrm{dL}$ x 10) $+(\operatorname{Linfocitos} / \mu \mathrm{L} \times 0,005)$.

- GPS: variable cualitativa ordinal. Tiene en cuenta los valores de PCR y albúmina. Se asigna 1 punto si la PCR es $>10 \mathrm{mg} / \mathrm{L}$ o si la albúmina es $<3,5$ g/dL. Puede presentar valores de 0,1 o 2 .

- NLR: variable cuantitativa, sin unidades al tratarse de un cociente con las mismas unidades en el numerador y en el denominador. Se obtiene mediante el cociente entre el valor total de neutrófilos y de linfocitos.

- PLR: variable cuantitativa, sin unidades al tratarse de un cociente con las mismas unidades en el numerador y en el denominador. Se obtiene mediante el cociente entre el valor total de plaquetas y de linfocitos. 


\section{Martín Bailón Cuadrado}

Hemos comprobado la normalidad de las distribuciones correspondientes a los 4 scores, utilizando la prueba de Kolmogorov-Smirnov. De este modo hemos podido evidenciar que algunos de ellos tienen distribuciones muy alejadas de la normalidad. Buscando reducir este alejamiento, hemos aplicado, en estos casos, una transformación logarítmica (logaritmo decimal). De esta forma, hemos conseguido unas distribuciones muestrales que soporten mejor la aplicación de procedimientos paramétricos, tanto para medir localización y correlación, como para posteriormente aplicar los métodos factoriales de reducción de dimensión. Así mismo, hemos comprobado, mediante la aplicación de coeficientes de correlación de Pearson, que estos scores están vinculados entre sí, lo que nos indica que muestran información redundante. Ello podría producir que tengamos una mayor imprecisión (mayor variabilidad en los estimadores de los parámetros) al estimar modelos predictivos que incluyeran estos factores como variables explicativas.

Buscando resumir la información de los scores en un conjunto más reducido de variables, hemos llevado a cabo un análisis factorial. Para obtenerlo hemos partido de las componentes principales, buscando las direcciones más informativas en su distribución multivariante, y posteriormente hemos transformado estas componentes aplicando una rotación Varimax, con el objetivo de maximizar la interpretación de las nuevas variables resultantes.

De este modo obtuvimos un conjunto más reducido de variables que recojan los aspectos más relevantes de la información relativa al estado nutricional e inflamatorio de los pacientes. Más tarde las utilizamos como variables explicativas en los modelos predictivos para la aparición de complicaciones postoperatorias tras la cirugía curativa del CCR. 
Las variables resultantes de este análisis se pueden expresar como combinación lineal de los cuatro scores, lo que permite calcular, tras la identificación de los correspondientes coeficientes, los valores que tomen futuros individuos en los mismos. El hecho de que estas nuevas variables aparezcan escaladas con media 0 y desviación típica 1 , con traducción automática a percentiles, permite interpretar los valores que tomen futuros pacientes.

Hemos relacionado con la morbilidad y mortalidad postoperatorias las cuatro variables definitorias del estado nutricional e inflamatorio (los cuatro scores) y las variables obtenidas en el análisis factorial.

\subsection{4.- VARIABLES INTRAOPERATORIAS.}

Las variables intraoperatorias que se registraron fueron:

- Localización de la tumoración: variable cualitativa dicotómica (colon/recto). Determinada bajo visión directa por parte del cirujano encargado de llevar a cabo la intervención.

- Técnica realizada: variable cualitativa (colectomía, proctectomía, AAP o procedimiento de Hartmann) determinada por el tipo de procedimiento realizado.

- Tiempo de intervención: variable cuantitativa, medida en minutos. Considerado desde la primera incisión hasta que se termina el cierre de la última en la piel. No se incluye el tiempo de anestesia previo ni posterior a la cirugía.

- Transfusión intraoperatoria de concentrados de hematíes: variable cualitativa dicotómica (sí/no). 


\section{Martín Bailón Cuadrado}

\subsection{5.- VARIABLES POSTOPERATORIAS.}

- Complicaciones globales: variable cualitativa dicotómica (sí/no). Cuando existe algún tipo de complicación.

- Complicaciones graves: variable cualitativa dicotómica (sí/no). Se define como aquella complicación que representa un grado $\geq$ III de la clasificación de Clavien-Dindo.

- Complicaciones infecciosas: variable cualitativa dicotómica (sí/no). Cuando existe alguna de las complicaciones infecciosas (neumonía, infección del tracto urinario, infección de la vía central, fístula o dehiscencia anastomótica, IHQ, colección intraabdominal).

- Fuga anastomótica: variable cualitativa dicotómica (sí/no). Descrita como defecto de la anastomosis intestinal que se evidencia por la presencia de débito de características intestinales en el drenaje (objetivado mediante análisis bioquímico de su contenido) o por la fuga de contraste intestinal en la TC.

- Reintervención: variable cualitativa dicotómica (sí/no). Cuando las complicaciones acaecidas obligan a reoperar al paciente.

- Éxitus: variable cualitativa dicotómica (sí/no). Cuando se produce el fallecimiento del paciente.

- Estancia postoperatoria prolongada: variable cualitativa dicotómica (sí/no). Se definirá como estancia postoperatoria prolongada cuando se encuentre por encima de la mediana de la estancia postoperatoria, medida en días de pernocta. 


\section{5.- ANÁLISIS ESTADÍSTICO.}

\subsection{1.- RECOGIDA Y TRATAMIENTO DE DATOS.}

Para la recogida de los datos se confeccionó una base de datos con el paquete estadístico SPSS ${ }^{\circledR}$ versión 18.0 (IBM Corporation ${ }^{\circledR}$, Armonk, New York, EE.UU.). Los datos fueron introducidos por una sola persona y revisados por un experto. Tras su depuración, fueron analizados utilizando el mismo programa estadístico. Dado que la recogida de datos fue prospectiva, las pérdidas se limitaron al 5\%, de modo que la pérdida de valores superior a esta cifra en una determinada variable fue considerada como un posible sesgo del estudio e informada en el análisis de resultados.

\subsection{2.- ESTADÍSTICA DESCRIPTIVA.}

La normalidad de las variables cuantitativas se estableció con la prueba de KolmogorovSmirnov. Las variables cuyas distribuciones no se alejaron de la normalidad fueron descritas como media \pm desviación estándar y las que presentaron distribuciones alejadas de la normalidad como mediana y rango intercuartílico (RIQ). Por su parte, las variables cualitativas y cuantitativas discretas fueron descritas mediante las frecuencias absolutas y relativas (porcentajes) de sus categorías. Se calcularon los intervalos de confianza al 95\% (IC 95\%) de los parámetros. Finalmente, se utilizaron histogramas de frecuencia para representar las variables cuantitativas y gráficos de barras o de sectores para las cualitativas. 


\section{Martín Bailón Cuadrado}

\subsection{3.- ESTADÍSTICA INFERENCIAL.}

\subsubsection{1.- ANÁLISIS UNIVARIANTE.}

Se confrontaron las variables demográficas, preoperatorias, intraoperatorias y definitorias del estado nutricional e inflamatorio con las variables postoperatorias.

Para estudiar la asociación entre variables cualitativas se utilizaron las pruebas de Chicuadrado, aplicando la Chi-cuadrado de Pearson para las tablas 2 por 2, la razón de verosimilitudes para más de 2 categorías, o el test exacto de Fisher para una frecuencia esperada inferior a 5 en más del 20\% de las casillas.

Para estudiar las diferencias entre medias independientes, para 2 grupos, se utilizó la prueba de la T de Student o la U de Mann-Whitney, dependiendo de las condiciones de aplicación (alejamiento o no de la distribución normal).

\subsubsection{2.- ANÁLISIS MULTIVARIANTE.}

Se incluyeron en los modelos predictivos para las variables postoperatorias aquellas variables demográficas, preoperatorias, intraoperatorias y definitorias del estado nutricional e inflamatorio que mostraron una significación estadística en el análisis univariante, con una $\mathrm{p} \leq 0,10$.

Estos modelos predictivos fueron estimados utilizando la regresión logística binaria. El nivel de significación estadística para que fueran incluidas en los modelos estimados vino 
dado por una $\mathrm{p} \leq 0,05$. Se obtuvo la curva receiver operating characteristic (ROC) para algunos de estos modelos junto con el área bajo la curva y los valores de sensibilidad y especificidad correspondientes a algún punto de corte.

\section{6.- ÉTICA Y ASPECTOS LEGALES.}

Este trabajo se realizó siguiendo las recomendaciones de la Declaración de Helsinki de 1964 (última enmienda en octubre de 2013 durante la 64a asamblea de la Asociación Médica Mundial).

Hemos contado con el apoyo de una fuente de financiación pública ya que forma parte de un proyecto de investigación de la Gerencia Regional de Salud de la Junta de Castilla y León, con título "Influencia del estado nutricional e inflamatorio preoperatorio en la morbilidad y mortalidad postoperatoria de la cirugía curativa de cáncer de colon y recto” y con número de expediente "GRS/1316/A/16", respaldado además por el Comité Ético de Investigación Clínica de nuestro centro.

No existe conflicto de intereses por parte de los investigadores. No se ha obtenido financiación por parte de ninguna entidad privada para la realización de este estudio.

\section{7.- BÚSQUEDA BIBLIOGRÁFICA.}

La búsqueda bibliográfica se realizó en la base de datos MEDLINE, uno de los componentes de PubMed, cuyos datos han sido desarrollados y se mantienen actualizados por el National Center for Biotechnology Information de la National Library of Medicine, la cual 


\section{Martín Bailón Cuadrado}

forma parte, a su vez, de los National Institutes of Health en los EE.UU., con el siguiente acceso:

http://www.ncbi.nlm.nih.gov/pubmed

La búsqueda inicial se planteó en base a términos libres y la definitiva mediante términos MeSH (Medical Subject Headings), utilizando los operadores boléanos, los límites de tiempo y el filtro de idioma para confeccionar la estrategia más adecuada. Los términos MeSH empleados serán: colorectal cancer, postoperative complications, morbidity, nutritional status, inflammatory status. Los idiomas seleccionados serán inglés y español.

Esta búsqueda bibliográfica se completó con la consulta de manuales y libros de texto actualizados, la consulta de las páginas web de diversas sociedades científicas y la comunicación directa con expertos. 


\section{4.- RESULTADOS.}


Martín Bailón Cuadrado 
Resultados

\section{4.- RESULTADOS.}

En el periodo de estudio (de septiembre de 2015 a febrero de 2017) se han realizado un total de 243 resecciones colorrectales en nuestra Unidad de Cirugía Colorrectal (Servicio de Cirugía General y Digestiva, HURH, Valladolid). Tras aplicar los criterios de inclusión y exclusión comentados previamente, hemos obtenido un tamaño muestral de 168 pacientes.

\section{1.- ANÁLISIS DESCRIPTIVO.}

\subsection{1.- VARIABLES DEMOGRÁFICAS.}

La variable "sexo" siguió la siguiente distribución: 107 (63,7\%) hombres y 61 (36,3\%) mujeres [Gráfico 1]. La variable "edad" presentó una distribución normal, con una media de 69,01 \pm 11,34 años (rango de 38 a 93 años) [Gráfico 2].

Gráfico 1. Gráfico de sectores que muestra la distribución por sexo.

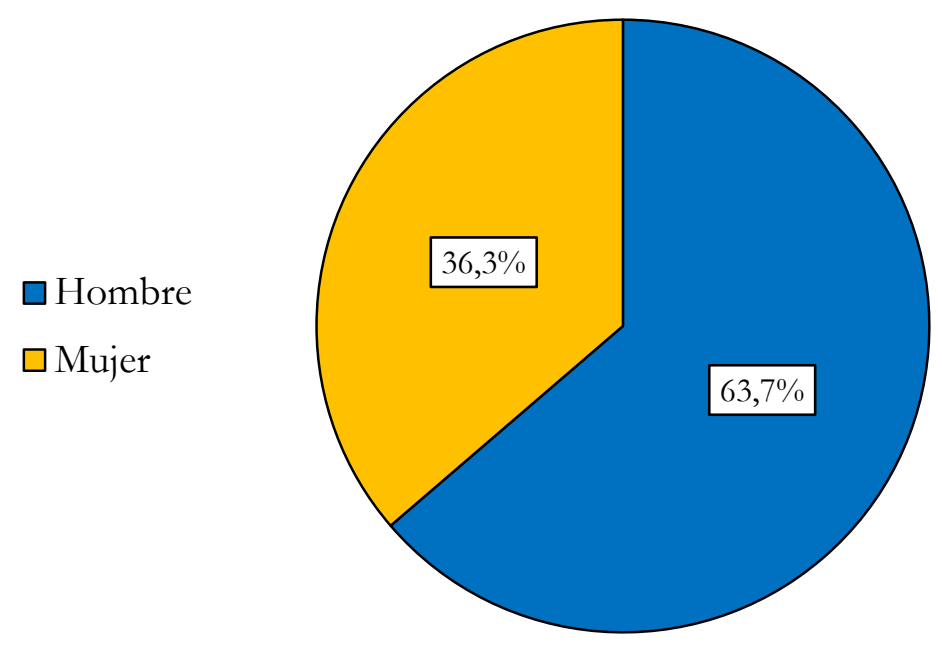




\section{Martín Bailón Cuadrado}

Gráfico 2. Histograma que muestra la distribución por edad.

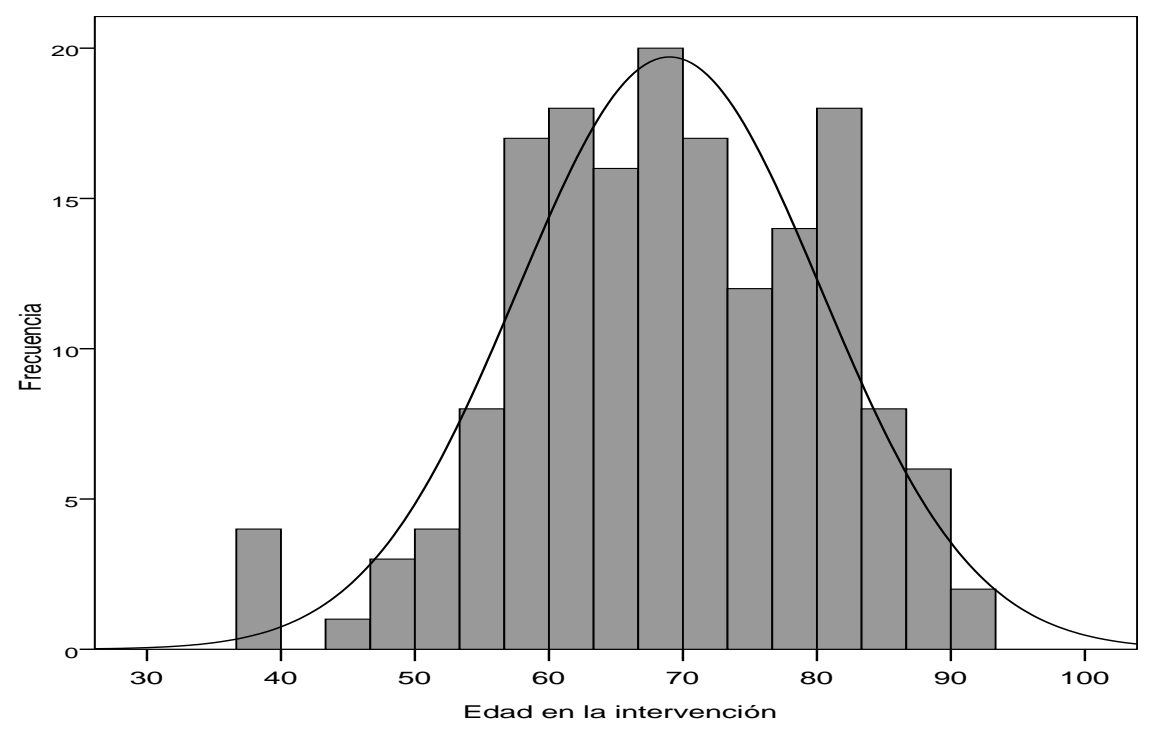

\subsection{2.- VARIABLES PREOPERATORIAS.}

La variable "IMC" mostró una distribución normal, con una media de 26,78 \pm 3,70 Kg/m² (rango de 17,67 a 40,23 Kg/m²) [Gráfico 3].

Gráfico 3. Histograma que muestra la distribución por IMC.

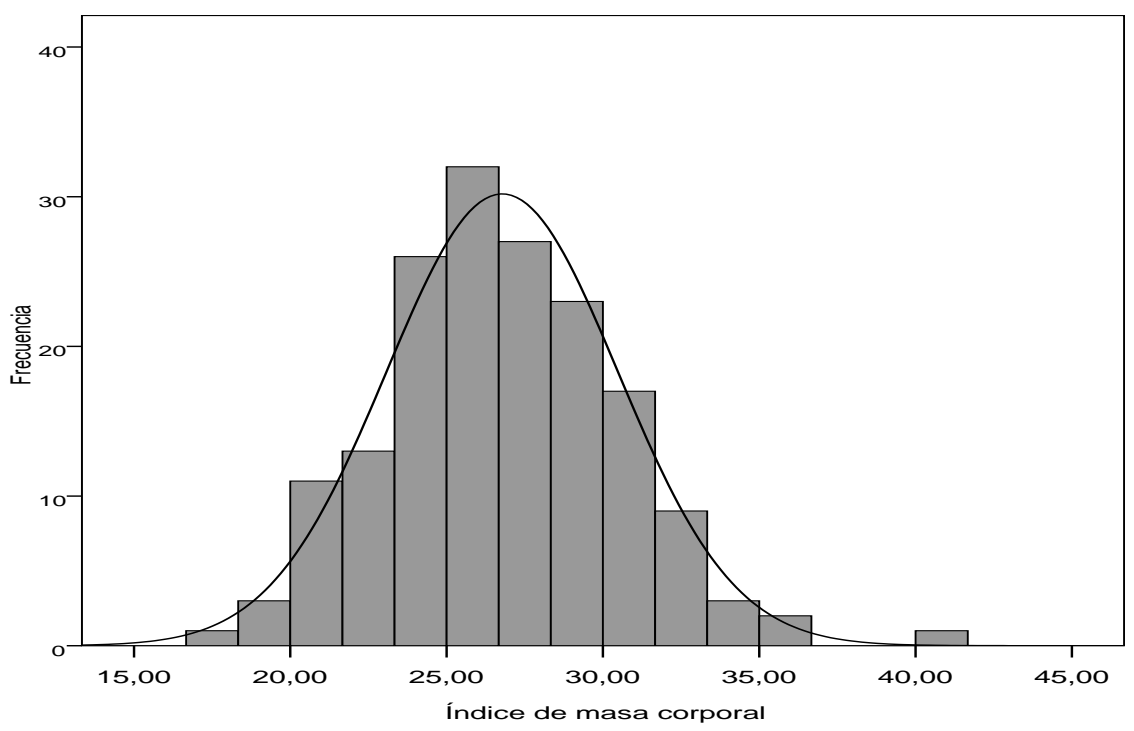


En cuanto a los antecedentes médicos de interés, 98 pacientes $(58,3 \%)$ presentaban HTA, $24(14,3 \%)$ DM, $60(35,7 \%)$ dislipemia, $46(27,4 \%)$ tabaquismo, $7(4,2 \%)$ insuficiencia cardiaca, 14 (8,3\%) cardiopatía isquémica y 9 (5,4\%) EPOC [Gráfico 4].

Gráfico 4. Diagrama de columnas que muestra la distribución por HTA, DM, dislipemia, tabaquismo, insuficiencia cardiaca, cardiopatía isquémica y EPOC.

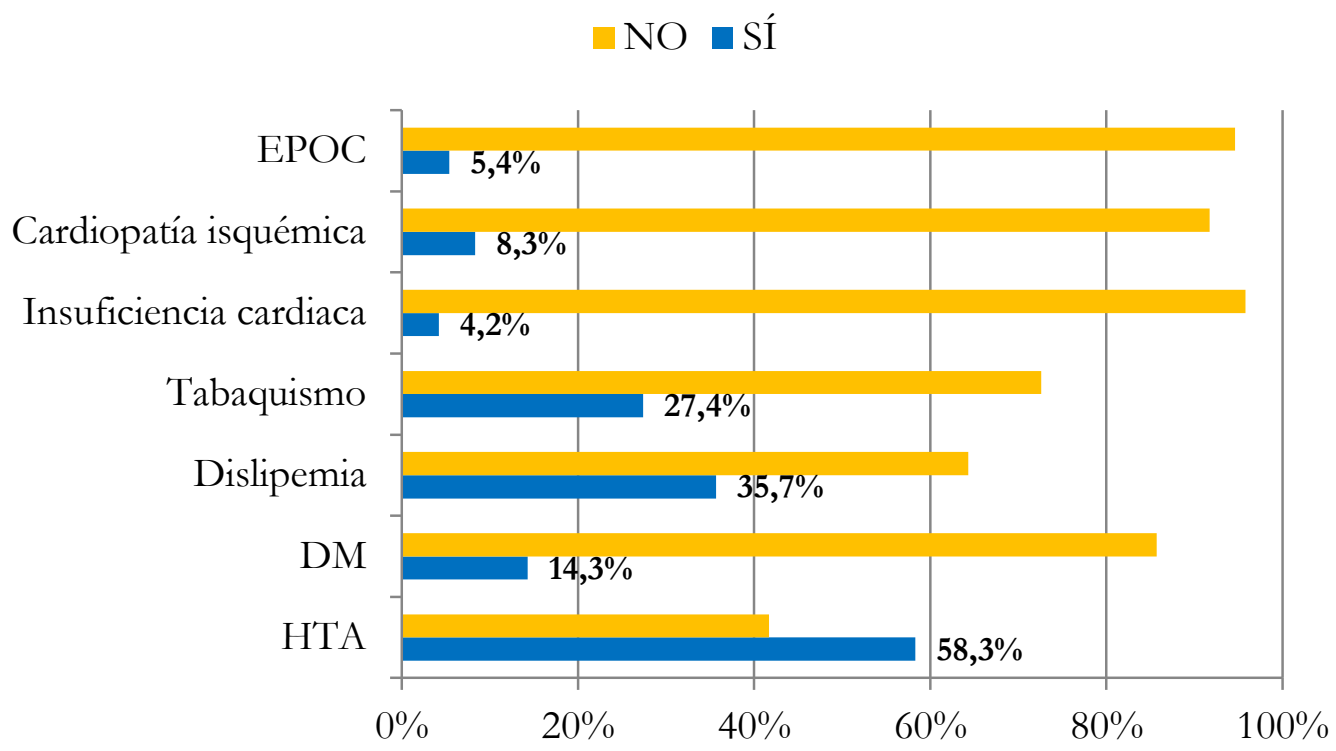

Siguiendo la clasificación de riesgo anestésico de la ASA, la distribución fue la siguiente: 8 pacientes (4,8\%) fueron grado I, $102(60,7 \%)$ grado II, $56(33,3 \%)$ grado III y $2(1,2 \%)$ grado IV. Por lo tanto, agrupando en nuestra variable dicotómica "riesgo anestésico", 58 $(34,5 \%)$ presentaban riesgo alto y $110(65,5 \%)$ riesgo bajo [Gráfico 5]. 


\section{Martín Bailón Cuadrado}

Gráfico 5. Diagrama de barras que muestra la distribución en cada uno de los grados de la clasificación de la ASA y diagrama de sectores que muestra la distribución de la variable “riesgo anestésico elevado".

Grados de la clasificación de la ASA

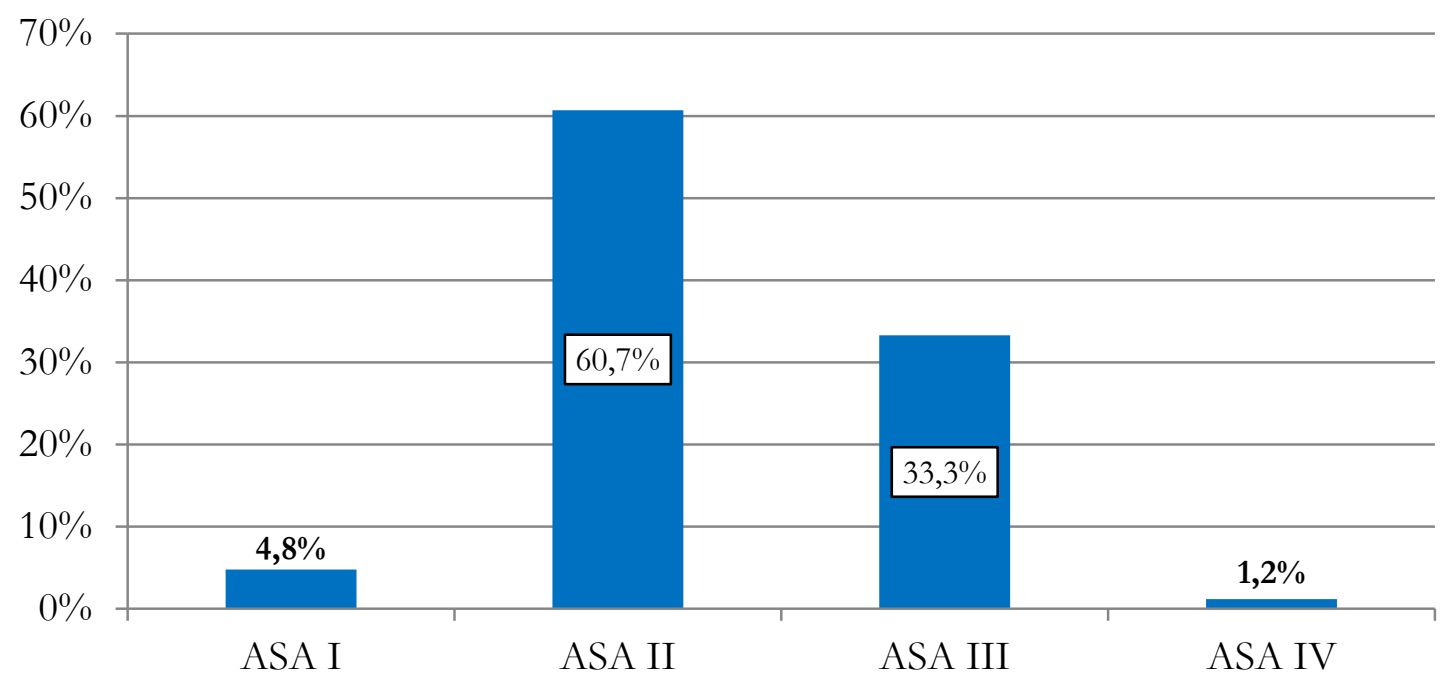

\section{Riesgo anestésico elevado}

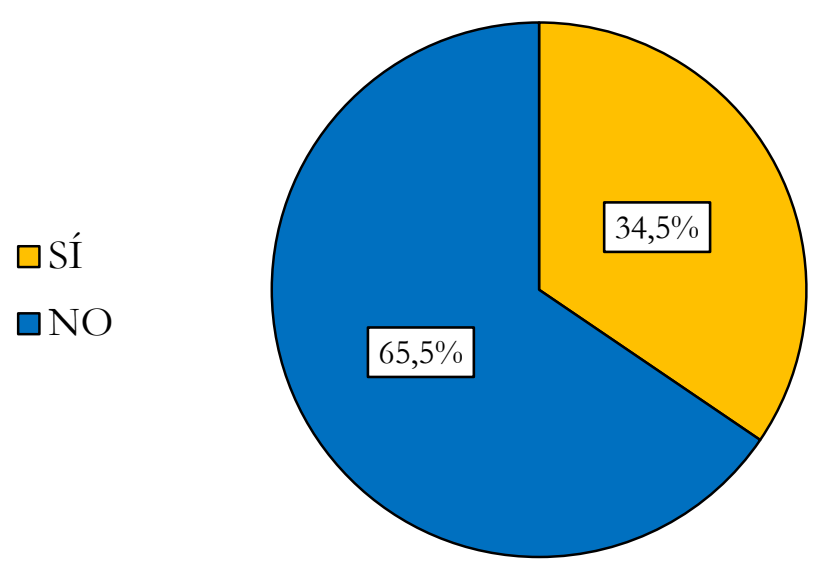

Un total de 18 pacientes $(10,7 \%)$ precisaron la colocación de una prótesis intraluminal endoscópica de forma previa a la cirugía. En cuanto al tratamiento neoadyuvante, 27 (16,1\%) recibieron QT y 33 (19,6\%) RT preoperatoria [Gráfico 6]. 
Gráfico 6. Diagrama de columnas que muestra la distribución de las variables "colocación de prótesis endoscópica", "QT neoadyuvante” y "RT neoadyuvante”.

ロ SÍ nO

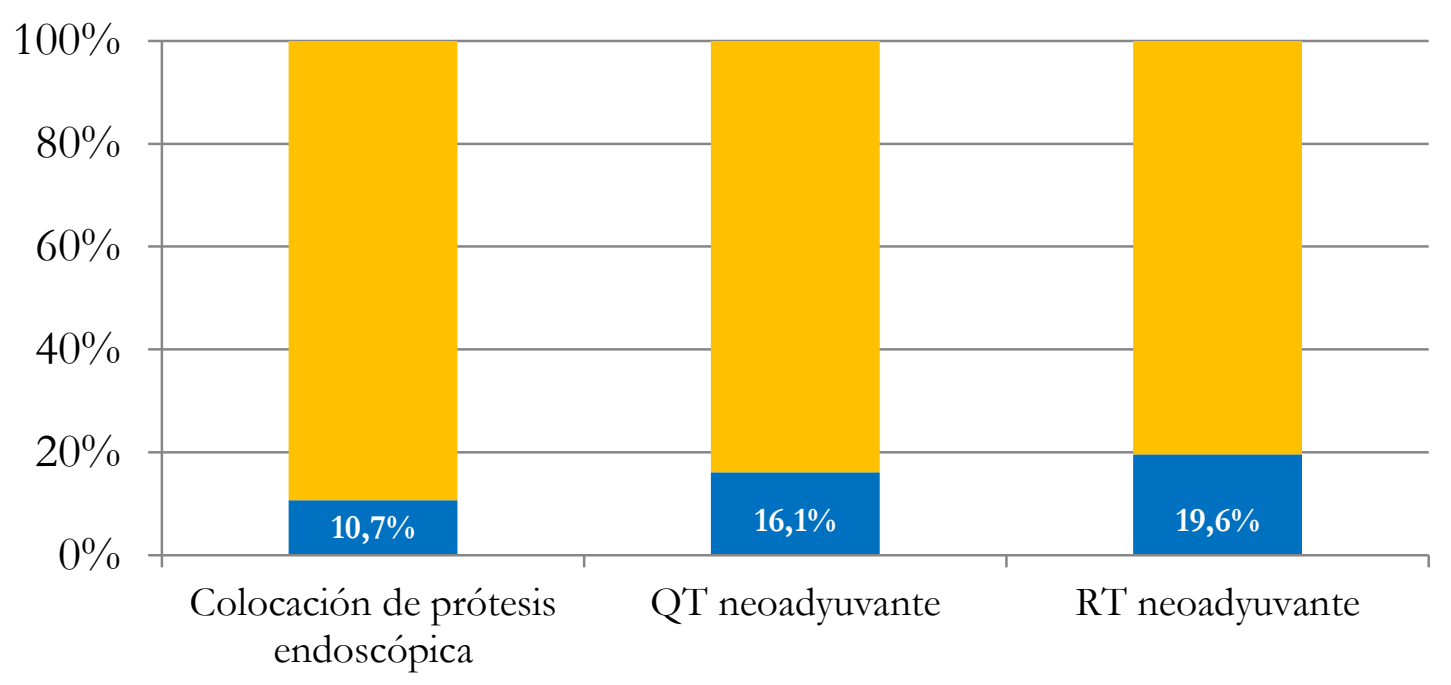

4.1.3.- VARIABLES DEFINITORIAS DEL ESTADO NUTRICIONAL E INFLAMATORIO.

A continuación se describe la distribución en función de los 4 scores que hemos utilizado para definir el estado nutricional e inflamatorio:

La variable "PNI" presentó una distribución normal, con una media de 44,88 \pm 6,08 (rango de 22 a 64) [Gráfico 7].

La variable "GPS" mostró la siguiente distribución: 104 pacientes $(61,9 \%)$ tuvieron una puntuación de $0,36(21,4 \%)$ de 1 y $28(16,7 \%)$ de 2 [Gráfico 8]. 


\section{Martín Bailón Cuadrado}

Gráfico 7. Histograma que muestra la distribución de la variable "PNI".

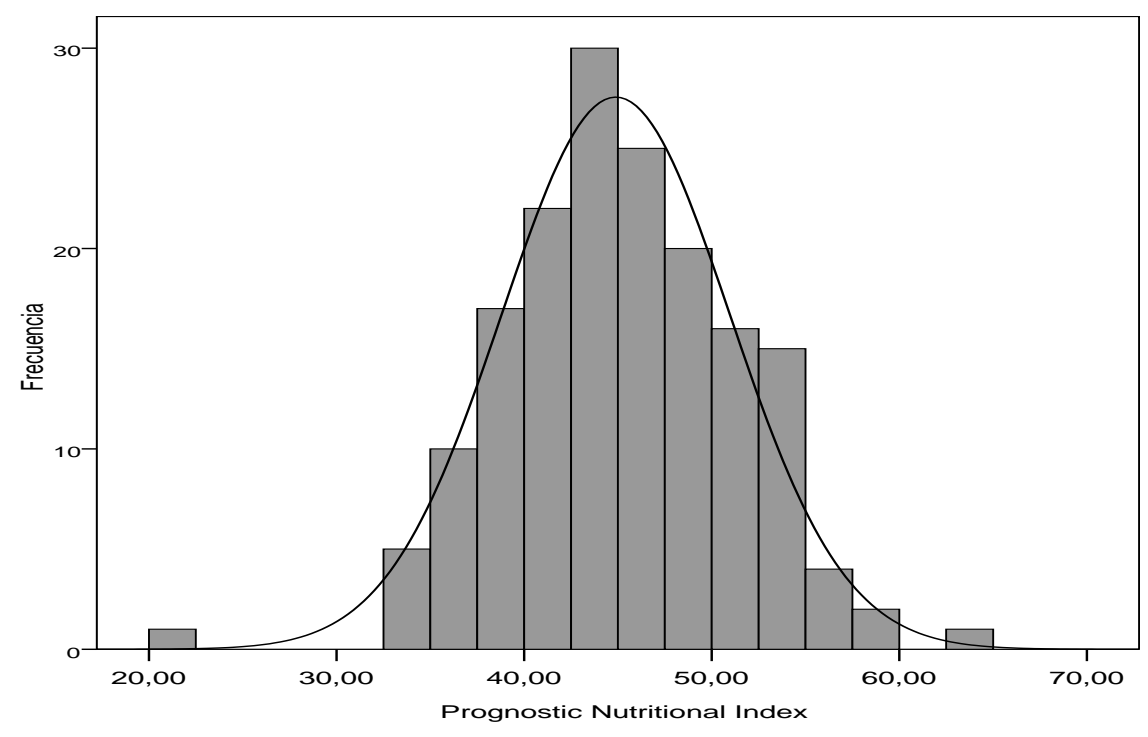

Gráfico 8. Diagrama de barras que muestra la distribución de la variable "GPS”.

\section{Glasgow Prognostic Score}

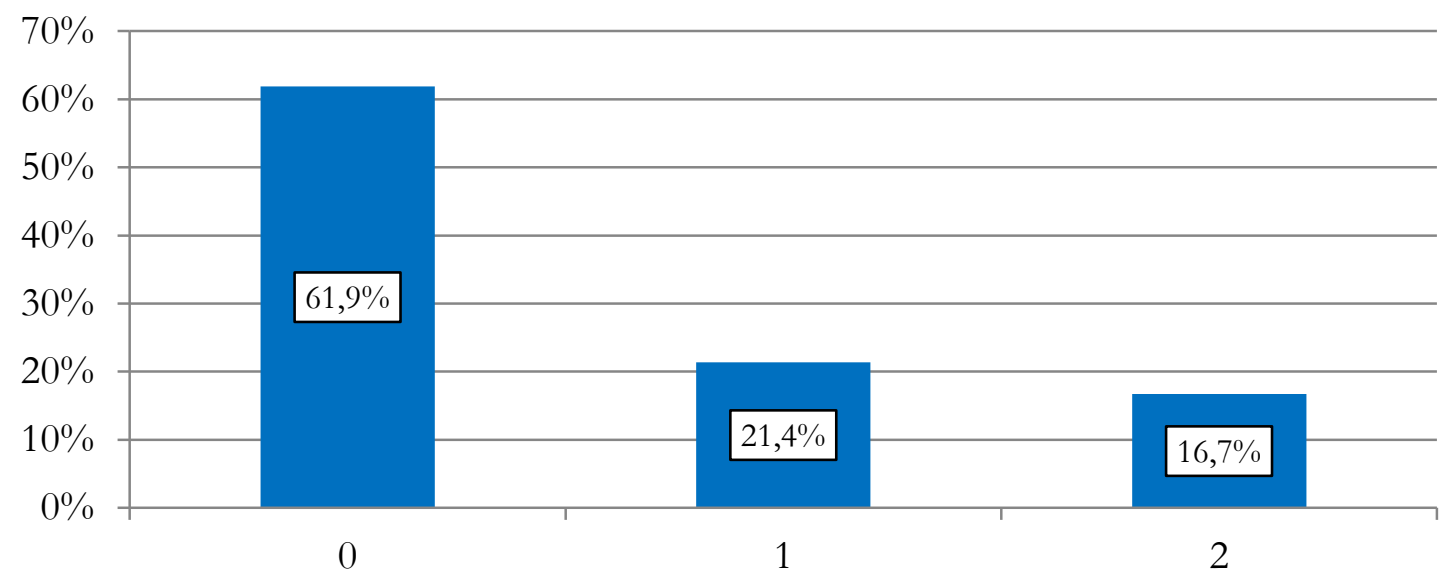

La variable "NLR" siguió una distribución no normal, con una mediana de 2,19 (RIQ de 1,68 a 3,28) [Gráfico 9].

La variable "PLR" presentó una distribución no normal, con una mediana de 135,28 (RIQ de 94,11-196,83) [Gráfico 10]. 
Gráfico 9. Histograma que muestra la distribución de la variable "NLR".

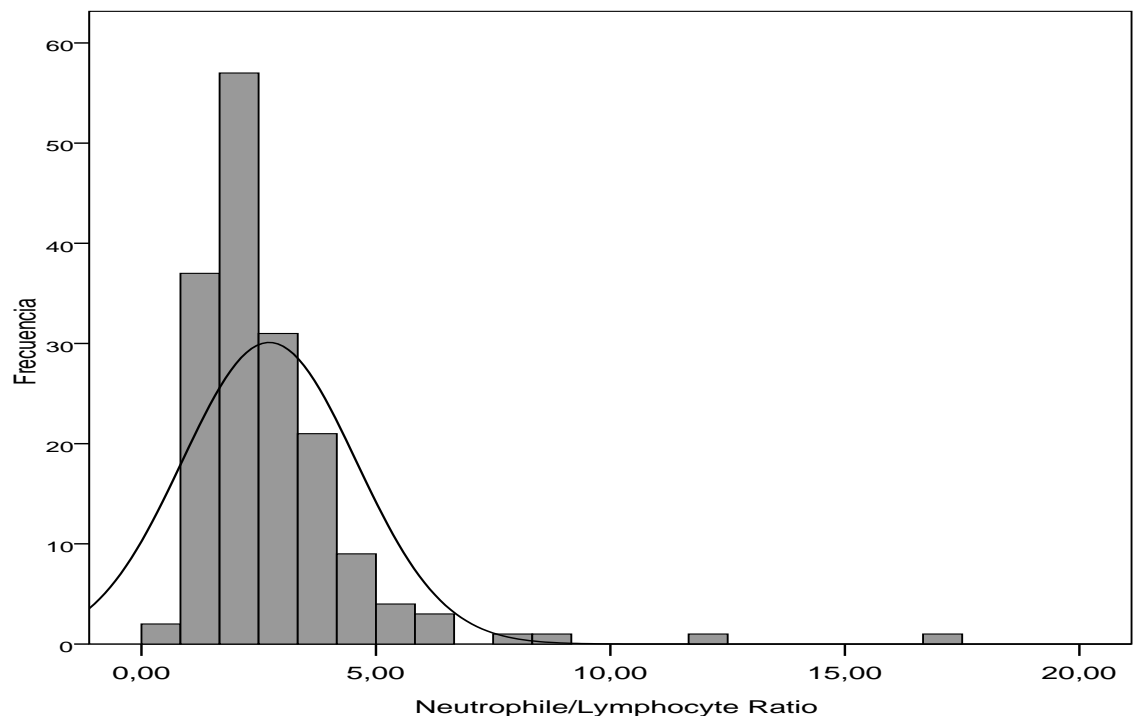

Gráfico 10. Histograma que muestra la distribución de la variable "PLR".

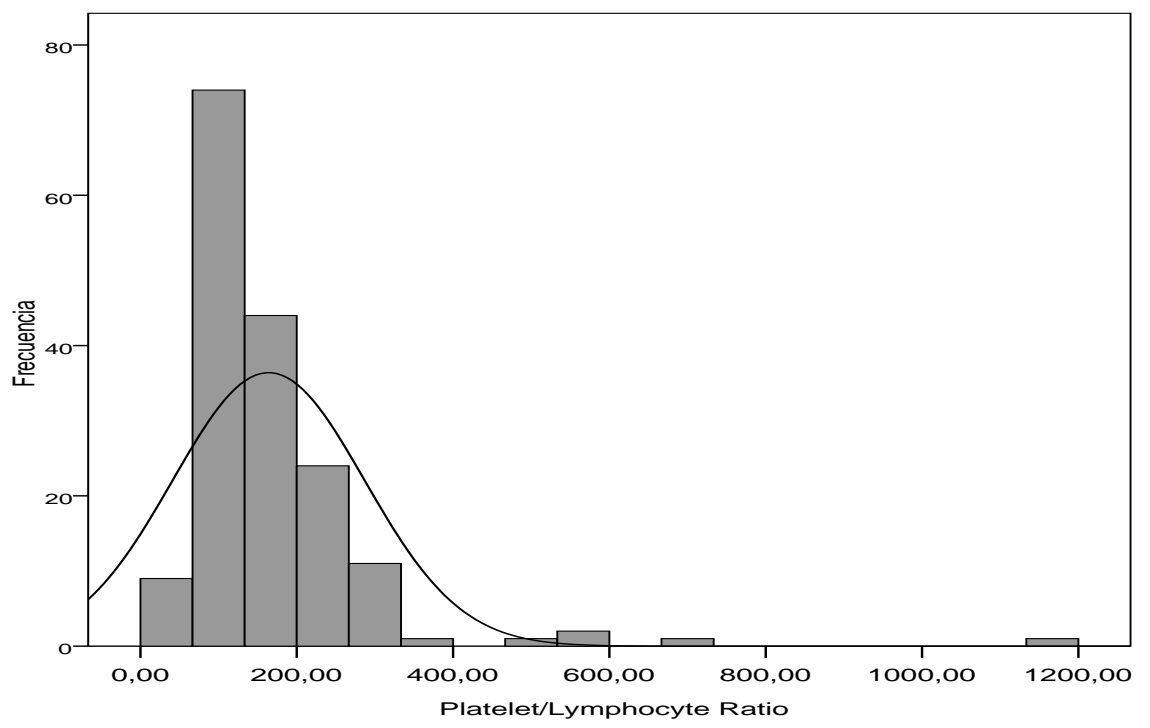




\section{Martín Bailón Cuadrado}

Estos scores se obtienen de unas determinadas variables analíticas (albúmina, PCR, neutrófilos, linfocitos y plaquetas) cuyos valores se describen en la tabla 10.

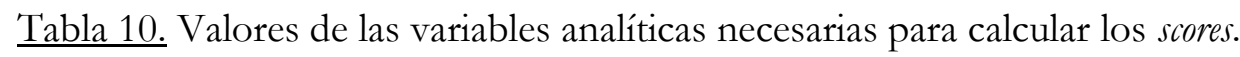

\begin{tabular}{|c|c|}
\hline \multicolumn{2}{|c|}{ VALORES DE LAS VARIABLES ANALÍTICAS } \\
\hline Albúmina & Media de $3,65 \pm 0,50 \mathrm{~g} / \mathrm{dL}$ (rango de 1,9 a 4,9$)$ \\
\hline PCR & Mediana de $4 \mathrm{mg} / \mathrm{L}($ RIQ de 2 a 10$)$ \\
\hline Neutrófilos & Mediana de 3550 por $\mu \mathrm{L}($ RIQ de 2900 a 4675$)$ \\
\hline Linfocitos & Media de $226059,52 \pm 72184,45$ por $\mu \mathrm{L}($ rango de 74000 a 554000$)$ \\
\hline Plaquetas & Media de $1677,98 \pm 706,21$ por $\mu \mathrm{L}($ rango de 400 a 6400$)$ \\
\hline
\end{tabular}

Se utilizó la correlación de Pearson para analizar el grado de interrelación entre los 4 scores definitorios del estado nutricional e inflamatorio. Ya que las variables "NLR" y "PLR" no se ajustaban al patrón de normalidad, tuvieron que ser "normalizadas" mediante la aplicación del logaritmo decimal (“Log NLR” y "Log PLR”). Observamos que las cuatro variables analizadas estaban vinculadas entre sí de una forma estadísticamente significativa $(\mathrm{p}<0,05)$ [Tabla 11]

Tabla 11. Correlación de Pearson entre los 4 scores definitorios del estado nutricional e inflamatorio.

\begin{tabular}{|c|l|c|c|c|c|}
\hline \multicolumn{2}{|c|}{ CORRELACIONES } & \multirow{2}{*}{ PNI } & GPS & Log NLR & Log PLR \\
\hline \multirow{2}{*}{ PNI } & Coeficiente de Pearson & & $-0,557$ & $-0,482$ & $-0,544$ \\
\cline { 2 - 2 } & Significación (bilateral) & & 0,0001 & 0,0001 & 0,0001 \\
\hline \multirow{2}{*}{ GPS } & Coeficiente de Pearson & $-0,557$ & & 0,164 & 0,161 \\
\cline { 2 - 3 } & Significación (bilateral) & 0,0001 & & 0,033 & 0,037 \\
\hline \multirow{2}{*}{ Log NLR } & Coeficiente de Pearson & $-0,482$ & 0,164 & & 0,785 \\
\cline { 2 - 4 } & Significación (bilateral) & 0,0001 & 0,033 & & \multirow{2}{*}{0,0001} \\
\hline \multirow{2}{*}{ Log PLR } & Coeficiente de Pearson & $-0,544$ & 0,161 & 0,785 & \\
\cline { 2 - 4 } & Significación (bilateral) & 0,0001 & 0,037 & 0,0001 & \\
\hline
\end{tabular}


Se llevó a cabo el análisis factorial para obtención de componentes principales, aplicando el método de rotación Varimax. Ya que las variables "NLR" y "PLR" no se ajustaban al patrón de normalidad, para este método estadístico también tuvieron que ser “normalizadas" mediante la aplicación del logaritmo decimal ("Log NLR" y "Log PLR”). Obtuvimos dos nuevas variables que denominamos "resultante A" y "resultante B":

- Resultante A: influenciada principalmente por el NLR y el PLR, en menor medida por el PNI, y apenas por el GPS.

- Resultantes B: influenciada principalmente por el GPS y el PNI, y en mucha menor medida por NLR y PLR.

En la tabla 12 se describe la influencia de cada uno de los cuatro scores en cada una de estas dos variables resultantes.

Tabla 12. Matriz de componentes rotados donde se describe la influencia de cada score sobre cada una de las 2 variables resultantes.

\begin{tabular}{|c|c|c|}
\hline ANÁLISIS FACTORIAL & Resultante A & Resultante B \\
\hline PNI & $-0,507$ & $-0,737$ \\
\hline GPS & $-0,002$ & 0,949 \\
\hline Log NLR & 0,924 & 0,118 \\
\hline Log PLR & 0,931 & 0,148 \\
\hline
\end{tabular}

Hemos utilizado la regresión lineal para obtener la fórmula necesaria para poder calcular las variables "resultante A" y "resultante B" desde el valor de cada uno de los scores que las constituyen:

- Resultante $\mathrm{A}=-$ 4,645 - (0,019 x PNI) - (0,304 x GPS $)+(2,322 \times \log$ NLR $)+$ $(2,236 \times \log$ PLR) 


\section{Martín Bailón Cuadrado}

- Resultante $\mathrm{B}=4,069-(0,074 \times \mathrm{PNI})+(0,966 \times \mathrm{GPS})-(0,607 \times \log$ NLR $)-$ $(0,491 \times \log$ PLR $)$

La variable "resultante A" siguió una distribución normal, con una media de $0 \pm 1$ (rango de - 2,652 a 3,661) [Gráfico 11].

La variable "resultante $B$ " siguió una distribución no normal, con una mediana de - 0,447 (RIQ de - 0,713 a 0,775) [Gráfico 12].

Gráfico 11. Histograma que muestra la distribución de la variable "resultante A".

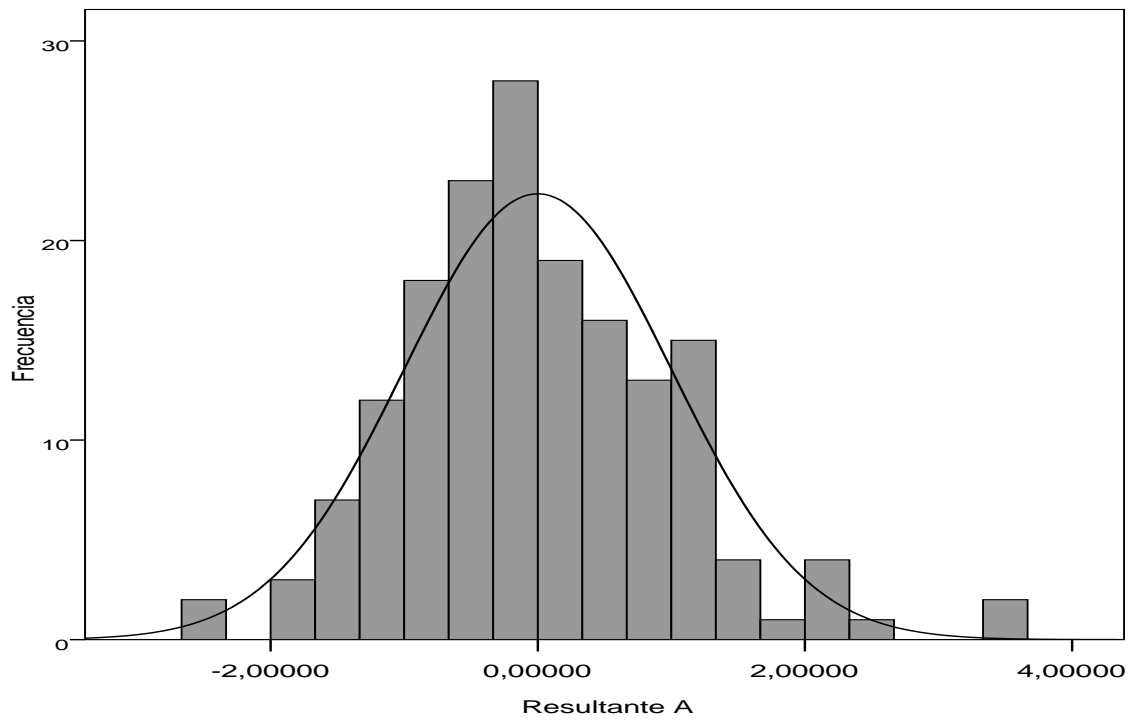


Gráfico 12. Histograma que muestra la distribución de la variable "resultante B".

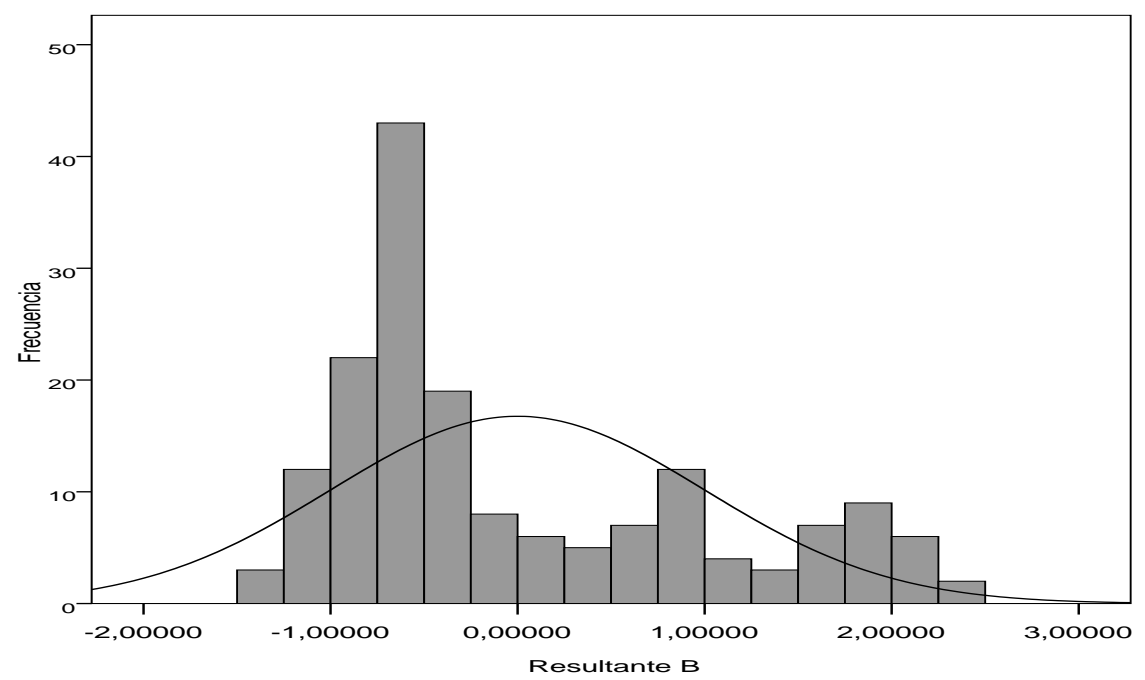

\subsection{4.- VARIABLES INTRAOPERATORIAS.}

Las neoplasias se localizaron en el colon en 121 pacientes (72\%) y en el recto en 47 (28\%)

[Gráfico 13]. Se realizó una colectomía en 98 (58,3\%), una proctectomía en 50 (29,8\%), una AAP en $12(7,1 \%)$ y un procedimiento de Hartmann en 8 (4,8\%) [Gráfico 14].

Gráfico 13. Diagrama de sectores que muestra la distribución por localización del tumor.

\section{Localización de la tumoración}

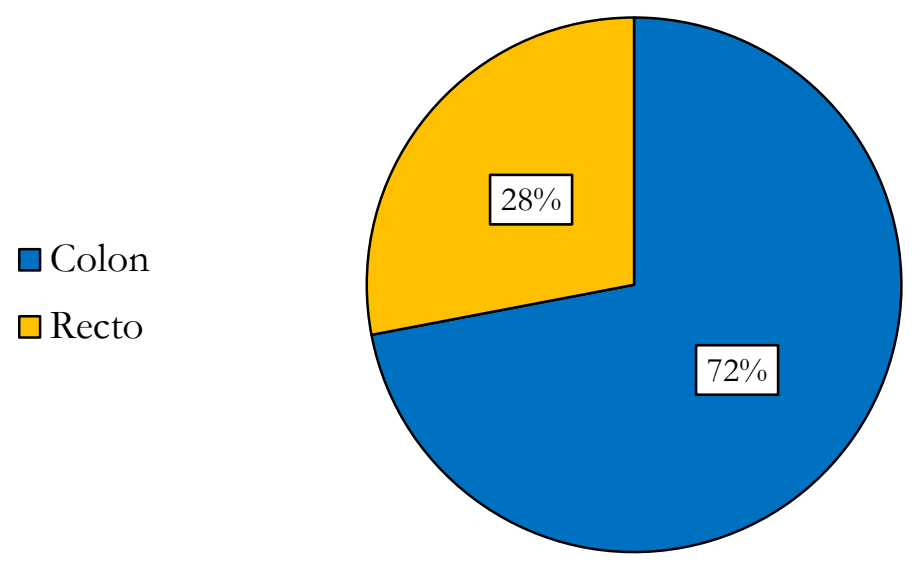




\section{Martín Bailón Cuadrado}

Gráfico 14. Diagrama de barras que muestra la distribución por técnica quirúrgica realizada.

Técnica quirúrgica realizada

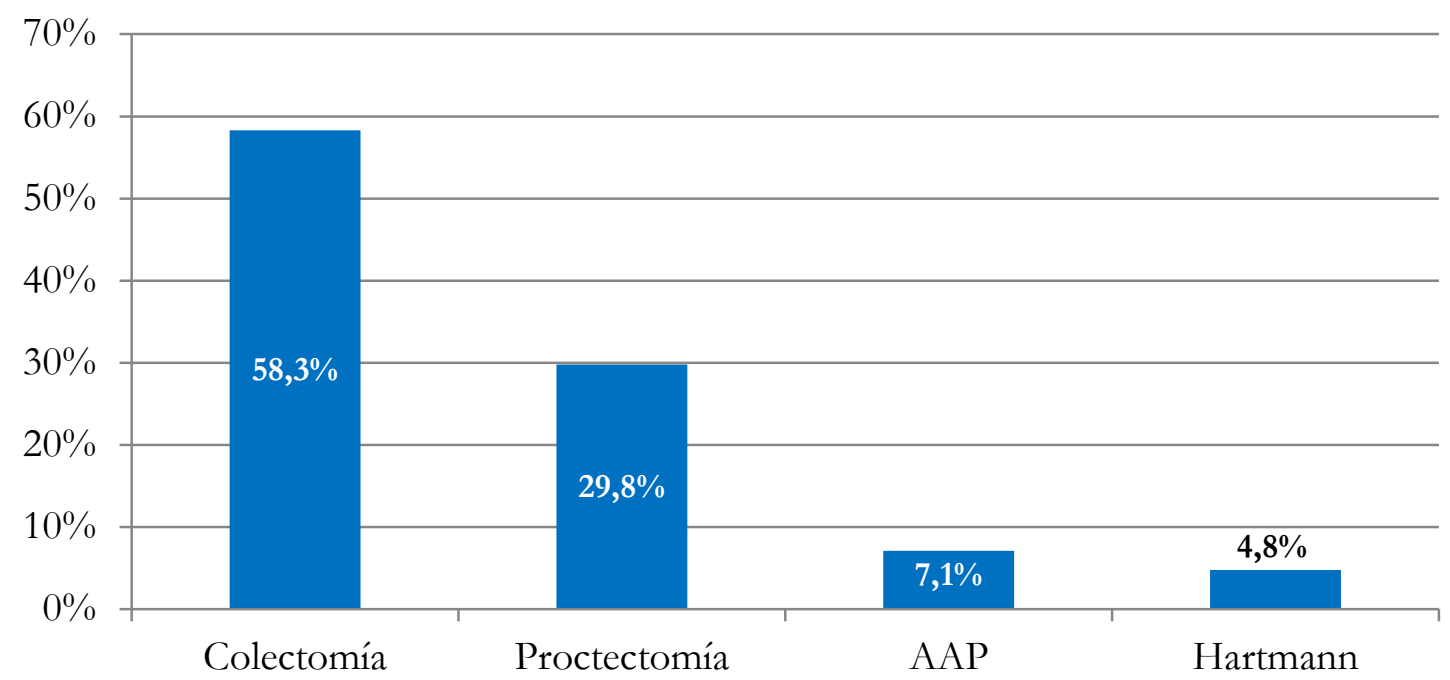

La variable "tiempo de intervención" siguió una distribución normal, con una media de 214,58 \pm 67,99 minutos (rango de 80 a 450 minutos) [Gráfico 15]. Sólo 3 pacientes (1,8\%) precisaron la transfusión de hemoderivados durante la cirugía.

Gráfico 15. Histograma que muestra la distribución por tiempo de intervención.

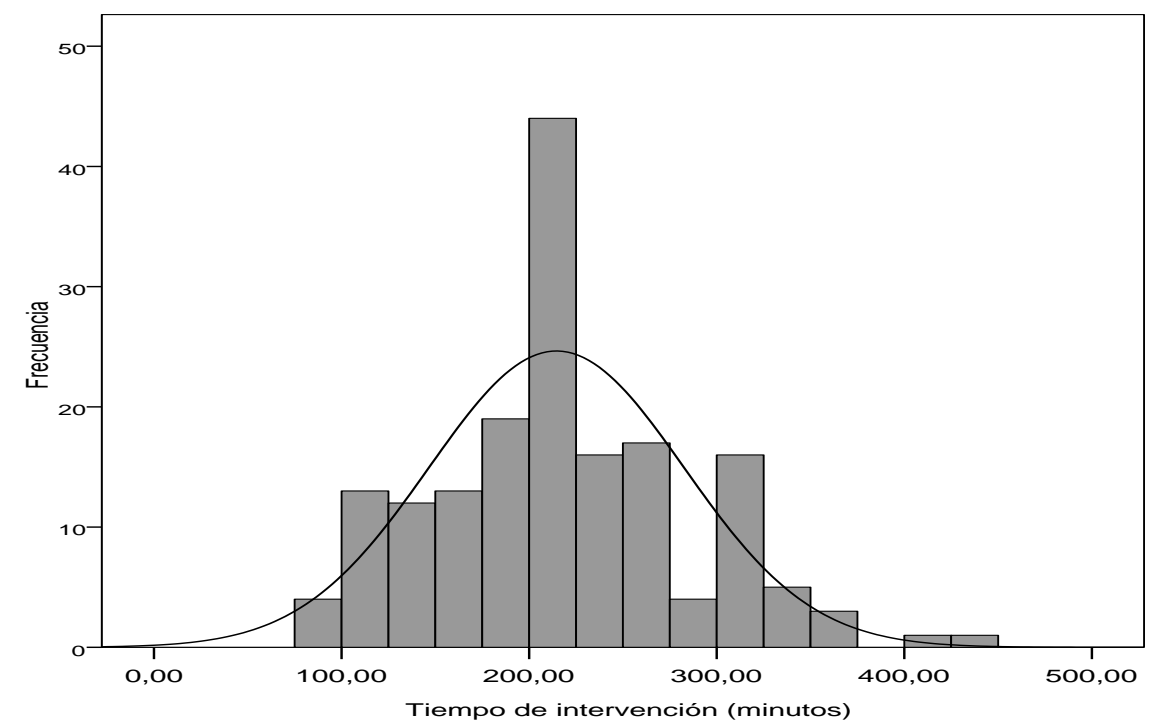




\subsection{5.- VARIABLES POSTOPERATORIAS.}

La distribución en función de las complicaciones acaecidas durante los primeros 30 días del periodo postoperatorio o hasta el alta hospitalaria en ingresos más prolongados fue la siguiente: un total de 55 pacientes $(32,7 \%)$ padecieron algún tipo de complicación, 33 $(19,6 \%)$ sufrieron complicaciones infecciosas, 11 de 148 pacientes con anastomosis $(7,4 \%)$ presentaron fuga anastomótica, $10(6,0 \%)$ tuvieron que ser reintervenidos y $3(1,8 \%)$ fallecieron [Gráfico 16].

Gráfico 16. Diagrama de columnas que muestra la distribución en base a las complicaciones postoperatorias.

$\square$ NO $\square$ SÍ

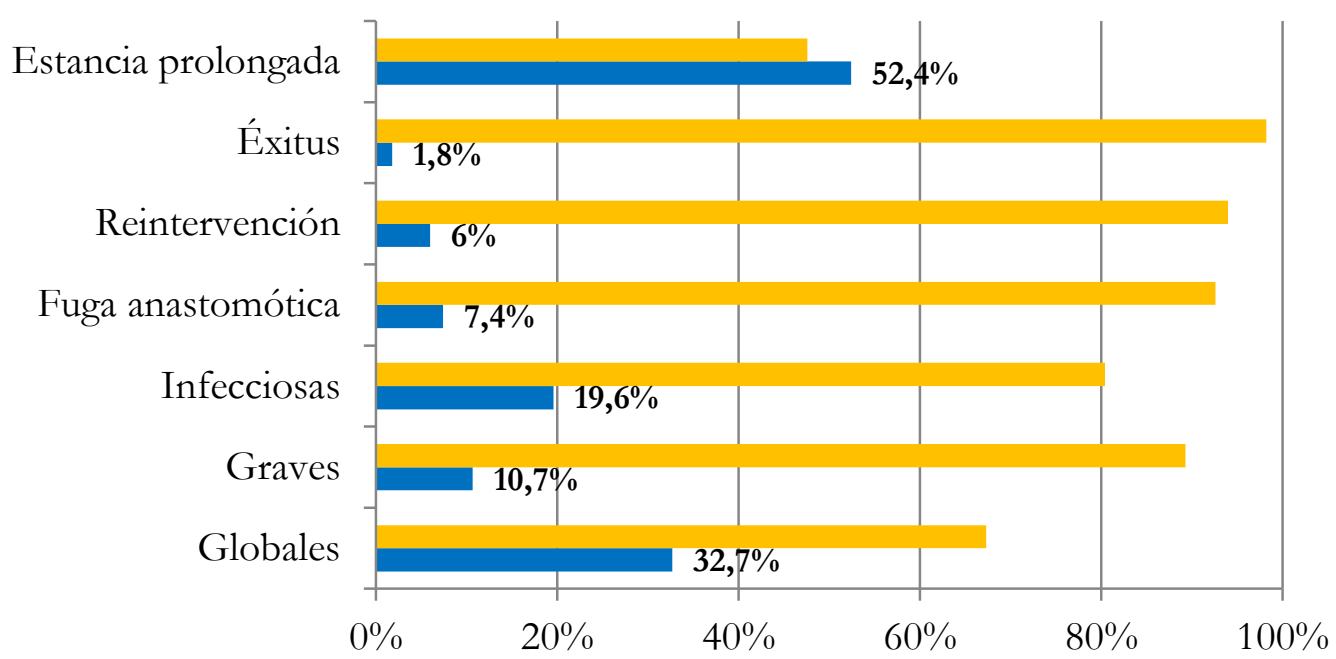




\section{Martín Bailón Cuadrado}

De los 55 pacientes en los que se registraron complicaciones, 19 (11,3\%) fueron grado I de la clasificación de Clavien-Dindo, 18 (10,7\%) grado II, 3 (1,78\%) grado IIIa, 5 (2,98\%) grado IIIb, 4 (2,38\%) grado IVa, $3(1,78 \%)$ grado IVb y $3(1,78 \%)$ grado V. Teniendo en cuenta esta distribución, 18 de los pacientes $(10,7 \%)$ sufrieron complicaciones graves (grado $\geq$ III de la clasificación de Clavien-Dindo) [Gráfico 17].

Gráfico 17. Diagrama de barras que muestra la distribución de las complicaciones siguiendo la clasificación de Clavien-Dindo.

\section{Grado de la clasificación de Clavien-Dindo}

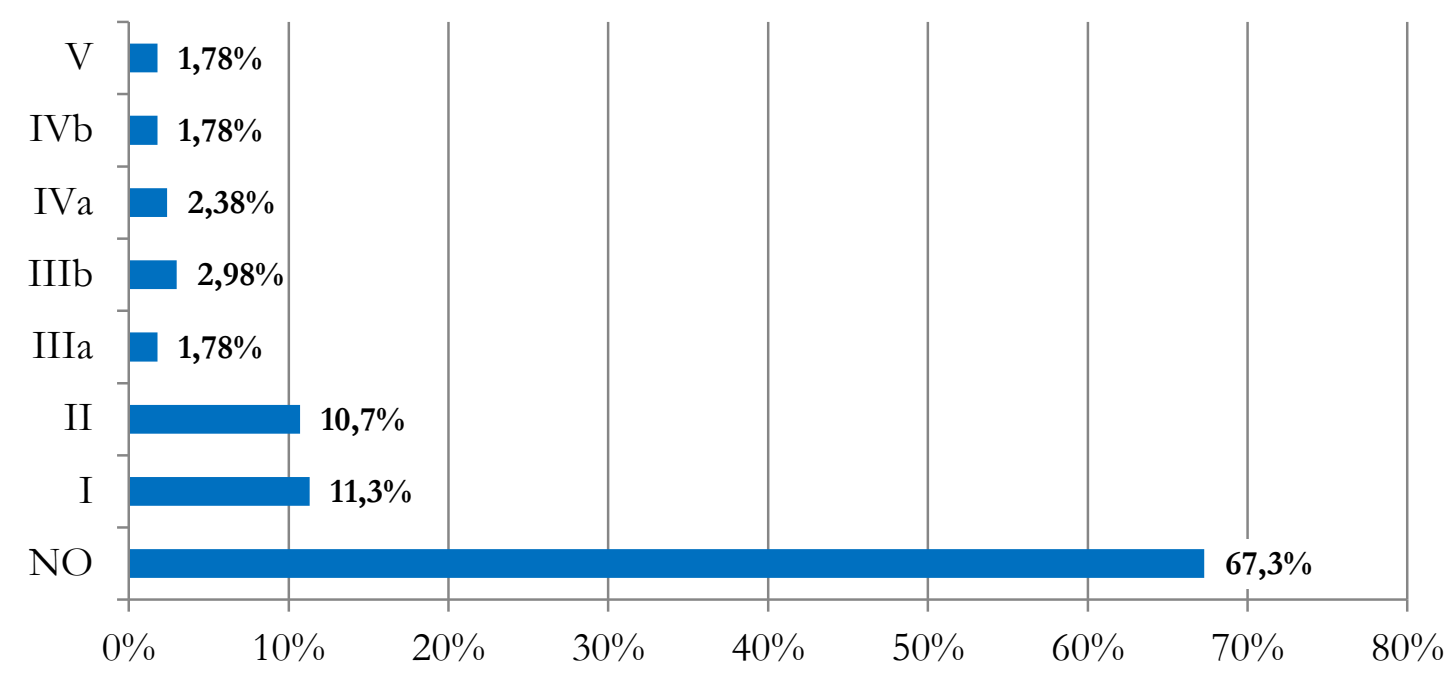

La estancia postoperatoria siguió una distribución no normal, con una mediana de 9 días (RIQ de 8 a 10 días). Tomando como punto de corte el valor de 9 días de la mediana, generamos la variable "estancia postoperatoria prolongada", que mostró la siguiente distribución: 88 pacientes $(52,4 \%)$ estuvieron ingresados 9 o más días tras la cirugía y 80 (47,6\%) lo estuvieron durante 8 o menos días [Gráfico 18]. 
Resultados

Gráfico 18. Histograma que muestra la distribución en función de la estancia postoperatoria (días).

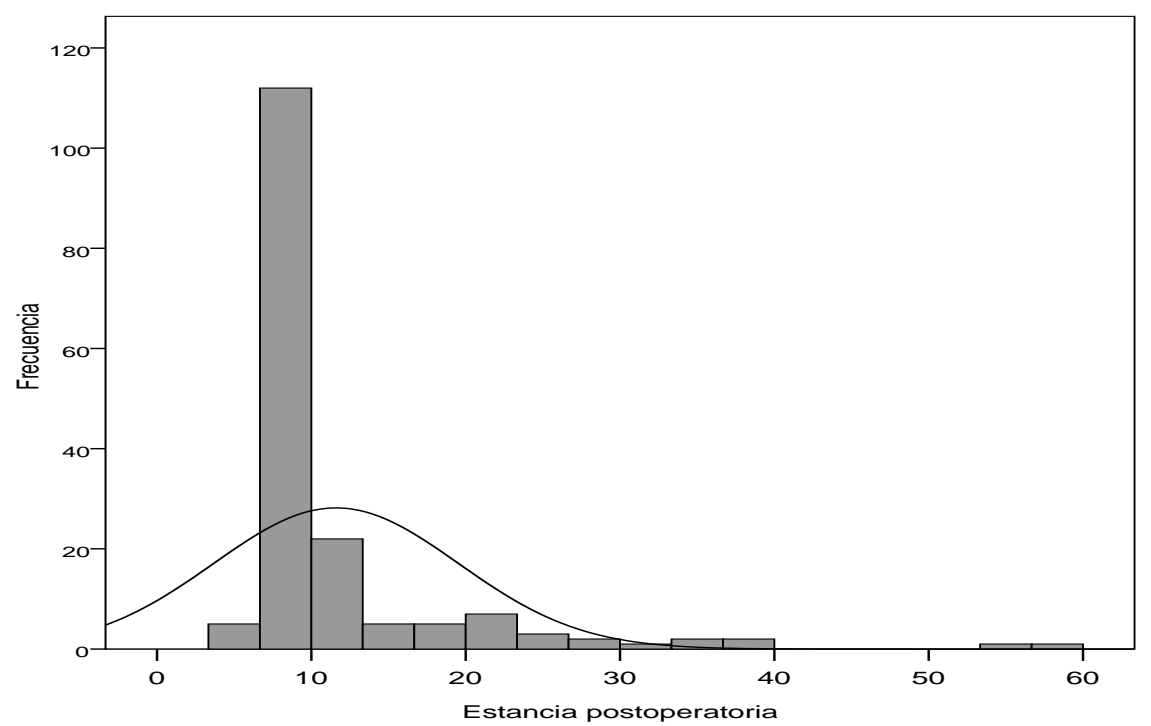




\section{Martín Bailón Cuadrado}

\section{2.- ANÁLISIS INFERENCIAL.}

Hemos analizado la relación existente entre las siete variable objeto de estudio (complicaciones globales, graves, infecciosas, fuga anastomótica, reintervención, éxitus y estancia postoperatoria prolongada) con el resto de variables recogidas para tratar de averiguar si estas tienen alguna influencia significativa con las primeras.

\subsection{1.- COMPLICACIONES GLOBALES.}

\subsubsection{1.- ANÁLISIS UNIVARIANTE.}

Como ya se expuso anteriormente, un total de 55 pacientes $(32,7 \%)$ sufrieron algún tipo de complicación. La distribución de las complicaciones globales en función de las variables analizadas se puede ver en la tabla 13.

Tras realizar el análisis univariante, nueve variables obtuvieron una $\mathrm{p}<0,1$ :

- Edad: los pacientes con complicaciones globales eran mayores, con una edad media de 72,95 \pm 10,72 años, que los no complicados, con una media de 67,09 $\pm 11,17$ años $(p=0,001)$.

- Riesgo anestésico: un 44,8\% de pacientes con riesgo alto sufrieron complicaciones frente a un 26,4\% con riesgo bajo $(p=0,015)$.

- Localización de la tumoración: el 28,1\% de pacientes con lesiones en el colon presentaron alguna complicación, frente al 44,7\% de aquellos con lesiones rectales $(\mathrm{p}=0,04)$. 
- Tipo de intervención: observamos que el 29,6\% de las colectomías sufrieron complicaciones, el $28 \%$ de las proctectomías, el $50 \%$ de las AAP y el $75 \%$ de los Hartmann $(\mathrm{p}=0,037)$.

- PNI: este score fue menor en los pacientes con complicaciones globales, con una media de 42,28 $\pm 7,14$, que en los no complicados, con una media de 46,15 $\pm 5,06$ $(p=0,001)$.

- GPS: observamos que las complicaciones se presentaron en el $21,2 \%$ de los pacientes con grado 0 , en el $41,7 \%$ de los grado 1 y en el $64,3 \%$ de los grado 2 ( $\mathrm{p}=$ $0,0001)$

- NLR: encontramos que la media fue de 3,16 $\pm 2,64$ en pacientes complicados y de $2,51 \pm 1,27$ en los no complicados $(p=0,088)$.

- PLR: obtuvimos una media de 195,25 \pm 172,12 en pacientes complicados y de $148,83 \pm 86,45$ en no complicados $(p=0,063)$.

- Resultante B: los pacientes que sufrieron complicaciones mostraron una media de $0,501 \pm 1,160$ frente a $-0,244 \pm 0,812$ en aquellos sin complicaciones $(p=0,0001)$

\subsubsection{2.- ANÁLISIS MULTIVARIANTE.}

Se realizó la regresión logística binaria con las nueve variables que consiguieron una $\mathrm{p}<0,1$ en el univariante y tres variables alcanzaron una significación estadística:

- Edad: obtuvimos una OR de 1,047 (IC 95\% = 1,012 - 1,084), $\mathrm{p}=0,008$. La curva ROC presentó un área bajo la curva de 0,658 (IC 95\% = 0,569-0,746). 


\section{Martín Bailón Cuadrado}

- Localización de la tumoración: mostró una OR de 3,520 (IC 95\% = 1,550 - 7,994), $\mathrm{p}=0,003$. La curva ROC presentó un área bajo la curva de 0,576 (IC 95\% $=0,482$ $-0,670)$.

- Resultante B: obtuvimos una OR de 2,239 (IC 95\% = 1,541 - 3,253), $\mathrm{p}=0,0001$. La curva ROC presentó un área bajo la curva de 0,684 (IC 95\% = 0,591 - 0,777), con unos valores de sensibilidad y especificidad del 65,5\% y 70,8\%, respectivamente.

En el gráfico 19 pueden verse las curvas ROC de estas 3 variables significativas.

Gráfico 19. Curvas ROC de las variables "edad", "localización de la tumoración" y "resultante B" para la variable "complicaciones globales".

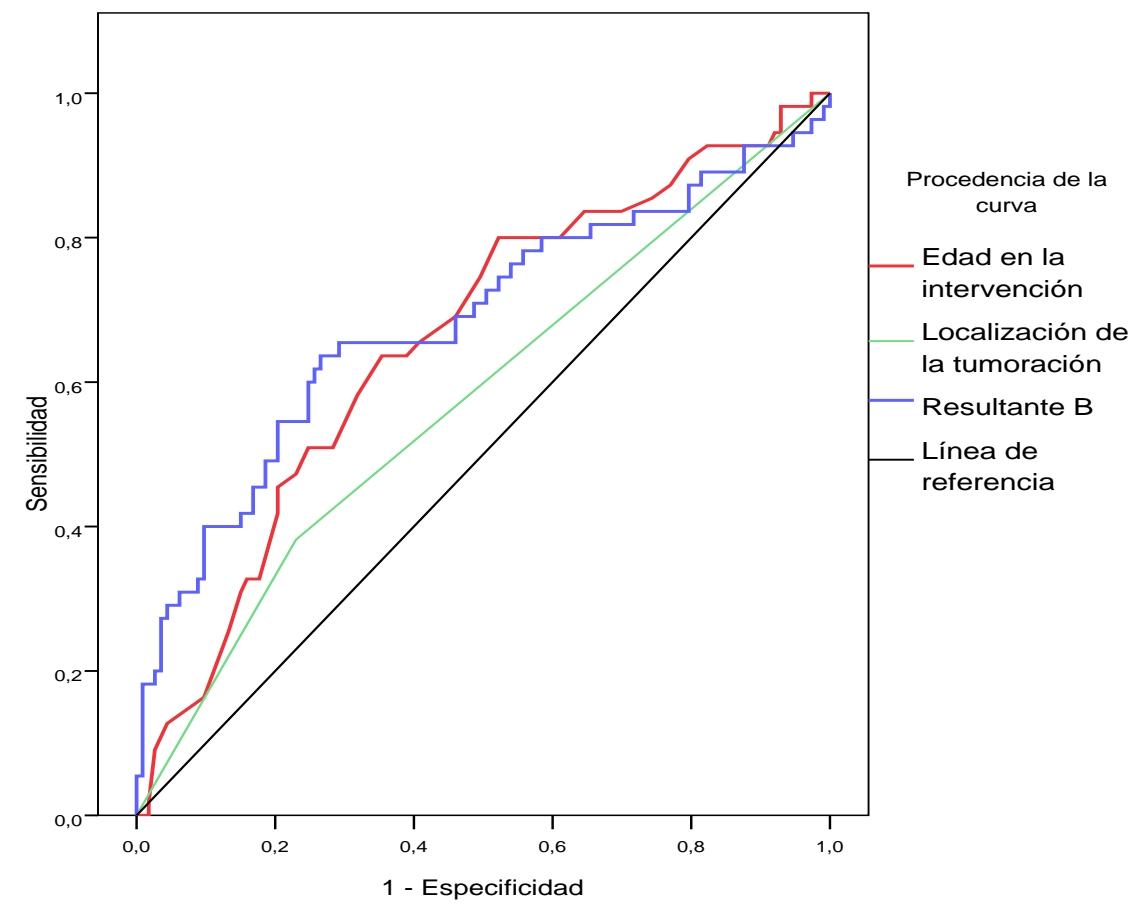


Tabla 13. Distribución de la variable "complicaciones globales" (los valores entre paréntesis representan porcentajes).

\begin{tabular}{|c|c|c|c|c|c|}
\hline \multirow{2}{*}{\multicolumn{2}{|c|}{ COMPLICACIONES GLOBALES }} & \multicolumn{3}{|c|}{ ANÁLISIS UNIVARIANTE } & \multirow{2}{*}{$\frac{\text { MULTIVARIANTE }}{\text { P-VALOR }}$} \\
\hline & & \multirow{2}{*}{$\begin{array}{c}\text { Sí } \\
36(33,6) \\
\end{array}$} & \multirow{2}{*}{$\begin{array}{c}\text { NO } \\
71(66,4)\end{array}$} & \multirow{3}{*}{$\begin{array}{c}\text { P-VALOR } \\
\text { N.S. }\end{array}$} & \\
\hline \multirow{2}{*}{ SEXO } & HOMBRE & & & & \\
\hline & MUJER & $19(31,1)$ & $42(68,9)$ & & \\
\hline EDAD & MEDIA (AÑOS) & 72,95 & 67,09 & 0,001 & 0,008 \\
\hline IMC & MEDIA (KG/M2) & 26,95 & 26,69 & N.S. & \\
\hline \multirow{2}{*}{ HTA } & SÍ & $34(34,7)$ & $64(65,3)$ & \multirow{2}{*}{ N.S. } & \\
\hline & NO & $21(30,0)$ & $49(70,0)$ & & \\
\hline \multirow{2}{*}{ DIABETES MELLITUS } & SÍ & $11(45,8)$ & $13(54,2)$ & \multirow{2}{*}{ N.S. } & \\
\hline & NO & $44(30,6)$ & $100(69,4)$ & & \\
\hline \multirow{2}{*}{ DISLIPEMIA } & Sí & $19(31,7)$ & $41(68,3)$ & \multirow{2}{*}{ N. S. } & \\
\hline & NO & $36(33,3)$ & $72(66,7)$ & & \\
\hline \multirow{2}{*}{ TABAQUISMO } & SÍ & $13(28,3)$ & $33(71,7)$ & \multirow{2}{*}{ N.S. } & \\
\hline & NO & $42(34,4)$ & $80(65,6)$ & & \\
\hline \multirow{2}{*}{$\begin{array}{l}\text { INSUFICIENCIA } \\
\text { CARDIACA }\end{array}$} & SÍ & $4(57,1)$ & $3(42,9)$ & \multirow{2}{*}{ N. S. } & \\
\hline & NO & $51(31,7)$ & $110(68,3)$ & & \\
\hline \multirow{2}{*}{$\begin{array}{l}\text { CARDIOPATÍA } \\
\text { ISQUÉMICA }\end{array}$} & SÍ & $5(35,7)$ & $9(64,3)$ & \multirow{2}{*}{ N.S. } & \\
\hline & $\mathrm{NO}$ & $50(32,5)$ & $104(67,5)$ & & \\
\hline \multirow{2}{*}{ EPOC } & SÍ & $3(33,3)$ & $6(66,7)$ & \multirow{2}{*}{ N.S. } & \\
\hline & NO & $52(32,7)$ & $107(67,3)$ & & \\
\hline \multirow{2}{*}{ RIESGO ANESTÉSICO } & ALTO & $26(44,8)$ & $32(55,2)$ & \multirow{2}{*}{0,015} & \multirow{2}{*}{ N.S. } \\
\hline & BAJO & $29(26,4)$ & $81(73,6)$ & & \\
\hline PRÓTESIS & SÍ & $6(33,3)$ & $12(66,7)$ & $\mathrm{NI}_{\mathrm{S}}$ & \\
\hline ENDOSCÓPICA & NO & $49(32,7)$ & $101(67,3)$ & N.S. & \\
\hline ОUIMIOTEP А PIA & SÍ & $8(29,6)$ & $19(70,4)$ & $N S_{1}$ & \\
\hline QUIVIUIERAPIA & NO & $47(33,3)$ & $94(66,7)$ & N. S. & \\
\hline & SÍ & $12(37,5)$ & $20(62,5)$ & $\mathrm{N}^{2}$ & \\
\hline RADIOTERAPIA & NO & $42(31,1)$ & $93(68,9)$ & N. S. & \\
\hline LOCALIZACIÓN DE LA & COLON & $34(28,1)$ & $87(71,9)$ & 004 & 0003 \\
\hline TUMORACIÓN & RECTO & $21(44,7)$ & $26(55,3)$ & 0,04 & 0,003 \\
\hline & COLECTOMÍA & $29(29,6)$ & $69(70,4)$ & & \\
\hline TIPO DE & PROCTECTOMÍA & $14(28,0)$ & $36(72,0)$ & 0037 & 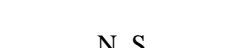 \\
\hline INTERVENCIÓN & AAP & $6(50,0)$ & $6(50,0)$ & 0,031 & N.S. \\
\hline & HARTMANN & $6(75,0)$ & $2(25,0)$ & & \\
\hline TIEMPO Q. & MEDIA (MIN.) & 220,36 & 211,77 & N.S. & \\
\hline TRANSFUSIÓN & Sí & $2(66,7)$ & $1(33,3)$ & $h^{2}$ & \\
\hline INTRAOPERATORIA & NO & $53(32,1)$ & $112(67,9)$ & & \\
\hline PNI & MEDIA & 42,28 & 46,15 & 0,001 & N.S. \\
\hline & 0 & $22(21,2)$ & $82(78,8)$ & & \\
\hline GPS & 1 & $15(41,7)$ & $21(58,3)$ & 0,0001 & N. S. \\
\hline & 2 & $18(64,3)$ & $10(35,7)$ & & \\
\hline NLR & MEDIA & 3,16 & 2,51 & 0,088 & N.S. \\
\hline PLR & MEDIA & 195,25 & 148,83 & 0,063 & N.S. \\
\hline RESULTANTE A & MEDIA & 0,177 & $-0,086$ & N.S. & \\
\hline RESULTANTE B & MEDIA & 0,501 & $-0,244$ & 0,0001 & 0,0001 \\
\hline
\end{tabular}




\section{Martín Bailón Cuadrado}

\subsection{2.- COMPLICACIONES GRAVES.}

\subsubsection{1.- ANÁLISIS UNIVARIANTE.}

Un total de 18 pacientes (10,7\%) padecieron complicaciones graves. La distribución de las complicaciones graves en función de las variables analizadas se puede ver en la tabla 14 .

Tras realizar el análisis univariante, tres variables obtuvieron una $\mathrm{p}<0,1$ :

- Edad: la edad media fue de 73,83 \pm 9,75 años entre los pacientes que presentaron complicaciones graves y de $68,43 \pm 11,4$ años entre los que no $(p=0,056)$.

- PNI: apreciamos que la media fue de 41,56 \pm 5,92 en aquellos que padecieron complicaciones graves y de 45,28 $\pm 6,00$ en los que no $(p=0,014)$.

- Resultante B: observamos una media de 0,574 $\pm 1,190$ entre los que sufrieron complicaciones graves y de $-0,069 \pm 0,956$ entre los que no $(p=0,009)$.

\subsubsection{2.- ANÁLISIS MULTIVARIANTE.}

Se realizó la regresión logística binaria con las tres variables que consiguieron una $\mathrm{p}<0,1$ en el univariante y tan sólo la variable "resultante B" consiguió una significación estadística: la OR fue de 1,773 (IC 95\% = 1,129 - 2,785), $\mathrm{p}=0,013$. La curva ROC presentó un área bajo la curva de 0,646 (IC 95\% =0,497 - 0,795) [Gráfico 20], con unos valores se sensibilidad y especificidad del 61,1\% y $76,0 \%$, respectivamente. 
Tabla 14. Distribución de la variable "complicaciones graves" (los valores entre paréntesis representan porcentajes).

\begin{tabular}{|c|c|c|c|c|c|}
\hline \multirow{2}{*}{\multicolumn{2}{|c|}{ COMPLICACIONES GRAVES }} & \multicolumn{3}{|c|}{ ANÁLISIS UNIVARIANTE } & \multirow{2}{*}{$\frac{\text { MULTIVARIANTE }}{\text { P-VALOR }}$} \\
\hline & & \multirow{2}{*}{$\begin{array}{c}\text { Sí } \\
11(10,3) \\
\end{array}$} & \multirow{2}{*}{$\begin{array}{c}\text { NO } \\
96(89,7)\end{array}$} & \multirow{3}{*}{$\begin{array}{c}\text { P-VALOR } \\
\text { N. S. }\end{array}$} & \\
\hline \multirow{2}{*}{ SEXO } & HOMBRE & & & & \\
\hline & MUJER & $7(11,5)$ & $54(88,5)$ & & \\
\hline EDAD & MEDIA (AÑOS) & 73,83 & 68,43 & 0,056 & N.S. \\
\hline IMC & MEDIA (KG/M2) & 26,87 & 26,77 & N.S. & \\
\hline \multirow{2}{*}{ HTA } & Sí & $11(11,2)$ & $87(88,8)$ & \multirow{2}{*}{ N.S. } & \\
\hline & NO & $7(10,0)$ & $63(90,0)$ & & \\
\hline \multirow{2}{*}{ DIABETES MELLITUS } & Sí & $1(4,2)$ & $23(95,8)$ & \multirow{2}{*}{ N. S. } & \\
\hline & NO & $17(11,8)$ & $127(88,2)$ & & \\
\hline \multirow{2}{*}{ DISLIPEMIA } & SÍ & $6(10,0)$ & $54(90,0)$ & \multirow{2}{*}{ N. S. } & \\
\hline & $\mathrm{NO}$ & $12(11,1)$ & $96(88,9)$ & & \\
\hline \multirow{2}{*}{ TABAQUISMO } & SÍ & $5(10,9)$ & $41(89,1)$ & \multirow{2}{*}{ N. S. } & \\
\hline & NO & $13(10,7)$ & $109(89,3)$ & & \\
\hline \multirow{2}{*}{$\begin{array}{l}\text { INSUFICIENCIA } \\
\text { CARDIACA }\end{array}$} & Sí & $2(28,6)$ & $5(71,4)$ & \multirow{2}{*}{ N. S. } & \\
\hline & NO & $16(9,9)$ & $145(90,1)$ & & \\
\hline \multirow{2}{*}{$\begin{array}{l}\text { CARDIOPATÍA } \\
\text { ISQUÉMICA }\end{array}$} & SÍ & $0(0,0)$ & $14(100,0)$ & \multirow{2}{*}{ N. S. } & \\
\hline & NO & $18(11,7)$ & $136(88,3)$ & & \\
\hline \multirow{2}{*}{ EPOC } & SÍ & $0(0,0)$ & $9(100,0)$ & \multirow{2}{*}{ N. S. } & \\
\hline & NO & $18(11,3)$ & $141(88,7)$ & & \\
\hline \multirow{2}{*}{ RIESGO ANESTÉSICO } & ALTO & $9(15,5)$ & $49(84,5)$ & \multirow{2}{*}{ N. S. } & \\
\hline & BAJO & $9(8,2)$ & $101(91,8)$ & & \\
\hline \multirow{2}{*}{$\begin{array}{c}\text { PRÓTESIS } \\
\text { ENDOSCÓPICA }\end{array}$} & SÍ & $2(11,1)$ & $16(88,9)$ & $\mathrm{NI}_{\mathrm{S}}$ & \\
\hline & $\mathrm{NO}$ & $16(10,7)$ & $134(89,3)$ & N.S. & \\
\hline ОUIMIOTEP А PIA & Sí & $3(11,1)$ & $24(88,9)$ & $N S_{-}$ & \\
\hline QUIVIUTERAPIA & $\mathrm{NO}$ & $15(10,6)$ & $126(89,4)$ & N. S. & \\
\hline R ADIOTER APIA & Sí & $3(9,1)$ & $30(90,9)$ & 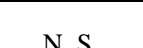 & \\
\hline КАDIUIEKAPIA & NO & $15(11,1)$ & $120(88,9)$ & & \\
\hline LOCALIZACIÓN DE LA & COLON & $11(9,1)$ & $110(90,9)$ & $\mathrm{N}^{2}$ & \\
\hline TUMORACIÓN & RECTO & $7(14,9)$ & $40(85,1)$ & N.S. & \\
\hline & COLECTOMÍA & $10(10,2)$ & $88(89,8)$ & & \\
\hline TIPO DE & PROCTECTOMÍA & $7(14,0)$ & $43(86,0)$ & $N S_{1}$ & \\
\hline INTERVENCIÓN & AAP & $0(0,0)$ & $12(100,0)$ & N.S. & \\
\hline & HARTMANN & $1(12,5)$ & $7(87,5)$ & & \\
\hline TIEMPO Q. & MEDIA (MIN.) & 216,67 & 214,33 & N. S. & \\
\hline TRANSFUSIÓN & Sí & $0(0,0)$ & $3(100,0)$ & $h^{2}$ & \\
\hline INTRAOPERATORIA & NO & $18(10,9)$ & $147(89,1)$ & & \\
\hline PNI & MEDIA & 41,56 & 45,28 & 0,014 & N.S. \\
\hline & 0 & $7(6,7)$ & $97(93,3)$ & & \\
\hline GPS & 1 & $6(16,7)$ & $30(83,3)$ & N. S. & \\
\hline & 2 & $5(17,9)$ & $23(82,1)$ & & \\
\hline NLR & MEDIA & 2,51 & 2,75 & N. S. & \\
\hline PLR & MEDIA & 156,41 & 164,94 & N.S. & \\
\hline RESULTANTE A & MEDIA & $-0,326$ & 0,039 & N. S. & \\
\hline RESULTANTE B & MEDIA & 0,574 & $-0,069$ & 0,009 & 0,013 \\
\hline
\end{tabular}




\section{Martín Bailón Cuadrado}

Gráfico 20. Curva ROC de la variable "resultante B" para la variable "complicaciones graves".

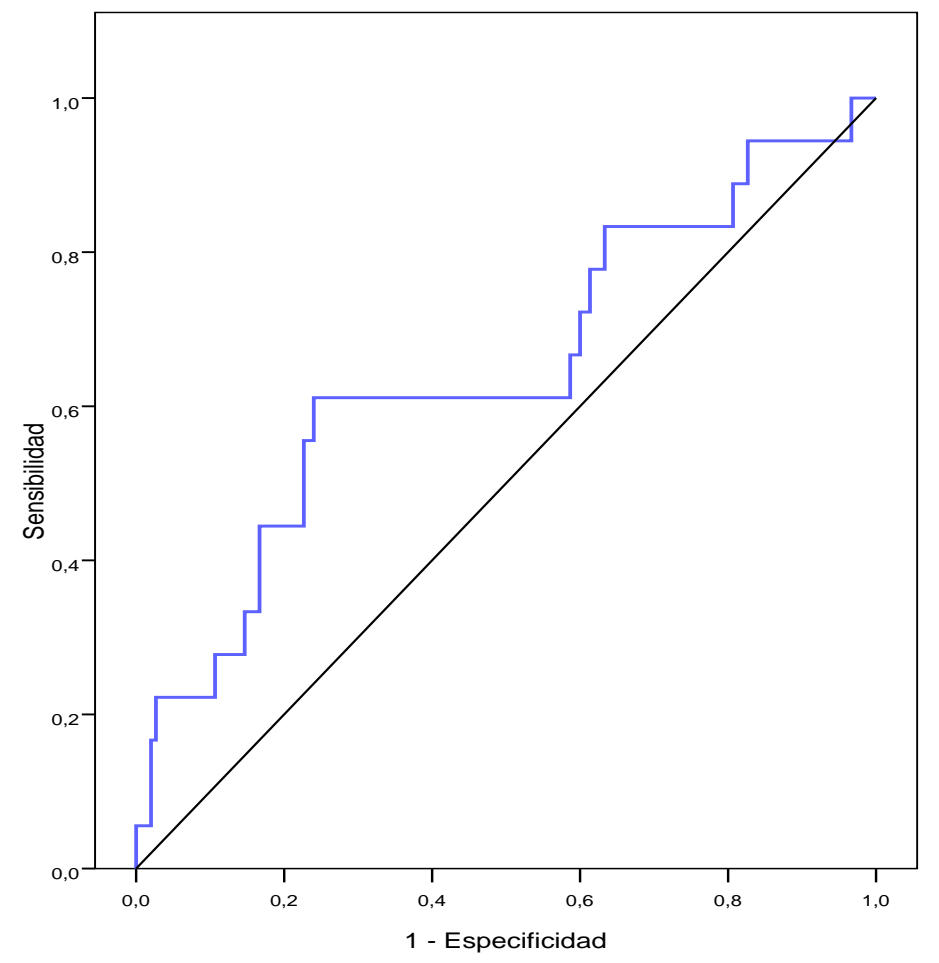

\subsection{3.- COMPLICACIONES INFECCIOSAS.}

\subsubsection{1.- ANÁLISIS UNIVARIANTE.}

Un total de 33 pacientes $(19,6 \%)$ padecieron algún tipo de complicación infecciosa. La distribución de las complicaciones infecciosas en función de las variables analizadas puede verse en la tabla 15.

Tras realizar el análisis univariante, seis variables obtuvieron una $\mathrm{p}<0,1$ : 
- Insuficiencia cardiaca: el $57,1 \%$ de los pacientes con insuficiencia cardiaca presentaron complicaciones infecciosas, frente a un $18,0 \%$ de aquellos sin insuficiencia cardiaca $(\mathrm{p}=0,028)$.

- Riesgo anestésico: un 27,6\% de pacientes con riesgo anestésico elevado sufrieron complicaciones infecciosas, frente al 15,5\% de los que tenían riesgo bajo $(\mathrm{p}=0,06)$.

- Localización del tumor: un 29,8\% de pacientes con lesiones rectales padecieron complicaciones infecciosas frente a un $15,7 \%$ de aquellos con lesiones situadas en el colon $(\mathrm{p}=0,039)$.

- PNI: la media entre los pacientes con complicaciones infecciosas fue de 41,61 \pm 5,73 frente a 45,69 $\pm 5,91$ en aquellos sin ellas $(p=0,001)$.

- GPS: observamos que las complicaciones infecciosas aparecieron en el 13,5\% de los pacientes con grado 0 , en el $22,2 \%$ de los grado 1 y en el 39,3\% de los grado 2 $(\mathrm{p}=0,013)$.

- Resultante B: la media fue de 0,539 $\pm 1,169$ entre los pacientes que sufrieron complicaciones graves y de $-0,132 \pm 0,911$ entre los que no $(p=0,004)$.

\subsubsection{2.- ANÁLISIS MULTIVARIANTE.}

Se realizó la regresión logística binaria con las seis variables que consiguieron una $\mathrm{p}<0,1$ en el análisis univariante y tan sólo la variable "PNI" consiguió una significación estadística: obtuvimos una OR de 0,890 (IC 95\% = 0,827 - 0,958), p = 0,002. La curva ROC presentó un área bajo la curva de 0,711 (IC 95\% = 0,605-0,817), con unos valores de sensibilidad y especificidad del 76,3\% y del 69,7\%, respectivamente. En el gráfico 21 puede verse la curva ROC correspondiente. 


\section{Martín Bailón Cuadrado}

Tabla 15. Distribución de la variable "complicaciones infecciosas" (los valores entre paréntesis representan porcentajes).

\begin{tabular}{|c|c|c|c|c|c|}
\hline \multirow{2}{*}{\multicolumn{2}{|c|}{ COMPLICACIONES INFECCIOSAS }} & \multicolumn{3}{|c|}{ ANÁLISIS UNIVARIANTE } & \multirow{2}{*}{$\begin{array}{c}\text { MULTIVARIANTE } \\
\text { P-VALOR }\end{array}$} \\
\hline & & \multirow{2}{*}{$\begin{array}{c}\text { Sí } \\
19(17,8) \\
\end{array}$} & \multirow{2}{*}{$\begin{array}{c}\text { NO } \\
88(82,2)\end{array}$} & \multirow{3}{*}{$\begin{array}{c}\text { P-VALOR } \\
\text { N. S. }\end{array}$} & \\
\hline \multirow{2}{*}{ SEXO } & HOMBRE & & & & \\
\hline & MUJER & $14(23,0)$ & $47(77,0)$ & & \\
\hline EDAD & MEDIA (AÑOS) & 70,97 & 68,53 & N. S. & \\
\hline IMC & MEDIA (KG/M2) & 26,88 & 26,75 & N.S. & \\
\hline \multirow{2}{*}{ HTA } & SÍ & $21(21,4)$ & $77(78,6)$ & \multirow{2}{*}{ N.S. } & \\
\hline & NO & $12(17,1)$ & $58(82,9)$ & & \\
\hline \multirow{2}{*}{ DIABETES MELLITUS } & SÍ & $5(20,8)$ & $19(79,2)$ & \multirow{2}{*}{ N. S. } & \\
\hline & NO & $28(19,4)$ & $116(80,6)$ & & \\
\hline \multirow{2}{*}{ DISLIPEMIA } & SÍ & $10(16,7)$ & $50(83,3)$ & \multirow{2}{*}{ N. S. } & \\
\hline & NO & $23(21,3)$ & $85(78,7)$ & & \\
\hline \multirow{2}{*}{ TABAQUISMO } & SÍ & $9(19,6)$ & $37(80,4)$ & \multirow{2}{*}{ N.S. } & \\
\hline & NO & $24(19,7)$ & $98(80,3)$ & & \\
\hline \multirow{2}{*}{$\begin{array}{l}\text { INSUFICIENCIA } \\
\text { CARDIACA }\end{array}$} & Sí & $4(57,1)$ & $3(42,9)$ & \multirow{2}{*}{0,028} & \multirow{2}{*}{ N. S. } \\
\hline & NO & $29(18,0)$ & $132(82,0)$ & & \\
\hline \multirow{2}{*}{$\begin{array}{l}\text { CARDIOPATÍA } \\
\text { ISQUÉMICA }\end{array}$} & SÍ & $3(21,4)$ & $11(78,6)$ & \multirow{2}{*}{ N. S. } & \\
\hline & $\mathrm{NO}$ & $30(19,5)$ & $124(80,5)$ & & \\
\hline \multirow{2}{*}{ EPOC } & SÍ & $1811,1)$ & $8(88,9)$ & \multirow{2}{*}{ N.S. } & \\
\hline & NO & $32(20,1)$ & $127(79,9)$ & & \\
\hline \multirow{2}{*}{ RIESGO ANESTÉSICO } & ALTO & $16(27,6)$ & $42(72,4)$ & \multirow{2}{*}{0,06} & \\
\hline & BAJO & $17(15,5)$ & $93(84,5)$ & & N.S. \\
\hline PRÓTESIS & SÍ & $2(11,1)$ & $16(88,9)$ & $\mathrm{N}^{2}$ & \\
\hline ENDOSCÓPICA & NO & $31(20,7)$ & $119(79,3)$ & N. S. & \\
\hline OUIMIOTER APIA & Sí & $7(25,9)$ & $20(74,1)$ & $\mathrm{N} S \mathrm{~S}$ & \\
\hline QUIVIUIERAPIA & $\mathrm{NO}$ & $26(18,4)$ & $115(81,6)$ & N. S. & \\
\hline & SÍ & $8(25,0)$ & $24(75,0)$ & $\mathrm{N} S$ & \\
\hline RADIOTERAPIA & NO & $25(18,5)$ & $110(81,5)$ & N. S. & \\
\hline LOCALIZACIÓN DE LA & COLON & $19(15,7)$ & $102(84,3)$ & 0030 & $\mathrm{~N} S$ \\
\hline TUMORACIÓN & RECTUM & $14(29,8)$ & $33(70,2)$ & 0,039 & N.S. \\
\hline & COLECTOMÍA & $17(17,3)$ & $81(82,7)$ & & \\
\hline TIPO DE & PROCTECTOMÍA & $10(20,0)$ & $40(80,0)$ & $\mathrm{N}^{2}$ & \\
\hline INTERVENCIÓN & AAP & $3(25,0)$ & $9(75,0)$ & N. S. & \\
\hline & HARTMANN & $3(37,5)$ & $5(62,5)$ & & \\
\hline TIEMPO Q. & MEDIA (MIN.) & 217,58 & 213,85 & N.S. & \\
\hline TRANSFUSIÓN & Sí & $1(33,3)$ & $2(66,7)$ & $\mathrm{N}^{2}$ & \\
\hline INTRAOPERATORIA & NO & $32(19,4)$ & $133(80,6)$ & & \\
\hline PNI & MEDIA & 41,61 & 45,69 & 0,001 & 0,002 \\
\hline & 0 & $14(13,5)$ & $90(86,5)$ & & \\
\hline GPS & 1 & $8(22,2)$ & $28(77,8)$ & 0,013 & N. S. \\
\hline & 2 & $11(39,3)$ & $17(60,7)$ & & \\
\hline NLR & MEDIA & 2,92 & 2,68 & N.S. & \\
\hline PLR & MEDIA & 207,01 & 153,52 & N. S. & \\
\hline RESULTANTE A & MEDIA & 0,181 & $-0,044$ & N.S. & \\
\hline RESULTANTE B & MEDIA & 0,539 & $-0,132$ & 0,004 & N. S. \\
\hline
\end{tabular}


Resultados

Gráfico 21. Curva ROC de la variable "PNI" para la variable "complicaciones infecciosas".

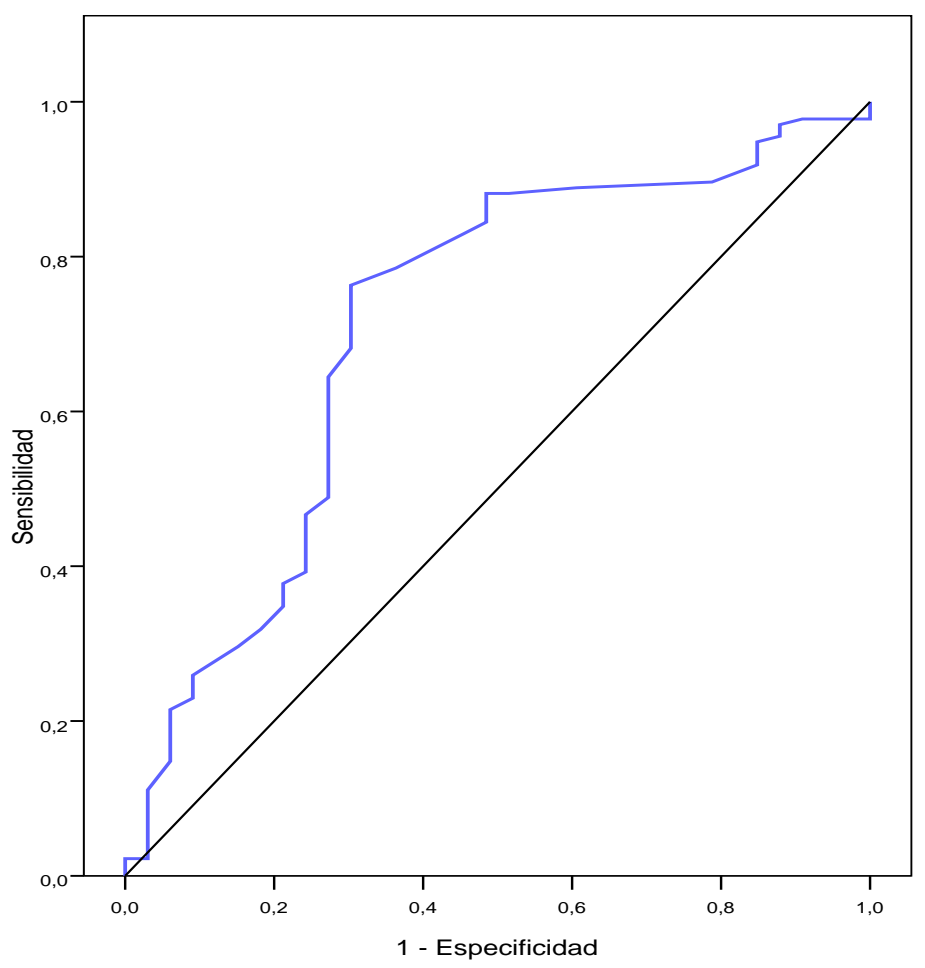

4.2.4.- FUGA ANASTOMÓTICA.

Esta complicación sólo ha sido analizada en aquellos pacientes en los que se realizó anastomosis, es decir, han sido eliminados para este análisis aquellos en los que se practicó una AAP o un procedimiento de Hartmann. Se ha realizado anastomosis en 148 de los 168 pacientes, 11 de los cuáles $(7,4 \%)$ han sufrido una fuga anastomótica.

\subsubsection{1.- ANÁLISIS UNIVARIANTE.}

La distribución de la fuga anastomótica en función de las variables analizadas se puede ver en la tabla 16. 


\section{Martín Bailón Cuadrado}

Tras realizar el análisis univariante, seis variables obtuvieron una $\mathrm{p}<0,1$ :

- QT: un $22,2 \%$ de pacientes sometidos a QT preoperatoria sufrieron fuga anastomótica en comparación el 5,4\% de los que no la recibieron $(p=0,03)$.

- Localización de la tumoración: un 23,3\% de pacientes con lesiones rectales sufrieron fuga anastomótica frente al $3,4 \%$ de aquellos con tumoraciones localizadas en el colon $(p=0,001)$.

- Tipo de intervención: un $14,0 \%$ de pacientes sometidos a una proctectomía padecieron fuga anastomótica en comparación con el 4,1\% de aquellos en los que se realizó una colectomía $(\mathrm{p}=0,044)$.

- Tiempo de intervención: la media fue de 240,91 \pm 89,58 minutos entre aquellos con fuga anastomótica frente a 204,45 $\pm 63,09$ minutos entre aquellos sin fuga $(\mathrm{p}=$ $0,077)$.

- PNI: observamos que aquellos pacientes con fuga anastomótica presentaban una media de 40,77 $\pm 4,75$ frente a una media de 45,17 $\pm 6,07$ en los que no padecían fuga $(p=0,020)$.

- Resultante B: obtuvimos una media de 0,581 \pm 1,147 entre los pacientes que sufrieron complicaciones graves y de $-0,062 \pm 0,988$ entre los que no $(p=0,042)$.

\subsubsection{2.- ANÁLISIS MULTIVARIANTE.}

Se realizó la regresión logística binaria con las seis variables que consiguieron una $\mathrm{p}<0,1$ en el univariante y dos variables alcanzaron una significación estadística: 
- Localización de la tumoración: obtuvimos una OR de 27,733 (IC 95\% = 4,253 180,850), $\mathrm{p}=0,001$. La curva ROC presentó un área bajo la curva de 0,734 (IC 95\% $=0,562-0,906)$.

- Resultante B: obtuvimos una OR de 3,208 (IC 95\% = 1,416-7,268), p = 0,005. La curva ROC presentó un área bajo la curva de 0,672 (IC 95\% = 0,510 - 0,833), con unos valores de sensibilidad y especificidad del 63,6\% y del 66,2\%, respectivamente.

En el gráfico 22 pueden verse las curvas ROC de las 2 variables que han resultado significativas en el análisis multivariante.

Gráfico 22. Curvas ROC de las variables "localización de la tumoración" y "resultante B" para la variable "fuga anastomótica".

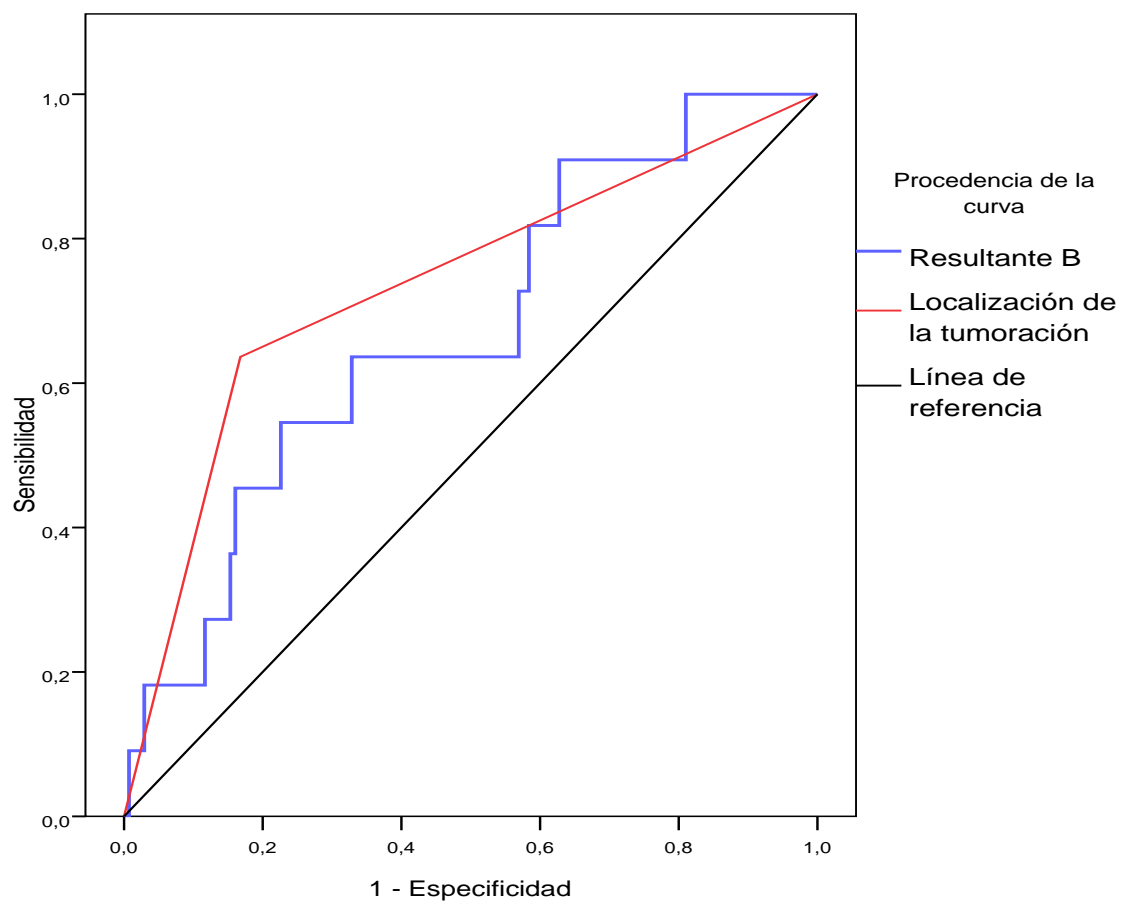




\section{Martín Bailón Cuadrado}

Tabla 16. Distribución de la variable "fuga anastomótica" (los valores entre paréntesis representan porcentajes).

\begin{tabular}{|c|c|c|c|c|c|}
\hline \multirow{2}{*}{\multicolumn{2}{|c|}{ FUGA ANASTOMÓTICA }} & \multicolumn{3}{|c|}{ ANÁLISIS UNIVARIANTE } & \multirow{2}{*}{$\begin{array}{c}\text { MULTIVARIANTE } \\
\text { P-VALOR }\end{array}$} \\
\hline & & \multirow{2}{*}{$\begin{array}{c}\text { Sí } \\
6(6,7) \\
\end{array}$} & \multirow{2}{*}{$\begin{array}{c}\text { NO } \\
84(93,3) \\
\end{array}$} & \multirow{3}{*}{$\begin{array}{c}\text { P-VALOR } \\
\text { N.S. }\end{array}$} & \\
\hline \multirow{2}{*}{ SEXO } & HOMBRE & & & & \\
\hline & MUJER & $5(8,6)$ & $53(91,4)$ & & \\
\hline EDAD & MEDIA (AÑOS) & 67,91 & 68,49 & N.S. & \\
\hline IMC & MEDIA (KG/M2) & 26,18 & 26,84 & N.S. & \\
\hline \multirow{2}{*}{ HTA } & SÍ & $8(9,5)$ & $76(90,5)$ & \multirow{2}{*}{ N. S. } & \\
\hline & NO & $3(4,7)$ & $61(95,3)$ & & \\
\hline \multirow{2}{*}{ DIABETES MELLITUS } & SÍ & $1(5,6)$ & $17(94,4)$ & \multirow{2}{*}{ N. S. } & \\
\hline & NO & $10(7,7)$ & $120(92,3)$ & & \\
\hline \multirow{2}{*}{ DISLIPEMIA } & SÍ & $3(6,0)$ & $47(94,0)$ & \multirow{2}{*}{ N. S. } & \\
\hline & NO & $8(8,2)$ & $90(91,8)$ & & \\
\hline \multirow{2}{*}{ TABAQUISMO } & SÍ & $5(12,2)$ & $36(87,8)$ & \multirow{2}{*}{ N.S. } & \\
\hline & NO & $6(5,6)$ & $101(94,4)$ & & \\
\hline \multirow{2}{*}{$\begin{array}{l}\text { INSUFICIENCIA } \\
\text { CARDIACA }\end{array}$} & Sí & $1(16,7)$ & $5(83,3)$ & \multirow{2}{*}{ N.S. } & \\
\hline & NO & $10(7,0)$ & $132(93,0)$ & & \\
\hline \multirow{2}{*}{$\begin{array}{l}\text { CARDIOPATÍA } \\
\text { ISQUÉMICA }\end{array}$} & SÍ & $0(0,0)$ & $9(100,0)$ & \multirow{2}{*}{ N. S. } & \\
\hline & NO & $11(7,9)$ & $128(92,1)$ & & \\
\hline \multirow{2}{*}{ EPOC } & SÍ & $0(0,0)$ & $6(100,0)$ & \multirow{2}{*}{ N.S. } & \\
\hline & $\mathrm{NO}$ & $11(7,7)$ & $131(92,3)$ & & \\
\hline \multirow{2}{*}{ RIESGO ANESTÉSICO } & ALTO & $4(8,7)$ & $42(91,3)$ & \multirow{2}{*}{ N. S. } & \\
\hline & BAJO & $7(6,9)$ & $95(93,1)$ & & \\
\hline \multirow{2}{*}{$\begin{array}{c}\text { PRÓTESIS } \\
\text { ENDOSCÓPICA }\end{array}$} & SÍ & $0(0,0)$ & $16(100,0)$ & \multirow{2}{*}{ N. S. } & \\
\hline & $\mathrm{NO}$ & $11(8,3)$ & $121(91,7)$ & & \\
\hline ОUНМОТЕР А РІА & SÍ & $4(22,2)$ & $14(77,8)$ & 002 & $\mathrm{NI} S$ \\
\hline QUIMIOTERAPIA & NO & $7(5,4)$ & $123(94,6)$ & 0,03 & N.S. \\
\hline RАDIOTEP А PIA & SÍ & $3(17,6)$ & $14(82,4)$ & $\mathrm{N} S$ & \\
\hline RADIOTERAPIA & NO & $8(6,1)$ & $123(93,9)$ & N.S. & \\
\hline LOCALIZACIÓN DE LA & COLON & $4(3,4)$ & $114(96,6)$ & 0001 & 0001 \\
\hline TUMORACIÓN & RECTO & $7(23,3)$ & $23(76,7)$ & 0,001 & 0,001 \\
\hline TIPO DE & COLECTOMÍA & $4(4,1)$ & $94(95,9)$ & 0044 & $N S_{1}$ \\
\hline INTERVENCIÓN & PROCTECTOMÍA & $7(14,0)$ & $43(86,0)$ & 0,044 & N.S. \\
\hline TIEMPO Q. & MEDIA (MIN.) & 240,91 & 204,45 & 0,077 & N. S. \\
\hline TRANSFUSIÓN & SÍ & $0(0,0)$ & $2(100,0)$ & $\mathrm{NIS}_{\mathrm{S}}$ & \\
\hline INTRAOPERATORIA & NO & $11(7,5)$ & $135(92,5)$ & N.S. & \\
\hline PNI & MEDIA & 40,77 & 45,17 & 0,02 & N.S. \\
\hline & 0 & $4(3,8)$ & $100(96,2)$ & & \\
\hline GPS & 1 & $4(11,1)$ & $32(88,9)$ & N. S. & \\
\hline & 2 & $3(10,7)$ & $25(89,3)$ & & \\
\hline NLR & MEDIA & 3,35 & 2,68 & N. S. & \\
\hline PLR & MEDIA & 247,56 & 158,17 & N. S. & \\
\hline RESULTANTE A & MEDIA & 0,274 & $-0,128$ & N. S. & \\
\hline RESULTANTE B & MEDIA & 0,581 & $-0,062$ & 0,042 & 0,005 \\
\hline
\end{tabular}




\subsection{5.- REINTERVENCIÓN.}

\subsubsection{1.- ANÁLISIS UNIVARIANTE.}

Un total de 10 pacientes $(6,0 \%)$ tuvieron que ser reintervenidos. La distribución de las reintervenciones en función de las variables analizadas se puede ver en la tabla 17.

Tras realizar el análisis univariante, tres variables obtuvieron una $\mathrm{p}<0,1$ :

- PNI: la media entre los pacientes reintervenidos fue de 40,35 \pm 4,81 frente a 45,17 $\pm 6,05$ en aquellos que no tuvieron que ser reoperados $(p=0,015)$.

- GPS: observamos que la distribución de pacientes que tuvieron que ser reoperados fue de $1,9 \%$ en los que presentaban grado 0 , de $13,9 \%$ en los grado 1 y de $10,7 \%$ en los grado $2(\mathrm{p}=0,019)$.

- Resultante B: obtuvimos una media de 0,929 $\pm 1,000$ entre los pacientes reintervenidos y de $-0,059 \pm 0,974$ en el resto $(p=0,002)$.

\subsubsection{2.- ANÁLISIS MULTIVARIANTE.}

Se realizó la regresión logística binaria con las tres variables que consiguieron una $p<0,1$ en el univariante y tan sólo la variable "resultante B" consiguió una significación estadística: obtuvimos una OR de 2,349 (IC 95\% = 1,281 - 4,305), p = 0,006. La curva ROC presentó un área bajo la curva de 0,760 (IC 95\% = 0,626 - 0,894), con unos valores de sensibilidad y especificidad del 70,0\% y del 76,6\%, respectivamente. En el gráfico 23 puede verse la curva ROC correspondiente. 


\section{Martín Bailón Cuadrado}

Tabla 17. Distribución de la variable "reintervención" (los valores entre paréntesis representan porcentajes).

\begin{tabular}{|c|c|c|c|c|c|}
\hline \multirow{2}{*}{\multicolumn{2}{|c|}{ REINTERVENCIÓN }} & \multicolumn{3}{|c|}{ ANÁLISIS UNIVARIANTE } & \multirow{2}{*}{$\begin{array}{c}\text { MULTIVARIANTE } \\
\text { P-VALOR }\end{array}$} \\
\hline & & \multirow{2}{*}{$\begin{array}{c}\text { Sí } \\
5(4,7) \\
\end{array}$} & \multirow{2}{*}{$\begin{array}{c}\text { NO } \\
102(95,3)\end{array}$} & \multirow{3}{*}{$\begin{array}{c}\text { P-VALOR } \\
\text { N.S. }\end{array}$} & \\
\hline \multirow{2}{*}{ SEXO } & HOMBRE & & & & \\
\hline & MUJER & $5(8,2)$ & $56(91,8)$ & & \\
\hline EDAD & MEDIA (AÑOS) & 72,3 & 68,8 & N. S. & \\
\hline IMC & MEDIA (KG/M2) & 25,67 & 26,85 & N.S. & \\
\hline \multirow{2}{*}{ HTA } & SÍ & $6(6,1)$ & $92(93,9)$ & \multirow{2}{*}{ N. S. } & \\
\hline & NO & $4(5,7)$ & $66(94,3)$ & & \\
\hline \multirow{2}{*}{ DIABETES MELLITUS } & SÍ & $1(4,2)$ & $23(95,8)$ & \multirow{2}{*}{ N. S. } & \\
\hline & NO & $9(6,3)$ & $135(93,8)$ & & \\
\hline \multirow{2}{*}{ DISLIPEMIA } & SÍ & $3(5,0)$ & $57(95,0)$ & \multirow{2}{*}{ N. S. } & \\
\hline & NO & $7(6,5)$ & $101(93,5)$ & & \\
\hline \multirow{2}{*}{ TABAQUISMO } & SÍ & $2(4,3)$ & $44(95,7)$ & \multirow{2}{*}{ N. S. } & \\
\hline & NO & $8(6,6)$ & $114(93,4)$ & & \\
\hline \multirow{2}{*}{$\begin{array}{l}\text { INSUFICIENCIA } \\
\text { CARDIACA }\end{array}$} & SÍ & $1(14,3)$ & $6(85,7)$ & \multirow{2}{*}{ N. S. } & \\
\hline & NO & $9(5,6)$ & $152(94,4)$ & & \\
\hline \multirow{2}{*}{$\begin{array}{l}\text { CARDIOPATÍA } \\
\text { ISQUÉMICA }\end{array}$} & SÍ & $0(0,0)$ & $14(100,0)$ & \multirow{2}{*}{ N. S. } & \\
\hline & NO & $10(6,5)$ & $144(93,5)$ & & \\
\hline \multirow{2}{*}{ EPOC } & SÍ & $0(0,0)$ & $9(100,0)$ & \multirow{2}{*}{ N.S. } & \\
\hline & NO & $10(6,3)$ & $149(93,7)$ & & \\
\hline \multirow{2}{*}{ RIESGO ANESTÉSICO } & ALTO & $5(8,6)$ & $53(91,4)$ & \multirow{2}{*}{ N. S. } & \\
\hline & BAJO & $5(4,5)$ & $105(95,5)$ & & \\
\hline \multirow{2}{*}{$\begin{array}{c}\text { PRÓTESIS } \\
\text { ENDOSCÓPICA }\end{array}$} & SÍ & $1(5,6)$ & $17(94,4)$ & $\mathrm{IT}_{\mathrm{C}}$ & \\
\hline & NO & $9(6,0)$ & $141(94,0)$ & N.S. & \\
\hline OUIMIOTER APIA & Sí & $1(3,7)$ & $26(96,3)$ & $\mathrm{N} S$ & \\
\hline QUIVIUIERAPIA & $\mathrm{NO}$ & $9(6,4)$ & $132(93,6)$ & N. S. & \\
\hline RADIOTFR APIA & SÍ & $0(0,0)$ & $33(100,0)$ & $\mathrm{NS}$ & \\
\hline КАDIUIEKAPIA & NO & $10(7,4)$ & $125(92,6)$ & N.S. & \\
\hline LOCALIZACIÓN DE LA & COLON & $7(5,8)$ & $114(94,2)$ & $h^{2}$ & \\
\hline TUMORACIÓN & RECTO & $3(6,4)$ & $44(93,6)$ & N.S. & \\
\hline & COLECTOMÍA & $7(7,1)$ & $91(92,9)$ & & \\
\hline TIPO DE & PROCTECTOMÍA & $3(6,0)$ & $47(94,0)$ & 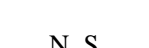 & \\
\hline INTERVENCIÓN & AAP & $0(0,0)$ & $12(100,0)$ & N. $\mathrm{S}$. & \\
\hline & HARTMANN & $0(0,0)$ & $8(100,0)$ & & \\
\hline TIEMPO Q. & MEDIA (MIN.) & 200 & 215,51 & N.S. & \\
\hline TRANSFUSIÓN & Sí & $0(0,0)$ & $3(100,0)$ & 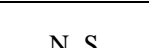 & \\
\hline INTRAOPERATORIA & NO & $10(6,1)$ & $155(93,9)$ & N.S. & \\
\hline PNI & MEDIA & 40,35 & 45,17 & 0,015 & N.S. \\
\hline & 0 & $2(1,9)$ & $102(98,1)$ & & \\
\hline GPS & 1 & $5(13,9)$ & $31(86,1)$ & 0,019 & N. S. \\
\hline & 2 & $3(10,7)$ & $25(89,3)$ & & \\
\hline NLR & MEDIA & 2,25 & 2,75 & N. S. & \\
\hline PLR & MEDIA & 137,59 & 165,7 & N.S. & \\
\hline RESULTANTE A & MEDIA & $-0,329$ & 0,021 & N.S. & \\
\hline RESULTANTE B & MEDIA & 0,929 & $-0,059$ & 0,002 & 0,006 \\
\hline
\end{tabular}


Resultados

Gráfico 23. Curva ROC de la variable "resultante B" para la variable "reintervención".

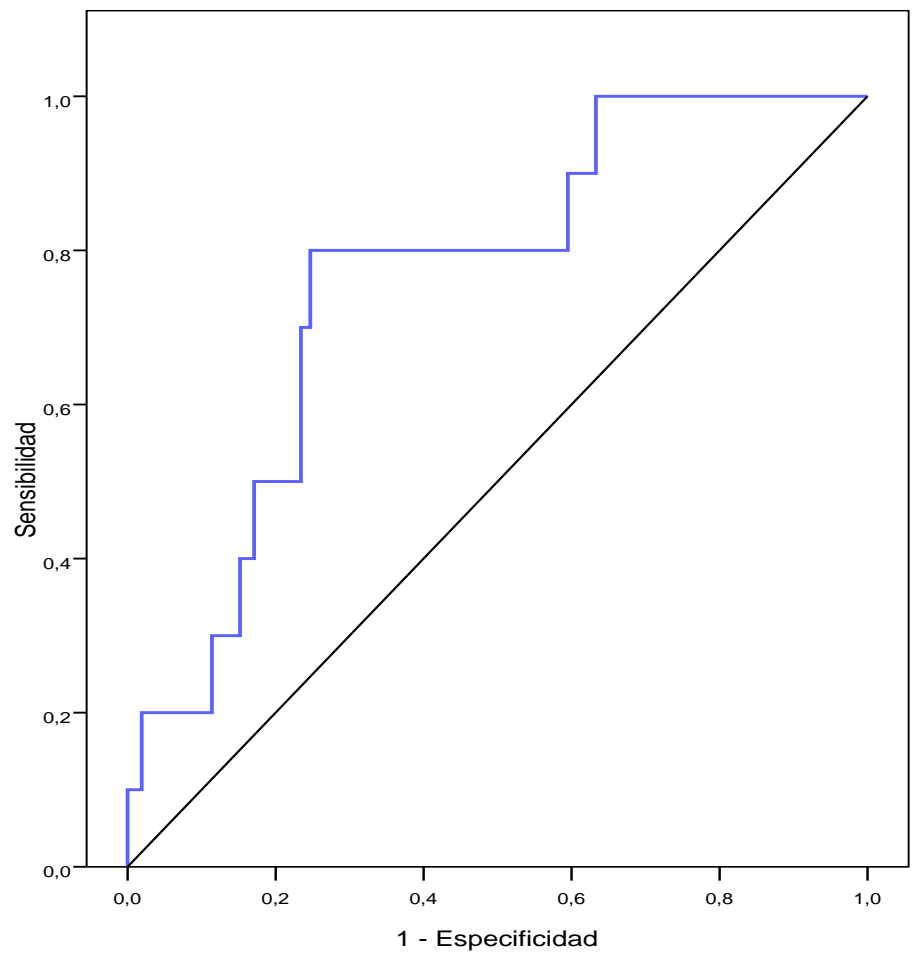

4.2.6.- ÉXITUS.

4.2.6.1.- ANÁLISIS UNIVARIANTE.

Un total de 3 pacientes $(1,8 \%)$ fallecieron en el postoperatorio. La distribución de los éxitus en función de las variables analizadas se puede ver en la tabla 18.

Tras realizar el análisis univariante, cuatro variables obtuvieron una $\mathrm{p}<0,1$ : 


\section{Martín Bailón Cuadrado}

- Edad: los pacientes fallecidos fueron mayores, con una media de $81 \pm 8$ años, que el resto, que presentaron una media de 68,79 $\pm 11,29$ años $(p=0,064)$.

- Insuficiencia cardiaca: un $28,6 \%$ de pacientes con insuficiencia cardiaca fallecieron durante el postoperatorio frente al $0,6 \%$ de aquellos sin insuficiencia cardiaca $(\mathrm{p}=$ $0,004)$.

- Riesgo anestésico: un 5,2\% de pacientes con riesgo anestésico elevado fallecieron durante el postoperatorio mientras que todos aquellos con riesgo bajo siguieron $\operatorname{vivos}(p=0,04)$.

- Tiempo de intervención: obtuvimos una media de 138,33 \pm 75,22 minutos entre los éxitus frente a 215,97 \pm 67,30 minutos entre los demás pacientes $(\mathrm{p}=0,05)$.

\subsubsection{2.- ANÁLISIS MULTIVARIANTE.}

Se realizó la regresión logística binaria con las cuatro variables que consiguieron una $\mathrm{p}<$ 0,1 en el univariante y sólo la variable "insuficiencia cardiaca" alcanzó una significación estadística. Obtuvimos una OR de 64 (IC 95\% = 4,947 - 828,036), p =0,001. La curva ROC presenta un área bajo la curva de 0,818 (IC 95\% = 0,493 - 1,143).

En el gráfico 24 podemos ver la curva ROC de la variable "insuficiencia cardiaca" para la variable "éxitus". 
Tabla 18. Distribución de la variable "éxitus" (los valores entre paréntesis representan porcentajes).

\begin{tabular}{|c|c|c|c|c|c|}
\hline \multirow{2}{*}{\multicolumn{2}{|c|}{ ÉXITUS }} & \multicolumn{3}{|c|}{ ANÁLISIS UNIVARIANTE } & \multirow{2}{*}{$\frac{\text { MULTIVARIANTE }}{\text { P-VALOR }}$} \\
\hline & & \multirow{2}{*}{$\begin{array}{c}\text { Sí } \\
2(1,9) \\
\end{array}$} & \multirow{2}{*}{$\begin{array}{c}\text { NO } \\
105(98,1) \\
\end{array}$} & \multirow{3}{*}{$\begin{array}{c}\text { P-VALOR } \\
\text { N.S. }\end{array}$} & \\
\hline \multirow{2}{*}{ SEXO } & HOMBRE & & & & \\
\hline & MUJER & $1(1,6)$ & $60(98,4)$ & & \\
\hline EDAD & MEDIA (AÑOS) & 81 & 68,79 & 0,064 & N. S. \\
\hline IMC & MEDIA (KG/M2) & 24,98 & 26,81 & N.S. & \\
\hline \multirow{2}{*}{ HTA } & SÍ & $3(3,1)$ & $95(96,9)$ & \multirow{2}{*}{ N. S. } & \\
\hline & NO & $0(0,0)$ & $10(100,0)$ & & \\
\hline \multirow{2}{*}{ DIABETES MELLITUS } & SÍ & $0(0,0)$ & $24(100,0)$ & \multirow{2}{*}{ N. S. } & \\
\hline & NO & $3(2,1)$ & $141(97,9)$ & & \\
\hline \multirow{2}{*}{ DISLIPEMIA } & SÍ & $2(3,3)$ & $58(96,7)$ & \multirow{2}{*}{ N. S. } & \\
\hline & NO & $1(0,9)$ & $107(99,1)$ & & \\
\hline \multirow{2}{*}{ TABAQUISMO } & SÍ & $1(2,2)$ & $45(97,8)$ & \multirow{2}{*}{ N.S. } & \\
\hline & NO & $2(1,6)$ & $120(98,4)$ & & \\
\hline \multirow{2}{*}{$\begin{array}{l}\text { INSUFICIENCIA } \\
\text { CARDIACA }\end{array}$} & Sí & $2(28,6)$ & $5(71,4)$ & \multirow{2}{*}{0,004} & \multirow{2}{*}{0,001} \\
\hline & NO & $1(0,6)$ & $160(99,4)$ & & \\
\hline \multirow{2}{*}{$\begin{array}{l}\text { CARDIOPATÍA } \\
\text { ISQUÉMICA }\end{array}$} & SÍ & $0(0,0)$ & $14(100,0)$ & \multirow{2}{*}{ N. S. } & \\
\hline & $\mathrm{NO}$ & $3(1,9)$ & $151(98,1)$ & & \\
\hline \multirow{2}{*}{ EPOC } & SÍ & $0(0,0)$ & $9(100,0)$ & \multirow{2}{*}{ N.S. } & \\
\hline & NO & $3(1,9)$ & $156(98,1)$ & & \\
\hline \multirow{2}{*}{ RIESGO ANESTÉSICO } & ALTO & $3(5,2)$ & $55(94,8)$ & \multirow{2}{*}{0,04} & $N S$ \\
\hline & BAJO & $0(0,0)$ & $110(100)$ & & N. S. \\
\hline PRÓTESIS & SÍ & $0(0,0)$ & $18(100,0)$ & $I_{C}$ & \\
\hline ENDOSCÓPICA & $\mathrm{NO}$ & $3(2,0)$ & $147(98,0)$ & N.S. & \\
\hline ОUIMIOTEP А PIA & Sí & $0(0,0)$ & $27(100,0)$ & $N S^{-}$ & \\
\hline QUIVIUIERAPIA & NO & $3(2,1)$ & $138(97,9)$ & N. S. & \\
\hline & SÍ & $0(0,0)$ & $32(100,0)$ & $\mathrm{N}^{2}$ & \\
\hline RADIOTERAPIA & NO & $3(2,2)$ & $132(97,8)$ & N. S. & \\
\hline LOCALIZACIÓN DE LA & COLON & $3(2,5)$ & $118(97,5)$ & $e^{2}$ & \\
\hline TUMORACIÓN & RECTO & $0(0,0)$ & $47(100,0)$ & N.S. & \\
\hline & COLECTOMÍA & $3(3,1)$ & $95(96,9)$ & & \\
\hline TIPO DE & PROCTECTOMÍA & $0(0,0)$ & $50(100,0)$ & $N^{2}$ & \\
\hline INTERVENCIÓN & AAP & $0(0,0)$ & $12(100,0)$ & N. S. & \\
\hline & HARTMANN & $0(0,0)$ & $8(100,0)$ & & \\
\hline TIEMPO Q. & MEDIA (MIN.) & 138,33 & 215,97 & 0,05 & N.S. \\
\hline TRANSFUSIÓN & Sí & $0(0,0)$ & $3(100,0)$ & $e^{2}$ & \\
\hline INTRAOPERATORIA & $\mathrm{NO}$ & $3(1,8)$ & $162(98,2)$ & N.S. & \\
\hline PNI & MEDIA & 43 & 44,92 & N.S. & \\
\hline & 0 & $1(1,0)$ & $103(99,0)$ & & \\
\hline GPS & 1 & $1(2,8)$ & $35(97,2)$ & N. S. & \\
\hline & 2 & $1(3,6)$ & $27(96,4)$ & & \\
\hline NLR & MEDIA & 2,33 & 2,73 & N. S. & \\
\hline PLR & MEDIA & 124,17 & 164,75 & N. S. & \\
\hline RESULTANTE A & MEDIA & $-0,555$ & 0,01 & N. S. & \\
\hline RESULTANTE B & MEDIA & 0,687 & $-0,012$ & N. S. & \\
\hline
\end{tabular}




\section{Martín Bailón Cuadrado}

Gráfico 24. Curva ROC de la variable "insuficiencia cardiaca” para la variable "éxitus".

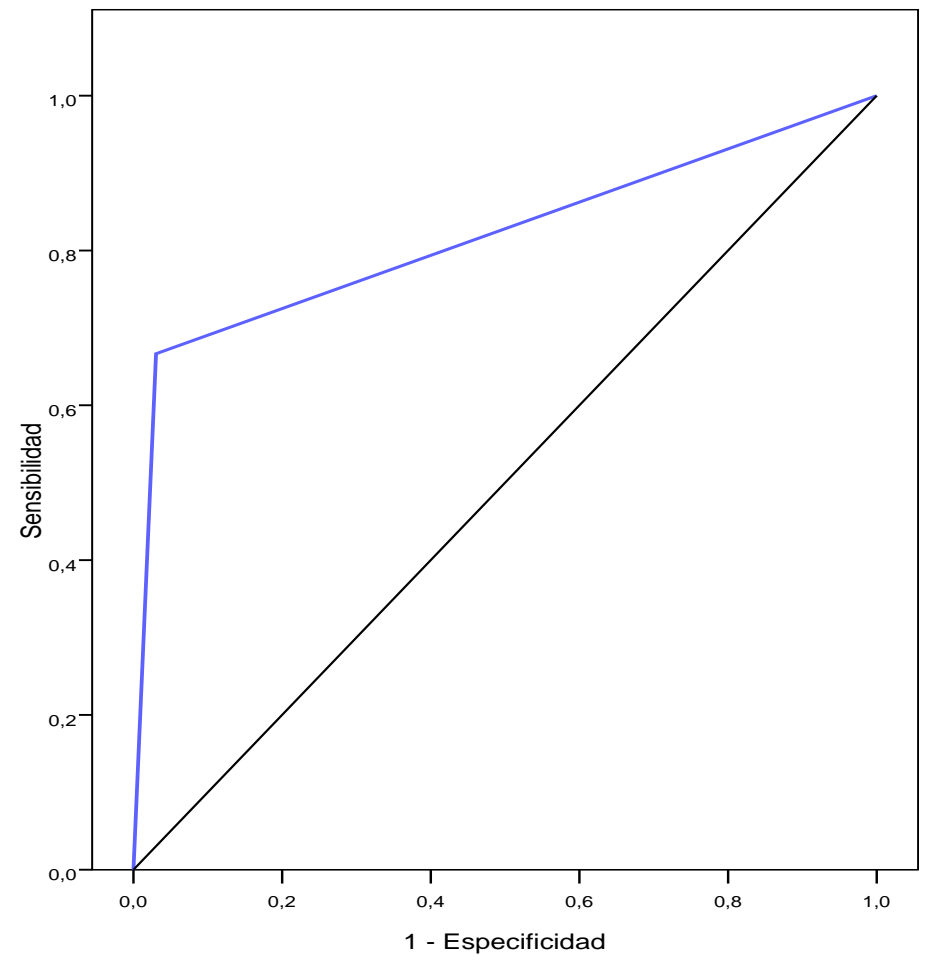

4.2.7.- ESTANCIA POSTOPERATORIA PROLONGADA.

\subsubsection{1.- ANÁLISIS UNIVARIANTE.}

La distribución de la estancia postoperatoria prolongada en función de las variables analizadas se puede ver en la tabla 19.

Tras realizar el análisis univariante, nueve variables obtuvieron una $\mathrm{p}<0,1$ :

- Edad: la edad media fue de 71,18 \pm 10,60 años en el grupo de estancia prolongada $y$ de $66,61 \pm 11,70$ años en los que tuvieron una estancia normal $(p=0,009)$. 
- Radioterapia: un $68,8 \%$ de pacientes con RT preoperatoria presentaron una estancia postoperatoria prolongada frente a un $48,1 \%$ de los que no la recibieron ( $\mathrm{p}$ $=0,036$.

- Localización de la tumoración: el 43,8\% de pacientes con lesiones en el colon mostraron una estancia prolongada, frente al $74,5 \%$ de aquellos con lesiones rectales $(p=0,0001)$.

- Tipo de intervención: la estancia postoperatoria prolongada se produjo en el 44,9\% de las colectomías, el $60,0 \%$ de las proctectomías, el 75,0\% de las AAP y el $62,5 \%$ de los Hartmann $(\mathrm{p}=0,098)$.

- Tiempo de intervención: obtuvimos una media de 223,41 $\pm 72,33$ minutos entre aquellos con una estancia postoperatoria prolongada frente a 204,88 $\pm 61,87$ minutos entre aquellos con estancia normal $(p=0,075)$.

- PNI: la media de pacientes con estancia prolongada fue de 43,99 \pm 6,64 frente a $45,86 \pm 5,27$ en aquellos con estancia normal $(p=0,046)$

- NLR: encontramos que la media fue de 3,01 $\pm 2,22$ en pacientes con estancia prolongada y de $2,41 \pm 1,28$ en los demás ( $p=0,036$ ).

- PLR: la media fue de $184,16 \pm 144,95$ en pacientes con estancia prolongada y de $141,87 \pm 88,14$ en el resto $(p=0,025)$

- Resultante A: los pacientes con una estancia postoperatoria prolongada obtuvieron una media de 0,188 $\pm 1,045$ frente a $-0,207 \pm 0,910$ en aquellos con una estancia normal $(\mathrm{p}=0,010)$. 


\section{Martín Bailón Cuadrado}

\subsubsection{2.- ANÁLISIS MULTIVARIANTE.}

Se realizó la regresión logística binaria con las nueve variables que consiguieron una $\mathrm{p}<0,1$ en el univariante y dos variables alcanzaron una significación estadística:

- Edad: obtuvimos una OR de 1,047 (IC 95\% $=1,016-1,079$ ), $\mathrm{p}=0,003$. La curva ROC mostró un área bajo la curva de 0,615 (IC 95\% = 0,530 - 0,701).

- Localización de la tumoración: obtuvimos una OR de 4,529 (IC 95\% = 2,058 9,966), $\mathrm{p}=0,0001$. La curva ROC presentó un área bajo la curva de 0,624 (IC 95\% $=0,539-0,708)$.

En el gráfico 25 pueden verse las curvas ROC de las 2 variables que han resultado significativas en el análisis multivariante.

Gráfico 25. Curvas ROC de las variables “edad” y "localización de la tumoración” para la variable "estancia postoperatoria prolongada".

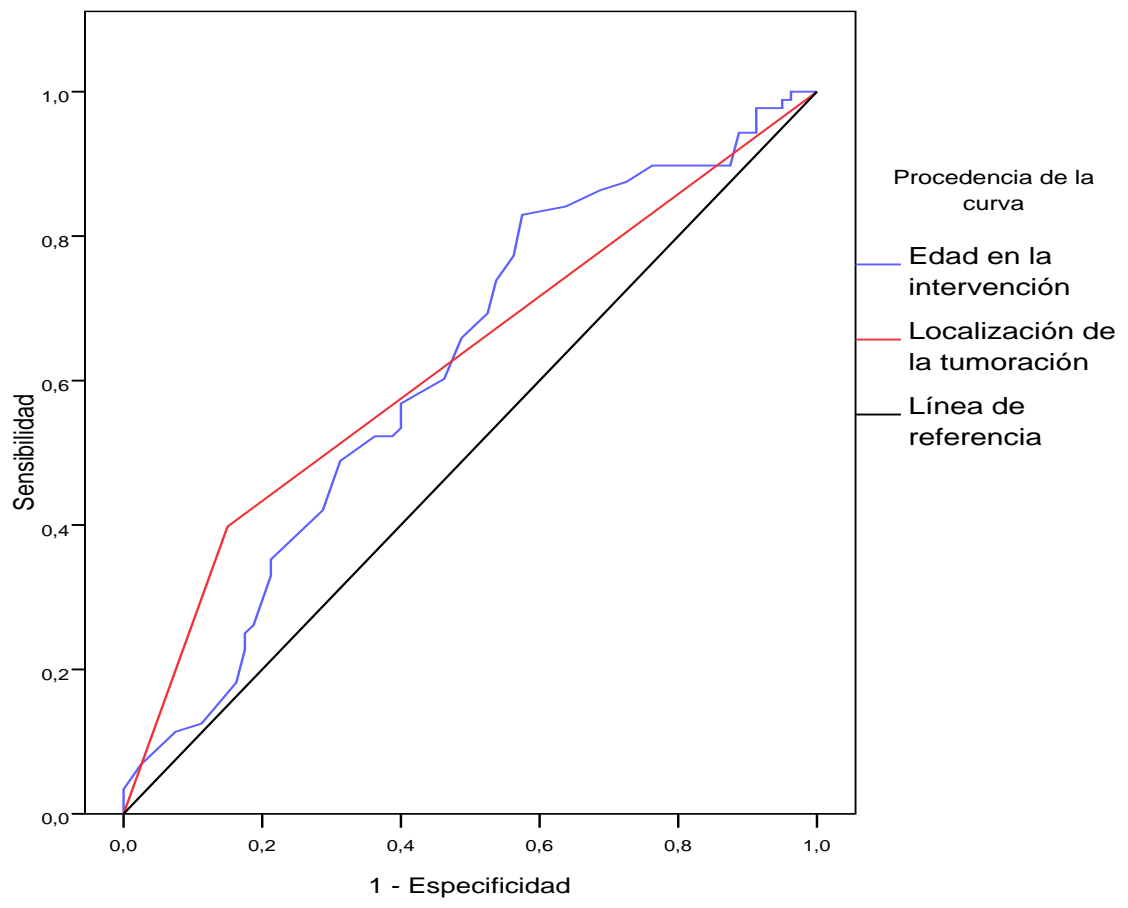


Tabla 19. Distribución de la variable "estancia postoperatoria prolongada" (los valores entre paréntesis representan porcentajes).

\begin{tabular}{|c|c|c|c|c|c|}
\hline \multirow{2}{*}{\multicolumn{2}{|c|}{ ESTANCIA PROLONGADA }} & \multicolumn{3}{|c|}{ ANÁLISIS UNIVARIANTE } & \multirow{2}{*}{$\frac{\text { MULTIVARIANTE }}{\text { P-VALOR }}$} \\
\hline & & \multirow{2}{*}{$\begin{array}{c}\text { Sí } \\
52(48,6) \\
\end{array}$} & \multirow{2}{*}{$\begin{array}{c}\text { NO } \\
55(51,4)\end{array}$} & \multirow{3}{*}{$\begin{array}{c}\text { P-VALOR } \\
\text { N.S. }\end{array}$} & \\
\hline \multirow{2}{*}{ SEXO } & HOMBRE & & & & \\
\hline & MUJER & $36(59,0)$ & $25(41,0)$ & & \\
\hline EDAD & MEDIA (AÑOS) & 71,18 & 66,61 & 0,009 & 0,003 \\
\hline IMC & MEDIA (KG/M2) & 27,09 & 26,44 & N.S. & \\
\hline \multirow{2}{*}{ HTA } & SÍ & $53(54,1)$ & $45(45,9)$ & \multirow{2}{*}{ N. S. } & \\
\hline & NO & $35(50,0)$ & $35(50,0)$ & & \\
\hline \multirow{2}{*}{ DIABETES MELLITUS } & SÍ & $14(58,3)$ & $10(41,7)$ & \multirow{2}{*}{ N. S. } & \\
\hline & NO & $74(51,4)$ & $70(48,6)$ & & \\
\hline \multirow{2}{*}{ DISLIPEMIA } & SÍ & $32(53,3)$ & $28(46,7)$ & \multirow{2}{*}{ N. S. } & \\
\hline & NO & $56(51,9)$ & $52(48,1)$ & & \\
\hline \multirow{2}{*}{ TABAQUISMO } & SÍ & $22(47,8)$ & $24(52,2)$ & \multirow{2}{*}{ N.S. } & \\
\hline & NO & $66(54,1)$ & $56(45,9)$ & & \\
\hline \multirow{2}{*}{$\begin{array}{l}\text { INSUFICIENCIA } \\
\text { CARDIACA }\end{array}$} & Sí & $6(85,7)$ & $1(14,3)$ & \multirow{2}{*}{ N. S. } & \\
\hline & NO & $82(50,9)$ & $79(49,1)$ & & \\
\hline \multirow{2}{*}{$\begin{array}{l}\text { CARDIOPATÍA } \\
\text { ISQUÉMICA }\end{array}$} & SÍ & $9(64,3)$ & $5(35,7)$ & \multirow{2}{*}{ N. S. } & \\
\hline & NO & $79(51,3)$ & $75(48,7)$ & & \\
\hline \multirow{2}{*}{ EPOC } & SÍ & $4(44,4)$ & $5(55,6)$ & \multirow{2}{*}{ N.S. } & \\
\hline & $\mathrm{NO}$ & $84(52,8)$ & $75(47,2)$ & & \\
\hline \multirow{2}{*}{ RIESGO ANESTÉSICO } & ALTO & $35(60,3)$ & $23(39,7)$ & \multirow{2}{*}{ N. S. } & \\
\hline & BAJO & $53(48,2)$ & $57(51,8)$ & & \\
\hline \multirow{2}{*}{$\begin{array}{c}\text { PRÓTESIS } \\
\text { ENDOSCÓPICA }\end{array}$} & SÍ & $12(66,7)$ & $6(33,3)$ & $I_{C}$ & \\
\hline & $\mathrm{NO}$ & $76(50,7)$ & $74(49,3)$ & N.S. & \\
\hline ОUIMIOTEP А PIA & Sí & $18(66,7)$ & $9(33,3)$ & $N S$ & \\
\hline QUIVIUIERAPIA & NO & $70(49,6)$ & $71(50,4)$ & N. S. & \\
\hline & SÍ & $22(68,8)$ & $10(31,3)$ & 0036 & $\mathrm{~N}^{2}$ \\
\hline RADIOTERAPIA & NO & $65(48,1)$ & $70(51,9)$ & 0,036 & N. S. \\
\hline LOCALIZACIÓN DE LA & COLON & $53(43,8)$ & $68(56,2)$ & 00001 & 00001 \\
\hline TUMORACIÓN & RECTO & $35(74,5)$ & $12(25,5)$ & 0,0001 & 0,0001 \\
\hline & COLECTOMÍA & $44(44,9)$ & $54(55,1)$ & & \\
\hline TIPO DE & PROCTECTOMÍA & $30(60,0)$ & $20(40,0)$ & 0098 & $h^{2}$ \\
\hline INTERVENCIÓN & AAP & $9(75,0)$ & $3(25,0)$ & 0,098 & N.S. \\
\hline & HARTMANN & $5(62,5)$ & $3(37,5)$ & & \\
\hline TIEMPO Q. & MEDIA (MIN.) & 223,41 & 204,88 & 0,075 & N.S. \\
\hline TRANSFUSIÓN & Sí & $2(66,7)$ & $1(33,3)$ & $e^{2}$ & \\
\hline INTRAOPERATORIA & NO & $86(52,1)$ & $79(47,9)$ & N.S. & \\
\hline PNI & MEDIA & 43,99 & 45,86 & 0,046 & N.S. \\
\hline & 0 & $52(50,0)$ & $52(50,0)$ & & \\
\hline GPS & 1 & $19(52,8)$ & $17(47,2)$ & N. S. & \\
\hline & 2 & $17(60,7)$ & $11(39,3)$ & & \\
\hline NLR & MEDIA & 3,01 & 2,41 & 0,036 & N.S. \\
\hline PLR & MEDIA & 184,16 & 141,87 & 0,025 & N.S. \\
\hline RESULTANTE A & MEDIA & 0,188 & $-0,207$ & 0,01 & N.S. \\
\hline RESULTANTE B & MEDIA & 0,074 & $-0,08$ & N. S. & \\
\hline
\end{tabular}


Martín Bailón Cuadrado 


\section{5.- DISCUSIÓN.}


Martín Bailón Cuadrado 


\section{5.- DISCUSIÓN.}

Hemos llevado a cabo un estudio observacional prospectivo en el que hemos pretendido analizar la influencia de los scores definitorios del estado nutricional e inflamatorio sobre las complicaciones postoperatorias tras la cirugía curativa del cáncer colorrectal (CCR).

En primer lugar, nuestra muestra fue de 168 pacientes intervenidos entre septiembre de 2015 y febrero de 2017, ambos incluidos. No obstantes, hay que indicar que el número de resecciones colorrectales es obviamente mayor en un hospital de tercer nivel como es el nuestro. Los criterios estrictos de inclusión y exclusión justifican esta cifra, ya que sólo hemos contemplado las cirugías programadas (se excluyen todos aquellos pacientes que tuvieron que ser intervenidos de forma urgente por una presentación sintomática de la tumoración que no permitía demorar la cirugía) y con carácter curativo (excluyendo tanto cirugías paliativas como procedimientos en los que no pudo obtenerse una resección R0). Así mismo, no se han incluido aquellos pacientes con estadio IV del American Joint Committee on Cancer (AJCC) que fueron intervenidos para resección de metástasis hepáticas (tanto de forma simultánea como diferida) o para procedimientos de cirugía de citorreducción y quimioterapia (QT) intraperitoneal.

\section{1.- ANÁLISIS DE VARIABLES DEMOGRÁFICAS Y PREOPERATORIAS.}

El 63,7\% de nuestra muestra fueron varones (107 hombre frente a 61 mujeres), valor que se asemeja a lo publicado en la literatura, donde esta cifra oscila entre el 55 y el $70 \%$ en trabajos que analizan la cirugía del CCR [141,207,228,233,291,292] [Gráfico 26]. 


\section{Martín Bailón Cuadrado}

Gráfico 26. Comparación de nuestros propios resultados con la literatura en cuanto a la distribución por sexo en pacientes intervenidos de CCR.

- VARONES MUJERES

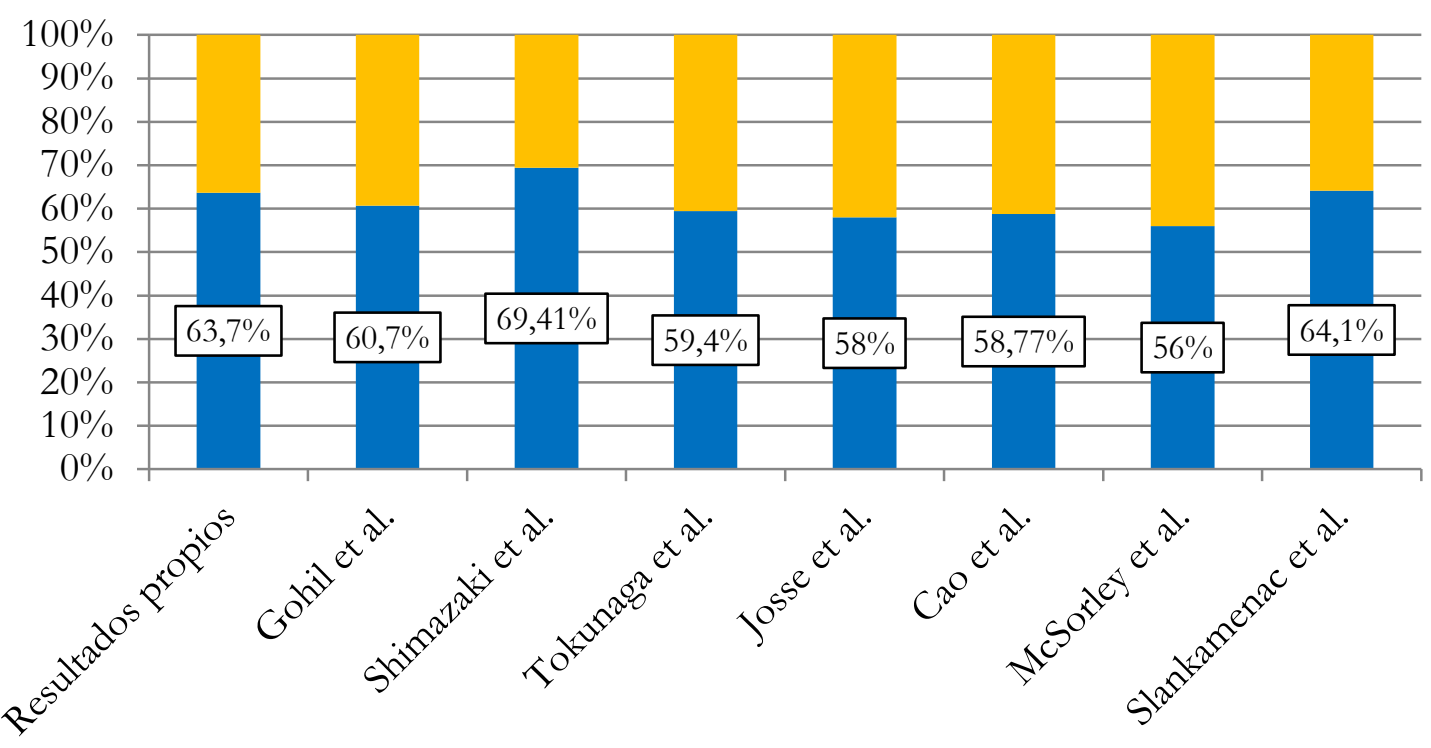

En grandes series de pacientes con CCR, el 55\% y el 62\% (para hombres y mujeres, respectivamente) de los casos aparecen por encima de los 65 años, y el 90\% por encima de los 50 años, incluyendo ambos sexos [293]. La edad media de nuestros pacientes en el momento de la intervención fue de 69,01 \pm 11,34 años (rango de 38 a 93 años), lo que se asemeja a publicaciones similares de otros autores, donde la edad de aparición se sitúa entre los 65 y los 75 años [Tabla 20].

Las variables preoperatorias reflejan la situación basal de los pacientes y son fundamentales a la hora de valorar el riesgo de desarrollar complicaciones durante el postoperatorio. Son aún más importantes si tenemos en cuenta que nos encontramos en una sociedad cada vez más sedentaria y que el CCR aparece a una edad media-alta. 
Tabla 20. Comparación de nuestros propios resultados con la literatura en cuanto a la edad en el momento de la intervención en pacientes con CCR.

\begin{tabular}{|c|c|}
\hline \multicolumn{2}{|c|}{ COMPARACIÓN CON LA LITERATURA DE LA EDAD } \\
\hline Resultados propios & Media de 69,01 \pm 11,34 años (rango de 38 a 93 años) \\
\hline MacKay et al. [294] & Mediana de 72 años (rango intercuartílico [RIQ] de 63 a 79) \\
\hline Gohil et al. [141] & Mediana de 72 años (RIQ de 65 a 79) \\
\hline Tokunaga et al. [207] & Mediana de 68 (rango de 19 a 93) \\
\hline Shimazaki et al. [228] & Media de $69,2 \pm 10,3$ años \\
\hline Artinyan et al. [295] & Media de $68,8 \pm 10,13$ años \\
\hline Josse et al. [233] & Mediana de 66 años (rango de 19 a 96) \\
\hline Cao et al. [291] & Mediana de 69 años (rango de 27 a 92) \\
\hline Slankamenac et al. [296] & Media de 65,1 años \\
\hline
\end{tabular}

Nuestros pacientes presentaron una media de índice de masa corporal (IMC) de 26,78 \pm $3,7 \mathrm{Kg} / \mathrm{m}^{2}$, lo que se corresponde con otras publicaciones y con registros donde el $78 \%$ de los pacientes con CCR poseen un IMC de entre 20 y $30 \mathrm{Kg} / \mathrm{m}^{2}$ [297]. [Tabla 21].

Tabla 21. Comparación de nuestros propios resultados con la literatura en cuanto al IMC en pacientes intervenidos de CCR.

\begin{tabular}{|c|c|}
\hline \multicolumn{2}{|c|}{ COMPARACIÓN CON LA LITERATURA DE LOS VALORES MEDIOS DE IMC } \\
\hline Resultados propios & Media de IMC de $26,78 \pm 3,7 \mathrm{Kg} / \mathrm{m}^{2}$ \\
\hline Shimazaki et al. $[228]$ & Media de IMC de $22,5 \pm 3,9 \mathrm{Kg} / \mathrm{m}^{2}$ \\
\hline Josse et al. $[233]$ & Mediana de $27 \mathrm{Kg} / \mathrm{m}^{2}(\mathrm{rango}$ de 15,1 a 76,4$)$ \\
\hline Slankamenac et al. $[296]$ & Media de $27,1 \mathrm{Kg} / \mathrm{m}^{2}$ \\
\hline
\end{tabular}

En cuanto a las comorbilidades de nuestra muestra de pacientes, destacamos que más de la mitad de los pacientes $(58,3 \%)$ presentaban hipertensión arterial (HTA), siendo menos frecuentes otros factores de riesgo cardiovascular como diabetes mellitus (DM) (14,3\%), dislipemia $(35,7 \%)$ o tabaquismo $(27,4 \%)$. Además, 7 pacientes $(4,2 \%)$ padecían 


\section{Martín Bailón Cuadrado}

insuficiencia cardiaca, 14 (8,3\%) cardiopatía isquémica y 9 (5,4\%) enfermedad pulmonar obstructiva crónica (EPOC). Estos datos están en consonancia con las grandes series de pacientes con CCR, que muestran tasas de 54,4\% de HTA, 18,1\% de DM, 8\% de dislipemia, 14,3\% de tabaquismo, 4,5\% de insuficiencia cardiaca, 3\% de cardiopatía isquémica y 4,9\% de EPOC. Podemos apreciar una mayor incidencia de dislipemia y tabaquismo en nuestros pacientes, lo que podría explicarse por un mayor sedentarismo de la población a la que atendemos en nuestro área [298-300].

En cuanto al riesgo anestésico, la mayoría de nuestros pacientes se agruparon en los grados II $(60,7 \%)$ y III $(33,3 \%)$ de la clasificación de la American Society of Anesthesiologists (ASA). Estos resultados se asemejan a otras series de pacientes de CCR, como podemos observar en las publicaciones de Manilich et al. [301] y de McSorley et al. [292], donde también predomina el grado II frente al grado III $(52,9 \%$ vs $42,0 \%$ y $45 \%$ vs $27 \%$, respectivamente). Por el contrario, Artinyan et al. [295] presentan una distribución en la que prevalecen los pacientes clasificados como ASA III (69,0\%) [Gráfico 27]. Esta última publicación muestra una tasa muy elevada de pacientes con ASA III, lo que posiblemente esté relacionado con el hecho de que se trata de una muestra formada por más de 12.000 veteranos procedentes del ejército de los Estados Unidos de América, con un 98\% de varones y un $7 \%$ de individuos dependientes para las actividades básicas. Esto podría justificar ese 69\% de pacientes con ASA III, aunque los autores no reflejan datos de enfermedades basales o factores de riesgo cardiovascular. 
Gráfico 27. Comparación de nuestros propios resultados con la literatura en cuanto a los valores de ASA en pacientes intervenidos de CCR.

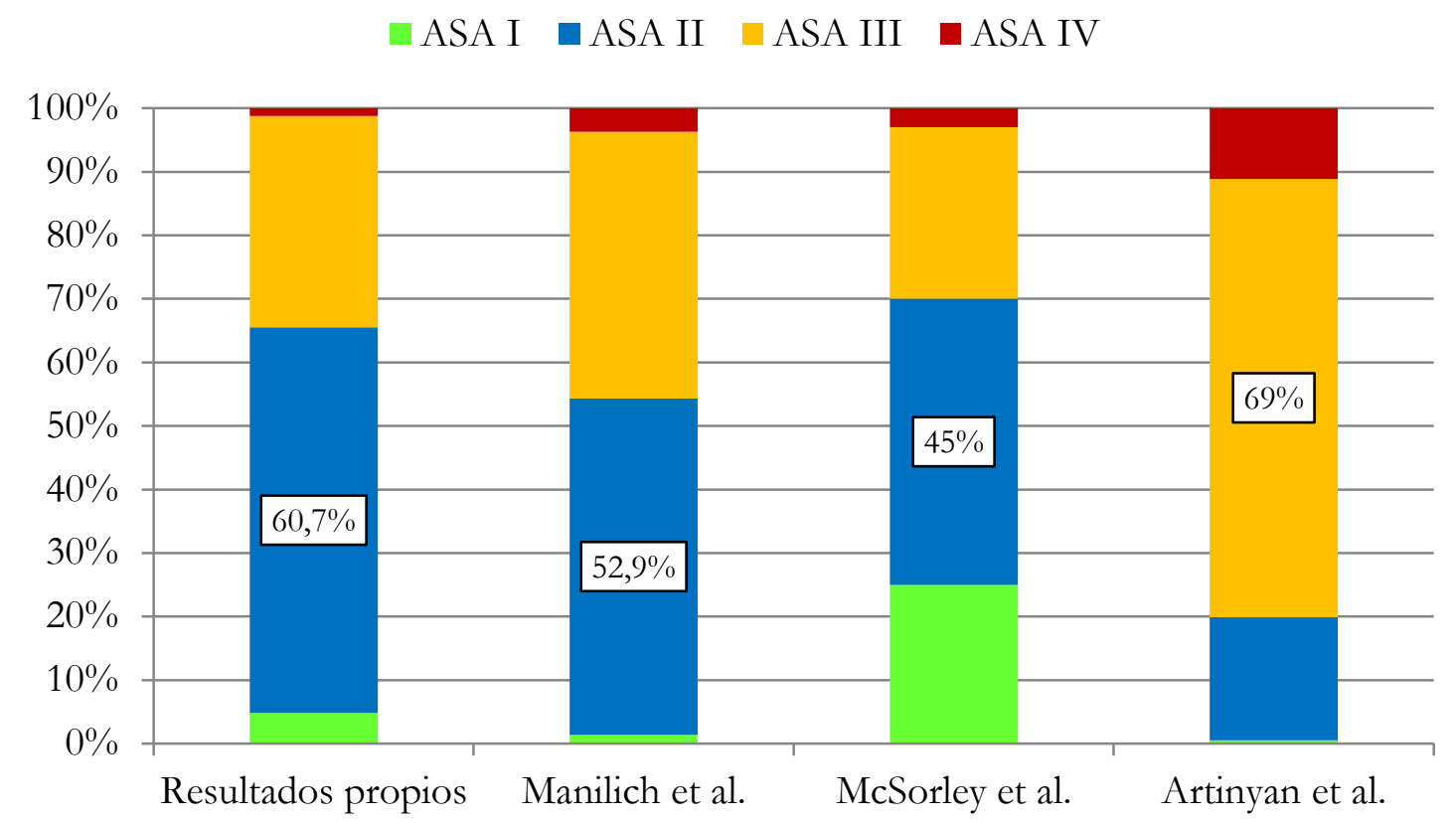

Definimos el riesgo anestésico elevado como aquellos pacientes que presentaban grados III o IV de la clasificación de la ASA. Teniendo en cuenta que casi no hay pacientes clasificados como grados I o IV, esta estratificación se puede reducir, a grandes rasgos, a la diferenciación entre grado II y III. De este modo, nuestra muestra contó con un 34,5\% de pacientes con riesgo elevado, datos similares a los procedentes de las series de Manilich et al. [301] y de McSorley et al. [292], que presentaron un 45,7\% y un 30\%, respectivamente, de pacientes con riesgo anestésico elevado, resultados muy inferiores al 80,1\% que mostraron Artinyan et al. [295].

La obstrucción intestinal aguda es una complicación del CCR que puede aparecer en el 7$29 \%$ de los pacientes [302]. En nuestro centro, la tendencia cuando atendemos a un paciente con CCR que muestra una obstrucción intestinal aguda es la de intentar colocar, 


\section{Martín Bailón Cuadrado}

de forma endoscópica, una prótesis auto-expandible para corregir la obstrucción intestinal. En nuestra muestra se colocó una prótesis endoscópica de forma previa a la cirugía en 18 pacientes $(10,7 \%)$, dato que se encuentra discretamente por encima de lo publicado, así Erichsen et al. describen una tasa del 6,3\%, en una serie danesa con casi 18.000 pacientes [303]. Los resultados a corto plazo, siguiendo este procedimiento, son buenos, ya que presentan una tasa de éxito superior al 90\%. A pesar de este dato, la tasa de perforación durante la colocación de este dispositivo se sitúa en torno al 4-5\%, por lo que las consecuencias de una complicación pueden ser muy graves [304,305]. A raíz de todo esto, las guías clínicas de la European Society of Gastrointestinal Endoscopy sólo recomiendan la prótesis endoscópica para lesiones obstructivas en pacientes mayores de 70 años y con un riesgo anestésico $\geq$ III de la ASA [306]. Sin embargo, en nuestra serie sólo un 16,7\% de los pacientes tratados con este procedimiento fueron ASA III o IV.

En los cánceres de recto con afectación T3/T4, sospecha de adenopatías patológicas, riesgo de afectación de la fascia mesorrectal o localización en el tercio inferior, el tratamiento más reconocido es la neoadyuvancia con QT y radioterapia (RT) de forma previa a la cirugía siempre que no existan contraindicaciones para cualquiera de estos tratamientos [140]. En nuestra muestra, 27 de los pacientes (16,1\%) recibieron QT neoadyuvante y $33(19,6 \%)$ RT neoadyuvante, con una proporción de tumores rectales del $28 \%$, lo que supone que aproximadamente un $70 \%$ de nuestros tumores rectales recibieron neoadyuvancia. Aunque el tratamiento neoadyuvante se plantea para lesiones rectales, en ocasiones se producen errores de localización en las pruebas diagnósticas preoperatorias (colonoscopia, resonancia magnética nuclear $[\mathrm{RMN}]$ ) y algunas lesiones que fueron catalogadas como rectales, en realidad se localizaban en el colon, y viceversa. La tasa de neoadyuvancia varía en función de las diferentes series de pacientes con CCR, ya que 
depende de la proporción de cánceres rectales, el estadio de los mismos, la precisión diagnóstica y los criterios de indicación de terapia neoadyuvante en los diferentes centros. Richards et al. [307] muestran una tasa de neoadyuvancia del $21 \%$, ya que cuentan con un $38 \%$ de lesiones rectales. Tokunaga et al. [207] (en 2015) registran un 8,5\% de tratamientos neoadyuvantes, con una proporción de tumores rectales muy similar (37,2\%). McSorley et al. [292] reflejan una tasa de tratamiento neoadyuvante del 15\%, con una proporción de tumores rectales del 36\%, lo que se asemeja mucho a nuestros propios datos. Tokunaga et al. [308], en un trabajo más reciente (2017), describen una tasa de tratamiento neoadyuvante del 4,5\%, sin aportar datos exactos del porcentajes de lesiones localizadas en recto.

\section{2.- DESCRIPCIÓN DEL ESTADO NUTRICIONAL E INFLAMATORIO.}

Como ya se ha expuesto previamente, en el paciente oncológico se genera una interacción entre el tumor y el propio huésped, lo que desencadena una reacción inflamatoria sistémica que, a su vez, conduce a una situación de desnutrición.

En los últimos años se ha estudiado en profundidad esta conexión existente entre el cáncer y el estado nutricional e inflamatorio de los pacientes oncológicos. De este modo, se han desarrollado una serie de scores que se han tratado de relacionar, principalmente, con el pronóstico oncológico de diversos cánceres. De todos los scores publicados hasta el momento, hemos utilizado en este trabajo cuatro de los más relevantes en la literatura: el Prognostic Nutritional Index (PNI), el Glasgow Prognostic Score (GPS), el Neutrophile/Lymphocyte Ratio (NLR) y el Platelet/Lymphocyte Ratio (PLR). 


\section{Martín Bailón Cuadrado}

Para tener la mayor fiabilidad del estado nutricional e inflamatorio del paciente en el momento de la cirugía, decidimos obtener los parámetros a emplear en los scores a partir de una analítica extraída en las 24 horas previas a la cirugía, con hemograma, bioquímica básica, coagulación, proteína $\mathrm{C}$ reactiva (PCR) y albúmina. Hemos sido muy sistemáticos en esta recogida y es de destacar que no hemos tenido pérdidas en ninguna de las variables que se precisan.

El GPS tiene unos valores claramente definidos $(0,1$ o 2) en función de los niveles de PCR y albúmina, mientras que el PNI, el NLR y el PLR son variables numéricas continuas que en la literatura habitualmente se transforman en variables dicotómicas utilizando puntos de corte adquiridos a partir de curvas receiver operating characteristic (ROC). Es poco frecuente encontrar dos publicaciones que utilicen el mismo punto de corte para un determinado score, lo que hace que los resultados obtenidos no sean fácilmente analizables ni extrapolables a otras muestras de pacientes. Hemos utilizado estos tres scores como variables continuas para explorar su capacidad predictiva y para poder interpretar de una forma más fiable nuestros resultados.

El PNI ha sido uno de scores definitorios del estado nutricional e inflamatorio que más se han utilizado en los últimos años para relacionarlo fundamentalmente con el pronóstico oncológico de diversos cánceres, principalmente del tracto digestivo. En nuestra muestra de pacientes el valor medio de PNI fue de 44,88 \pm 6,08 (rango de 22 a 64), resultados que son muy similares a los que encontramos en la literatura (valores medios entre 42 y 51) [Tabla 22]. 
Tabla 22. Comparación de nuestros propios resultados con la literatura en cuanto a los valores medios de PNI en pacientes intervenidos de CCR.

\begin{tabular}{|c|c|}
\hline \multicolumn{2}{|c|}{ COMPARACIÓN CON LA LITERATURA DE LOS VALORES MEDIOS DE PNI } \\
\hline Resultados propios & Media de 44,88 \pm 6,08 (rango de 22 a 64) \\
\hline Mohri et al. [206] & Media de 45,5 (rango de 28,2 a 61,5 ) \\
\hline Shibutani et al. [203] & Media de 47,9 (rango de 32,45 a 61,36) \\
\hline Tokunaga et al. [207] & Media de 46,94 (rango de 19,19 a 64,09) \\
\hline Yang et al. [201] & Media de 51,3 (rango de 32,3 a 71,2 ) \\
\hline Jian-hui et al. [202] & Media de 50,2 (rango de 24,9 a 70,0$)$ \\
\hline Park et al. [204] & Mediana de 48,2 (RIQ de 44,4 a 52,5) \\
\hline Cao et al. [291] & Media de 42,9 (rango de 27,8 a 60,9 ) \\
\hline
\end{tabular}

El GPS es otro score indicador del estado nutricional e inflamatorio que también ha sido ampliamente analizado para valorar el pronóstico oncológico de diversos cánceres y que, como sabemos, puede tomar los valores de 0,1 o 2 . En nuestra serie, al igual que en la mayor parte de los trabajos publicados (Ishizuka et al. [211], Moyes et al. [218], Choi et al.[213], Lin et al. [212]), predominaron los pacientes con un GPS de 0 (61,9\%), siendo menor la proporción de aquellos con GPS de 1 (21,4\%) o con GPS de 2 (16,7\%). A diferencia de estos resultados, en algunas series como las de Elahi et al. [309] y Eren et al. [215], predominan los pacientes con GPS de 1 (43\% y 47,8\%, respectivamente). [Gráfico 28].

El NLR es un score inflamatorio también ampliamente empleado en relación con el pronóstico oncológico de diversos cánceres. En nuestra muestra de pacientes encontramos una mediana de 2,19 (RIQ de 1,68 a 3,28), valor discretamente más bajo que los que podemos observar en la literatura. Otros autores no describen los valores medios de este score, sino que establecen puntos de corte obtenidos a partir de curvas ROC y describen la 


\section{Martín Bailón Cuadrado}

distribución de sus pacientes en base a estos valores de referencia, como puede apreciarse en la tabla 23.

Gráfico 28. Comparación de nuestros propios resultados con la literatura en cuanto a los valores de GPS en pacientes intervenidos de CCR.

$\square$ GPS $0 \quad$ GPS $1 \quad$ aPS 2

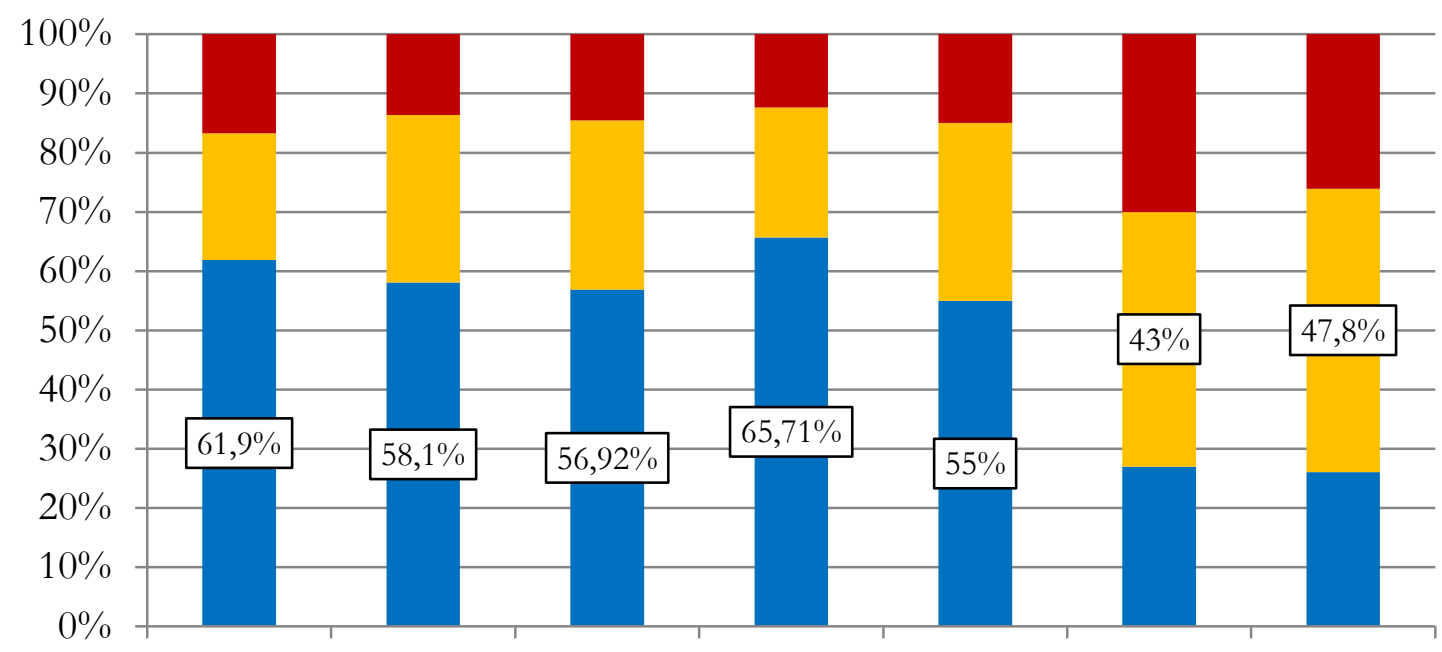

Resultados Ishizuka et Moyes et Choi et al. Lin et al. Elahi et al. Eren et al. propios al. al.

Tabla 23. Comparación de nuestros propios resultados con la literatura en cuanto a los valores de NLR en pacientes intervenidos de CCR.

\begin{tabular}{|c|c|}
\hline \multicolumn{2}{|c|}{ COMPARACIÓN CON LA LITERATURA DE LOS VALORES DE NLR } \\
\hline Resultados propios & Mediana de 2,19 (RIQ de 1,68 a 3,28) \\
\hline Emir et al. [234] & Media de 2,88 (rango de 0,42 a 23,55 ) \\
\hline Khan et al. [232] & Media de $5,4 \pm 6,8$ \\
\hline Kim et al. [310] & Media 4,54 $\pm 5,83$ \\
\hline Kubo et al. [239] & $56 \%$ con NLR $\geq 2,1$ \\
\hline Josse et al. [233] & $61,4 \%$ con NLR $\geq 2,3$ \\
\hline Choi et al. [240] & $47,7 \%$ de con NLR $\geq 2,6$ \\
\hline Pine et al. [238] & $24,6 \%$ con NLR $\geq 5$ \\
\hline
\end{tabular}


Por último, el PLR es otro score inflamatorio que también se ha utilizado principalmente para estudiar su influencia sobre el pronóstico oncológico de diferentes cánceres, pero no ha sido tan analizada su relación con el desarrollo de complicaciones postoperatorias, como hemos pretendido hacer nosotros. La mediana de nuestra serie fue de 135,28 (RIQ de 94,11 a 196,83), siendo estos resultados algo inferiores a los que describe la literatura, al igual que sucedía con el NLR [Tabla 24].

Tabla 24. Comparación de nuestros propios resultados con la literatura en cuanto a los valores de PLR en pacientes intervenidos de CCR.

\begin{tabular}{|c|c|}
\hline \multicolumn{2}{|c|}{ COMPARACIÓN CON LA LITERATURA DE LOS VALORES DE PLR } \\
\hline Resultados propios & Mediana de 135,28 (RIQ de 94,11 a 196,83) \\
\hline Azab et al. $[311]$ & Tercil medio con rango de 148 a 244 \\
\hline Choi et al. $[240]$ & $9,3 \%$ con PLR $\geq 295$ \\
\hline Emir et al. $[234]$ & Media de 193,06 (rango de 19,86 a 885,71) \\
\hline You et al. [245] & Media de 169,1 \\
\hline Kim et al. $[310]$ & Media de $200,17 \pm 168,96$ \\
\hline
\end{tabular}

Una de nuestras premisas es que los cuatro scores analizados utilizan variables comunes, por lo que no sería extraño que presentasen información redundante y que estuviesen relacionados entre sí. Tras "normalizar" las variables "NLR" y "PLR" mediante la aplicación del logaritmo decimal a ambas y llevar a cabo la prueba de correlación de Pearson, observamos cómo cada uno de los cuatro scores se vinculó con los otros tres de forma estadísticamente significativa, confirmando nuestra hipótesis.

Esto nos llevó a realizar el análisis factorial partiendo de las componentes principales, que posteriormente fueron transformadas para obtener las dos nuevas variables, independientes 


\section{Martín Bailón Cuadrado}

entre sí, que resumen los datos procedentes de cada uno de los cuatro scores, eliminando la información redundante entre ellos.

La variable "resultante A" resultó estar influenciada principalmente por los scores "NLR" y "PLR", derivadas de variables obtenidas del hemograma y que describen el componente celular de la respuesta inflamatoria.

Por su parte, la variable "resultante B" se relacionó fundamentalmente con los scores "PNI" y "GPS", derivadas principalmente de la albúmina y de la PCR, y que se vinculan a la fracción humoral de la respuesta inflamatoria.

$\mathrm{Al}$ tratarse de un método de sintetizar información que resulta ser novedoso dentro de la literatura médica, no tenemos forma de comparar los valores obtenidos para estas nuevas variables y establecer si son extrapolables a otras poblaciones. Dado que estas variables se han relacionado de forma relevante con la morbilidad y mortalidad postoperatorias tras la cirugía curativa del CCR, sería interesante evaluar esta premisa en muestras similares y en muestras procedentes de otras poblaciones, para poder validar nuestros resultados.

\section{3.- ANÁLISIS DE VARIABLES INTRAOPERATORIAS.}

La localización de la tumoración en el CCR tiene una relevancia destacable ya que las lesiones rectales tienen un peor pronóstico oncológico y la cirugía que requieren asocia una mayor morbilidad y mortalidad que aquellas situadas en el colon. En nuestra muestra, sólo el 28\% presentaron una lesión localizada en el recto (47 de los 168 pacientes). Estos resultados no difieren de los que describe la literatura, donde predomina el cáncer de colon 
con mayor o menor preponderancia en función de las series, como podemos ver en el gráfico 29 [202,204,206,207,286,295,312].

Gráfico 29. Comparación de nuestros propios resultados con la literatura en cuanto a la localización de la tumoración en pacientes intervenidos de CCR.

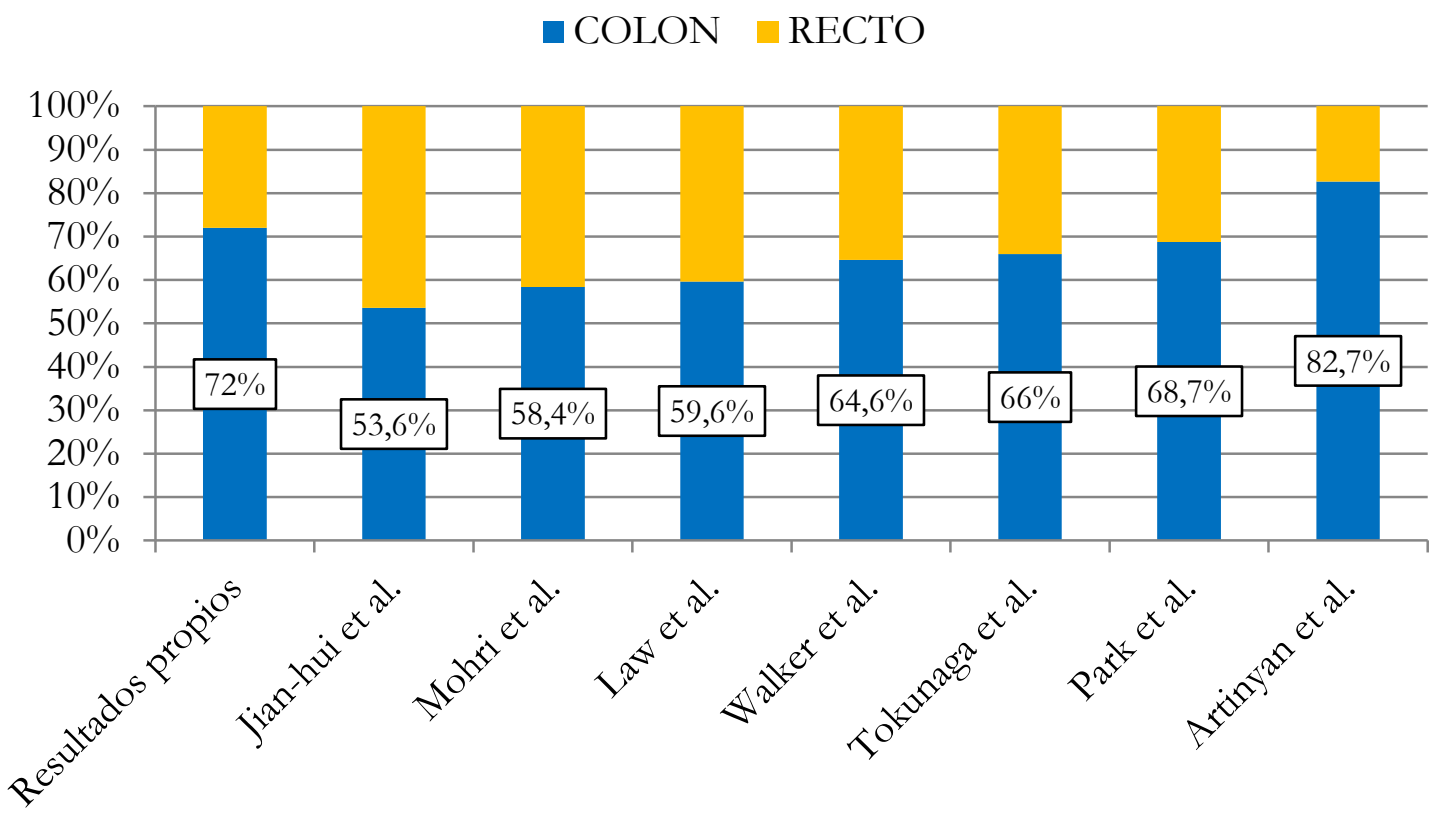

La localización de la tumoración no sólo nos condiciona la morbimortalidad sino también la técnica quirúrgica. Al ubicarse de forma predominante en colon, lógicamente la técnica más empleada fue la colectomía (98 pacientes, un 58,3\%). En el recto, en función de diferentes condicionantes que ya hemos mencionado, la técnica de elección sería la proctectomía con anastomosis, siempre que sea factible desde el punto de vista técnico y anatómico. La amputación abdominoperineal (AAP) o procedimiento de Miles se reserva para lesiones muy distales en las que la resección con criterios oncológicos de la tumoración no permite mantener la integridad del plano del elevador del ano ni la del 


\section{Martín Bailón Cuadrado}

aparato esfinteriano. Finalmente, el procedimiento de Hartmann se emplea en lesiones rectales o sigmoideas en las que, a pesar de poder realizarse una anastomosis primaria desde el punto de vista quirúrgico, se decide realizar una colostomía terminal por peculiaridades del paciente, como pueden ser riesgo anestésico muy elevado, mal estado general, grave deterioro nutricional o presencia de incontinencia fecal de forma previa a la cirugía. En nuestra serie se realizó una proctectomía en 50 pacientes (29,8\%), una AAP en 12 (7,1\% del total, 25,5\% de los cánceres de recto) y un procedimiento de Hartmann en 8 (4,8\% del total, 17\% de los cánceres de recto). Estas cifras reflejan que nuestras tasas de AAP y de procedimientos de Hartmann son mayores que las que podemos encontrar en la literatura. Harrison et al. [313] muestran un 4,4\% de AAP y un 3,9\% de procedimientos de Hartmann sobre el total de cirugías para CCR. Manilich et al. [301] refieren que en tan sólo un 5,4\% de pacientes se llevó a cabo una AAP o un procedimiento de Hartmann, aunque en esta serie se engloban diferentes procedimientos de cirugía colorrectal, tanto urgentes como programados, para patologías muy diversas y no sólo oncológicas (CCR, colitis ulcerosa, enfermedad de Crohn, diverticulosis/diverticulitis, oclusión intestinal, poliposis colónica, etc.). Sin embargo, Morris et al. [314] describen resultados muy similares a los nuestros, con una tasa del $23 \%$ de AAP y del $9,5 \%$ de procedimientos de Hartmann para cirugías de cáncer de recto, en una serie que analiza un gran número de pacientes procedentes de la base de datos del National Health System del Reino Unido.

El tiempo quirúrgico se ha relacionado con la aparición de complicaciones postoperatorias y con un peor pronóstico oncológico tras la cirugía del CCR [273,313]. En nuestra muestra, el tiempo de intervención presentó una media de 214,58 \pm 67,99 minutos (rango de 80 a 450 minutos), aunque debemos tener en cuenta que se han incluido pacientes intervenidos mediante laparotomía y mediante abordaje laparoscópico, que habitualmente conlleva un 
mayor tiempo quirúrgico. Estos resultados están discretamente por encima de los valores que reflejan algunas series, como las de Jestin et al. [315], Shimazaki et al. [228] o Moghadamyeghaneh et al. [298]. Sin embargo, otros autores como Shibutani et al. [203], Slankamenac et al. [296] o Mohri et al. [206] muestran cifras similares a las nuestras [Tabla 25].

Tabla 25. Comparación de nuestros propios resultados con la literatura en cuanto al tiempo de intervención en pacientes intervenidos de CCR.

\begin{tabular}{|c|c|}
\hline \multicolumn{2}{|c|}{ COMPARACIÓN CON LA LITERATURA DEL TIEMPO DE INTERVENCIÓN } \\
\hline Resultados propios & Media de 214,58 \pm 67,99 minutos (rango de 80 a 450 minutos) \\
\hline Jestin et al. $[315]$ & Mediana de 180 minutos (rango de 75 a 285) \\
\hline Shimazaki et al. $[228]$ & Media de $180,2 \pm 81,4$ minutos \\
\hline Moghadamyeghaneh et al. $[298]$ & Media de $182 \pm 100$ minutos \\
\hline Shibutani et al. $[203]$ & Media de 206 minutos (rango de 93 a 687) \\
\hline Slankamenak et al. $[296]$ & Media de 240 minutos \\
\hline Mohri et al. [206] & $48,1 \%$ de pacientes por encima de 240 minutos \\
\hline
\end{tabular}

$\mathrm{Al}$ igual que con el tiempo operatorio elevado, la transfusión intraoperatoria también se ha relacionado con una mayor tasa de complicaciones postoperatorias y con peores resultados oncológicos tras cirugía para el CCR. En nuestra muestra, sólo 3 pacientes (1,8\%) precisaron de transfusión de hemoderivados durante la intervención. Estos datos son más favorables a los que podemos encontrar en series de pacientes con tasas de transfusión de en torno al $10-15 \%[295,301,316]$, pero similares a otras con tasas por debajo del $5 \%$ [233,292,296] [Gráfico 30]. 


\section{Martín Bailón Cuadrado}

Gráfico 30. Comparación de nuestros propios resultados con la literatura en cuanto a la transfusión intraoperatoria en pacientes intervenidos de CCR.

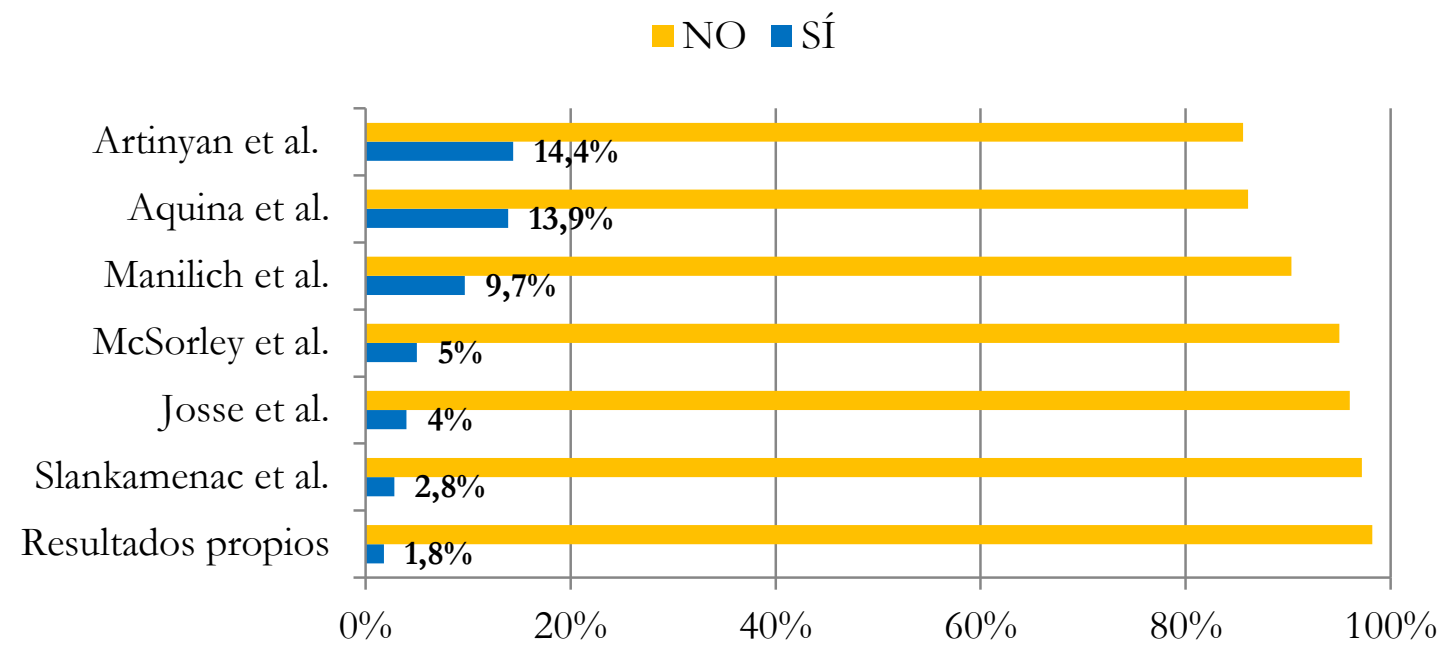

\section{4.- COMPLICACIONES POSTOPERATORIAS E INFLUENCIA DE LOS SCORES.}

Las complicaciones postoperatorias son uno de los principales puntos de preocupación del cirujano, ya que no solo influyen en la calidad de vida del paciente a corto plazo, sino que se ha observado que condicionan el pronóstico oncológico a largo plazo [285].

Desde el inicio de la Medicina, hemos intentado disminuir las consecuencias negativas de nuestros actos. Esto se vuelve crucial en la Cirugía, donde se maximiza la agresión que generamos al paciente. Con esa intención hemos definido siete variables vinculadas con la morbilidad y mortalidad postoperatorias y las hemos relacionado con diversas variables demográficas, preoperatorias, intraoperatorias y definitorias del estado nutricional e inflamatorio, con el afán de desvelar algún tipo de influencia de éstas sobre las primeras. 
Nuevamente tenemos que destacar que hemos sido sumamente sistemáticos a la hora de registrar todas y cada una de las complicaciones acaecidas durante los 30 primeros días del periodo postoperatorio o hasta el alta domiciliaria en el caso de acontecer ingresos más prolongados.

En los pacientes intervenidos de cirugía curativa para CCR, es escaso el número de trabajos que analizan el efecto de los scores sobre la morbilidad y mortalidad. La gran mayoría de ellos son retrospectivos y sólo utilizan uno o dos de ellos, centrándose preferentemente en las complicaciones globales y graves.

Este es el motivo por el que nuestro trabajo reviste notable interés y resulta altamente novedoso puesto que hemos incluido el análisis de los cuatro scores más representativos y contrastados en la literatura (PNI, GPS, NLR y PLR) y además hemos evaluado, mediante una recogida prospectiva de datos, su asociación con siete variables postoperatorias relacionadas con la morbilidad y mortalidad tras la cirugía curativa para CCR, tratando de obtener una mayor información de qué ocurre con los pacientes sometidos a esta cirugía.

Como ya se ha mencionado anteriormente, hemos comprobado que los cuatro scores empleados en este trabajo están correlacionados entre sí, lo que supone que presentan información redundante y por eso podría alterarse su potencia de predicción desde el punto de vista estadístico. Por este motivo, hemos diseñado las dos variables resultantes expuestas, que creemos describen con mayor precisión el estado nutricional e inflamatorio de nuestros pacientes. 


\section{Martín Bailón Cuadrado}

Hemos realizado un análisis univariante y multivariante para determinar aquellos factores (demográficos, preoperatorios, intraoperatorios y definitorios del estado nutricional e inflamatorio) que tienen influencia sobre el desarrollo de morbilidad y mortalidad, y lo hemos comparado con trabajos recientes con una metodología y planteamiento similar.

Para una mejor comprensión, dividiremos este apartado en los mismos epígrafes empleados en los resultados, mencionando los datos obtenidos y los factores que influyen en cada una de las complicaciones.

\subsection{1.- COMPLICACIONES GLOBALES.}

Registramos en nuestra muestra que un total de 55 pacientes $(32,7 \%)$ padecieron algún tipo de complicación, resultados similares a los que se describen en la literatura entre pacientes intervenidos de CCR, con tasas de complicaciones globales entre el $25 \%$ y el $40 \%$ [206,207,233,292,295,296,298,317]. Sin embargo, otros autores presentan incidencias inferiores al 20\%, como Cao et al. [291] con un 17,1\%, Shimazaki et al. [228]con un 18,8\% o Moyes et al. [218] con un 18,9\% [Gráfico 31], lo que posiblemente se relaciona con el rigor con el que se registran las complicaciones, a la hora de incluir cualquier evento adverso o sólo aquellos más relevantes. 
Gráfico 31. Comparación de nuestros propios resultados con la literatura en cuanto a la tasa de complicaciones globales en pacientes intervenidos de CCR.

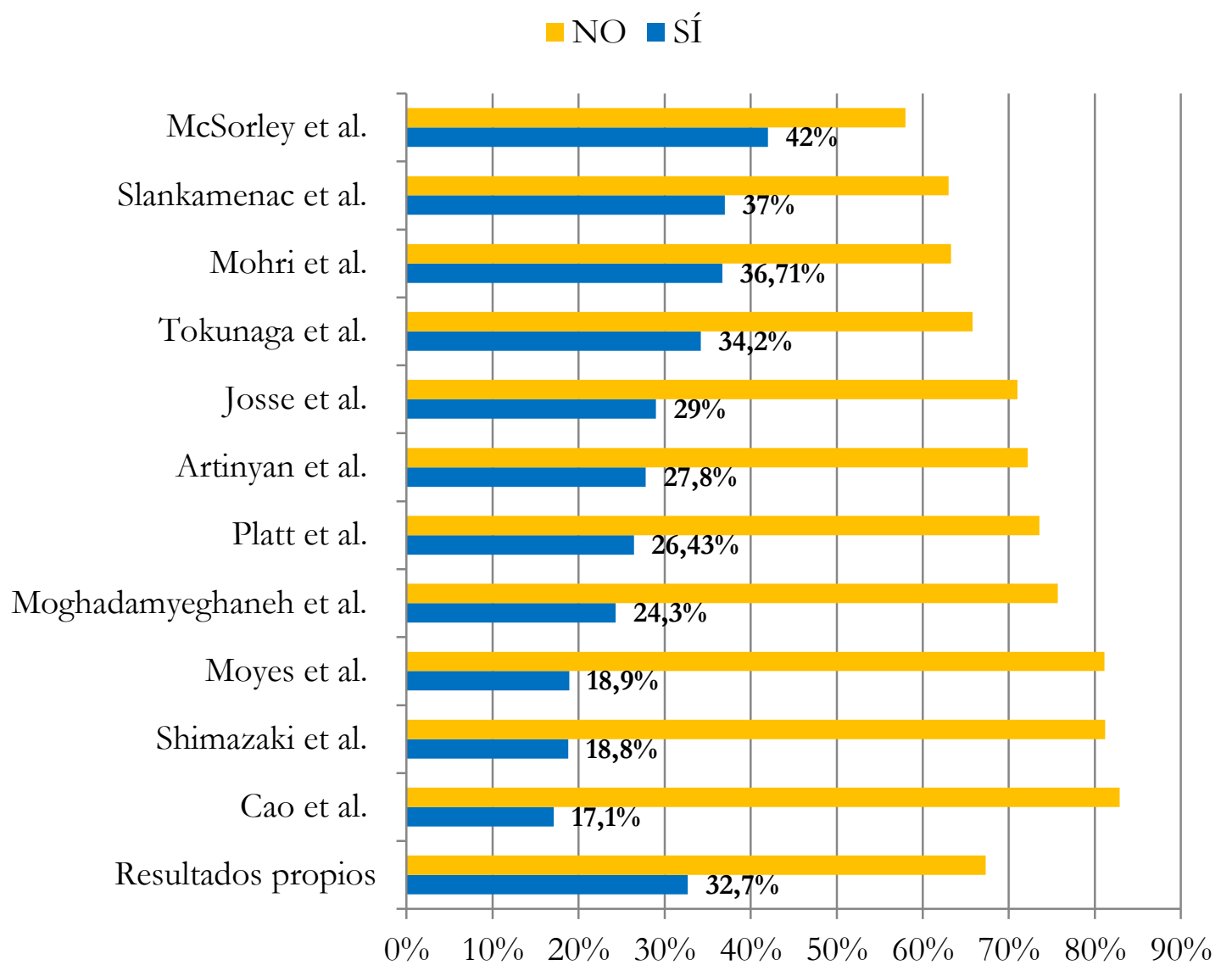

En nuestra muestra, las variables que resultaron significativas para la aparición de complicaciones globales tras el análisis univariante fueron la edad, el riesgo anestésico alto, la localización del tumor, el tiempo de intervención, los cuatros scores definitorios del estado nutricional e inflamatorio y la resultante B.

Después de realizar el análisis multivariante, tres variables resultaron significativas: la edad, la localización del tumor y la resultante B. Para la edad obtuvimos una odds ratio (OR) de $1,047$ (intervalo de confianza al 95\% [IC 95\%] $=1,012-1,084), p=0,008$. Para la localización del tumor la OR fue de 3,520 (IC 95\% = 1,550-7,994), p =0,003, lo que 


\section{Martín Bailón Cuadrado}

implica que el riesgo de sufrir complicaciones globales es tres veces y media mayor para los cánceres de recto que para los de colon.

La resultante B mostró una OR de 2,239 (IC 95\% = 1,541 - 3,253), p = 0,0001, con una sensibilidad y especificidad del 65,5\% y del 70,8\%, respectivamente.

Shimazaki et al. [228] presentaron en 2015 un estudio retrospectivo llevado a cabo en el Ibaraki Medical Center (Japón) con 85 pacientes intervenidos de cirugía para el CCR. Analizaron la influencia del Granulocyte/Lymphocyte Ratio (GLR) y de otras variables sobre la aparición de complicaciones globales. El GLR es un score que valora la respuesta inflamatoria y cuyo valor se puede asimilar al del NLR. En este trabajo utilizaron el GLR como una variable continua y compararon el valor medio del mismo en los pacientes complicados y no complicados.

La tasa de complicaciones globales fue del 18,8\%. Apreciaron que existían diferencias en cuanto al valor medio del GLR entre los pacientes complicados y los no complicados (6,73 $\pm 10,38$ vs $3,49 \pm 2,78, \mathrm{p}<0,05)$, así como al valor medio de volumen de sangrado intraoperatorio $(299,8 \pm 361,7 \mathrm{~mL}$ vs $155,6 \pm 268,6 \mathrm{~mL}, \mathrm{p}<0,05)$.

Tras realizar el análisis multivariante, el GLR alcanzó significación estadística en su relación con el desarrollo de complicaciones globales, con una OR de 2,18 (IC 95\% = 1,11 - 4,27), $\mathrm{p}=$ 0,023. Lo mismo sucedió con el volumen de sangrado intraoperatorio, que también mantuvo la significación estadística tras el análisis multivariante.

A diferencia de Shimazaki et al. [228], nosotros hemos utilizado el NLR, cuyo valor puede ser equiparable al del GLR, según hemos indicado. Para nuestra muestra, observamos que la media de NLR fue mayor entre aquellos pacientes con complicaciones globales en comparación con los que no las presentaron (3,16 vs 2,51, p =0,088), pero tras el análisis 
multivariante este score no consiguió significación estadística, a diferencia del GLR para Shimazaki et al. En nuestro caso, la variable que se relacionó con la aparición de complicaciones globales de forma muy significativa fue la resultante $B$, que está influenciada principalmente por el PNI y por el GPS, y de forma mucho menos importante por el NLR y el PLR, lo que se enfrenta, en cierto modo, a los resultados obtenidos por estos autores.

Otra de las diferencias que podemos apreciar es que Shimazaki et al. [228] han analizado la influencia del sangrado intraoperatorio sobre el desarrollo de complicaciones postoperatorias, mientras que nosotros hemos empleado la variable "transfusión intraoperatoria". Estas dos formas de medir la pérdida de sangre durante la intervención no son comparables, ya que la que utilizan estos autores refleja de forma más fidedigna la cantidad de sangre que se ha perdido, mientras que nosotros hemos empleado una variable dicotómica que sólo aparece cuando el sangrado es importante. Por lo tanto, no podemos deducir si el volumen de sangrado intraoperatorio se relaciona con las complicaciones globales en nuestra serie de pacientes. En cualquier caso, la variable "transfusión intraoperatoria" no resultó significativa, ni en el análisis univariante, para las complicaciones globales en nuestra muestra.

Además, advertimos en nuestra serie que la edad y la localización del tumor también se vincularon con la aparición de complicaciones globales, lo que no sucedió en el trabajo de Shimazaki et al. [228], donde estas dos variables no consiguieron significación para las complicaciones globales ni siquiera en el análisis univariante.

Mohri et al. [206] publicaron en 2013 un estudio retrospectivo llevado a cabo en el Mie University Hospital (Japón) con 365 pacientes intervenidos de cirugía para el CCR entre enero de 2001 y diciembre de 2006. Analizaron la relación del PNI y de otras variables 


\section{Martín Bailón Cuadrado}

sobre la aparición de complicaciones globales y graves (grado $\geq$ III de la clasificación de Clavien-Dindo). Utilizaron la curva ROC y establecieron un punto de corte para el PNI en 45, creando dos grupos (PNI alto y PNI bajo).

La tasa de complicaciones globales en la muestra fue del 36,71\%, apreciándose diferencias entre ambos grupos de PNI, con una incidencia mayor en el grupo con PNI bajo en comparación con el grupo con PNI alto (42,6\% vs 32\%, p = 0,004).

Tras el análisis multivariante el PNI alcanzó significación estadística, actuando como factor independiente, con una OR de 1,84 (IC 95\% = 1,17 - 2,91), $\mathrm{p}=0,008$. También se observó que un tiempo de intervención superior a 4 horas se vinculaba de forma significativa con las complicaciones globales, con una OR de 2,09 (IC 95\% = 1,22 - 3,61), $\mathrm{p}=0,007$.

Mohri et al. han analizado el tiempo de intervención como una variable dicotómica, utilizando como punto de corte el valor de 4 horas, mientras que nosotros hemos empleado el tiempo quirúrgico como una variable numérica continua. Teniendo en cuenta que estos autores han establecido su punto de corte de manera arbitraria, consideramos que nuestra actitud no distorsiona la naturaleza de esta variable, lo que permite interpretar mejor los resultados y hacerlos más extrapolables a otras muestras de pacientes. En todo caso, el tiempo de intervención no se relacionó con las complicaciones globales en nuestra muestra, ni siquiera en el análisis univariante.

Tokunaga et al. [207] presentaron en 2015 un trabajo retrospectivo desarrollado en el Kumamoto University Hospital (Japón) con 556 pacientes intervenidos de cirugía curativa para CCR entre marzo de 2005 y agosto de 2014. Evaluaron la influencia del PNI y de otras variables sobre la aparición de complicaciones globales y graves (grado $\geq$ III de la 
clasificación de Clavien-Dindo). Utilizando la curva ROC, establecieron un punto de corte de 45,5 para el PNI y generaron dos cohortes (PNI alto y PNI bajo).

La tasa de complicaciones globales en el conjunto de la muestra fue del 34,2\%, sin encontrarse diferencias en el análisis univariante entre los dos grupos de PNI en cuanto a la proporción de complicaciones globales $(37,2 \%$ vs $32,0 \%, \mathrm{p}=0,201)$.

Cao et al. [291] publicaron en 2017 un estudio retrospectivo desarrollado en el Beijing Hospital (China) con 228 pacientes intervenidos de cirugía curativa de CCR entre enero de 2009 y enero de 2012. Analizaron la influencia del PNI y de otras variables sobre la aparición de complicaciones globales y graves (grado $\geq$ III de la clasificación de ClavienDindo). Utilizando la curva ROC, establecieron un punto de corte de 44,55 para el PNI y generaron dos grupos (PNI alto y PNI bajo).

Las complicaciones globales aparecieron en el $16,7 \%$ de los pacientes de la muestra. Observaron que la proporción de aquellos con complicaciones era mayor en el grupo con PNI bajo en comparación con el grupo con PNI alto $(23,5 \%$ vs 7,29\%, p =0,002). Así mismo, la tasa de complicaciones era mayor en aquellos pacientes con un IMC elevado $(\geq$ $\left.18,5 \mathrm{Kg} / \mathrm{m}^{2}, \mathrm{p}=0,004\right)$.

Tras realizar el análisis multivariante, el PNI bajo se manifestó como un importante factor de riesgo frente al desarrollo de complicaciones globales, aunque sin llegar a alcanzar la significación estadística, presentando una OR de 2,41 (IC 95\% $=0,96-6,06), \mathrm{p}=0,06$. Lo mismo sucedió para el IMC, que no mantuvo su significación tras el multivariante, mostrando una OR de 2,49 (IC 95\% = 0,96-6,46), $\mathrm{p}=0,059$.

Cao et al. han utilizado el IMC como variable dicotómica empleando como punto de corte el valor de $18,5 \mathrm{Kg} / \mathrm{m}^{2}$, mientras que nosotros hemos mantenido la naturaleza continua de esta variable. Posiblemente la cifra utilizada por estos autores haga referencia al límite 


\section{Martín Bailón Cuadrado}

inferior de la horquilla de IMC normal de acuerdo a la clasificación de la Organización Mundial de la Salud, aunque no lo refieren así en su publicación. De cualquier manera, esta variable no ha manifestado significación para la aparición de complicaciones globales en nuestra muestra ni tan siquiera en el análisis univariante.

Si comparamos nuestro trabajo con los de Mohri et al. [206], Tokunaga et al. [207] y Cao et al. [291] en cuanto a la influencia del PNI sobre las complicaciones globales, podemos apreciar que en todos ellos se utilizan las curvas ROC para establecer puntos de corte y generar dos grupos de riesgo, mientras que nosotros hemos aplicado este score como una variable continua.

Queremos destacar que en estos tres estudios diferentes se han utilizado tres puntos de corte diferentes para el PNI, lo que hace que los resultados sean difícilmente interpretables y extrapolables a otras muestras, como ya hemos discutido previamente. Todos estos motivos nos han llevado a mantener la naturaleza continua de esta variable.

Sólo en el trabajo de Mohri et al. el PNI alcanza la significación estadística tras el análisis multivariante para las complicaciones globales, no sucediendo así en nuestro trabajo, ni en el de Cao et al., ni en el de Tokunaga et al.

En nuestro estudio destacó la resultante B (influenciada de forma importante por el PNI) como factor de riesgo independiente para las complicaciones globales, donde alcanzó significación estadística tras el análisis multivariante, como también lo hicieron la edad y la localización de la tumoración.

La edad no resultó significativa, ni siquiera tras el análisis univariante, en ninguno de estos tres trabajos, y la localización de la tumoración (colon vs recto) alcanzó significación tras el univariante sólo para Mohri et al., situación que no se mantuvo tras el multivariante. 


\subsection{2.- COMPLICACIONES GRAVES.}

Quizás, más interesante que la morbilidad global sería diferenciar a aquellos pacientes que sufren una morbilidad grave. En este sentido, desde que fuera publicada en 2004 la clasificación de Clavien-Dindo, que agrupa las complicaciones postoperatorias en función de su gravedad, es habitual en la literatura encontrar la severidad de las complicaciones descrita de este modo, entendiendo como complicación grave aquella con un grado $\geq$ III.

Siguiendo esta clasificación de Clavien-Dindo, apreciamos que 18 pacientes (10,7\%) de nuestra muestra sufrieron complicaciones graves, dato equiparable a lo publicado en la literatura, donde esta tasa oscila entre el 6\% y el 15\% [206,207,233,291,292,296] [Gráfico 32].

Para la presentación de complicaciones graves (grado $\geq$ III en la clasificación de ClavienDindo), las variables que mostraron significación tras el análisis univariante fueron la edad, el PNI y la resultante B. Tras realizar el análisis multivariante, la única variable que resultó significativa fue la resultante $\mathrm{B}$, con una OR de 1,773 (IC 95\% $=1,129-2,785), \mathrm{p}=0,013$, y con una sensibilidad y especificidad del $61,1 \%$ y del $76,0 \%$, respectivamente. 


\section{Martín Bailón Cuadrado}

Gráfico 32. Comparación de nuestros propios resultados con la literatura en cuanto a la tasa de complicaciones graves en pacientes intervenidos de CCR.

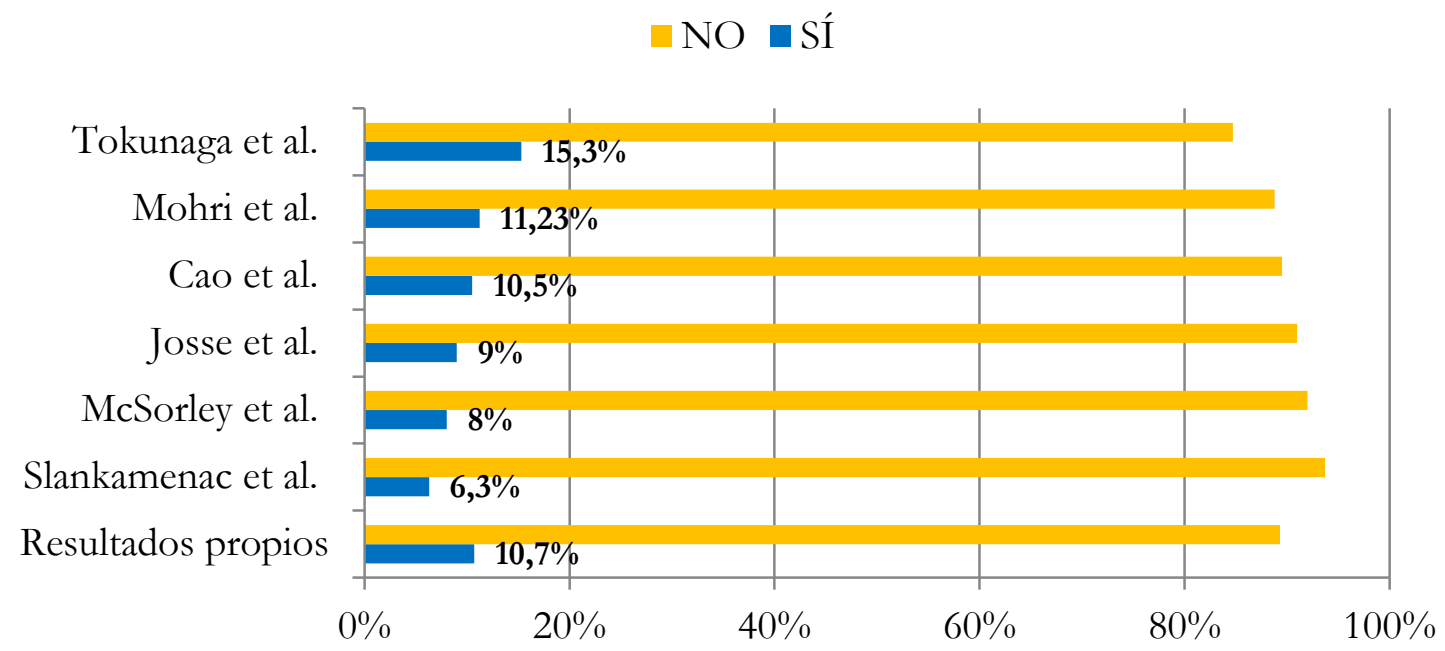

Josse et al. [233] publicaron en 2016 un estudio retrospectivo desarrollado en el University Health Network de Toronto (Canadá) con 583 pacientes intervenidos de cirugía curativa para el CCR entre 2004 y 2012. Analizaron la influencia del NLR y de otras variables sobre la aparición de complicaciones graves (grado $\geq$ III de la clasificación de Clavien-Dindo) y de fuga anastomótica. Utilizaron la curva ROC para establecer 2,3 como punto de corte para el NLR y, de esta manera, generar dos cohortes (NLR alto y NLR bajo). La tasa de complicaciones graves fue del 9\%, observándose diferencias entre ambos grupos de NLR, con una mayor incidencia en el grupo con NLR alto en comparación con el grupo con NLR bajo $(11,45 \%$ vs 4,89\%, $\mathrm{p}=0,007)$. Tras realizar el análisis multivariante, el NLR alcanzó significación estadística a la hora de vincularse con la aparición de complicaciones graves, con una OR de 2,25 (IC 95\% = 1,12 - 4,52), $\mathrm{p}=0,023$. El sexo y la edad, que resultaron significativos en el univariante, no mantuvieron esa asociación estadística tras el multivariante. 
Apreciamos, también en este caso, cómo se ha transformado una variable de naturaleza continua en una dicotómica mediante la aplicación de un punto de corte que, siendo más o menos arbitrario, hace que los resultados obtenidos sólo sean aplicables a su serie de pacientes.

Comparando nuestro trabajo con la publicación de Josse et al. [233], observamos que para estos autores el NLR se vincula de forma significativa con las complicaciones graves, mientras que en nuestro estudio este score no alcanzó significación ni en el univariante.

En nuestra serie fue la resultante B la que mostró una gran relevancia a la hora de predecir el desarrollo de complicaciones graves. Si tenemos en consideración que el valor de la resultante B viene determinado fundamentalmente por el PNI y el GPS, y apenas por el NLR y el PLR, podemos interpretar que nuestros resultados se contraponen a los expuestos por Josse et al.

Para estos autores, el sexo y la edad alcanzaron significación en el análisis univariante, mientras que para nosotros sólo lo hizo la edad y no el sexo. En cualquier caso, tanto para ellos como para nosotros, estas dos variables no mantuvieron esa condición en el multivariante.

Mohri et al. [206], en su publicación descrita previamente, en la que relacionaban el PNI con la aparición de complicaciones globales y graves, refieren que el 11,23\% de sus pacientes padecieron complicaciones graves, observándose diferencias entre ambos grupos de PNI, con una mayor proporción en el grupo con PNI bajo en comparación con el grupo con PNI alto $(15,4 \%$ vs $7,9 \%, \mathrm{p}=0,02)$. Las complicaciones graves también fueron mayores para el sexo masculino y para un tiempo quirúrgico superior a las 4 horas, con una $\mathrm{p}=0,04$ en ambos casos, tras realizar el análisis univariante. 


\section{Martín Bailón Cuadrado}

Tras el análisis multivariante evidenciaron que el PNI era el único factor que se relacionaba de forma significativa con el desarrollo de complicaciones graves, con una OR de 2,29 (IC $95 \%=1,17-4,59), \mathrm{p}=0,002$.

Como destacábamos antes, Mohri et al. transforman el tiempo de intervención en una variable dicotómica utilizando un punto de corte arbitrario, dificultando la extrapolación de sus resultados a otras series de pacientes. A diferencia de estos autores, en nuestra muestra no obtuvieron significación en el análisis univariante ni el sexo ni el tiempo quirúrgico.

Tokunaga et al. [207], en su trabajo citado anteriormente, en el que vinculaban el PNI con la aparición de complicaciones globales y graves, describen que estas últimas se manifestaron en un 15,3\% de los pacientes, evidenciándose diferencias significativas tras el análisis univariante en cuanto a la proporción de complicaciones graves entre el grupo con PNI bajo y el grupo con PNI alto $(22,1 \%$ vs $10,1 \%, \mathrm{p}<0,001)$.

Tras realizar el estudio multivariante, el PNI alcanzó significación estadística, mostrándose como un factor de riesgo independiente para el desarrollo de complicaciones graves, con una OR de 2,06 (IC 95\% = 1,22 - 3,50), $\mathrm{p}=0,007$.

En este artículo se evidenció además que el IMC elevado $\left(\geq 18,5 \mathrm{Kg} / \mathrm{m}^{2}\right)$, la localización tumoral (colon vs recto), el sexo y la QT neoadyuvante se relacionaban de forma significativa con las complicaciones graves tras el análisis univariante, pero sólo el sexo y la QT mantuvieron esta condición tras el multivariante. El sexo presentó una OR de 3,41 (IC $95 \%=1,95-6,29), \mathrm{p}<0,001$, exhibiendo un mayor riesgo para aquellos pacientes de sexo masculino. La OR de la QT neoadyuvante fue de 2,44 (IC 95\% = 1,19 - 4,88), p = 0,016. A diferencia de estos autores, en nuestra serie ni el IMC, ni la localización tumoral, ni el sexo, ni la QT neoadyuvante se vincularon con una mayor tasa de complicaciones graves ni siquiera en el análisis univariante. 
En el artículo de Cao et al. [291], comentado previamente, en el que relacionaban el PNI con el desarrollo de complicaciones globales y graves, describen que las complicaciones graves se presentaron en un 10,5\% de los pacientes. También en este caso se apreció que la proporción de complicaciones graves era mayor en el grupo con PNI bajo que en el grupo con PNI alto $(15,9 \%$ vs 3,1\%, p = 0,005). Tras llevar a cabo el análisis multivariante, el PNI alcanzó significación estadística, actuando como un factor de riesgo independiente para el desarrollo de complicaciones graves, con una OR de 4,03 (IC 95\% $=1,10-14,71), p=$ 0,035 .

En su publicación, el IMC también se relacionó de forma estadísticamente significativa con las complicaciones graves, con una OR de 3,26 (IC 95\% = 1,17-9,07), p = 0,024. Aunque hay que destacar que estos autores han transformado el IMC en una variable dicotómica utilizando un valor que se podría considerar arbitrario, haciendo que sus resultados no puedan ser comparados con los de nuestra serie, en la que hemos empleado esta variable como numérica continua.

Si comparamos nuestro estudio con los de Mohri et al. [206], Tokunaga et al. [207] y Cao et al. [291] en cuanto a la influencia del PNI sobre las complicaciones graves, podemos destacar que las tres publicaciones reflejan que el PNI es un factor de riesgo independiente para las complicaciones graves, alcanzando significación estadística tras el multivariante. En nuestra serie, el PNI alcanzó significación estadística para las complicaciones graves sólo tras llevar a cabo el análisis univariante, pero esta no se mantuvo en el multivariante, donde la única variable que alcanzó significación fue la resultante B. Hay que señalar que esta última variable está influenciada fundamentalmente por el PNI, lo que puede hacer que éste último no alcance por sí mismo la significación tras el multivariante. 


\section{Martín Bailón Cuadrado}

\subsection{3.- COMPLICACIONES INFECCIOSAS.}

Considerando como complicación infecciosa la presencia de una infección de cualquier origen (neumonía, infección del tracto urinario, infección de la vía central, fístula o dehiscencia anastomótica, infección de herida quirúrgica [IHQ], colección intraabdominal), observamos que en nuestra muestra 33 pacientes $(19,6 \%)$ sufrieron alguna de ellas. Nuevamente, estos datos no difieren de los reflejado en la literatura, donde la tasa de complicaciones infecciosas se sitúa entre el 8\% y el 27\% [218,228,291,292,294,295,298,317] [Gráfico 33].

Gráfico 33. Comparación de nuestros propios resultados con la literatura en cuanto a la tasa de complicaciones infecciosas en pacientes intervenidos de CCR.

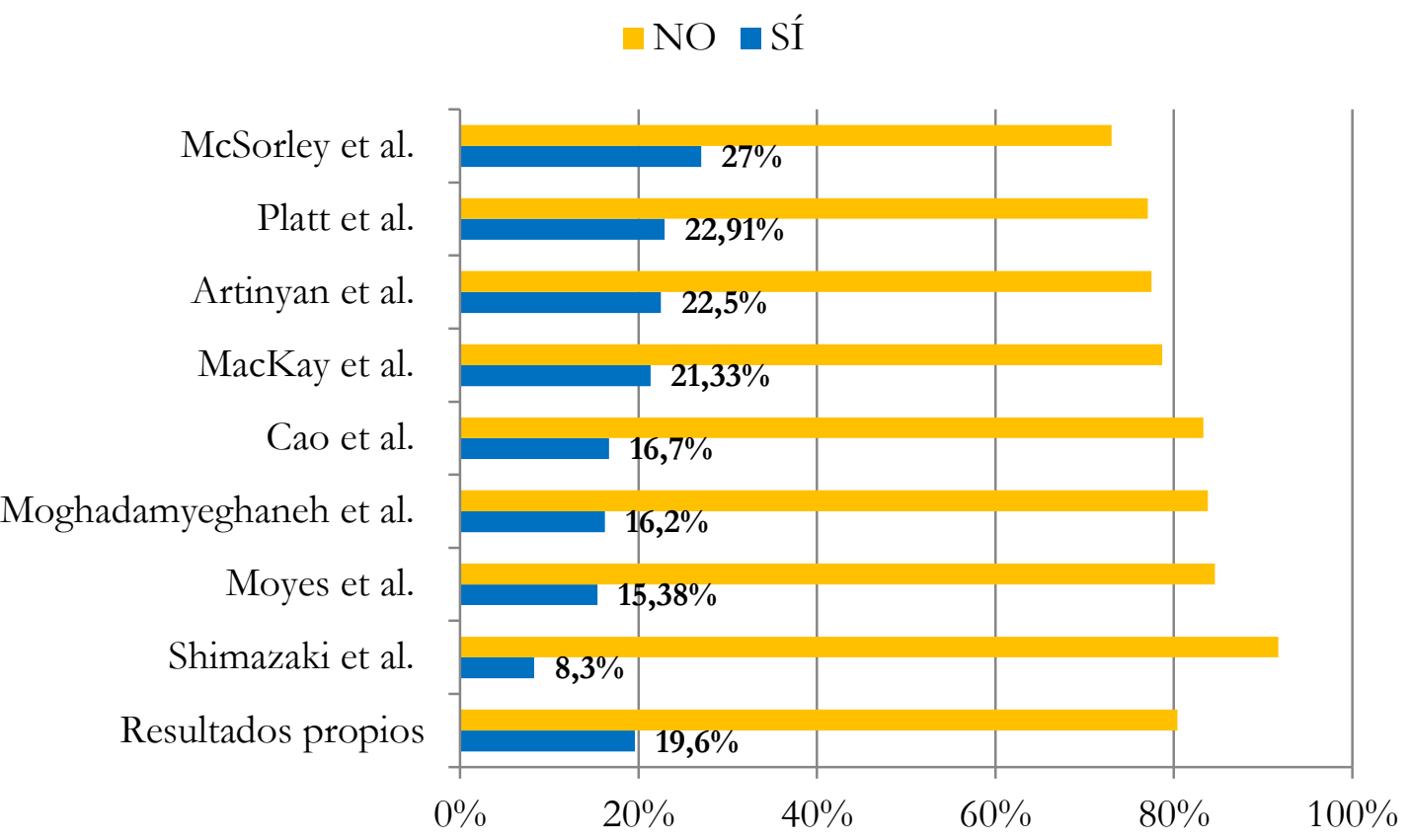


A la hora de predecir el desarrollo de complicaciones infecciosas, las variables que alcanzaron significación tras el análisis univariante fueron la insuficiencia cardiaca, el riesgo anestésico alto, la localización del tumor, el PNI, el GPS y la resultante B. Pero tras el análisis multivariante, la única variable que resultó relevante fue el PNI, que obtuvo una OR de $0,890($ IC $95 \%=0,827-0,958), p=0,002$, con una sensibilidad y especificidad del $76,3 \%$ y del 69,7\%, respectivamente. Este valor describe al PNI, en nuestra muestra, como un factor protector frente a la aparición de complicaciones infecciosas.

Moyes et al. [218] publicaron en 2009 un estudio retrospectivo realizado en el Glasgow Royal Infirmary (Reino Unido) con 455 pacientes intervenidos de cirugía curativa para el CCR entre enero de 2003 y octubre de 2007. Analizaron la influencia del Modified Glasgow Prognostic Score (mGPS) (en la mayor parte de los casos el valor es idéntico al GPS) y de otras variables sobre el desarrollo de complicaciones infecciosas.

La distribución de los pacientes de su muestra en función del mGPS fue la siguiente: 259 (56,92\%) fueron mGPS 0, $130(28,57 \%)$ mGPS 1 y $66(14,51 \%)$ mGPS 2. La tasa de complicaciones infecciosas fue del 15,38\%, observándose diferencias en cuanto a la proporción de las mismas entre los tres grupos de mGPS (10\% para mGPS 0, 16\% para mGPS 1 y 36\% para mGPS 2, p < 0,001) en el análisis univariante. Así mismo, la tasa de complicaciones infecciosas también fue mayor en las cirugías urgentes, en los casos de contaminación peritoneal y en situaciones de leucocitosis ( $>11.000$ leucocitos $/ \mu \mathrm{L}$ ), con una $\mathrm{p}=0,001$ en el univariante.

Tras realizar el análisis multivariante, el mGPS también alcanzó significación estadística, con una OR de 1,76 (IC 95\% = 1,22 - 2,55), $\mathrm{p}=$ 0,003. La leucocitosis y la contaminación peritoneal también se mostraron como factores de riesgo independientes a la hora de 


\section{Martín Bailón Cuadrado}

predecir la aparición de complicaciones infecciosas, con una OR, tras el multivariante, de $1,46($ IC $95 \%=1,01-2,11)$ y de 4,91 (IC 95\% = 1,60 - 15,08), respectivamente.

En comparación con nuestro trabajo, Moyes et al. [218] analizaron la influencia del mGPS, mientras que nosotros hemos utilizado el GPS. Apreciaron que el mGPS se comportaba como un factor de riesgo independiente para complicaciones infecciosas, mientras que para nuestra muestra de pacientes el GPS sólo resultó significativo en el análisis univariante.

En nuestra serie, el PNI y la resultante B mostraron su relevancia en el univariante, aunque sólo el PNI mantuvo esa significación tras llevar a cabo el multivariante.

Nuevamente debemos señalar que existe información redundante entre los diferentes scores, de tal modo que al analizar de forma simultánea el PNI y el GPS (ambos resultaron significativos en nuestro univariante para las complicaciones infecciosas), corremos el riesgo de no examinar de forma adecuada la capacidad predictiva de cada uno de ellos por separado. Dicho de otra manera, si el único score que hubiésemos analizado hubiese sido el GPS, no sería de extrañar que éste hubiese mantenido esa significación tras llevar a cabo el análisis multivariante.

También debemos reflexionar sobre el hecho de que el PNI haya predominado sobre la resultante $\mathrm{B}$ en el análisis multivariante para las complicaciones infecciosas, cuando sabemos que la resultante B se encuentra influida principalmente por el PNI y el GPS, por lo que resume de forma más fehaciente la información nutricional e inflamatoria procedente de estos dos scores. Esto da más valor aún a la capacidad predictiva que presenta el PNI para predecir el desarrollo de complicaciones infecciosas en nuestra muestra. 
Así mismo, queremos destacar que para estos autores la urgencia de la intervención y la presencia de peritonitis se relacionaron de algún modo con el desarrollo de complicaciones infecciosas. Por el contrario, nuestros criterios de inclusión fueron mucho más estrictos y sólo hemos considerado aquellas cirugías que se realizaron de forma programada. Por este motivo, los resultados de este trabajo no pueden ser comparados con series en las que no se analizan pacientes intervenidos de forma urgente.

\subsection{4.- FUGA ANASTOMÓTICA.}

La fuga anastomótica posiblemente sea la complicación más temida por todo cirujano, ya que condiciona el periodo postoperatorio del paciente, obligando a la reintervención del mismo en muchas ocasiones. Además algunos trabajos concluyen que la aparición de esta complicación no sólo condiciona el postoperatorio inmediato sino que también supone un peor pronóstico oncológico [286].

En nuestra muestra realizamos anastomosis en 148 pacientes, de los cuales $11(7,4 \%)$ sufrieron una fuga anastomótica. Estos resultados son discretamente superiores a los que podemos encontrar en algunos estudios recientes, con tasas entre el $2 \%$ y el $6 \%$ [206,218,228,233,291,292,294,317]. Por el contrario, otros autores muestran cifras más elevadas de fuga anastomótica en pacientes sometidos a cirugía curativa de CCR, datos que estarían más en consonancia con los nuestros, así Woeste et al. [318] notifican una tasa del 7,6\%, van Westreenen et al. [319] del 8,8\%, Singh et al. [320] del 9,6\% y Almeida et al. [321] del 13,87\%, [Gráfico 34]. 


\section{Martín Bailón Cuadrado}

Estas discrepancias existentes en la literatura entre las tasas de fuga anastomótica se pueden deber a diferencias en la definición de esta complicación y a lo rigurosos que hayan sido los investigadores durante el proceso de recopilación de datos. Queremos destacar que hemos sido muy estrictos a la hora de definir la presencia de fuga anastomótica en nuestros pacientes, bien por la extravasación de contraste desde la luz intestinal en la tomografía computarizada (TC) o bien por la presencia de un débito de características intestinales en el drenaje, y no en función de la repercusión clínica, mientras que en la literatura podemos encontrar series que nos hablan de fuga anastomótica clínicamente significativa. La tendencia preponderante en nuestro Servicio de dejar drenaje en prácticamente todas las resecciones colorrectales y mantenerlo de forma prolongada nos ha permitido objetivar en el débito del drenaje la existencia de una fuga anastomótica mediante el análisis bioquímico de su contenido, en muchas ocasiones sin ningún trascendencia clínica. No obstante, somos conscientes de la tendencia actual a no dejar drenaje, si bien este no es un objetivo de nuestro estudio.

Un total de seis variables se mostraron relevantes tras el análisis univariante para la predicción de fuga anastomótica: la QT neoadyuvante, la localización de la tumoración, el tipo de intervención realizada, el tiempo quirúrgico, el PNI y la resultante B. Tras llevar a cabo el análisis multivariante, sólo dos variables alcanzaron significación estadística: la localización de la tumoración y la resultante B.

La localización del tumor presentó una OR de 27,733 (IC 95\% = 4,253 - 180,850), p = 0,001. Esto supone que las lesiones localizadas en el recto, para nuestra muestra, tienen casi 28 veces más riesgo de sufrir una fuga anastomótica que aquellas ubicadas en el colon. La resultante B obtuvo una OR de 3,208 (IC 95\% = 1,416-7,268), $\mathrm{p}=0,005$, con una sensibilidad y especificidad del 63,6\% y $66,2 \%$, respectivamente. 
Gráfico 34. Comparación de nuestros propios resultados con la literatura en cuanto a la tasa de fuga anastomótica en pacientes intervenidos de CCR.

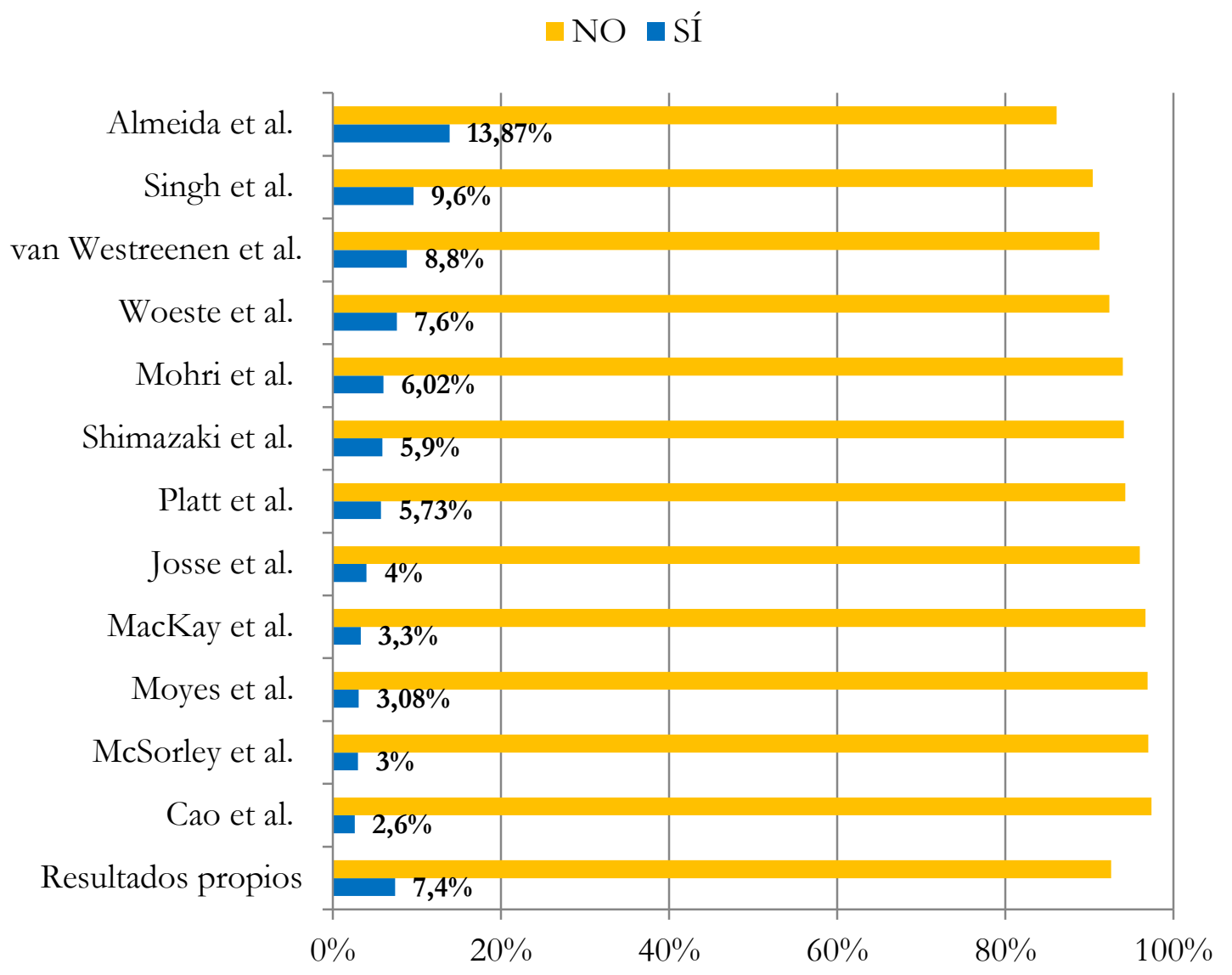

Josse et al. [233], en su trabajo descrito previamente, analizaron la influencia del NLR y de otras variables sobre el desarrollo de complicaciones graves y de fuga anastomótica. Esta última complicación presentó una tasa del 4\%, observándose que el NLR se relacionaba de forma importante con su aparición, quedando muy próximo a alcanzar la significación estadística tras el análisis multivariante, con una OR de 2,96 (IC 95\% = 0,99-8,91), p = 0,053 . 


\section{Martín Bailón Cuadrado}

Como ya indicamos previamente, estos autores utilizan un punto de corte obtenido a partir de curvas ROC para transformar esta variable continua en una dicotómica, por lo que queremos recalcar que sus resultados no son fácilmente extrapolables a otras series de pacientes. Tanto para Josse et al. como para nuestra serie, el NLR no se mostró como un factor de riesgo independiente para la aparición de fuga anastomótica.

En nuestro trabajo, la localización del tumor y la resultante B alcanzaron significación estadística para la fuga anastomótica tras la realización del análisis multivariante, mientras que para Josse et al. [233] la ubicación de la lesión no alcanza significación ni siquiera en el univariante.

\subsection{5.- REINTERVENCIÓN.}

Otras de las situaciones que ensombrece el pronóstico del paciente es la necesidad de reintervención, que le somete a un nuevo estrés y aumenta de forma muy relevante la morbilidad y la mortalidad. Suele producirse en el postoperatorio precoz por la presencia de una hemorragia intrabdominal o en el postoperatorio tardío por la aparición de una fuga anastomótica.

Hasta un total de 10 pacientes $(6,0 \%)$ de nuestra muestra tuvieron que ser reintervenidos, dato que se encuentra por encima de los resultados que describen algunos artículos, aunque podemos destacar que existe una gran heterogeneidad en la tasa de reintervención entre las distintas publicaciones que analizan esta complicación, con tasas que oscilan entre el 0,3\% y el 12,5\% [Tabla 26]. 
Tabla 26. Comparación de nuestros propios resultados con la literatura en cuanto a la tasa de reintervención en pacientes intervenidos de CCR.

\begin{tabular}{|c|c|}
\hline COMPARACIÓN CON LA LITERATURA DE LA TASA DE REINTERVENCIÓN \\
\hline Resultados propios & $6,0 \%$ \\
\hline Slankamenac et al. [296] & $0,3 \%$ \\
\hline Mohri et al. [206] $[301]$ & $1,9 \%$ \\
\hline Manilich et al. [301] & $5,2 \%$ \\
\hline Michaels et al. [322] & $6,7 \%$ \\
\hline van Westreenen et al. [319] & $12,5 \%$ \\
\hline
\end{tabular}

En cuanto a la tasa de reintervención, el PNI, el GPS y la resultante B alcanzaron significación en el análisis univariante, pero sólo ésta última mantuvo esta condición tras la realización del multivariante, obteniendo una OR de 2,349 (IC 95\% = 1,281 - 4,305), p = 0,006, con una sensibilidad y especificidad del 70,0\% y del 76,6\%, respectivamente.

La reintervención constituye una complicación grave de por sí, ya que supone un grado IIIb de la clasificación de Clavien-Dindo, aunque en ocasiones estos pacientes pueden presentar algún fallo orgánico asociado, lo que equivaldría a un grado IVa o IVb. De los diez pacientes de nuestra serie que tuvieron que ser reintervenidos, la causa fue la fuga anastomótica en seis ocasiones, la hemorragia en dos y la oclusión intestinal en otras dos. Además, dos de los que necesitaron ser reoperados finalmente terminaron falleciendo.

Tras llevar a cabo una amplia revisión bibliográfica no hemos encontrado publicaciones con una metodología similar a la nuestra en las que se analice la relación existente entre los scores definitorios del estado nutricional e inflamatorio y la tasa de reintervención tras cirugía curativa para el CCR, por lo que creemos que puede ser una aportación interesante 


\section{Martín Bailón Cuadrado}

de nuestro trabajo el hecho de ser capaces de detectar un grupo de pacientes de alto riesgo de requerir una reintervención y poder así anticiparnos.

\subsection{6.- ÉXITUS.}

Al igual que con la morbilidad, es muy importante tener en cuenta en cualquier procedimiento quirúrgico la mortalidad del mismo. No es una complicación habitual pero se presenta en determinadas circunstancias, ya que el CCR afecta en ocasiones a personas de edad muy avanzada, desnutridas y con un mal estado general, en las que el estrés de la cirugía puede llevar al fallecimiento si sobreviene alguna complicación relevante durante el periodo postoperatorio.

Nuestra mortalidad fue del 1,8\% (3 pacientes), considerada durante los 30 primeros días del postoperatorio o hasta el alta hospitalaria en el caso de ingresos más prolongados. Estos datos se encuentran en consonancia con lo publicado en la literatura, donde encontramos tasas de éxitus de entre el 1\% y el 3\% [Tabla 27].

Tabla 27. Comparación de nuestros propios resultados con la literatura en cuanto a la tasa de éxitus en pacientes intervenidos de CCR.

\begin{tabular}{|c|c|}
\hline COMPARACIÓN CON LA LITERATURA DE LA TASA DE ÉXITUS \\
\hline Resultados propios & $1,8 \%$ \\
\hline MacKay et al. [294] & $1,3 \%$ \\
\hline Platt et al. [317] & $2,86 \%$ \\
\hline Shimazaki et al. [228] & $2,4 \%$ \\
\hline Moghadamyeghaneh et al. [298] & $1,2 \%$ \\
\hline Artinyan $e t$ al. [295] & $3,1 \%$ \\
\hline Slankamenac et al. [296] & $1,8 \%$ \\
\hline McSorley et al. [292] & $1,0 \%$ \\
\hline
\end{tabular}


Hasta cuatro variables consiguieron la significación estadística tras el análisis univariante para el éxitus: la edad, la insuficiencia cardiaca, el riesgo anestésico alto y el tiempo quirúrgico. Pero sólo la presencia de insuficiencia cardiaca se mostró significativa tras llevar a cabo el análisis multivariante, con una OR de 64 (IC 95\% = 4,947 - 828,036), p = 0,001. Esto supone que los pacientes con insuficiencia cardiaca presentan, en nuestra muestra, 64 veces más riesgo de fallecer durante el postoperatorio que aquellos que no la padecen. $\mathrm{Al}$ igual que sucedía con la reintervención, tras una amplia revisión bibliográfica no hemos encontrado publicaciones con una metodología similar a la nuestra en las que se analice la relación existente entre los scores definitorios del estado nutricional e inflamatorio y la tasa de éxitus tras cirugía curativa para el CCR.

\subsection{7.- ESTANCIA POSTOPERATORIA PROLONGADA.}

Toda esta morbimortalidad, así como las características propias de cada paciente, el tipo de intervención realizada y el criterio del cirujano responsable condicionan la estancia postoperatoria. En nuestra serie la estancia mediana fue de 9 días (RIQ de 8 a 10), que está en rango con lo publicado por otros grupos, con medianas de entre 8 y 11 días [Tabla 28].

Hemos utilizado la mediana de estancia postoperatoria de nuestra muestra como punto de corte para transformar esta variable continua en dicotómica, ya que no hay publicaciones en la literatura que establezcan el número de días de pernocta a partir de los cuales se considera estancia postoperatoria prolongada. El criterio que hemos utilizado es, por tanto, arbitrario y sólo aplicable a nuestra serie. 


\section{Martín Bailón Cuadrado}

Tabla 28. Comparación de nuestros propios resultados con la literatura en cuanto a la estancia hospitalaria postoperatoria en pacientes intervenidos de CCR.

\begin{tabular}{|c|c|}
\hline COMPARACIÓN CON LA LITERATURA DE LA ESTANCIA POSTOPERATORIA \\
\hline Resultados propios & Mediana de 9 días (RIQ de 8 a 10) \\
\hline Platt et al. [317] $[$ Mediana de 11 días \\
\hline Gohil et al. $[141]$ & Mediana de 10 días (RIQ de 7 a 15) \\
\hline Slankamenac et al. $[296]$ & Mediana de 8 días (RIQ de 6 a 12) \\
\hline
\end{tabular}

La estancia postoperatoria prolongada resultó influenciada tras el análisis univariante por un total de nueve variables: la edad, la RT neoadyuvante, la localización de la tumoración, el tipo de intervención llevada a cabo, el tiempo quirúrgico, el PNI, el NLR, el PLR y la resultante A.

Sólo la edad y la localización de la tumoración resultaron significativas, tras el análisis multivariante, a la hora de predecir la estancia postoperatoria prolongada. Para la edad obtuvimos una OR de 1,047 (IC 95\% = 1,016 - 1,079), $\mathrm{p}=0$,003. La localización de la tumoración presentó una OR de 4,529 (IC 95\% = 2,058 - 9,966), $\mathrm{p}=0,0001$, lo que supone que las lesiones ubicadas en el recto tiene un riesgo cuatro veces y media mayor que aquellas localizadas en el colon de que su estancia postoperatoria se prolongue por encima de la mediana. Este resultado no es de extrañar, ya que hemos observado que la ubicación del tumor se comportaba como un factor de riesgo independiente para las complicaciones globales y para la fuga anastomótica, lo que justifica que estos pacientes sufran un ingreso postoperatorio por encima de la mediana de la muestra.

Gohil et al. [141] publicaron en 2014 un estudio retrospectivo llevado a cabo en el Pilgrim Hospital de Lincolnshire (Reino Unido) con 196 pacientes intervenidos entre 2010 y 2011 de cirugía curativa para el CCR. Analizaron la influencia de la albúmina, el NLR y otras 
variables sobre la estancia hospitalaria postoperatoria. Utilizaron la curva ROC para obtener puntos de corte para la albúmina $(34,5 \mathrm{~g} / \mathrm{L})$ y para el NLR $(4,3)$ y crear dos grupos para cada variable. La estancia hospitalaria postoperatoria presentó una mediana de 10 días (RIQ de 7 a 15), de tal modo que consideraron estancia postoperatoria prolongada por encima de 15 días. Observaron que tanto la albúmina como el NLR mostraron relevancia tras el análisis univariante, pero sólo la albúmina alcanzó significación estadística tras el multivariante, con una OR de 0,0472 (0,24-0,92), $\mathrm{p}=0,027$. Esto refleja que valores elevados de albúmina de forma preoperatoria actúan como factor protector frente a una estancia postoperatoria prolongada tras cirugía curativa para el CCR.

En comparación con el trabajo de Gohil et al. [141], nosotros sólo apreciamos significación estadística en la edad y en la localización del tumor para una estancia postoperatoria prolongada tras llevar a cabo el análisis multivariante. Ninguno de los scores examinados manifestó relevancia tras el multivariante, aunque el PNI, el NLR, el PLR y la resultante A fueron significativos en el análisis univariante.

Tanto para estos autores como para nosotros, el NLR fue relevante en el univariante, pero esta situación no se sostuvo tras realizar el análisis multivariante. En nuestra serie, la resultante A (influenciada de forma muy importante por el NLR) también resultó significativa tras el univariante.

Para estos autores tampoco alcanzó significación tras el multivariante el score analizado por ellos, pero sí lo hizo un valor analítico aislado como es la albúmina. Esta proteína forma parte de la composición de dos de los scores que hemos evaluado en este trabajo, como son el GPS y el PNI (alcanzando este último significación tras el univariante para la estancia postoperatoria prolongada). 


\section{Martín Bailón Cuadrado}

De nuevo queremos recordar la información recurrente que existe entre los distintos scores (al estar constituidos por variables relacionadas y, en algunos casos, idénticas), lo que hace que al analizar varios de ellos de forma simultánea, se pierda la capacidad de estimar la potencia que tendrían por separado para predecir la aparición de una determinada complicación. Hemos observado cómo hasta cuatro de los scores analizados en nuestra serie alcanzaron la significación estadística en el análisis univariante pero no mantuvieron esa condición tras el multivariante. Si hubiesen sido analizados por separado, posiblemente alguno o varios de ellos habrían continuado siendo significativos tras llevar a cabo el multivariante.

\section{5.- APLICABILIDAD.}

Las dos variables resultantes que hemos obtenido se pueden expresar en una fórmula como la combinación lineal de los scores utilizados, tras la aplicación de su correspondiente coeficiente a cada uno de ellos. Esto permite calcular el valor que mostraría un nuevo paciente desde los valores analíticos que componen cada uno de los scores. A su vez, esta fórmula se podría integrar en una página web o en una aplicación móvil de cara a poder estimar de forma rápida y sencilla el riesgo que presenta un paciente de padecer determinadas complicaciones postoperatorias, ya que hemos apreciado que la resultante B es un factor de riesgo independiente para la aparición de complicaciones globales y graves, para la fuga anastomótica y para la reintervención tras la cirugía curativa del CCR. 


\section{6.- LIMITACIONES.}

El presente estudio muestra una serie de limitaciones que se enumeran y discuten a continuación:

- Se trata de un trabajo unicéntrico y contamos con un escaso tamaño muestral, con 168 pacientes. Sin embargo otros trabajos con una metodología y planteamiento similares, diseñados con el objetivo de analizar las complicaciones postoperatorias tras la cirugía colorrectal, contaban con un número similar de pacientes, como MacKay et al. con 150, Gohil et al. con 196 o Shimazaki et al. con 85 [141,228,294].

- Se han aplicado unos estrictos criterios de inclusión y exclusión, de tal modo que hemos trabajado con una muestra de pacientes en los que existía un diagnóstico anatomopatológico de adenocarcinoma colorrectal, a los que se les ha realizado una cirugía curativa, y excluyendo aquellas intervenciones realizadas de forma urgente. Esto hace que los resultados obtenidos en este trabajo puedan no ser extrapolables a otra población más amplia de pacientes intervenidos de cirugía colorrectal.

- En este estudio hemos generado dos nuevos scores, cuyos resultados no han sido validados en otra muestra distinta procedente de la misma población. 
Martín Bailón Cuadrado 
6.- CONCLUSIONES. 
Martín Bailón Cuadrado 


\section{6.- CONCLUSIONES.}

1) Los pacientes intervenidos para cirugía curativa del cáncer colorrectal en el Hospital Universitario Río Hortega de Valladolid fueron predominantemente varones en la séptima y octava década de vida, con sobrepeso, hipertensión arterial, un riesgo anestésico grado II y sus lesiones se localizaron principalmente en el colon.

2) El estado nutricional e inflamatorio preoperatorio de nuestros pacientes, definido por los scores empleados, fue el siguiente: un 61,9\% presentaron un GPS de 0, el PNI mostró una media de 44,88, el NLR una mediana de 2,19 y el PLR una mediana de 135,28.

3) Se comprobó que estos cuatro scores están correlacionados entre sí y que poseen información reiterativa, lo que podría alterar su potencia de predicción desde el punto de vista estadístico.

4) Hemos creado dos nuevas variables (resultante A y resultante B) con el objetivo de definir con mayor precisión el estado nutricional e inflamatorio de nuestros pacientes. La resultante A se encontró influenciada mayoritariamente por el NLR y el PLR, mientras que la resultante B vino determinada fundamentalmente por el PNI y el GPS.

5) Un 32,7\% de los pacientes padecieron algún tipo de complicación (graves en un 10,7\%), con una mortalidad del 1,8\%. Un 19,6\% padecieron complicaciones infecciosas, un 7,4\% de los pacientes en los que se llevó a cabo anastomosis 


\section{Martín Bailón Cuadrado}

experimentaron una fuga anastomótica, un 6,0\% tuvieron que ser reoperados y un $52,4 \%$ presentaron una estancia postoperatoria prolongada.

6) El GPS, el NLR, el PLR y la resultante A no manifestaron una vinculación relevante con la aparición de ningún tipo de complicación postoperatoria.

7) Valores altos de PNI se comportaron como un factor protector independiente frente al desarrollo de complicaciones infecciosas.

8) La resultante B fue un factor de riesgo independiente de complicaciones globales y graves, de fuga anastomótica y de reintervención.

9) Ninguno de los seis scores utilizados se asoció al éxitus o a la estancia postoperatoria prolongada.

10) Hemos comprobado que la alteración del estado nutricional e inflamatorio preoperatorio de los pacientes oncológicos de nuestra muestra se asocia a una mayor incidencia de morbilidad postoperatoria. 


\section{7.- BIBLIOGRAFÍA.}


Martín Bailón Cuadrado 


\section{7.- BIBLIOGRAFÍA.}

1. Aran V, Victorino AP, Thuler LC, Ferreira CG, Levine JS, Ahnen DJ, et al. Colorectal Cancer: Epidemiology, Disease Mechanisms and Interventions to Reduce Onset and Mortality. Clin Colorectal Cancer. 2016 Feb;15(3):195-203.

2. Jemal A, Bray F, Center MM, Ferlay J, Ward E, Forman D. Global cancer statistics. CA Cancer J Clin. 2011 Mar;61(2):69-90.

3. Doubeni CA, Laiyemo AO, Major JM, Schootman M, Lian M, Park Y, et al. Socioeconomic status and the risk of colorectal cancer: an analysis of more than a half million adults in the National Institutes of Health-AARP Diet and Health Study. Cancer. 2012 Jul 15;118(14):3636-44.

4. Willett WC. Diet and cancer: an evolving picture. JAMA. 2005;293(2):233-4.

5. Doubeni CA, Major JM, Laiyemo AO, Schootman M, Zauber AG, Hollenbeck AR, et al. Contribution of behavioral risk factors and obesity to socioeconomic differences in colorectal cancer incidence. J Natl Cancer Inst. 2012 Sep 19;104(18):1353-62.

6. Jemal A, Siegel R, Xu J WE. Cancer statistics, 2010. CA Cancer J Clin. 2010;60(5):277-300.

7. Siegel RL, Miller KD, Jemal A. Cancer statistics, 2016. CA Cancer J Clin. 2016 Jan;66(1):7-30.

8. Davis DM, Marcet JE, Frattini JC, Prather AD, Mateka JJL, Nfonsam VN, et al. Is It Time to Lower the Recommended Screening Age for Colorectal Cancer? J Am Coll Surg. 2011 Sep;213(3):352-61.

9. Ahnen DJ, Wade SW, Jones WF, Sifri R, Mendoza Silveiras J, Greenamyer J, et al. The increasing incidence of young-onset colorectal cancer: a call to action. Mayo 


\section{Martín Bailón Cuadrado}

Clin Proc. 2014 Feb;89(2):216-24.

10. Chang DT, Pai RK, Rybicki LA, Dimaio MA, Limaye M, Jayachandran P, et al. Clinicopathologic and molecular features of sporadic early-onset colorectal adenocarcinoma: an adenocarcinoma with frequent signet ring cell differentiation, rectal and sigmoid involvement, and adverse morphologic features. Mod Pathol. 2012 Aug;25(8):1128-39.

11. Mork ME, You YN, Ying J, Bannon SA, Lynch PM, Rodriguez-Bigas MA, et al. High Prevalence of Hereditary Cancer Syndromes in Adolescents and Young Adults With Colorectal Cancer. J Clin Oncol. 2015 Nov 1;33(31):3544-9.

12. Mamazza J, Gordon PH. The changing distribution of large intestinal cancer. Dis Colon Rectum. 1982 Sep;25(6):558-62.

13. Ryerson AB, Eheman CR, Altekruse SF, Ward JW, Jemal A, Sherman RL et al. Annual Report to the Nation on the Status of Cancer, 1975-2012, featuring the increasing incidence of liver cancer. Cancer. 2016 May 1;122(9):1312-37.

14. Johns LE, Houlston RS. A systematic review and meta-analysis of familial colorectal cancer risk. Am J Gastroenterol. 2001 Oct;96(10):2992-3003.

15. Samadder NJ, Smith KR, Hanson H, Pimentel R, Wong J, Boucher K, et al. Increased Risk of Colorectal Cancer Among Family Members of All Ages, Regardless of Age of Index Case at Diagnosis. Clin Gastroenterol Hepatol. 2015 Dec;13(13):2305-2311.e2.

16. Lieberman DA, Holub JL, Moravec MD, Eisen GM, Peters D, Morris CD. Prevalence of colon polyps detected by colonoscopy screening in asymptomatic black and white patients. JAMA. 2008 Sep 24;300(12):1417-22.

17. Schroy PC, Coe A, Chen CA, O’Brien MJ, Heeren TC. Prevalence of advanced colorectal neoplasia in white and black patients undergoing screening colonoscopy 
in a safety-net hospital. Ann Intern Med. 2013 Jul 2;159(1):13-20.

18. Brenner H, Hoffmeister M, Arndt V, Haug U. Gender differences in colorectal cancer: implications for age at initiation of screening. Br J Cancer. 2007 Mar 12;96(5):828-31.

19. Ferlitsch M, Reinhart K, Pramhas S, Wiener C, Gal O, Bannert C, et al. Sex-specific prevalence of adenomas, advanced adenomas, and colorectal cancer in individuals undergoing screening colonoscopy. JAMA. 2011 Sep 28;306(12):1352-8.

20. Nguyen SP, Bent S, Chen YH TJ. Gender as a risk factor for advanced neoplasia and colorectal cancer: a systematic review and meta-analysis. Clin Gastroenterol Hepatol. 2009;7(6):676-81.

21. Regula J, Rupinski M, Kraszewska E, Polkowski M, Pachlewski J, Orlowska J, et al. Colonoscopy in colorectal-cancer screening for detection of advanced neoplasia. $\mathrm{N}$ Engl J Med. 2006 Nov 2;355(18):1863-72.

22. Botteri E, Iodice S, Bagnardi V, Raimondi S, Lowenfels AB, Maisonneuve P, et al. Smoking and Colorectal Cancer: A Meta-analysis. JAMA. 2008 Dec 17;300(23):2765-78.

23. Lynch HT, Lynch PM, Lanspa SJ, Snyder CL, Lynch JF, Boland CR. Review of the Lynch syndrome: history, molecular genetics, screening, differential diagnosis, and medicolegal ramifications. Clin Genet. 2009 Jul;76(1):1-18.

24. Ligtenberg MJ, Kuiper RP, Chan TL, Goossens M, Hebeda KM, Voorendt M, et al. Heritable somatic methylation and inactivation of MSH2 in families with Lynch syndrome due to deletion of the 3' exons of TACSTD1. Nat Genet. 2009;41(1):1127.

25. Kuiper RP, Vissers LELM, Venkatachalam R, Bodmer D, Hoenselaar E, Goossens M, et al. Recurrence and variability of germline EPCAM deletions in Lynch 


\section{Martín Bailón Cuadrado}

syndrome. Hum mutat. 2011 Apr;32(4):407-14.

26. Tannergård P, Liu T, Weger A, Nordenskjöld M, Lindblom A. Tumorigenesis in colorectal tumors from patients with hereditary non-polyposis colorectal cancer. Hum Genet. 1997 Nov;101(1):51-5.

27. Peltomäki P, Lothe RA, Aaltonen LA, Pylkkänen L, Nyström-Lahti M, Seruca R, et al. Microsatellite instability is associated with tumors that characterize the hereditary non-polyposis colorectal carcinoma syndrome. Cancer Res. 1993 Dec 15;53(24):5853-5.

28. Hampel H, Stephens JA, Pukkala E, Sankila R, Aaltonen LA, Mecklin J-P, et al. Cancer Risk in Hereditary Nonpolyposis Colorectal Cancer Syndrome: Later Age of Onset. Gastroenterology. 1996;129(2):415-21.

29. Bonadona V, Bonaïti B, Olschwang S, Grandjouan S, Huiart L, Longy M, et al. Cancer risks associated with germline mutations in MLH1, MSH2, and MSH6 genes in Lynch syndrome. JAMA. 2011 Jun 8;305(22):2304-10.

30. Watson P, Vasen HFA, Mecklin J-P, Bernstein I, Aarnio M, Järvinen HJ, et al. The risk of extra-colonic, extra-endometrial cancer in the Lynch syndrome. Int J cancer. 2008 Jul 15;123(2):444-9.

31. Vasen HF, Watson P, Mecklin JP LH. New clinical criteria for hereditary nonpolyposis colorectal cancer (HNPCC, Lynch syndrome) proposed by the International Collaborative group on HNPCC. Gastroenterology. 1999;116(6):14536.

32. Umar A, Boland CR, Terdiman JP, Syngal S, de la Chapelle A, Rüschoff J, et al. Revised Bethesda Guidelines for hereditary nonpolyposis colorectal cancer (Lynch syndrome) and microsatellite instability. J Natl Cancer Inst. 2004 Feb 18;96(4):2618. 
33. Balmaña J, Balaguer F, Cervantes A, Arnold D, ESMO Guidelines Working Group. Familial risk-colorectal cancer: ESMO Clinical Practice Guidelines. Ann Oncol. 2013 Oct;24 Suppl 6:vi73-80.

34. Vasen HFA, Blanco I, Aktan-Collan K, Gopie JP, Alonso A, Aretz S, et al. Revised guidelines for the clinical management of Lynch syndrome (HNPCC): recommendations by a group of European experts. Gut. 2013 Jun;62(6):812-23.

35. Parry S, Win AK, Parry B, Macrae FA, Gurrin LC, Church JM, et al. Metachronous colorectal cancer risk for mismatch repair gene mutation carriers: the advantage of more extensive colon surgery. Gut. 2011 Jul 1;60(7):950-7.

36. Bisgaard ML, Fenger K, Bülow S, Niebuhr E, Mohr J. Familial adenomatous polyposis (FAP): frequency, penetrance, and mutation rate. Hum Mutat. 1994;3(2):121-5.

37. Björk J, Akerbrant H, Iselius L, Alm T, Hultcrantz R. Epidemiology of familial adenomatous polyposis in Sweden: changes over time and differences in phenotype between males and females. Scand J Gastroenterol. 1999 Dec;34(12):1230-5.

38. Lipton L, Tomlinson I. The genetics of FAP and FAP-like syndromes. Fam Cancer. 2006;5(3):221-6.

39. Bertario L, Russo A, Sala P, Varesco L, Giarola M, Mondini P et al. Multiple Approach to the Exploration of Genotype-Phenotype Correlations in Familial Adenomatous Polyposis. J Clin Oncol. 2003 May 1;21(9):1698-707.

40. Vasen HFA, Moslein G, Alonso A, Aretz S, Bernstein I, Bertario L, et al. Guidelines for the clinical management of familial adenomatous polyposis (FAP). Gut. 2008 May 1;57(5):704-13.

41. Sieber OM, Lipton L, Crabtree M, Heinimann K, Fidalgo P, Phillips RKS, et al. Multiple Colorectal Adenomas, Classic Adenomatous Polyposis, and Germ-Line 


\section{Martín Bailón Cuadrado}

Mutations in MYH. N Engl J Med. 2003;348(9):791-9.

42. Terdiman JP. MYH-associated disease: attenuated adenomatous polyposis of the colon is only part of the story. Gastroenterol . 2009;137(6):1883-6.

43. Vogt S, Jones N, Christian D, Engel C, Nielsen M, Kaufmann A, et al. Expanded Extracolonic Tumor Spectrum in MUTYH-Associated Polyposis. Gastroenterology. 2009;137(6):1976-1985.e10.

44. Sayed MG, Ahmed AF, Ringold JR, Anderson ME, Bair JL, Mitros FA, et al. Germline SMAD4 or BMPR1A mutations and phenotype of juvenile polyposis. Ann Sug Oncol. 2002;9(9):901-6.

45. Schreibman IR, Baker M, Amos C, McGarrity TJ. The hamartomatous polyposis syndromes: a clinical and molecular review. Am J Gastroenterol. 2005 Feb;100(2):476-90.

46. Aretz S, Stienen D, Uhlhaas S, Stolte M, Entius MM, Loff S et al. High proportion of large genomic deletions and a genotype phenotype update in 80 unrelated families with juvenile polyposis syndrome. J Med Genet. 2007;44(11):702-9.

47. Westerman AM, Entius MM, de Baar E, Boor PP, Koole R, van Velthuysen ML, et al. Peutz-Jeghers syndrome: 78-year follow-up of the original family. Lancet. 1999;353(9160):1211-5.

48. Hearle N, Schumacher V, Menko FH, Olschwang S, Boardman LA, Gille JJ et al. Frequency and spectrum of cancers in the Peutz-Jeghers syndrome. Clin Cancer Res. 2006;12(10):3209-15.

49. Moiel D, Thompson J. Early detection of colon cancer-the kaiser permanente northwest 30-year history: how do we measure success? Is it the test, the number of tests, the stage, or the percentage of screen-detected patients? Perm J. 2011;15(4):30-8. 
50. Aldridge MC, Phillips RK, Hittinger R, Fry JS, Fielding LP. Influence of tumour site on presentation, management and subsequent outcome in large bowel cancer. $\mathrm{Br} \mathrm{J}$ Surg. 1986 Aug;73(8):663-70.

51. Runkel NS, Schlag P, Schwarz V, Herfarth C. Outcome after emergency surgery for cancer of the large intestine. Br J Surg. 1991 Feb;78(2):183-8.

52. Beart RW, Melton LJ, Maruta M, Dockerty MB, Frydenberg HB, O’Fallon WM. Trends in right and left-sided colon cancer. Dis Colon Rectum. 1983 Jun;26(6):3938.

53. Farrands PA, Hardcastle JD. Colorectal screening by a self-completion questionnaire. Gut. 1984 May;25(5):445-7.

54. Acher PL, Al-Mishlab T, Rahman M, Bates T. Iron-deficiency anaemia and delay in the diagnosis of colorectal cancer. Color Dis. 2003 Mar;5(2):145-8.

55. Beart RW, Steele GD, Menck HR, Chmiel JS, Ocwieja KE, Winchester DP. Management and survival of patients with adenocarcinoma of the colon and rectum: a national survey of the Commission on Cancer. J Am Coll Surg. 1995 Sep;181(3):225-36.

56. de Dombal FT, Matharu SS, Staniland JR, Wilson DH, MacAdam WA, Gunn AA, et al. Presentation of cancer to hospital as “acute abdominal pain”. Br J Surg. 1980 Jun;67(6):413-6.

57. Ohman U. Prognosis in patients with obstructing colorectal carcinoma. Am J Surg. 1982 Jun;143(6):742-7.

58. Wolmark N, Wieand HS, Rockette HE, Fisher B, Glass A, Lawrence W, et al. The prognostic significance of tumor location and bowel obstruction in Dukes B and C colorectal cancer. Findings from the NSABP clinical trials. Ann Surg. 1983 Dec;198(6):743-52. 


\section{Martín Bailón Cuadrado}

59. Saegesser F, Sandblom P. Ischemic lesions of the distended colon: a complication of obstructive colorectal cancer. Am J Surg. 1975 Mar;129(3):309-15.

60. Umpleby HC, Williamson RC. Survival in acute obstructing colorectal carcinoma. Dis Colon Rectum. 1984 May;27(5):299-304.

61. Moreno CC, Mittal PK, Sullivan PS, Rutherford R, Staley CA, Cardona K, et al. Colorectal Cancer Initial Diagnosis: Screening Colonoscopy, Diagnostic Colonoscopy, or Emergent Surgery, and Tumor Stage and Size at Initial Presentation. Clin Colorectal Cancer. 2016;15(1):67-73.

62. Saidi HS, Karuri D, Nyaim EO. Correlation of clinical data, anatomical site and disease stage in colorectal cancer. East Afr Med J. 2008 Jun;85(6):259-62.

63. Sinatra MA, St John DJ, Young GP. Interference of plant peroxidases with guaiacbased fecal occult blood tests is avoidable. Clin Chem. 1999 Jan;45(1):123-6.

64. Parente F, Bargiggia S, Boemo C, Vailati C, Bonoldi E, Ardizzoia A, et al. Anatomic distribution of cancers and colorectal adenomas according to age and sex and relationship between proximal and distal neoplasms in an i-FOBT-positive averagerisk Italian screening cohort. Int J Colorectal Dis. 2014 Jan;29(1):57-64.

65. Levin B, Lieberman DA, McFarland B, Andrews KS, Brooks D, Bond J, et al. Screening and Surveillance for the Early Detection of Colorectal Cancer and Adenomatous Polyps, 2008: A Joint Guideline From the American Cancer Society, the US Multi-Society Task Force on Colorectal Cancer, and the American College of Radiology. Gastroenterology. 2008 May;134(5):1570-95.

66. Hewitson P, Glasziou P, Irwig L, Towler B, Watson E. Screening for colorectal cancer using the faecal occult blood test, Hemoccult. Cochrane database Syst Rev. 2007;(1):CD001216.

67. Hundt S, Haug U, Brenner H. Comparative evaluation of immunochemical fecal 
occult blood tests for colorectal adenoma detection. Ann Intern Med. 2009 Feb 3;150(3):162-9.

68. Levi Z, Birkenfeld S, Vilkin A, Bar-Chana M, Lifshitz I, Chared M, et al. A higher detection rate for colorectal cancer and advanced adenomatous polyp for screening with immunochemical fecal occult blood test than guaiac fecal occult blood test, despite lower compliance rate. A prospective, controlled, feasibility study. Int J cancer. 2011 May 15;128(10):2415-24.

69. Luo Y-X, Chen D-K, Song S-X, Wang L, Wang J-P. Aberrant methylation of genes in stool samples as diagnostic biomarkers for colorectal cancer or adenomas: a metaanalysis. Int J Clin Pract. 2011 Dec;65(12):1313-20.

70. Imperiale TF, Ransohoff DF, Itzkowitz SH, Levin TR, Lavin P, Lidgard GP, et al. Multitarget stool DNA testing for colorectal-cancer screening. N Engl J Med. 2014 Apr 3;370(14):1287-97.

71. Winawer SJ, Stewart ET, Zauber AG, Bond JH, Ansel H, Waye JD, et al. A comparison of colonoscopy and double-contrast barium enema for surveillance after polypectomy. National Polyp Study Work Group. N Engl J Med. 2000 Jun $15 ; 342(24): 1766-72$.

72. Toma J, Paszat LF, Gunraj N, Rabeneck L. Rates of new or missed colorectal cancer after barium enema and their risk factors: a population-based study. Am J Gastroenterol. 2008 Dec;103(12):3142-8.

73. Walter LC, de Garmo P, Covinsky KE. Association of older age and female sex with inadequate reach of screening flexible sigmoidoscopy. Am J Med. 2004;116(3):1748.

74. Gatto NM, Frucht H, Sundararajan V, Jacobson JS, Grann VR, Neugut AI. Risk of perforation after colonoscopy and sigmoidoscopy: a population-based study. J Natl 


\section{Martín Bailón Cuadrado}

Cancer Inst. 2003 Feb 5;95(3):230-6.

75. Schoenfeld P, Cash B, Flood A, Dobhan R, Eastone J, Coyle W, et al. Colonoscopic screening of average-risk women for colorectal neoplasia. N Engl J Med. 2005 May 19;352(20):2061-8.

76. van Rijn JC, Reitsma JB, Stoker J, Bossuyt PM, van Deventer SJ, Dekker E. Polyp miss rate determined by tandem colonoscopy: a systematic review. Am J Gastroenterol. 2006 Feb;101(2):343-50.

77. Iqbal CW, Cullinane DC, Schiller HJ, Sawyer MD, Zietlow SP, Farley DR. Surgical management and outcomes of 165 colonoscopic perforations from a single institution. Arch Surg. 2008 Jul;143(7):701-6-7.

78. Nishihara R, Wu K, Lochhead P, Morikawa T, Liao X, Qian ZR, et al. Long-term colorectal-cancer incidence and mortality after lower endoscopy. N Engl J Med. 2013 Sep 19;369(12):1095-105.

79. Brenner H, Chang-Claude J, Jansen L, Knebel P, Stock C HM. Reduced risk of colorectal cancer up to 10 years after screening, surveillance, or diagnostic colonoscopy. Gastroenterology. 2014;146(3):709-17.

80. Brenner H, Chang-Claude J, Seiler CM, Rickert A, Hoffmeister M. Protection from colorectal cancer after colonoscopy: a population-based, case-control study. Ann Intern Med. 2011 Jan 4;154(1):22-30.

81. Baxter NN, Goldwasser MA, Paszat LF, Saskin R, Urbach DR, Rabeneck L. Association of colonoscopy and death from colorectal cancer. Ann Intern Med. 2009 Jan 6;150(1):1-8.

82. Singh H, Nugent Z, Demers AA, Kliewer EV, Mahmud SM BC. The reduction in colorectal cancer mortality after colonoscopy varies by site of the cancer. Gastroenterology. 2010;139(4):1128-37. 
83. Pickhardt PJ, Choi JR, Hwang I, Butler JA, Puckett ML, Hildebrandt HA, et al. Computed tomographic virtual colonoscopy to screen for colorectal neoplasia in asymptomatic adults. N Engl J Med. 2003 Dec 4;349(23):2191-200.

84. Zalis ME, Blake MA, Cai W, Hahn PF, Halpern EF, Kazam IG, et al. Diagnostic accuracy of laxative-free computed tomographic colonography for detection of adenomatous polyps in asymptomatic adults: a prospective evaluation. Ann Intern Med. 2012 May 15;156(10):692-702.

85. Johnson CD, Chen M-H, Toledano AY, Heiken JP, Dachman A, Kuo MD, et al. Accuracy of CT colonography for detection of large adenomas and cancers. N Engl J Med. 2008 Sep 18;359(12):1207-17.

86. Stoop EM, de Haan MC, de Wijkerslooth TR, Bossuyt PM, van Ballegooijen M, Nio CY, et al. Participation and yield of colonoscopy versus non-cathartic CT colonography in population-based screening for colorectal cancer: a randomised controlled trial. Lancet Oncol. 2012 Jan;13(1):55-64.

87. Kim DH, Pickhardt PJ, Taylor AJ, Leung WK, Winter TC, Hinshaw JL, et al. CT colonography versus colonoscopy for the detection of advanced neoplasia. N Engl J Med. 2007 Oct 4;357(14):1403-12.

88. Benson AB, Venook AP, Cederquist L, Chan E, Chen Y-J, Cooper HS, et al. Colon Cancer, Version 1.2017, NCCN Clinical Practice Guidelines in Oncology. J Natl Compr Canc Netw. 2017 Mar;15(3):370-98.

89. Benson AB, Venook AP, Bekaii-Saab T, Chan E, Chen Y-J, Cooper HS, et al. Rectal Cancer, Version 2.2015. J Natl Compr Canc Netw. 2015 Jun;13(6):719-28; quiz 728.

90. Nagata K, Endo S, Kudo S, Kitanosono T, Kushihashi T. CT air-contrast enema as a preoperative examination for colorectal cancer. Dig Surg. 2004;21(5-6):352-8.

91. Utano K, Endo K, Togashi K, Sasaki J, Kawamura HJ, Horie H, et al. Preoperative 


\section{Martín Bailón Cuadrado}

T staging of colorectal cancer by CT colonography. Dis Colon Rectum. 2008 Jun;51(6):875-81.

92. Filippone A, Ambrosini R, Fuschi M, Marinelli T, Genovesi D, Bonomo L. Preoperative $\mathrm{T}$ and $\mathrm{N}$ staging of colorectal cancer: accuracy of contrast-enhanced multi-detector row CT colonography--initial experience. Radiology. 2004 Apr;231(1):83-90.

93. Flor N, Mezzanzanica M, Rigamonti P, Rocco EG, Bosari S, Ceretti AP, et al. Contrast-enhanced computed tomography colonography in preoperative distinction between T1-T2 and T3-T4 staging of colon cancer. Acad Radiol. 2013 May;20(5):590-5.

94. Mainenti PP, Cirillo LC, Camera L, Persico F, Cantalupo T, Pace L, et al. Accuracy of single phase contrast enhanced multidetector CT colonography in the preoperative staging of colo-rectal cancer. Eur J Radiol. 2006 Dec;60(3):453-9.

95. Zerhouni EA, Rutter C, Hamilton SR, Balfe DM, Megibow AJ, Francis IR, et al. CT and MR imaging in the staging of colorectal carcinoma: report of the Radiology Diagnostic Oncology Group II. Radiology. 1996 Aug;200(2):443-51.

96. Volders D, Bols A, Haspeslagh M, Coenegrachts K. Model-based iterative reconstruction and adaptive statistical iterative reconstruction techniques in abdominal CT: comparison of image quality in the detection of colorectal liver metastases. Radiology. 2013 Nov;269(2):469-74.

97. Brown G, Kirkham A, Williams GT, Bourne M, Radcliffe AG, Sayman J, et al. High-resolution MRI of the anatomy important in total mesorectal excision of the rectum. AJR Am J Roentgenol. 2004 Feb;182(2):431-9.

98. Al-Sukhni E, Milot L, Fruitman M, Beyene J, Victor JC, Schmocker S, et al. Diagnostic accuracy of MRI for assessment of T category, lymph node metastases, 
and circumferential resection margin involvement in patients with rectal cancer: a systematic review and meta-analysis. Ann Surg Oncol. 2012 Jul;19(7):2212-23.

99. Beets-Tan RGH, Beets GL. Rectal cancer: review with emphasis on MR imaging. Radiology. 2004 Aug;232(2):335-46.

100. Gowdra Halappa V, Corona Villalobos CP, Bonekamp S, Gearhart SL, Efron J, Herman J, et al. Rectal imaging: part 1, High-resolution MRI of carcinoma of the rectum at 3 T. AJR Am J Roentgenol. 2012 Jul;199(1):W35-42.

101. Taylor FGM, Quirke P, Heald RJ, Moran BJ, Blomqvist L, Swift IR, et al. Preoperative magnetic resonance imaging assessment of circumferential resection margin predicts disease-free survival and local recurrence: 5-year follow-up results of the MERCURY study. J Clin Oncol. 2014 Jan 1;32(1):34-43.

102. Brown G, Richards CJ, Bourne MW, Newcombe RG, Radcliffe AG, Dallimore NS, et al. Morphologic predictors of lymph node status in rectal cancer with use of highspatial-resolution MR imaging with histopathologic comparison. Radiology. 2003 May;227(2):371-7.

103. Kim CK, Kim SH, Chun HK, Lee W-Y, Yun S-H, Song S-Y, et al. Preoperative staging of rectal cancer: accuracy of 3-Tesla magnetic resonance imaging. Eur Radiol. 2006 May;16(5):972-80.

104. Muhi A, Ichikawa T, Motosugi U, Sou H, Nakajima H, Sano K, et al. Diagnosis of colorectal hepatic metastases: comparison of contrast-enhanced CT, contrastenhanced US, superparamagnetic iron oxide-enhanced MRI, and gadoxetic acidenhanced MRI. J Magn Reson Imaging. 2011 Aug;34(2):326-35.

105. Kim YK, Lee YH, Kwak HS, Kim CS, Han YM. Detection of liver metastases: Gadoxetic acid-enhanced three-dimensional MR imaging versus ferucarbotranenhanced MR imaging. Eur J Radiol. 2010 Jan;73(1):131-6. 


\section{Martín Bailón Cuadrado}

106. Puli SR, Bechtold ML, Reddy JBK, Choudhary A, Antillon MR, Brugge WR. How good is endoscopic ultrasound in differentiating various $\mathrm{T}$ stages of rectal cancer? Meta-analysis and systematic review. Ann Surg Oncol. 2009 Feb;16(2):254-65.

107. Lin S, Luo G, Gao X, Shan H, Li Y, Zhang R, et al. Application of endoscopic sonography in preoperative staging of rectal cancer: six-year experience. J Ultrasound Med. 2011 Aug;30(8):1051-7.

108. Fernández-Esparrach G, Ayuso-Colella JR, Sendino O, Pagés M, Cuatrecasas M, Pellisé M, et al. EUS and magnetic resonance imaging in the staging of rectal cancer: a prospective and comparative study. Gastrointest Endosc. 2011 Aug;74(2):347-54.

109. Zhu J, Huang P, Ding K, Zhang X, Liu C, Liu X, et al. [Clinical value of radial endorectal ultrasound in the assessment of preoperative staging of rectal carcinoma]. Zhonghua Zhong Liu Za Zhi. 2013 Feb;35(2):148-53.

110. Granero-Castro P, Muñoz E, Frasson M, García-Granero A, Esclapez P, Campos S, et al. Evaluation of mesorectal fascia in mid and low anterior rectal cancer using endorectal ultrasound is feasible and reliable: a comparison with MRI findings. Dis Colon Rectum. 2014 Jun;57(6):709-14.

111. Halefoglu A-M, Yildirim S, Avlanmis O, Sakiz D, Baykan A. Endorectal ultrasonography versus phased-array magnetic resonance imaging for preoperative staging of rectal cancer. World J Gastroenterol. 2008 Jun 14;14(22):3504-10.

112. Ünsal B, Alper E, Baydar B, Arabul M, Aslan F, Çelık M, et al. The efficacy of endoscopic ultrasonography in local staging of rectal tumors. Turk J Gastroenterol. 2012;23(5):530-4.

113. Marone P, de Bellis M, D’Angelo V, Delrio P, Passananti V, Di Girolamo E, et al. Role of endoscopic ultrasonography in the loco-regional staging of patients with rectal cancer. World J Gastrointest Endosc. 2015 Jun 25;7(7):688-701. 
114. Nelson H, Petrelli N, Carlin A, Couture J, Fleshman J, Guillem J, et al. Guidelines 2000 for colon and rectal cancer surgery. J Natl Cancer Inst. 2001 Apr 18;93(8):58396.

115. Engstrom PF, Arnoletti JP, Benson AB, Chen Y-J, Choti MA, Cooper HS, et al. NCCN Clinical Practice Guidelines in Oncology: colon cancer. J Natl Compr Canc Netw. 2009 Sep;7(8):778-831.

116. Chang GJ, Rodriguez-Bigas MA, Skibber JM, Moyer VA. Lymph node evaluation and survival after curative resection of colon cancer: systematic review. J Natl Cancer Inst. 2007 Mar 21;99(6):433-41.

117. Monson JRT, Weiser MR, Buie WD, Chang GJ, Rafferty JF, Buie WD, et al. Practice parameters for the management of rectal cancer (revised). Dis Colon Rectum. 2013 May;56(5):535-50.

118. Fitzgerald TL, Brinkley J, Zervos EE. Pushing the envelope beyond a centimeter in rectal cancer: oncologic implications of close, but negative margins. J Am Coll Surg. 2011 Nov;213(5):589-95.

119. Kim Y-W, Kim N-K, Min B-S, Huh H, Kim J-S, Kim J-Y, et al. Factors associated with anastomotic recurrence after total mesorectal excision in rectal cancer patients. J Surg Oncol. 2009 Jan 1;99(1):58-64.

120. Leo E, Belli F, Miceli R, Mariani L, Gallino G, Battaglia L, et al. Distal clearance margin of $1 \mathrm{~cm}$ or less: a safe distance in lower rectum cancer surgery. Int J Colorectal Dis. 2009 Mar;24(3):317-22.

121. de la Fuente SG, Mantyh CR. Reconstruction techniques after proctectomy: what's the best? Clin Colon Rectal Surg. 2007 Aug;20(3):221-30.

122. Hüttner FJ, Tenckhoff S, Jensen K, Uhlmann L, Kulu Y, Büchler MW, et al. Metaanalysis of reconstruction techniques after low anterior resection for rectal cancer. 


\section{Martín Bailón Cuadrado}

Br J Surg. 2015 Jun;102(7):735-45.

123. Heald RJ, Husband EM, Ryall RD. The mesorectum in rectal cancer surgery--the clue to pelvic recurrence? Br J Surg. 1982 Oct;69(10):613-6.

124. Nagtegaal ID, Quirke P. What is the role for the circumferential margin in the modern treatment of rectal cancer? J Clin Oncol. 2008 Jan 10;26(2):303-12.

125. Gosens MJEM, Klaassen RA, Tan-Go I, Rutten HJT, Martijn H, van den Brule AJC, et al. Circumferential margin involvement is the crucial prognostic factor after multimodality treatment in patients with locally advanced rectal carcinoma. Clin Cancer Res. 2007 Nov 15;13(22 Pt 1):6617-23.

126. Park JS, Huh JW, Park YA, Cho YB, Yun SH, Kim HC, et al. A circumferential resection margin of $1 \mathrm{~mm}$ is a negative prognostic factor in rectal cancer patients with and without neoadjuvant chemoradiotherapy. Dis Colon Rectum. 2014 Aug;57(8):933-40.

127. Lin H-H, Lin J-K, Lin C-C, Lan Y-T, Wang H-S, Yang S-H, et al. Circumferential margin plays an independent impact on the outcome of rectal cancer patients receiving curative total mesorectal excision. Am J Surg. 2013 Nov;206(5):771-7.

128. Tilney HS, Rasheed S, Northover JM, Tekkis PP. The influence of circumferential resection margins on long-term outcomes following rectal cancer surgery. Dis Colon Rectum. 2009 Oct;52(10):1723-9.

129. Rullier E, Denost Q, Vendrely V, Rullier A, Laurent C. Low Rectal Cancer. Dis Colon Rectum. 2013 May;56(5):560-7.

130. Marks JH, Valsdottir EB, Rather AA, Nweze IC, Newman DA, Chernick MR. Fewer than 12 lymph nodes can be expected in a surgical specimen after high-dose chemoradiation therapy for rectal cancer. Dis Colon Rectum. 2010 Jul;53(7):1023-9.

131. Morcos B, Baker B, Al Masri M, Haddad H, Hashem S. Lymph node yield in rectal 
cancer surgery: effect of preoperative chemoradiotherapy. Eur J Surg Oncol. 2010 Apr;36(4):345-9.

132. Miller ED, Robb BW, Cummings OW, Johnstone PAS. The effects of preoperative chemoradiotherapy on lymph node sampling in rectal cancer. Dis Colon Rectum. 2012 Sep;55(9):1002-7.

133. Govindarajan A, Gönen M, Weiser MR, Shia J, Temple LK, Guillem JG, et al. Challenging the feasibility and clinical significance of current guidelines on lymph node examination in rectal cancer in the era of neoadjuvant therapy. J Clin Oncol. 2011 Dec 1;29(34):4568-73.

134. de Campos-Lobato LF, Stocchi L, de Sousa JB, Buta M, Lavery IC, Fazio VW, et al. Less than 12 nodes in the surgical specimen after total mesorectal excision following neoadjuvant chemoradiation: it means more than you think! Ann Surg Oncol. 2013 Oct;20(11):3398-406.

135. Zheng Z, Jemal A, Lin CC, Hu C-Y, Chang GJ. Comparative effectiveness of laparoscopy vs open colectomy among nonmetastatic colon cancer patients: an analysis using the National Cancer Data Base. J Natl Cancer Inst. 2015 Mar;107(3):dju491.

136. Wilson MZ, Hollenbeak CS, Stewart DB. Laparoscopic colectomy is associated with a lower incidence of postoperative complications than open colectomy: a propensity score-matched cohort analysis. Colorectal Dis. 2014 May;16(5):382-9.

137. Braga M, Frasson M, Vignali A, Zuliani W, Civelli V, Di Carlo V. Laparoscopic vs. open colectomy in cancer patients: long-term complications, quality of life, and survival. Dis Colon Rectum. 2005 Dec;48(12):2217-23.

138. Deijen CL, Vasmel JE, de Lange-de Klerk ESM, Cuesta MA, Coene P-PLO, Lange JF, et al. Ten-year outcomes of a randomised trial of laparoscopic versus open 


\section{Martín Bailón Cuadrado}

surgery for colon cancer. Surg Endosc. 2017 Oct 12;31(6):2607-15.

139. Kuhry E, Schwenk WF, Gaupset R, Romild U, Bonjer HJ. Long-term results of laparoscopic colorectal cancer resection. Cochrane database Syst Rev. 2008 Apr 16;(2):CD003432.

140. Sauer R, Becker H, Hohenberger W, Rödel C, Wittekind C, Fietkau R, et al. Preoperative versus postoperative chemoradiotherapy for rectal cancer. N Engl J Med. 2004 Oct 21;351(17):1731-40.

141. Gohil R, Rishi M, Tan BHL. Pre-operative serum albumin and neutrophillymphocyte ratio are associated with prolonged hospital stay following colorectal cancer surgery. Br J Med Med Res. 2014 Jan 1;4(1):481-7.

142. Park J, Yoon SM, Yu CS, Kim JH, Kim TW, Kim JC. Randomized phase 3 trial comparing preoperative and postoperative chemoradiotherapy with capecitabine for locally advanced rectal cancer. Cancer. 2011 Aug 15;117(16):3703-12.

143. Gérard J-P, Conroy T, Bonnetain F, Bouché O, Chapet O, Closon-Dejardin M-T, et al. Preoperative radiotherapy with or without concurrent fluorouracil and leucovorin in T3-4 rectal cancers: results of FFCD 9203. J Clin Oncol. 2006 Oct 1;24(28):4620_ 5.

144. Bosset J-F, Calais G, Mineur L, Maingon P, Radosevic-Jelic L, Daban A, et al. Enhanced tumorocidal effect of chemotherapy with preoperative radiotherapy for rectal cancer: preliminary results--EORTC 22921. J Clin Oncol. 2005 Aug 20;23(24):5620-7.

145. Ceelen WP, Van Nieuwenhove Y, Fierens K. Preoperative chemoradiation versus radiation alone for stage II and III resectable rectal cancer. Cochrane database Syst Rev. 2009;(1):CD006041.

146. Bujko K, Nowacki MP, Nasierowska-Guttmejer A, Michalski W, Bebenek M, Kryj 
M. Long-term results of a randomized trial comparing preoperative short-course radiotherapy with preoperative conventionally fractionated chemoradiation for rectal cancer. Br J Surg. 2006 Oct;93(10):1215-23.

147. Ngan SY, Burmeister B, Fisher RJ, Solomon M, Goldstein D, Joseph D, et al. Randomized trial of short-course radiotherapy versus long-course chemoradiation comparing rates of local recurrence in patients with T3 rectal cancer: Trans-Tasman Radiation Oncology Group trial 01.04. J Clin Oncol. 2012 Nov 1;30(31):3827-33.

148. Hofheinz R-D, Wenz F, Post S, Matzdorff A, Laechelt S, Hartmann JT, et al. Chemoradiotherapy with capecitabine versus fluorouracil for locally advanced rectal cancer: a randomised, multicentre, non-inferiority, phase 3 trial. Lancet Oncol. 2012 Jun;13(6):579-88.

149. O'Connell MJ, Colangelo LH, Beart RW, Petrelli NJ, Allegra CJ, Sharif S, et al. Capecitabine and oxaliplatin in the preoperative multimodality treatment of rectal cancer: surgical end points from National Surgical Adjuvant Breast and Bowel Project trial R-04. J Clin Oncol. 2014 Jun 20;32(18):1927-34.

150. Aschele C, Cionini L, Lonardi S, Pinto C, Cordio S, Rosati G, et al. Primary tumor response to preoperative chemoradiation with or without oxaliplatin in locally advanced rectal cancer: pathologic results of the STAR-01 randomized phase III trial. J Clin Oncol. 2011 Jul 10;29(20):2773-80.

151. Allegra CJ, Yothers G, O'Connell MJ, Beart RW, Wozniak TF, Pitot HC, et al. Neoadjuvant 5-FU or Capecitabine Plus Radiation With or Without Oxaliplatin in Rectal Cancer Patients: A Phase III Randomized Clinical Trial. J Natl Cancer Inst. 2015 Nov;107(11):djv248.

152. Gérard J-P, Azria D, Gourgou-Bourgade S, Martel-Lafay I, Hennequin C, Etienne P-L, et al. Clinical outcome of the ACCORD 12/0405 PRODIGE 2 randomized 


\section{Martín Bailón Cuadrado}

trial in rectal cancer. J Clin Oncol. 2012 Dec 20;30(36):4558-65.

153. Gérard J-P, Azria D, Gourgou-Bourgade S, Martel-Laffay I, Hennequin C, Etienne P-L, et al. Comparison of two neoadjuvant chemoradiotherapy regimens for locally advanced rectal cancer: results of the phase III trial ACCORD 12/0405-Prodige 2. J Clin Oncol. 2010 Apr 1;28(10):1638-44.

154. Rödel C, Graeven U, Fietkau R, Hohenberger W, Hothorn T, Arnold D, et al. Oxaliplatin added to fluorouracil-based preoperative chemoradiotherapy and postoperative chemotherapy of locally advanced rectal cancer (the German CAO/ARO/AIO-04 study): final results of the multicentre, open-label, randomised, phase 3 trial. Lancet Oncol. 2015 Aug;16(8):979-89.

155. Rödel C, Liersch T, Becker H, Fietkau R, Hohenberger W, Hothorn T, et al. Preoperative chemoradiotherapy and postoperative chemotherapy with fluorouracil and oxaliplatin versus fluorouracil alone in locally advanced rectal cancer: initial results of the German CAO/ARO/AIO-04 randomised phase 3 trial. Lancet Oncol. 2012 Jul;13(7):679-87.

156. Mohiuddin M, Paulus R, Mitchell E, Hanna N, Yuen A, Nichols R, et al. Neoadjuvant chemoradiation for distal rectal cancer: 5-year updated results of a randomized phase 2 study of neoadjuvant combined modality chemoradiation for distal rectal cancer. Int J Radiat Oncol Biol Phys. 2013 Jul 1;86(3):523-8.

157. Roh MS, Colangelo LH, O’Connell MJ, Yothers G, Deutsch M, Allegra CJ, et al. Preoperative multimodality therapy improves disease-free survival in patients with carcinoma of the rectum: NSABP R-03. J Clin Oncol. 2009 Nov 1;27(31):5124-30.

158. Lam C-W, Chen WT-L, Liu M-T, Chang C-S, Huang T-M, Hsu G-H, et al. Effect of preoperative concurrent chemoradiotherapy in locally advanced low rectal cancer after radical resection surgery. Int Surg. 90(1):53-9. 
159. Roels S, Duthoy W, Haustermans K, Penninckx F, Vandecaveye V, Boterberg T, et al. Definition and delineation of the clinical target volume for rectal cancer. Int J Radiat Oncol Biol Phys. 2006 Jul 15;65(4):1129-42.

160. Uehara K, Hiramatsu K, Maeda A, Sakamoto E, Inoue M, Kobayashi S, et al. Neoadjuvant oxaliplatin and capecitabine and bevacizumab without radiotherapy for poor-risk rectal cancer: N-SOG 03 Phase II trial. Jpn J Clin Oncol. 2013 Oct;43(10):964-71.

161. Dewdney A, Cunningham D, Tabernero J, Capdevila J, Glimelius B, Cervantes A, et al. Multicenter randomized phase II clinical trial comparing neoadjuvant oxaliplatin, capecitabine, and preoperative radiotherapy with or without cetuximab followed by total mesorectal excision in patients with high-risk rectal cancer (EXPERT-C). J Clin Oncol. 2012 May 10;30(14):1620-7.

162. Helbling D, Bodoky G, Gautschi O, Sun H, Bosman F, Gloor B, et al. Neoadjuvant chemoradiotherapy with or without panitumumab in patients with wild-type KRAS, locally advanced rectal cancer (LARC): a randomized, multicenter, phase II trial SAKK 41/07. Ann Oncol Off J Eur Soc Med Oncol. 2013 Mar;24(3):718-25.

163. Bujko K, Bujko M, Pietrzak L. Clinical target volume for rectal cancer: in regard to Roels et al. (Int J Radiat Oncol Biol Phys 2006;65:1129-1142). Int J Radiat Oncol Biol Phys. 2007 May 1;68(1):313.

164. Yu T-K, Bhosale PR, Crane CH, Iyer RB, Skibber JM, Rodriguez-Bigas MA, et al. Patterns of locoregional recurrence after surgery and radiotherapy or chemoradiation for rectal cancer. Int J Radiat Oncol Biol Phys. 2008 Jul 15;71(4):1175-80.

165. Wolmark N, Rockette H, Wickerham DL, Fisher B, Redmond C, Fisher ER, et al. Adjuvant therapy of Dukes' A, B, and C adenocarcinoma of the colon with portal- 


\section{Martín Bailón Cuadrado}

vein fluorouracil hepatic infusion: preliminary results of National Surgical Adjuvant Breast and Bowel Project Protocol C-02. J Clin Oncol. 1990 Sep;8(9):1466-75.

166. Quasar Collaborative Group, Gray R, Barnwell J, McConkey C, Hills RK, Williams NS, et al. Adjuvant chemotherapy versus observation in patients with colorectal cancer: a randomised study. Lancet (London, England). 2007 Dec 15;370(9604):2020-9.

167. Efficacy of adjuvant fluorouracil and folinic acid in B2 colon cancer. International Multicentre Pooled Analysis of B2 Colon Cancer Trials (IMPACT B2) Investigators. J Clin Oncol. 1999 May;17(5):1356-63.

168. Gill S, Loprinzi CL, Sargent DJ, Thomé SD, Alberts SR, Haller DG, et al. Pooled analysis of fluorouracil-based adjuvant therapy for stage II and III colon cancer: who benefits and by how much? J Clin Oncol. 2004 May 15;22(10):1797-806.

169. André T, Boni C, Navarro M, Tabernero J, Hickish T, Topham C, et al. Improved overall survival with oxaliplatin, fluorouracil, and leucovorin as adjuvant treatment in stage II or III colon cancer in the MOSAIC trial. J Clin Oncol. 2009 Jul 1;27(19):3109-16.

170. Kuebler JP, Wieand HS, O’Connell MJ, Smith RE, Colangelo LH, Yothers G, et al. Oxaliplatin combined with weekly bolus fluorouracil and leucovorin as surgical adjuvant chemotherapy for stage II and III colon cancer: results from NSABP C-07. J Clin Oncol. 2007 Jun 1;25(16):2198-204.

171. Yothers G, O'Connell MJ, Allegra CJ, Kuebler JP, Colangelo LH, Petrelli NJ, et al. Oxaliplatin as adjuvant therapy for colon cancer: updated results of NSABP C-07 trial, including survival and subset analyses. J Clin Oncol. 2011 Oct 1;29(28):376874.

172. Haller DG, Tabernero J, Maroun J, de Braud F, Price T, Van Cutsem E, et al. 
Capecitabine plus oxaliplatin compared with fluorouracil and folinic acid as adjuvant therapy for stage III colon cancer. J Clin Oncol. 2011 Apr 10;29(11):1465-71.

173. André T, de Gramont A, Vernerey D, Chibaudel B, Bonnetain F, Tijeras-Raballand A, et al. Adjuvant Fluorouracil, Leucovorin, and Oxaliplatin in Stage II to III Colon Cancer: Updated 10-Year Survival and Outcomes According to BRAF Mutation and Mismatch Repair Status of the MOSAIC Study. J Clin Oncol. 2015 Dec 10;33(35):4176-87.

174. Shah MA, Renfro LA, Allegra CJ, André T, de Gramont A, Schmoll H-J, et al. Impact of Patient Factors on Recurrence Risk and Time Dependency of Oxaliplatin Benefit in Patients With Colon Cancer: Analysis From Modern-Era Adjuvant Studies in the Adjuvant Colon Cancer End Points (ACCENT) Database. J Clin Oncol. 2016 Mar 10;34(8):843-53.

175. Gastrointestinal Tumor Study Group. Prolongation of the disease-free interval in surgically treated rectal carcinoma. N Engl J Med. 1985 Jun 6;312(23):1465-72.

176. Krook JE, Moertel CG, Gunderson LL, Wieand HS, Collins RT, Beart RW, et al. Effective surgical adjuvant therapy for high-risk rectal carcinoma. N Engl J Med. 1991 Mar 14;324(11):709-15.

177. Fisher B, Wolmark N, Rockette H, Redmond C, Deutsch M, Wickerham DL, et al. Postoperative adjuvant chemotherapy or radiation therapy for rectal cancer: results from NSABP protocol R-01. J Natl Cancer Inst. 1988 Mar 2;80(1):21-9.

178. O'Connell MJ, Martenson JA, Wieand HS, Krook JE, Macdonald JS, Haller DG, et al. Improving adjuvant therapy for rectal cancer by combining protracted-infusion fluorouracil with radiation therapy after curative surgery. N Engl J Med. 1994 Aug 25;331(8):502-7.

179. Miller RC, Sargent DJ, Martenson JA, Macdonald JS, Haller D, Mayer RJ, et al. 


\section{Martín Bailón Cuadrado}

Acute diarrhea during adjuvant therapy for rectal cancer: a detailed analysis from a randomized intergroup trial. Int J Radiat Oncol Biol Phys. 2002 Oct 1;54(2):409-13.

180. Tepper JE, O'Connell MJ, Petroni GR, Hollis D, Cooke E, Benson AB, et al. Adjuvant postoperative fluorouracil-modulated chemotherapy combined with pelvic radiation therapy for rectal cancer: initial results of intergroup 0114. J Clin Oncol. 1997 May;15(5):2030-9.

181. Tepper JE, O’Connell M, Niedzwiecki D, Hollis DR, Benson AB, Cummings B, et al. Adjuvant therapy in rectal cancer: analysis of stage, sex, and local control--final report of intergroup 0114. J Clin Oncol. 2002 Apr 1;20(7):1744-50.

182. Kalofonos HP, Bamias A, Koutras A, Papakostas P, Basdanis G, Samantas E, et al. A randomised phase III trial of adjuvant radio-chemotherapy comparing Irinotecan, 5FU and Leucovorin to 5FU and Leucovorin in patients with rectal cancer: a Hellenic Cooperative Oncology Group Study. Eur J Cancer. 2008 Aug;44(12):1693700.

183. Hong YS, Nam B-H, Kim K-P, Kim JE, Park SJ, Park YS, et al. Oxaliplatin, fluorouracil, and leucovorin versus fluorouracil and leucovorin as adjuvant chemotherapy for locally advanced rectal cancer after preoperative chemoradiotherapy (ADORE): an open-label, multicentre, phase 2, randomised controlled trial. Lancet Oncol. 2014 Oct;15(11):1245-53.

184. Fearon K, Strasser F, Anker SD, Bosaeus I, Bruera E, Fainsinger RL, et al. Definition and classification of cancer cachexia: an international consensus. Lancet Oncol. 2011 May;12(5):489-95.

185. Blum D, Stene GB, Solheim TS, Fayers P, Hjermstad MJ, Baracos VE, et al. Validation of the Consensus-Definition for Cancer Cachexia and evaluation of a classification model--a study based on data from an international multicentre project 
(EPCRC-CSA). Ann Oncol. 2014 Aug;25(8):1635-42.

186. Lu H, Ouyang W, Huang C. Inflammation, a key event in cancer development. Mol Cancer Res. 2006 Apr;4(4):221-33.

187. Roxburgh CSD, McMillan DC. Cancer and systemic inflammation: treat the tumour and treat the host. Br J Cancer. 2014 Mar 18;110(6):1409-12.

188. Maeda K, Shibutani M, Otani H, Nagahara H, Ikeya T, Iseki Y, et al. Inflammationbased factors and prognosis in patients with colorectal cancer. World J Gastrointest Oncol. 2015 Aug 15;7(8):111-7.

189. Nazha B, Moussaly E, Zaarour M, Weerasinghe C, Azab B. Hypoalbuminemia in colorectal cancer prognosis: Nutritional marker or inflammatory surrogate? World J Gastrointest Surg. 2015 Dec 27;7(12):370-7.

190. Kratz F. Albumin as a drug carrier: Design of prodrugs, drug conjugates and nanoparticles. J Control Release. 2008;132(3):171-83.

191. Fleck A, Raines G, Hawker F, Trotter J, Wallace PI, Ledingham IM CK. Increased vascular permeability: a major cause of hypoalbuminaemia in disease and injury. Lancet. 1985;1(8432):781-4.

192. Davis MP, Dreicer R, Walsh D, Lagman R, LeGrand SB. Appetite and cancerassociated anorexia: a review. J Clin Oncol. 2004 Apr 15;22(8):1510-7.

193. Alemán MR, Santolaria F, Batista N, de La Vega MJ, González-Reimers E, Milena A, et al. Leptin role in advanced lung cancer. A mediator of the acute phase response or a marker of the status of nutrition? Cytokine. 2002 Jul;19(1):21-6.

194. Wyke SM, Tisdale MJ. NF-kappaB mediates proteolysis-inducing factor induced protein degradation and expression of the ubiquitin-proteasome system in skeletal muscle. Br J Cancer. 2005 Feb 28;92(4):711-21.

195. Russell ST, Zimmerman TP, Domin BA, Tisdale MJ. Induction of lipolysis in vitro 


\section{Martín Bailón Cuadrado}

and loss of body fat in vivo by zinc- $\alpha 2$-glycoprotein. Biochim Biophys Acta - Mol Cell Biol Lipids. 2004;1636(1):59-68.

196. Russell ST, Hirai K, Tisdale MJ. Role of beta3-adrenergic receptors in the action of a tumour lipid mobilizing factor. Br J Cancer. 2002 Feb 1;86(3):424-8.

197. Barber MD, McMillan DC, Wallace AM, Ross JA, Preston T, Fearon KCH. The response of leptin, interleukin-6 and fat oxidation to feeding in weight-losing patients with pancreatic cancer. Br J Cancer. 2004 Mar 22;90(6):1129-32.

198. Strasser F, Palmer JL, Schover LR, Yusuf SW, Pisters K, Vassilopoulou-Sellin R, et al. The impact of hypogonadism and autonomic dysfunction on fatigue, emotional function, and sexual desire in male patients with advanced cancer: a pilot study. Cancer. 2006 Dec 15;107(12):2949-57.

199. Yun AJ, Lee PY, Bazar KA, Calvet X, Martinez J., Martinez M, et al. Modulation of autonomic balance by tumors and viruses. Med Hypotheses. 2004 Jan;63(2):344-51.

200. Onodera T, Goseki N, Kosaki G. [Prognostic nutritional index in gastrointestinal surgery of malnourished cancer patients]. Nihon Geka Gakkai Zasshi. 1984 Sep;85(9):1001-5.

201. Yang Y, Gao P, Chen X, Song Y, Shi J, Zhao J, et al. Prognostic significance of preoperative prognostic nutritional index in colorectal cancer: results from a retrospective cohort study and a meta-analysis. Oncotarget. 2016;7(36):58543-52.

202. Jian-Hui C, Iskandar EA, Cai S-I, Chen C-Q, Wu H, Xu J-B, et al. Significance of Onodera's prognostic nutritional index in patients with colorectal cancer: a large cohort study in a single Chinese institution. Tumour Biol. 2016 Mar 5;37(3):327783.

203. Shibutani M, Maeda K, Nagahara H, Ohtani H, Iseki Y, Ikeya T, et al. The prognostic significance of the postoperative prognostic nutritional index in patients 
with colorectal cancer. BMC Cancer. 2015;15:521.

204. Park BK, Park JW, Han EC, Ryoo S-B, Han S-W, Kim T-Y, et al. Systemic inflammatory markers as prognostic factors in stage IIA colorectal cancer. J Surg Oncol. 2016 Aug;114(2):216-21.

205. Nozoe T, Kohno M, Iguchi T, Mori E, Maeda T, Matsukuma A, et al. The prognostic nutritional index can be a prognostic indicator in colorectal carcinoma. Surg Today. 2012 Jun;42(6):532-5.

206. Mohri Y, Inoue Y, Tanaka K, Hiro J, Uchida K, Kusunoki M. Prognostic nutritional index predicts postoperative outcome in colorectal cancer. World J Surg. 2013 Nov;37(11):2688-92.

207. Tokunaga R, Sakamoto Y, Nakagawa S, Miyamoto Y, Yoshida N, Oki E, et al. Prognostic Nutritional Index Predicts Severe Complications, Recurrence, and Poor Prognosis in Patients With Colorectal Cancer Undergoing Primary Tumor Resection. Dis Colon Rectum. 2015 Nov;58(11):1048-57.

208. Sun K, Chen S, Xu J, Li G, He Y. The prognostic significance of the prognostic nutritional index in cancer: a systematic review and meta-analysis. J Cancer Res Clin Oncol. 2014 Sep;140(9):1537-49.

209. Forrest LM, McMillan DC, McArdle CS, Angerson WJ, Dunlop DJ. Comparison of an inflammation-based prognostic score (GPS) with performance status (ECOG) in patients receiving platinum-based chemotherapy for inoperable non-small-cell lung cancer. Br J Cancer. 2004 May 4;90(9):1704-6.

210. Elahi MM, McMillan DC, McArdle CS, Angerson WJ, Sattar N. Score based on hypoalbuminemia and elevated C-reactive protein predicts survival in patients with advanced gastrointestinal cancer. Nutr Cancer. 2004;48(2):171-3.

211. Ishizuka M, Nagata H, Takagi K, Iwasaki Y, Kubota K. Inflammation-based 


\section{Martín Bailón Cuadrado}

prognostic system predicts postoperative survival of colorectal cancer patients with a normal preoperative serum level of carcinoembryonic antigen. Ann Surg Oncol. 2012 Oct;19(11):3422-31.

212. Lin M-S, Huang J-X, Yu H. Prognostic significance of Glasgow prognostic score in patients with stage II colorectal cancer. Int J Clin Exp Med. 2015;8(10):19138-43.

213. Choi KW, Hong SW, Chang YG, Lee WY, Lee B, Paik IW, et al. Inflammationbased score (Glasgow prognostic score) as an independent prognostic factor in colorectal cancer patients. Ann Surg Treat Res. 2014 Jun;86(6):309-13.

214. Sugimoto K, Komiyama H, Kojima Y, Goto M, Tomiki Y, Sakamoto K. Glasgow prognostic score as a prognostic factor in patients undergoing curative surgery for colorectal cancer. Dig Surg. 2012;29(6):503-9.

215. Eren T, Burcu B, Tombalak E, Ozdemir T, Leblebici M, Ozemir IA, et al. Clinical Significance of the Glasgow Prognostic Score for Survival after Colorectal Cancer Surgery. J Gastrointest Surg. 2016 Jun;20(6):1231-8.

216. Cao X, Yu T, Zhao G, Xiao G. [Predictive value of Glasgow prognostic score in patients with colorectal cancer undergoing laparoscopic radical resection]. Zhonghua Wei Chang Wai Ke Za Zhi. 2016 Oct 25;19(10):1133-8.

217. McMillan DC, Crozier JEM, Canna K, Angerson WJ, McArdle CS. Evaluation of an inflammation-based prognostic score (GPS) in patients undergoing resection for colon and rectal cancer. Int J Colorectal Dis. 2007 Aug;22(8):881-6.

218. Moyes LH, Leitch EF, McKee RF, Anderson JH, Horgan PG, McMillan DC. Preoperative systemic inflammation predicts postoperative infectious complications in patients undergoing curative resection for colorectal cancer. Br J Cancer. 2009 Apr 21;100(8):1236-9.

219. Sagawa M, Yoshimatsu K, Yokomizo H, Yano Y, Nakayama M, Usui T, et al. 
[Onodera's prognostic nutritional index (PNI) and the modified Glasgow Prognostic Score (mGPS) in colorectal cancer surgery]. Gan To Kagaku Ryoho. 2014 Oct;41(10):1273-5.

220. Proctor MJ, Morrison DS, Talwar D, Balmer SM, Fletcher CD, O'Reilly DSJ, et al. A comparison of inflammation-based prognostic scores in patients with cancer. A Glasgow Inflammation Outcome Study. Eur J Cancer. 2011 Nov;47(17):2633-41.

221. Proctor MJ, Talwar D, Balmar SM, O’Reilly DSJ, Foulis AK, Horgan PG, et al. The relationship between the presence and site of cancer, an inflammation-based prognostic score and biochemical parameters. Initial results of the Glasgow Inflammation Outcome Study. Br J Cancer. 2010 Sep 7;103(6):870-6.

222. Proctor MJ, Morrison DS, Talwar D, Balmer SM, O'Reilly DSJ, Foulis AK, et al. An inflammation-based prognostic score (mGPS) predicts cancer survival independent of tumour site: a Glasgow Inflammation Outcome Study. Br J Cancer. 2011 Feb 15;104(4):726-34.

223. Petrelli F, Barni S, Coinu A, Bertocchi P, Borgonovo K, Cabiddu M, et al. The Modified Glasgow Prognostic Score and Survival in Colorectal Cancer: A Pooled Analysis of the Literature. Rev Recent Clin Trials. 2015;10(2):135-41.

224. Adachi T, Hinoi T, Hattori M, Egi H, Shimomura M, Saito Y, et al. The modified Glasgow prognostic score for early mortality in patients with synchronous peritoneal carcinomatosis from colorectal cancer. Surg Today. 2015 Nov;45(11):1396-403.

225. Inoue Y, Iwata T, Okugawa Y, Kawamoto A, Hiro J, Toiyama Y, et al. Prognostic significance of a systemic inflammatory response in patients undergoing multimodality therapy for advanced colorectal cancer. Oncology. 2013;84(2):100-7.

226. Kishiki T, Masaki T, Matsuoka H, Kobayashi T, Suzuki Y, Abe N, et al. Modified Glasgow prognostic score in patients with incurable stage IV colorectal cancer. Am 


\section{Martín Bailón Cuadrado}

J Surg. 2013 Aug;206(2):234-40.

227. Tabuchi T, Shimazaki J, Satani T, Nakachi T, Watanabe Y, Tabuchi T. The perioperative granulocyte/lymphocyte ratio is a clinically relevant marker of surgical stress in patients with colorectal cancer. Cytokine. 2011;53(2):243-8.

228. Shimazaki J, Tabuchi T, Nakachi T, Motohashi G, Nishida K, Ubukata H, et al. Preoperative granulocyte/lymphocyte ratio as a predictive marker of post-operative complications in patients with colorectal cancer. Oncol Lett. 2015 Jan;9(1):425-9.

229. Shimazaki J, Goto Y, Nishida K, Tabuchi T, Motohashi G, Ubukata H, et al. In patients with colorectal cancer, preoperative serum interleukin-6 level and granulocyte/lymphocyte ratio are clinically relevant biomarkers of long-term cancer progression. Oncology. 2013;84(6):356-61.

230. Onozawa H, Fukuchi M, Suzuki O, Hatano S, Matsuzawa T, Kuwabara K, et al. [Significance of the granulocyte-to-lymphocyte ratio as a prognostic predictor in patients with stage IV colorectal cancer undergoing chemotherapy]. Gan To Kagaku Ryoho. 2014 Oct;41(10):1307-9.

231. Walsh SR, Cook EJ, Goulder F, Justin TA, Keeling NJ. Neutrophil-lymphocyte ratio as a prognostic factor in colorectal cancer. J Surg Oncol. 2005 Sep 1;91(3):181-4.

232. Khan AA, Akritidis G, Pring T, Alagarathnam S, Roberts G, Raymond R, et al. The Neutrophil-to-Lymphocyte Ratio as a Marker of Lymph Node Status in Patients with Rectal Cancer. Oncology. 2016 Jun 9;91(2):69-77.

233. Josse JM, Cleghorn MC, Ramji KM, Jiang H, Elnahas A, Jackson TD, et al. The neutrophil-to-lymphocyte ratio predicts major perioperative complications in patients undergoing colorectal surgery. Colorectal Dis. 2016 Jul;18(7):O236-42.

234. Emir S, Aydin M, Can G, Bali I, Yildirim O, Öznur M, et al. Comparison of colorectal neoplastic polyps and adenocarcinoma with regard to NLR and PLR. Eur 
Rev Med Pharmacol Sci. 2015 Oct;19(19):3613-8.

235. Zou Z-Y, Liu H-L, Ning N, Li S-Y, DU X-H, Li R. Clinical significance of preoperative neutrophil lymphocyte ratio and platelet lymphocyte ratio as prognostic factors for patients with colorectal cancer. Oncol Lett. 2016 Mar;11(3):2241-8.

236. Li M-X, Liu X-M, Zhang X-F, Zhang J-F, Wang W-L, Zhu Y, et al. Prognostic role of neutrophil-to-lymphocyte ratio in colorectal cancer: a systematic review and meta-analysis. Int J cancer. 2014 May 15;134(10):2403-13.

237. Shin JS, Suh KW, Oh SY. Preoperative neutrophil to lymphocyte ratio predicts survival in patients with T1-2N0 colorectal cancer. J Surg Oncol. 2015 Nov;112(6):654-7.

238. Pine JK, Morris E, Hutchins GG, West NP, Jayne DG, Quirke P, et al. Systemic neutrophil-to-lymphocyte ratio in colorectal cancer: the relationship to patient survival, tumour biology and local lymphocytic response to tumour. Br J Cancer. 2015 Jul 14;113(2):204-11.

239. Kubo H, Murayama Y, Arita T, Kuriu Y, Nakanishi M, Otsuji E. The Prognostic Value of Preoperative Neutrophil-to-Lymphocyte Ratio in Colorectal Cancer. World J Surg. 2016;40(11):2796-802.

240. Choi WJ, Cleghorn MC, Jiang H, Jackson TD, Okrainec A, Quereshy FA. Preoperative Neutrophil-to-Lymphocyte Ratio is a Better Prognostic Serum Biomarker than Platelet-to-Lymphocyte Ratio in Patients Undergoing Resection for Nonmetastatic Colorectal Cancer. Ann Surg Oncol. 2015 Dec;22 Suppl 3:S603-13.

241. Kwon H-C, Kim SH, Oh SY, Lee S, Lee JH, Choi H-J, et al. Clinical significance of preoperative neutrophil-lymphocyte versus platelet-lymphocyte ratio in patients with operable colorectal cancer. Biomarkers. 2012 May;17(3):216-22.

242. Ozawa T, Ishihara S, Nishikawa T, Tanaka T, Tanaka J, Kiyomatsu T, et al. The 


\section{Martín Bailón Cuadrado}

preoperative platelet to lymphocyte ratio is a prognostic marker in patients with stage II colorectal cancer. Int J Colorectal Dis. 2015 Sep;30(9):1165-71.

243. Peng $\mathrm{H}-\mathrm{X}$, Lin $\mathrm{K}$, He B-S, Pan Y-Q, Ying H-Q, Hu X-X, et al. Platelet-tolymphocyte ratio could be a promising prognostic biomarker for survival of colorectal cancer: a systematic review and meta-analysis. FEBS Open Bio. 2016 Jul;6(7):742-50.

244. Tan D, Fu Y, Su Q, Wang H. Prognostic role of platelet-lymphocyte ratio in colorectal cancer: A systematic review and meta-analysis. Medicine (Baltimore). 2016 Jun;95(24):e3837.

245. You J, Zhu G-Q, Xie L, Liu W-Y, Shi L, Wang O-C, et al. Preoperative platelet to lymphocyte ratio is a valuable prognostic biomarker in patients with colorectal cancer. Oncotarget. 2016 Mar 24;7(18):25516-27.

246. Watanabe J, Otani S, Sakamoto T, Arai Y, Hanaki T, Amisaki M, et al. Prognostic indicators based on inflammatory and nutritional factors after pancreaticoduodenectomy for pancreatic cancer. Surg Today. 2016 Feb 11;46(11):1258-67.

247. Davis CJ, Sowa D, Keim KS, Kinnare K, Peterson S. The use of prealbumin and Creactive protein for monitoring nutrition support in adult patients receiving enteral nutrition in an urban medical center. JPEN J Parenter Enteral Nutr. 2012 Mar;36(2):197-204.

248. Telem DA, Chin EH, Nguyen SQ, Divino CM. Risk Factors for Anastomotic Leak Following Colorectal Surgery. Arch Surg. 2010 Apr 1;145(4):371.

249. Labgaa I, Joliat G-R, Kefleyesus A, Mantziari S, Schäfer M, Demartines N, et al. Is postoperative decrease of serum albumin an early predictor of complications after major abdominal surgery? A prospective cohort study in a European centre. BMJ 
Open. 2017 Apr 8;7(4):e013966.

250. Chiang JM, Chang CJ, Jiang SF, Yeh CY, You JF, Hsieh PS, et al. Pre-operative serum albumin level substantially predicts post-operative morbidity and mortality among patients with colorectal cancer who undergo elective colectomy. Eur J Cancer Care (Engl). 2017 Mar;26(2):e12403.

251. Bae H-J, Lee H-J, Han D-S, Suh Y-S, Lee Y-H, Lee H-S, et al. Prealbumin levels as a useful marker for predicting infectious complications after gastric surgery. J Gastrointest Surg. 2011 Dec 12;15(12):2136-44.

252. Zhou J, Hiki N, Mine S, Kumagai K, Ida S, Jiang X, et al. Role of Prealbumin as a Powerful and Simple Index for Predicting Postoperative Complications After Gastric Cancer Surgery. Ann Surg Oncol. 2017 Feb 8;24(2):510-7.

253. Veldkamp R, Kuhry E, Hop WCJ, Jeekel J, Kazemier G, Bonjer HJ, et al. Laparoscopic surgery versus open surgery for colon cancer: short-term outcomes of a randomised trial. Lancet Oncol. 2005 Jul;6(7):477-84.

254. van der Pas MH, Haglind E, Cuesta MA, Fürst A, Lacy AM, Hop WC, et al. Laparoscopic versus open surgery for rectal cancer (COLOR II): short-term outcomes of a randomised, phase 3 trial. Lancet Oncol. 2013 Mar;14(3):210-8.

255. Longo WE, Virgo KS, Johnson FE, Oprian CA, Vernava AM, Wade TP, et al. Risk factors for morbidity and mortality after colectomy for colon cancer. Dis Colon Rectum. 2000 Jan;43(1):83-91.

256. Bilimoria KY, Bentrem DJ, Merkow RP, Nelson H, Wang E, Ko CY, et al. Laparoscopic-assisted vs. Open Colectomy for Cancer: Comparison of Short-term Outcomes from 121 Hospitals. J Gastrointest Surg. 2008 Nov 24;12(11):2001-9.

257. Moghadamyeghaneh Z, Hwang G, Hanna MH, Phelan MJ, Carmichael JC, Mills SD, et al. Even modest hypoalbuminemia affects outcomes of colorectal surgery 


\section{Martín Bailón Cuadrado}

patients. Am J Surg. 2015 Aug;210(2):276-84.

258. Veyrie N, Ata T, Muscari F, Couchard A-C, Msika S, Hay J-M, et al. Anastomotic Leakage after Elective Right Versus Left Colectomy for Cancer: Prevalence and Independent Risk Factors. J Am Coll Surg. 2007 Dec;205(6):785-93.

259. Cosse C, Sabbagh C, Chapuis-Roux E, Prevot F, Rebibo L, Regimbeau JM. Placement of a microdialysis catheter during laparoscopic rectal cancer surgery to assess anastomotic leak. Tech Coloproctol. 2016 Nov 23;20(11):785-9.

260. Moug SJ, McCarthy K, Coode-Bate J, Stechman MJ, Hewitt J. Laparoscopic versus open surgery for colorectal cancer in the older person: A systematic review. Ann Med Surg. 2015 Sep;4(3):311-8.

261. Hunt SA, Baker DW, Chin MH, Cinquegrani MP, Feldman AM, Francis GS, et al. ACC/AHA guidelines for the evaluation and management of chronic heart failure in the adult: executive summary. J Heart Lung Transplant. 2002 Feb;21(2):189-203.

262. Wright RS, Anderson JL, Adams CD, Bridges CR, Casey DE, Ettinger SM, et al. 2011 ACCF/AHA Focused Update Incorporated Into the ACC/AHA 2007 Guidelines for the Management of Patients With Unstable Angina/Non-STElevation Myocardial Infarction. J Am Coll Cardiol. 2011 May;57(19):e215-367.

263. American Thoracic Society, Infectious Diseases Society of America. Guidelines for the management of adults with hospital-acquired, ventilator-associated, and healthcare-associated pneumonia. Am J Respir Crit Care Med. 2005 Feb 15;171(4):388-416.

264. Butt Y, Kurdowska A, Allen TC. Acute Lung Injury: A Clinical and Molecular Review. Arch Pathol Lab Med. 2016 Apr;140(4):345-50.

265. Canaud B. [Postoperative acute renal failure: definition, diagnostic and prognostic criteria]. Ann Fr Anesth Reanim. 2005 Feb;24(2):125-33. 
266. Kelley RE. Stroke in the postoperative period. Med Clin North Am. 2001 Sep;85(5):1263-76.

267. Schwarz NT, Kalff JC, Türler A, Speidel N, Grandis JR, Billiar TR, et al. Selective jejunal manipulation causes postoperative pan-enteric inflammation and dysmotility. Gastroenterology. 2004 Jan;126(1):159-69.

268. Slim K, Vicaut E, Panis Y, Chipponi J. Meta-analysis of randomized clinical trials of colorectal surgery with or without mechanical bowel preparation. Br J Surg. 2004 Sep;91(9):1125-30.

269. Wong NY, Eu KW. A Defunctioning Ileostomy Does Not Prevent Clinical Anastomotic Leak After a Low Anterior Resection: A Prospective, Comparative Study. Dis Colon Rectum. 2005 Nov;48(11):2076-9.

270. August DA, Serrano D, Poplin E. "Spontaneous," delayed colon and rectal anastomotic complications associated with bevacizumab therapy. J Surg Oncol. 2008 Feb 1;97(2):180-5.

271. National Nosocomial Infections Surveillance (NNIS) System Report, Data Summary from January 1992-June 2001, issued August 2001. Am J Infect Control. 2001 Dec;29(6):404-21.

272. Awad SS, Elhabash SI, Lee L, Farrow B, Berger DH. Increasing incidence of methicillin-resistant Staphylococcus aureus skin and soft-tissue infections: reconsideration of empiric antimicrobial therapy. Am J Surg. 2007 Nov;194(5):60610.

273. Lipska MA, Bissett IP, Parry BR, Merrie AEH. Anastomotic leakage after lower gastrointestinal anastomosis: men are at a higher risk. ANZ J Surg. 2006 Jul;76(7):579-85.

274. Mörner MEM, Edgren G, Martling A, Gunnarsson U, Egenvall M. Preoperative 


\section{Martín Bailón Cuadrado}

anaemia and perioperative red blood cell transfusion as prognostic factors for recurrence and mortality in colorectal cancer-a Swedish cohort study. Int J Colorectal Dis. 2017 Feb 21;32(2):223-32.

275. Kirchhoff P, Dincler S, Buchmann P. A Multivariate Analysis of Potential Risk Factors for Intra- and Postoperative Complications in 1316 Elective Laparoscopic Colorectal Procedures. Ann Surg. 2008 Aug;248(2):259-65.

276. Dindo D, Demartines N, Clavien P-A. Classification of surgical complications: a new proposal with evaluation in a cohort of 6336 patients and results of a survey. Ann Surg. 2004 Aug;240(2):205-13.

277. Valero G, Luján JA, Hernández Q, de las Heras M, Pellicer E, Serrano A, et al. Neoadjuvant radiation and chemotherapy in rectal cancer does not increase postoperative complications. Int J Colorectal Dis. 2003 Nov 15;18(6):495-9.

278. Milgrom SA, Goodman KA, Nash GM, Paty PB, Guillem JG, Temple LK, et al. Neoadjuvant Radiation Therapy Prior to Total Mesorectal Excision for Rectal Cancer is Not Associated with Postoperative Complications Using Current Techniques. Ann Surg Oncol. 2014 Jul 7;21(7):2295-302.

279. Cammà C, Giunta M, Fiorica F, Pagliaro L, Craxì A, Cottone M, et al. Preoperative Radiotherapy for Resectable Rectal Cancer. JAMA. 2000 Aug 23;284(8):1008.

280. Schiffmann L, Wedermann N, Gock M, Prall F, Klautke G, Fietkau R, et al. Intensified neoadjuvant radiochemotherapy for rectal cancer enhances surgical complications. BMC Surg. 2013 Dec 30;13(1):43.

281. Turner II, Russell GB, Blackstock AW, Levine EA. Impact of neoadjuvant therapy on postoperative complications in patients undergoing resection for rectal adenocarcinoma. Am Surg. 2004 Dec;70(12):1045-9.

282. Jonker FHW, Tanis PJ, Coene P-PLO, van der Harst E. Impact of Neoadjuvant 
Radiotherapy on Complications After Hartmann Procedure for Rectal Cancer. Dis Colon Rectum. 2015 Oct;58(10):931-7.

283. Holubar SD, Brickman RK, Greaves SW, Ivatury SJ. Neoadjuvant Radiotherapy: A Risk Factor for Short-Term Wound Complications after Radical Resection for Rectal Cancer? J Am Coll Surg. 2016 Aug;223(2):291-8.

284. McSorley ST, Horgan PG, McMillan DC. The impact of the type and severity of postoperative complications on long-term outcomes following surgery for colorectal cancer: A systematic review and meta-analysis. Crit Rev Oncol Hematol. 2016 Jan;97:168-77.

285. Pucher PH, Aggarwal R, Qurashi M, Darzi A. Meta-analysis of the effect of postoperative in-hospital morbidity on long-term patient survival. Br J Surg. 2014 Nov;101(12):1499-508.

286. Law WL, Choi HK, Lee YM, Ho JWC, Seto CL. Anastomotic Leakage is Associated with Poor Long-Term Outcome in Patients After Curative Colorectal Resection for Malignancy. J Gastrointest Surg. 2007 Feb 15;11(1):8-15.

287. Mirnezami A, Mirnezami R, Chandrakumaran K, Sasapu K, Sagar P, Finan P. Increased Local Recurrence and Reduced Survival From Colorectal Cancer Following Anastomotic Leak. Ann Surg. 2011 May;253(5):890-9.

288. Krarup P-M, Nordholm-Carstensen A, Jorgensen LN, Harling H. Anastomotic Leak Increases Distant Recurrence and Long-Term Mortality After Curative Resection for Colonic Cancer. Ann Surg. 2014 May;259(5):930-8.

289. Lu ZR, Rajendran N, Lynch AC, Heriot AG, Warrier SK. Anastomotic Leaks After Restorative Resections for Rectal Cancer Compromise Cancer Outcomes and Survival. Dis Colon Rectum. 2016 Mar;59(3):236-44.

290. Nachiappan S, Askari A, Malietzis G, Giacometti M, White I, Jenkins JT, et al. The 


\section{Martín Bailón Cuadrado}

Impact of Anastomotic Leak and Its Treatment on Cancer Recurrence and Survival Following Elective Colorectal Cancer Resection. World J Surg. 2015 Apr 2;39(4):1052-8.

291. Cao X, Zhao G, Yu T, An Q, Yang H, Xiao G. Preoperative Prognostic Nutritional Index Correlates with Severe Complications and Poor Survival in Patients with Colorectal Cancer Undergoing Curative Laparoscopic Surgery: A Retrospective Study in a Single Chinese Institution. Nutr Cancer. 2017 Apr 3;69(3):454-63.

292. McSorley ST, Roxburgh CSD, Horgan PG, McMillan DC. The Impact of Preoperative Dexamethasone on the Magnitude of the Postoperative Systemic Inflammatory Response and Complications Following Surgery for Colorectal Cancer. Ann Surg Oncol. 2017 Aug 1;24(8):2104-12.

293. Siegel RL, Miller KD, Fedewa SA, Ahnen DJ, Meester RGS, Barzi A, et al. Colorectal cancer statistics, 2017. CA Cancer J Clin. 2017 May 6;67(3):177-93.

294. MacKay GJ, Molloy RG, O’Dwyer PJ. C-reactive protein as a predictor of postoperative infective complications following elective colorectal resection. Color Dis. 2011 May;13(5):583-7.

295. Artinyan A, Orcutt ST, Anaya DA, Richardson P, Chen GJ, Berger DH. Infectious postoperative complications decrease long-term survival in patients undergoing curative surgery for colorectal cancer: a study of 12,075 patients. Ann Surg. 2015 Mar;261(3):497-505.

296. Slankamenac K, Slankamenac M, Schlegel A, Nocito A, Rickenbacher A, Clavien PA, et al. Impact of postoperative complications on readmission and long-term survival in patients following surgery for colorectal cancer. Int J Colorectal Dis. 2017 Jun 14;32(6):805-11.

297. Hede P, Sörensson MÅ, Polleryd P, Persson K, Hallgren T. Influence of BMI on 
short-term surgical outcome after colorectal cancer surgery: a study based on the Swedish national quality registry. Int J Colorectal Dis. 2015 Sep 16;30(9):1201-7.

298. Moghadamyeghaneh Z, Hanna MH, Carmichael JC, Mills SD, Pigazzi A, Stamos MJ. Preoperative Leukocytosis in Colorectal Cancer Patients. J Am Coll Surg. 2015 Jul;221(1):207-14.

299. Hang J, Cai B, Xue P, Wang L, Hu H, Zhou Y, et al. The Joint Effects of Lifestyle Factors and Comorbidities on the Risk of Colorectal Cancer: A Large Chinese Retrospective Case-Control Study. Ellis NA, editor. PLoS One. 2015 Dec 28;10(12):e0143696.

300. Parés-Badell O, Banqué M, Macià F, Castells X, Sala M. Impact of comorbidity on survival by tumour location: Breast, colorectal and lung cancer (2000-2014). Cancer Epidemiol. 2017 Aug 3;49:66-74.

301. Manilich E, Vogel JD, Kiran RP, Church JM, Seyidova-Khoshknabi D, Remzi FH. Key Factors Associated With Postoperative Complications in Patients Undergoing Colorectal Surgery. Dis Colon Rectum. 2013 Jan;56(1):64-71.

302. Frago R, Ramirez E, Millan M, Kreisler E, del Valle E, Biondo S. Current management of acute malignant large bowel obstruction: a systematic review. Am J Surg. 2014 Jan;207(1):127-38.

303. Erichsen R, Horváth-Puhó E, Jacobsen J, Nilsson T, Baron J, Sørensen H. Longterm mortality and recurrence after colorectal cancer surgery with preoperative stenting: a Danish nationwide cohort study. Endoscopy. 2015 Jan 15;47(6):517-24.

304. Kavanagh DO, Nolan B, Judge C, Hyland JMP, Mulcahy HE, O'Connell PR, et al. A comparative study of short- and medium-term outcomes comparing emergent surgery and stenting as a bridge to surgery in patients with acute malignant colonic obstruction. Dis Colon Rectum. 2013 Apr;56(4):433-40. 


\section{Martín Bailón Cuadrado}

305. Sabbagh C, Chatelain D, Trouillet N, Mauvais F, Bendjaballah S, Browet F, et al. Does use of a metallic colon stent as a bridge to surgery modify the pathology data in patients with colonic obstruction? A case-matched study. Surg Endosc. 2013 Oct 10;27(10):3622-31.

306. van Hooft J, van Halsema E, Vanbiervliet G, Beets-Tan R, DeWitt J, Donnellan F, et al. Self-expandable metal stents for obstructing colonic and extracolonic cancer: European Society of Gastrointestinal Endoscopy (ESGE) Clinical Guideline. Endoscopy. 2014 Oct 17;46(11):990-1053.

307. Richards CH, Leitch EF, Horgan PG, Anderson JH, McKee RF, McMillan DC. The relationship between patient physiology, the systemic inflammatory response and survival in patients undergoing curative resection of colorectal cancer. Br J Cancer. 2010 Oct 26;103(9):1356-61.

308. Tokunaga R, Sakamoto Y, Nakagawa S, Izumi D, Kosumi K, Taki K, et al. Comparison of systemic inflammatory and nutritional scores in colorectal cancer patients who underwent potentially curative resection. Int J Clin Oncol. 2017 Feb $17 ; 22(4): 740-8$.

309. Elahi MM, McMillan DC, McArdle CS, Angerson WJ, Sattar N. Score based on hypoalbuminemia and elevated C-reactive protein predicts survival in patients with advanced gastrointestinal cancer. Nutr Cancer. 2004 Mar;48(2):171-3.

310. Kim JH, Lee JY, Kim HK, Lee JW, Jung SG, Jung K, et al. Prognostic significance of the neutrophil-to-lymphocyte ratio and platelet-to-lymphocyte ratio in patients with stage III and IV colorectal cancer. World J Gastroenterol. 2017 Jan $21 ; 23(3): 505$

311. Azab B, Mohammad F, Shah N, Vonfrolio S, Lu W, Kedia S, et al. The value of the pretreatment neutrophil lymphocyte ratio vs. platelet lymphocyte ratio in predicting 
the long-term survival in colorectal cancer. Cancer Biomarkers. 2014 Aug 11;14(5):303-12.

312. Walker KG, Bell SW, Rickard MJFX, Mehanna D, Dent OF, Chapuis PH, et al. Anastomotic leakage is predictive of diminished survival after potentially curative resection for colorectal cancer. Ann Surg. 2004 Aug;240(2):255-9.

313. Harrison OJ, Smart NJ, White P, Brigic A, Carlisle ER, Allison AS, et al. Operative Time and Outcome of Enhanced Recovery After Surgery After Laparoscopic Colorectal Surgery. JSLS J Soc Laparoendosc Surg. 2014;18(2):265-72.

314. Morris E, Quirke P, Thomas JD, Fairley L, Cottier B, Forman D. Unacceptable variation in abdominoperineal excision rates for rectal cancer: time to intervene? Gut. 2008 Dec 30;57(12):1690-7.

315. Jestin P, Påhlman L, Gunnarsson U. Risk factors for anastomotic leakage after rectal cancer surgery: a case-control study. Color Dis. 2008 Aug 21;10(7):715-21.

316. Aquina CT, Blumberg N, Probst CP, Becerra AZ, Hensley BJ, Noyes K, et al. Large Variation in Blood Transfusion Use After Colorectal Resection. Dis Colon Rectum. 2016 May;59(5):411-8.

317. Platt JJ, Ramanathan ML, Crosbie RA, Anderson JH, McKee RF, Horgan PG, et al. C-reactive protein as a predictor of postoperative infective complications after curative resection in patients with colorectal cancer. Ann Surg Oncol. 2012 Dec 18;19(13):4168-77.

318. Woeste G, Müller C, Bechstein WO, Wullstein C. Increased serum levels of Creactive protein precede anastomotic leakage in colorectal surgery. World J Surg. 2010 Jan 2;34(1):140-6.

319. van Westreenen HL, Ijpma FF, Wevers KP, Afzali H, Patijn GA. Reoperation After Colorectal Surgery Is an Independent Predictor of the 1-Year Mortality Rate. Dis 


\section{Martín Bailón Cuadrado}

Colon Rectum. 2011 Nov;54(11):1438-42.

320. Singh PP, Zeng ISL, Srinivasa S, Lemanu DP, Connolly AB, Hill AG. Systematic review and meta-analysis of use of serum C-reactive protein levels to predict anastomotic leak after colorectal surgery. Br J Surg. 2014 Mar;101(4):339-46.

321. Almeida AB, Faria G, Moreira H, Pinto-de-Sousa J, Correia-da-Silva P, Maia JC. Elevated serum C-reactive protein as a predictive factor for anastomotic leakage in colorectal surgery. Int J Surg. 2012;10(2):87-91.

322. Michaels AD, Mullen MG, Guidry CA, Krebs ED, Turrentine FE, Hedrick TL, et al. Unplanned Reoperation Following Colorectal Surgery: Indications and Operations. J Gastrointest Surg. 2017; [Epub ahead of print].

Valladolid, a 25 de agosto de 2017 